Cochrane Database of Systematic Reviews

\title{
Patient education in the management of coronary heart disease
} (Review)

Anderson L, Brown JPR, Clark AM, Dalal H, Rossau HKK, Bridges C, Taylor RS

Anderson L, Brown JPR, Clark AM, Dalal H, Rossau HKK, Bridges C, Taylor RS.

Patient education in the management of coronary heart disease.

Cochrane Database of Systematic Reviews 2017, Issue 6. Art. No.: CD008895.

DOI: 10.1002/14651858.CD008895.pub3.

www.cochranelibrary.com 
TABLE OF CONTENTS

HEADER 1

ABSTRACT

PLAIN LANGUAGE SUMMARY

SUMMARY OF FINDINGS

BACKGROUND

OBJECTIVES

METHODS

Figure 1.

RESULTS

Figure 2.

Figure 3.

Figure 4.

Figure 5.

DISCUSSION

AUTHORS' CONCLUSIONS

ACKNOWLEDGEMENTS

REFERENCES

CHARACTERISTICS OF STUDIES

DATA AND ANALYSES

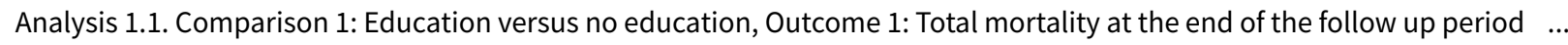

Analysis 1.2. Comparison 1: Education versus no education, Outcome 2: Fatal and/or non-fatal MI

Analysis 1.3. Comparison 1: Education versus no education, Outcome 3: Other fatal and/or non-fatal cardiovascular events ...

Analysis 1.4. Comparison 1: Education versus no education, Outcome 4: Total revascularisations (including CABG and PCI) ....

Analysis 1.5. Comparison 1: Education versus no education, Outcome 5: Hospitalisations

Analysis 1.6. Comparison 1: Education versus no education, Outcome 6: Withdrawals 
[Intervention Review]

\section{Patient education in the management of coronary heart disease}

Lindsey Anderson ${ }^{1}$, James PR Brown ${ }^{2}$, Alexander M Clark ${ }^{3}$, Hasnain Dalal ${ }^{4}$, Henriette Knold K Rossau ${ }^{5}$, Charlene Bridges ${ }^{6}$, Rod S Taylor 7

1Institute of Health Research, University of Exeter Medical School, Exeter, UK. 2Department of Anesthesia, BC Women's Hospital, Vancouver, BC, Canada. ${ }^{3}$ Faculty of Nursing, University of Alberta, Edmonton, Canada. ${ }^{4}$ Department of Primary Care, University of Exeter Medical School, Truro Campus, Knowledge Spa, Royal Cornwall Hospitals Trust, Truro, UK. ${ }^{5}$ Danish Knowledge Centre for Rehabilitation and Palliative Care, University of Southern Denmark and Region of Southern Denmark, Copenhagen, Denmark. 6Institute of Health Informatics Research, University College London, London, UK. ${ }^{7} \mathrm{MRC} / \mathrm{CSO}$ Social and Public Health Sciences Unit \& Robertson Centre for Biostatistics, Institute of Health and Well Being, University of Glasgow, Glasgow, UK

Contact address: Rod S Taylor, rod.taylor@gla.ac.uk.

Editorial group: Cochrane Heart Group.

Publication status and date: Stable (no update expected for reasons given in 'What's new'), published in Issue 6, 2021.

Citation: Anderson L, Brown JPR, Clark AM, Dalal H, Rossau HKK, Bridges C, Taylor RS. Patient education in the management of coronary heart disease. Cochrane Database of Systematic Reviews 2017, Issue 6. Art. No.: CD008895. DOI: 10.1002/14651858.CD008895.pub3.

Copyright $(2017$ The Cochrane Collaboration. Published by John Wiley \& Sons, Ltd.

\section{A B S T R A C T}

\section{Background}

Coronary heart disease (CHD) is the single most common cause of death globally. However, with falling CHD mortality rates, an increasing number of people live with CHD and may need support to manage their symptoms and improve prognosis. Cardiac rehabilitation is a complex multifaceted intervention which aims to improve the health outcomes of people with CHD. Cardiac rehabilitation consists of three core modalities: education, exercise training and psychological support. This is an update of a Cochrane systematic review previously published in 2011, which aims to investigate the specific impact of the educational component of cardiac rehabilitation.

\section{Objectives}

1. To assess the effects of patient education delivered as part of cardiac rehabilitation, compared with usual care on mortality, morbidity, health-related quality of life (HRQOL) and healthcare costs in patients with CHD.

2. To explore the potential study level predictors of the effects of patient education in patients with CHD (e.g. individual versus group intervention, timing with respect to index cardiac event).

\section{Search methods}

We updated searches from the previous Cochrane review, by searching the Cochrane Central Register of Controlled Trials (CENTRAL) (Cochrane Library, Issue 6, 2016), MEDLINE (Ovid), Embase (Ovid), PsycINFO (Ovid) and CINAHL (EBSCO) in June 2016. Three trials registries, previous systematic reviews and reference lists of included studies were also searched. No language restrictions were applied.

\section{Selection criteria}

1. Randomised controlled trials (RCTs) where the primary interventional intent was education delivered as part of cardiac rehabilitation.

2. Studies with a minimum of six-months follow-up and published in 1990 or later.

3. Adults with a diagnosis of CHD.

\section{Data collection and analysis}

Two review authors independently screened all identified references for inclusion based on the above inclusion criteria. One author extracted study characteristics from the included trials and assessed their risk of bias; a second review author checked data. Two 
independent reviewers extracted outcome data onto a standardised collection form. For dichotomous variables, risk ratios and $95 \%$ confidence intervals $(\mathrm{Cl})$ were derived for each outcome. Heterogeneity amongst included studies was explored qualitatively and quantitatively. Where appropriate and possible, results from included studies were combined for each outcome to give an overall estimate of treatment effect. Given the degree of clinical heterogeneity seen in participant selection, interventions and comparators across studies, we decided it was appropriate to pool studies using random-effects modelling. We planned to undertake subgroup analysis and stratified meta-analysis, sensitivity analysis and meta-regression to examine potential treatment effect modifiers. We used the Grading of Recommendations Assessment, Development and Evaluation (GRADE) approach to evaluate the quality of the evidence and the GRADE profiler (GRADEpro GDT) to create summary of findings tables.

\section{Main results}

This updated review included a total of 22 trials which randomised 76,864 people with CHD to an education intervention or a 'no education' comparator. Nine new trials ( 8215 people) were included for this update. We judged most included studies as low risk of bias across most domains. Educational 'dose' ranged from one 40 minute face-to-face session plus a 15 minute follow-up call, to a four-week residential stay with 11 months of follow-up sessions. Control groups received usual medical care, typically consisting of referral to an outpatient cardiologist, primary care physician, or both.

We found no difference in effect of education-based interventions on total mortality (13 studies, 10,075 participants; $189 / 5187$ (3.6\%) versus 222/4888 (4.6\%); random effects risk ratio (RR) $0.80,95 \% \mathrm{Cl} 0.60$ to 1.05; moderate quality evidence). Individual causes of mortality were reported rarely, and we were unable to report separate results for cardiovascular mortality or non-cardiovascular mortality. There was no evidence of a difference in effect of education-based interventions on fatal and/or non fatal myocardial infarction (MI) (2 studies, 209 participants; $7 / 107$ (6.5\%) versus $12 / 102$ (11.8\%); random effects RR $0.63,95 \% \mathrm{Cl} 0.26$ to 1.48; very low quality of evidence). However, there was some evidence of a reduction with education in fatal and/or non-fatal cardiovascular events (2 studies, 310 studies; $21 / 152$ (13.8\%) versus $61 / 158$ (38.6\%); random effects RR $0.36,95 \% \mathrm{Cl} 0.23$ to 0.56 ; low quality evidence). There was no evidence of a difference in effect of education on the rate of total revascularisations (3 studies, 456 participants; 5/228 (2.2\%) versus 8/228 (3.5\%); random effects RR 0.58, $95 \% \mathrm{Cl} 0.19$ to 1.71 ; very low quality evidence) or hospitalisations ( 5 studies, 14,849 participants; $656 / 10048$ (6.5\%) versus $381 / 4801$ (7.9\%); random effects $\mathrm{RR} 0.93,95 \% \mathrm{Cl} 0.71$ to 1.21 ; very low quality evidence). There was no evidence of a difference between groups for all cause withdrawal (17 studies, 10,972 participants; 525/5632 (9.3\%) versus 493/5340 (9.2\%); random effects RR $1.04,95 \%$ Cl 0.88 to 1.22 ; low quality evidence). Although some health-related quality of life (HRQoL) domain scores were higher with education, there was no consistent evidence of superiority across all domains.

\section{Authors' conclusions}

We found no reduction in total mortality, in people who received education delivered as part of cardiac rehabilitation, compared to people in control groups (moderate quality evidence). There were no improvements in fatal or non fatal MI, total revascularisations or hospitalisations, with education. There was some evidence of a reduction in fatal and/or non-fatal cardiovascular events with education, but this was based on only two studies. There was also some evidence to suggest that education-based interventions may improve HRQoL. Our findings are supportive of current national and international clinical guidelines that cardiac rehabilitation for people with CHD should be comprehensive and include educational interventions together with exercise and psychological therapy. Further definitive research into education interventions for people with $\mathrm{CHD}$ is needed.

\section{PLAIN LANGUAGE SUMMARY}

\section{Education for people with coronary heart disease}

\section{Review question}

What are the effects of patient education delivered as part of cardiac rehabilitation, compared with usual care on mortality, morbidity, health-related quality of life (HRQOL) and healthcare costs in patients with coronary heart disease (CHD)?

\section{Background}

Coronary heart disease (CHD) is the single most common cause of death globally. However, more people now live with heart disease and may need support to manage symptoms and reduce risk of future problems such as heart attacks. Education is a common element of cardiac rehabilitation, which aims to improve the health and outcomes of people with heart disease. This is an update of a review last published in 2011.

\section{Search date}

We searched up to June 2016.

\section{Study characteristics}


We searched the scientific literature for randomised controlled trials (experiments that randomly allocate participants to one of two or more treatment groups) looking at the effectiveness of education-based treatments compared with no education in people of all ages with CHD.

We included nine new trials which involved 8215 people with coronary heart disease that compared patient education with no education. We included a total of 22 trials that studied 76,864 people with heart disease, most of whom had survived heart attack, and had undergone heart bypass surgery or angioplasty (a procedure which opens blocked vessels that supply blood to heart muscle).

\section{Study funding sources}

Sixteen studies reported sources of funding; six did not report funding sources. One study was funded by an industrial sponsor, four by health insurance companies and 11 by government or public sources.

\section{Key results}

Findings of this update are similar to the last review version (2011). Patient education, as part of a cardiac rehabilitation programme, does not contribute to fewer deaths, further heart attacks, heart by-pass or angioplasty, or admission to hospital for heart-related problems. There is some evidence of fewer other heart-related events and improvements in health-related quality of life with education-based interventions. Individual causes of death were not reported, so we were unable to determine how many people in the studies died from heart-related causes or other causes of death.

Although there is insufficient information at present to fully understand the benefits or harms of patient education for people with heart disease, our findings broadly support current guidelines that people with heart disease should receive comprehensive rehabilitation that includes education. Further research is needed to evaluate the most clinically and cost-effective ways of providing education for people with heart disease.

\section{Quality of evidence}

Overall, evidence was assessed as very low to moderate quality. 


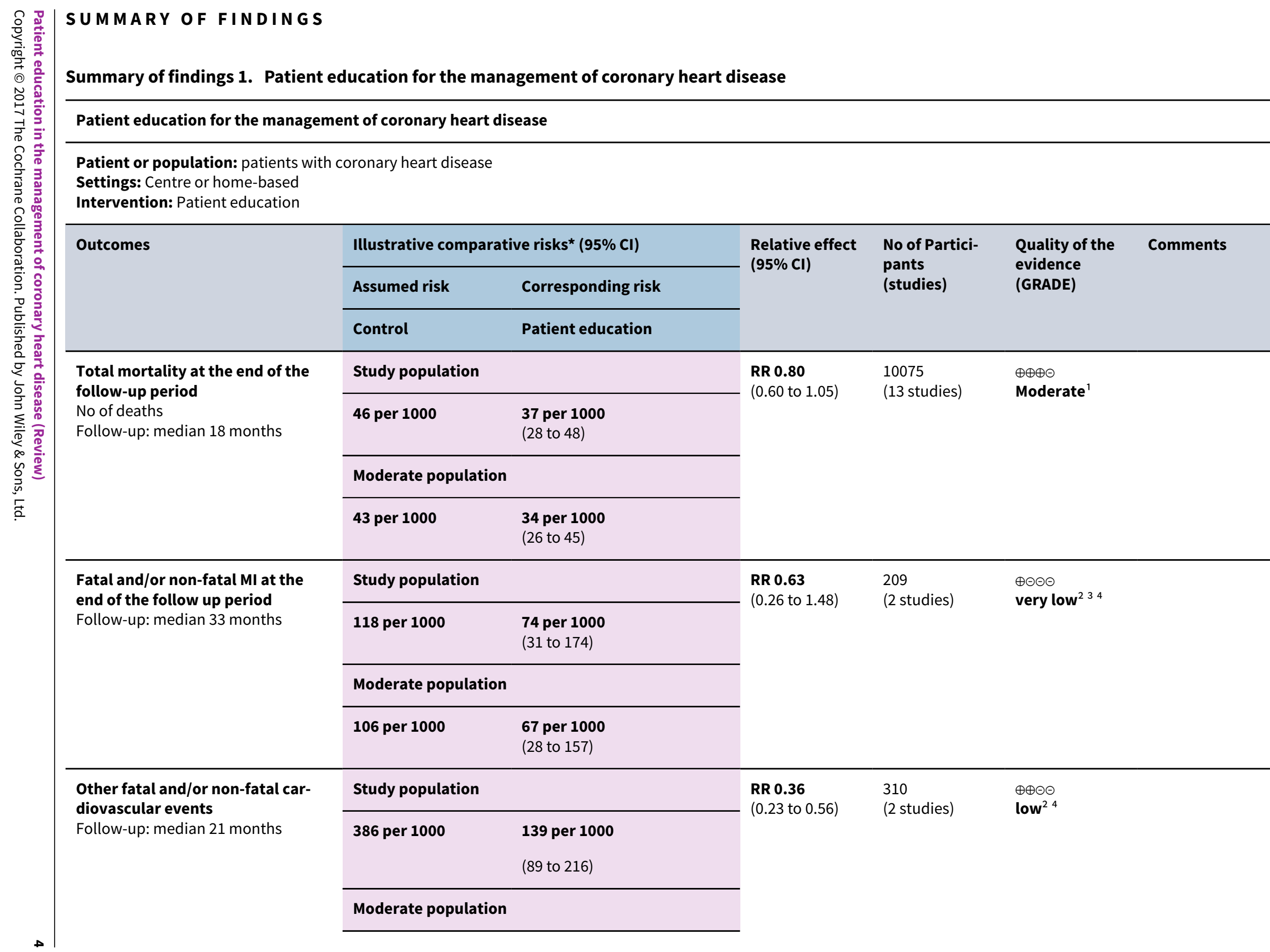

Patient or population: patients with coronary heart diseas

Settings: Centre or home-based

Study population

RR 0.80

10075

$\oplus \oplus \oplus \oplus$

Fatal and/or non-fatal MI at th

end of the follow up period

RR $\mathbf{0 . 6 3}$

209

$\oplus \ominus \odot \odot$

Follow-up: median 33 months 


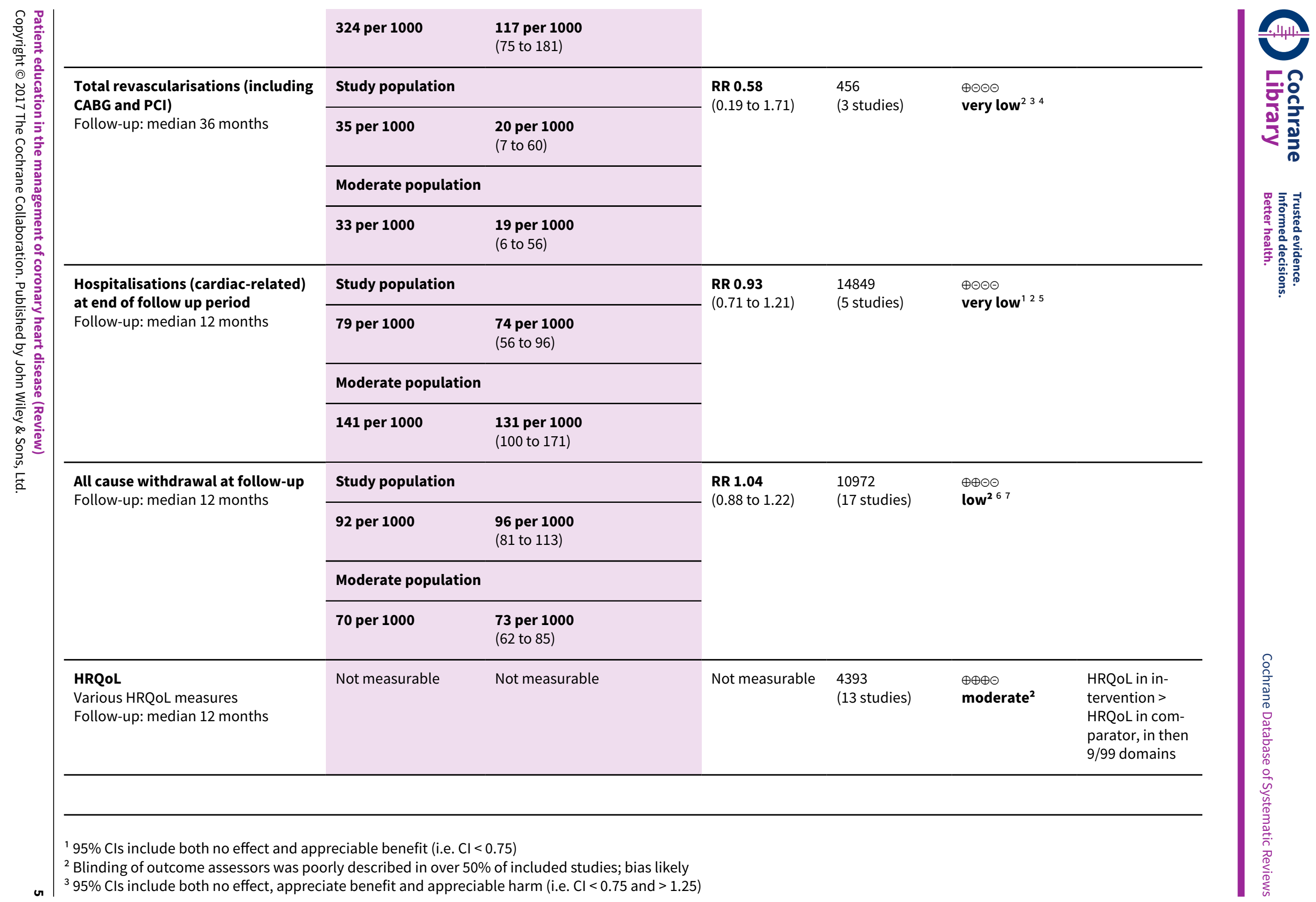




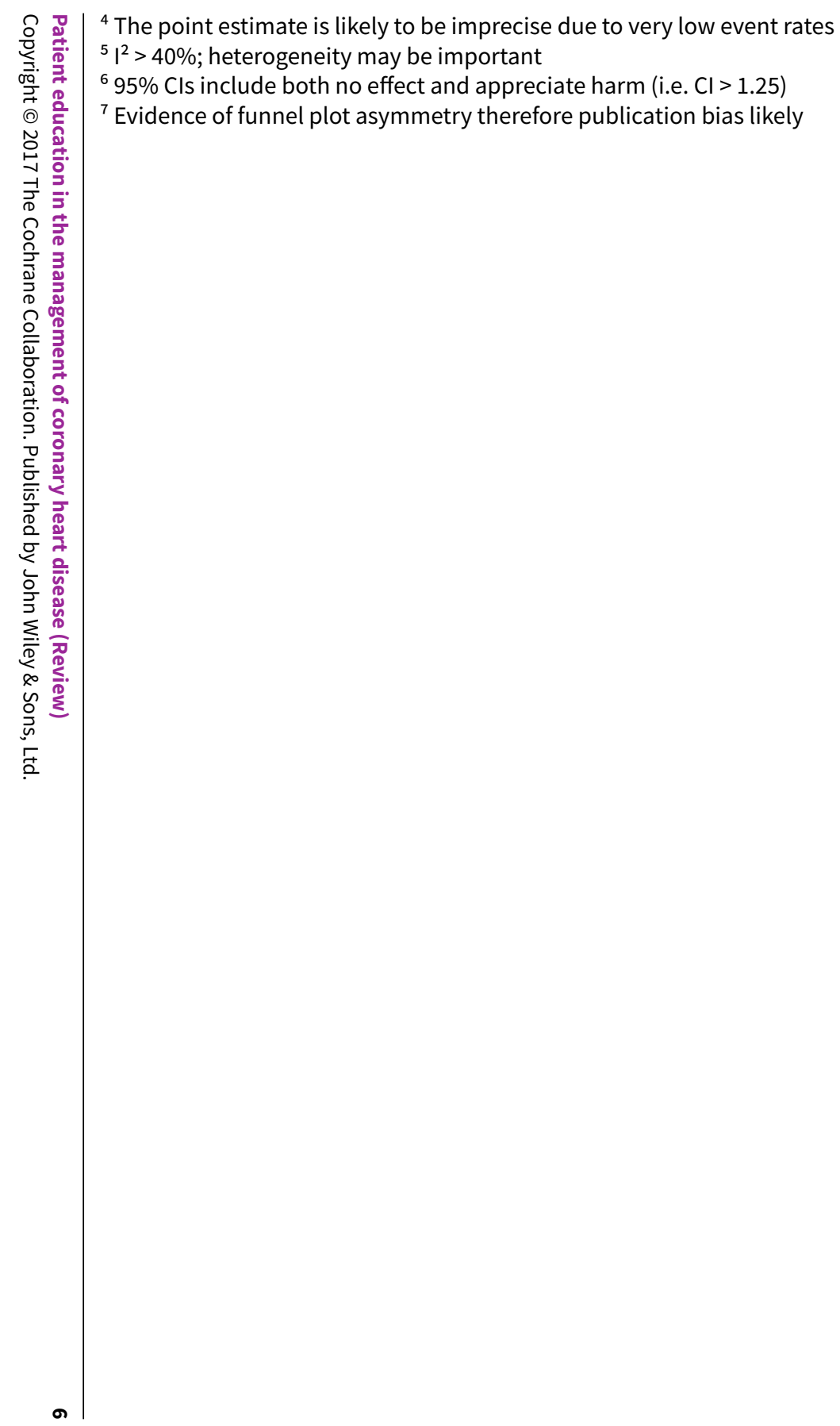




\section{B A C K G R O U N D}

\section{Description of the condition}

Coronary heart disease (CHD) is the largest cause of death globally. In 2105, an estimated 8,8 million people died from CHD worldwide (WHO 2017). In the United Kingdom (UK), an estimated 2.3 million people live with $\mathrm{CHD}$, and in 2014, the condition accounted for around 69,000 deaths (15\% of male deaths and $10 \%$ of female deaths), and 3.4\% of all inpatient episodes in men and $1.4 \%$ in women (BHF 2015). Most cardiovascular diseases can be prevented by addressing behavioural risk factors such as smoking, unhealthy diet and obesity, physical inactivity and harmful use of alcohol. Indeed, through early detection strategies, advanced medical treatment, lifestyle changes and risk factor reductions, UK agestandardised CHD death rates declined by $73 \%$ for all ages, and $81 \%$ for those dying before the age of 75, between 1974 and 2013 (BHF 2015). Nonetheless, with falling CHD mortality rates, an increasing number of people live with $\mathrm{CHD}$ and may need support to manage their symptoms and improve prognosis.

\section{Description of the intervention}

Based on evidence from previous meta-analyses and systematic reviews, exercise-based cardiac rehabilitation following a cardiac event is a Class I recommendation from the American College of Cardiology/American Heart Association (Balady 2011; Kulik 2015) and the European Society of Cardiology (ESC 2012; ESC 2016; Smith 2011). Many definitions of cardiac rehabilitation have been proposed. The following definition encompasses the key concepts of cardiac rehabilitation: "The coordinated sum of activities required to influence favourably the underlying cause of cardiovascular disease, as well as to provide the best possible physical, mental and social conditions, so that the patients may, by their own efforts, preserve or resume optimal functioning in their community and through improved health behaviour, slow or reverse progression of disease" (BACPR 2012). Cardiac rehabilitation is a complex intervention that may involve a variety of therapies, including exercise, risk factor education, behaviour change, psychological support, and strategies that are aimed at targeting traditional risk factors for cardiovascular disease. Cardiac rehabilitation is an essential part of contemporary heart disease care and is considered a priority in countries with a high prevalence of CHD.

Patient education is defined as "the process by which health professionals and others impart information to patients that will alter their health behaviours or improve their health status" (Koongstvedt 2001). Self-management education programmes are designed to allow people with chronic conditions to take an active part in managing their own condition (Foster 2007). They are complex behavioural interventions which target patient education and promote self-care behaviour and riskfactor modification and aim to improve health outcomes and decrease the incidence of complications for patients by supporting, not replacing, medical care (Walker 2003). This in turn may lead to reduced hospitalisations and medical appointments and an associated reduction in costs, both to the patient and the healthcare system (Ferri 2007). Educational interventions within cardiac care increase patients' knowledge and facilitate behaviour change (Ghisi 2014). Educational interventions in cardiac care have been shown to increase physical activity, and lead to healthier dietary habits and smoking cessation, although any related improvement in response to cardiac symptoms, medication compliance or psychosocial well-being is more equivocal (Ghisi 2014).

The delivery of patient education programmes can vary substantially, and may be classroom- or home-based, group or individual, tailored or generic. Common topics include nutrition, exercise, risk factor modification, psychosocial wellbeing, and medications (Ghisi 2014). Duration, frequency and ongoing maintenance or re-inforcement also varies between programmes. Some programmes are developed according to validated educational theory and by trained professionals who are part of an interdisciplinary team, whilst others are delivered by peers. Some programmes may use adjunctive written materials or videotapes that supplement clinical consultations, while Internetand mobile phone-based applications may be used to deliver educational material and messages to patients (Neubeck 2009). Telephone follow-up is increasingly used by healthcare providers to reach patients more frequently and in their own environment without the burden of a clinic visit (Phillips 2014).

Both the American College of Cardiology/American Heart Association and the European Society of Cardiology recognise education as an important component of comprehensive cardiac rehabilitation programmes and give a Class I recommendation that patients with non-ST-elevation acute coronary syndromes (ACS) and individuals with very high cardiovascular disease risk, should be educated about appropriate cholesterol management, blood pressure, smoking cessation, and lifestyle management (Amsterdam 2014; ESC 2016; Perk 2012). Exercise and psychological interventions are the subject of recent Cochrane systematic review updates (Anderson 2016; Richards 2017). Whilst these reviews have considered trials that have included education as a cointervention, this review update specifically focuses on the impact of the educational component of cardiac rehabilitation for patients with CHD.

\section{Why it is important to do this review}

Two meta-analyses of education for people with $\mathrm{CHD}$ were published in the 1990s (Dusseldorp 1999; Mullen 1992). Mullen 1992 demonstrated a significant reduction in mortality associated with patient education (weighted average effect size 0.24 standard deviation units, $95 \% \mathrm{Cl} 0.14$ to 0.33 ), which translated into a $19 \%$ improvement in mortality. The average effects for morbidity (reinfarction and re-hospitalisation) were not found to be significant. However, one randomised controlled trial (RCT) was excluded from analysis because it was an outlier as it demonstrated a large positive effect size (Rahe 1979). Dusseldorp 1999 investigated the co-interventions of health education and stress management and concluded that these programmes yielded a mean reduction of $34 \%$ in cardiac mortality and a $29 \%$ reduction in re-infarction. A Cochrane Review was subsequently published in 2011 which identified 13 RCTs randomising a total of 68,556 participants (Brown 2011). Brown 2011 incorporated new evidence and addressed concerns relating to the generalisability of the results of the two earlier meta-analyses to the wider CHD population, and their applicability to policy formation, improved medical treatment of people with $\mathrm{CHD}$, and the changing provision of cardiac rehabilitation services. Brown 2011 did not find evidence that education reduced total mortality, cardiac morbidity, revascularisation or hospitalisation compared to control, while there was some evidence to suggest that education may improve 
health-related quality of life (HRQoL) and reduce overall healthcare costs. A more recent systematic review investigated the impact of education on patients' knowledge and health behaviour change in people with CHD (Ghisi 2014), but to our knowledge, there have been no other recent meta-analyses which have updated the evidence on the effect of education delivered as part of cardiac rehabilitation, on mortality, morbidity and $\mathrm{HRQ}$ oL in this population.

The American College of Cardiology/American Heart Association and the European Society of Cardiology recognise education as an important component of comprehensive cardiac rehabilitation programmes and give a Class I recommendation that people with non-ST-elevation ACS and those with very high cardiovascular disease risk should be educated about appropriate cholesterol management, blood pressure, smoking cessation, and lifestyle management (Amsterdam 2014; ESC 2016; Perk 2012).

This update aimed to use additional RCT evidence published since the 2011 Cochrane Review to re-assess the effectiveness of education compared with usual care on mortality, risk of hospital admission, myocardial infarction, revascularisation, HRQoL and healthcare costs in people with CHD.

\section{O B J E C T IVES}

1. To assess the effects of patient education delivered as part of cardiac rehabilitation, compared with usual care on mortality, morbidity, health-related quality of life (HRQoL) and healthcare costs in patients with $\mathrm{CHD}$.

2. To explore the potential study level predictors of the effects of patient education in patients with CHD (e.g. individual versus group intervention, timing with respect to index cardiac event).

\section{METHODS}

\section{Criteria for considering studies for this review}

\section{Types of studies}

To reflect contemporary coronary heart disease (CHD) practice we included randomised controlled trials (RCTs) published after 1990.

\section{Types of participants}

We included studies where participants were adults (aged $\geq 18$ years):

- who had experienced a myocardial infarction (MI);

- who underwent revascularisation (coronary artery bypass grafting (CABG), percutaneous coronary intervention ( $\mathrm{PCl}$ ) or coronary artery stenting); or

- who had angina pectoris or CHD defined by angiography.

We excluded studies of education programmes which included participants who:

- had received heart valve surgery;

- suffered from heart failure;

- were heart transplantation recipients;

- were implanted with cardiac-resynchronisation therapy; or

- were implanted with defibrillators.

\section{Types of interventions}

We identified RCTs where patient education was the primary intention of the cardiac rehabilitation intervention with a followup period of at least six months. We excluded studies of cardiac rehabilitation where exercise or psychological intervention were the primary focus for investigation. These latter components of cardiac rehabilitation have been investigated in recently updated Cochrane Reviews of exercise-based cardiac rehabilitation (Anderson 2016) and psychological cardiac rehabilitation interventions for people with CHD (Richards 2017).

For the purposes of this review, patient education was defined as the following:

1. instructional activities organised in a systematic way involving personal direct contact between a health professional and CHD patients with or without significant others: e.g. spouse, family member;

2. delivered as an inpatient, or outpatient in a community-based intervention setting or programme;

3. included some form of structured knowledge transfer about CHD, its causes, treatments or methods of secondary prevention; and

4. delivered in a face-to-face format, in groups or on a one-toone basis. We also included alternative interactive methods of educational delivery such as 'telehealth' (telephone, e-mail, Internet and teleconference between educator and patient).

We included only study interventions that met all the above criteria.

We excluded general information provision, which is not organised in a systematic way (e.g. written guidance given to a patient on leaving the cardiac care unit or personal communication with a healthcare provider), which was considered to be usual care.

Given the multifaceted nature of cardiac rehabilitation we excluded studies where exercise and psychological therapies, or both, were provided and patient education was not stated to be a primary intervention.

We particularly sought studies designed to assess the independent effect of education (e.g. patient education plus usual care versus usual care alone; patient education, usual care and exercise versus usual care and exercise alone; patient education, usual care and psychological intervention versus usual care and psychological intervention alone).

\section{Types of outcome measures}

The aim of the review was to include studies that reported event data (e.g. mortality, cardiovascular events). We excluded studies that only measured alternative outcomes such as changes in smoking, diet, blood pressure or effect of education on patient knowledge. We elected not to include these alternative surrogate outcomes because we considered event rates to be more significant.

\section{Primary outcomes}

- Total mortality.

- Cardiovascular mortality.

- Non-cardiovascular mortality.

- Fatal and/or non-fatal myocardial infarction (MI). 
- Other fatal and/or non-fatal cardiovascular events.

\section{Secondary outcomes}

- Total revascularisations (including coronary artery bypass grafting (CABG) and percutaneous coronary intervention ( $\mathrm{PCI})$ ).

- Hospitalisations (total number of cardiac-related patient admissions in the follow-up period following the intervention).

- Withdrawals.

- Health-related quality of life (HRQoL, using validated measures e.g. Short Form Health Survey SF-36, Sickness Impact Profile, Nottingham Health Profile).

- Adverse events.

- Healthcare costs and cost-effectiveness.

We excluded any study that did not measure one or more of these outcomes.

\section{Search methods for identification of studies}

\section{Electronic searches}

We searched the following databases on 30 June 2016:

- CENTRAL Issue 6, 2016 (in the Cochrane Library);

- MEDLINE (Ovid) 1946 to June week 32016 ;

- Embase (Ovid) 1980 to 2016 week 26;

- PsycINFO (Ovid) 1806 to June week 32016 ; and

- CINAHL (EBSCO) 1937 to 30 June 2016.
The search strategies were designed with reference to those used previously (Brown 2011). We searched the databases using a strategy combining selected MeSH terms and free text terms relating to patient education and $\mathrm{CHD}$, with filters applied to limit to RCTs. We used the Cochrane sensitivity-maximising RCT filter for MEDLINE, and for Embase, terms recommended in the Cochrane Handbook were applied (Lefebvre 2011). Adaptations of this filter were applied to CINAHL and PsycINFO. We translated the MEDLINE search strategy for use in the other databases using the appropriate controlled vocabulary as applicable. We imposed no language or other limitations and gave consideration to variations in terms used and spellings of terms in different countries so that studies would not be missed by the search strategy because of such variations. See Appendix 1 for details of the search strategies used.

Ongoing trials were identified from searching the following trial registries in May 2016:

- UK Clinical Trials Gateway (https://www.ukctg.nihr.ac.uk/)

- ClinicalTrials.gov (https://clinicaltrials.gov)

- ICTRP WHO International Clinical Trials Registry Platform (http://apps.who.int/trialsearch/)

Search results reporting was conducted in accordance with PRISMA (Moher 2009). A flow diagram is included, which provides information about the number of studies identified, included and excluded, and reasons for exclusions (Figure 1). 
Figure 1. PRISMA flow diagram

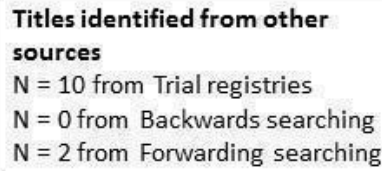

\begin{tabular}{|l|}
\hline RCTs included from \\
2011 review \\
$N=13$ \\
(N $=24$ publications) \\
\hline
\end{tabular}

$\mathrm{N}=2$

RCTs from updated search
$N=9$
(N $=17$ publications)

bibliographies \& screened for retrieval

$\mathrm{N}=3918$

$N=2749$ after de-duplication
Titles excluded

$\mathrm{N}=2639$

Full text articles excludec

$\mathrm{N}=84$

- Inappropriate population $\mathrm{N}=3$

- Inappropriate intervention $\mathrm{N}=36$

- Inappropriate comparator $\mathrm{N}=6$

- Inappropriate outcomes $\mathrm{N}=19$

- Not an RCT design $\mathrm{N}=7$

- Follow-up less than 6 months $\mathrm{N}=13$

Plus 5 studies classified as on-going in the 2011 update were excluded as they didn't meet our inclusion criteria

\section{Ongoing studies}

$\mathrm{N}=16$

Studies awaiting classification

$\mathrm{N}=5$

\section{Searching other resources}

Reference lists of all eligible trials, systematic reviews and metaanalyses were searched for additional studies. Attempts were made to contact all study authors to obtain relevant information not available in the published manuscript.

\section{Data collection and analysis}

\section{Selection of studies}

Titles and abstracts of studies identified by the search strategy were screened by two independent review authors (LA, RST) and obviously irrelevant studies were discarded. The full-text reports of all potentially relevant abstracts were obtained (LA) and assessed independently for eligibility (LA, RST). Any disagreement was resolved by discussion. Excluded studies and reasons for exclusion are detailed in the Characteristics of excluded studies table.

\section{Data extraction and management}

One review author (LA) extracted study characteristics of included RCTs using a standardised data collection form which had been piloted on two RCTs included in the review. Data on patient characteristics (e.g. age, sex, CHD diagnosis) details of the intervention (including duration, frequency and delivery), description of usual care and length of follow-up were extracted. A second author (HKR) checked all extracted data for accuracy.
Two independent review authors (LA, HKR) extracted outcome data onto a standardised collection form. If data were presented numerically (in tables or text) and graphically (in figures), the numeric data were used because of possible measurement error when estimating from graphs. Any discrepancies were resolved by arbitration. One review author (LA) transferred extracted data into Review Manager 5.3 (RevMan 2014), and a second author (RST) checked data for accuracy against the systematic reviews.

If there were multiple reports of the same study, we assessed the duplicate publications for additional data. We extracted outcome results at all follow-up points post-randomisation. We contacted study authors where necessary to provide additional information.

\section{Assessment of risk of bias in included studies}

One review author (LA) assessed the risk of bias in included studies using Cochrane's recommended tool, which is a domain-based critical evaluation of the following core risk of bias items: the quality of random sequence generation and allocation concealment, description of withdrawals, blinding of outcome assessment, and presence of selective reporting (Higgins 2011). We also assessed three further quality criteria: whether the study groups were balanced at baseline, if the study groups received comparable care (apart from the educational component of the intervention), and whether an intention-to-treat analysis was undertaken. The criteria 
used for assessing these last three risk of bias domains are as follows.

\section{Groups balanced at baseline}

- Low risk of bias: the characteristics of the participants in the intervention and control groups at baseline is reported to be comparable or can be judged to be comparable in terms of likely main prognostic factors.

- Uncertain risk of bias: it is not reported whether the participants' characteristics in the two groups are balanced at baseline and there is inadequate information reported to assess this.

- High risk of bias: there is evidence of substantive imbalance in the baseline characteristics of the intervention and control groups with regard to likely major prognostic factors.

\section{Intention-to-treat analysis}

- Low risk of bias: the trial reports that the analyses were conducted according to an intention-to-treat analysis, and includes all the principles of such an analysis, e.g. keeping participants in the intervention groups to which they were randomised, regardless of the intervention they actually received; and measures outcome data on all or the majority of participants (i.e. $>80 \%$ of those randomised) or includes imputation of all missing data in the analysis, using appropriate methodology, e.g. multiple imputation.

- Uncertain risk of bias: it is unclear if the trial has performed an intention-to-treat analysis.

- High risk of bias: the trial does not include an intention-to-treat analysis, or there is a substantive loss of outcome data (e.g. $>20 \%$ ) and analyses are performed according to imputation methods known to create bias such as last observation carried forward.

\section{Groups received comparable treatment (except exercise)}

- Low risk of bias: all co-interventions were delivered equally across intervention and control groups.

- Uncertain risk of bias: there was insufficient information to access whether co-interventions were equally delivered across groups.

- High risk of bias: the co-interventions were not delivered equally across intervention and control groups.

All risk of bias assessments were checked by a second review author (HKR) and any discrepancies were resolved by arbitration. Details of the assessments of risk of bias for each included trial are shown in the Characteristics of included studies table.

\section{Measures of treatment effect}

For dichotomous variables, risk ratios (RR) and 95\% confidence intervals $(\mathrm{Cl})$ were derived for each outcome. If any continuous variables had been reported, mean differences and $95 \% \mathrm{Cl}$ would have been calculated for each outcome.

\section{Unit of analysis issues}

In accordance with Section 9.3.1 of the Cochrane Handbook for Systematic Reviews of Intervention (Higgins 2011), we ensured that the analysis was appropriate to the level at which randomisation occurred. All studies included in this review were simple parallel group RCTs, and so there were no issues relating to unit of analysis.

\section{Dealing with missing data}

We contacted investigators or study sponsors to verify key study characteristics and obtain missing numerical outcome data where possible (for example when a study is identified as an abstract only). Had this not been possible, and the missing data were thought to introduce serious bias, we planned to explore the impact of including such studies on the overall assessment of results by a sensitivity analysis.

\section{Assessment of heterogeneity}

We explored heterogeneity amongst included studies qualitatively (by comparing the characteristics of included studies) and quantitatively (using the $\mathrm{Chi}^{2}$ test of heterogeneity and $\mathrm{I}^{2}$ statistic). We used a threshold of $\mathrm{I}^{2}$ greater than $50 \%$ for both dichotomous and continuous outcomes to determine the statistical model to be used for meta-analysis.

\section{Assessment of reporting biases}

The funnel plot and the Egger test were used to examine small study bias (Egger 1997).

\section{Data synthesis}

We processed data in accordance with Cochrane Handbook for Systematic Reviews of Interventions guidance (Deeks 2011). Where appropriate and possible, results from included studies were combined for each outcome to give an overall estimate of treatment effect. Given the degree of clinical heterogeneity seen in participant selection, interventions and comparators across studies, we decided it was appropriate to pool studies using random-effects modelling.

With the exception of total mortality, the review did not identify sufficient data to allow stratified meta-analysis at different common follow-up timings (e.g. 6 or 12 months postrandomisation). Instead, we pooled studies at their longest followup unless otherwise stated.

\section{Summary of findings table}

Two independent review authors (LA, RST) used the Grading of Recommendations Assessment, Development and Evaluation (GRADE) approach to interpret result findings and used GRADEpro GDT 2014 to import data from Review Manager to create a 'Summary of findings table'. We created a 'Summary of findings' table using the following outcomes: total mortality, fatal and/ or non-fatal $\mathrm{MI}$, total revascularisations, other fatal and/or nonfatal cardiovascular events, hospitalisations, withdrawals and HRQoL. We used the five GRADE considerations (study limitations, consistency of effect, imprecision, indirectness and publication bias) to assess the quality of a body of evidence as it relates to the studies that contribute data to the meta-analyses for the prespecified outcomes. We used methods and recommendations described in Section 8.5 and Chapter 12 of the Cochrane Handbook for Systematic Reviews of Interventions using GRADEpro GDT 2014 software (Higgins 2011). We justified all decisions to downgrade the quality of studies using footnotes, and made comments to aid readers' understanding of the review where necessary.

\section{Subgroup analysis and investigation of heterogeneity}

As stated in the protocol, we planned to undertake subgroup analysis and stratified meta-analysis, sensitivity analysis and meta- 
regression to examine potential treatment effect modifiers. We intended to test the following a priori hypotheses that there may be differences in the effect of education on total mortality and withdrawal across particular subgroups:

- CHD case mix (MI-only trials versus other trials).

- Dose and nature of structured patient education. Assessed on the basis of the number and nature of education sessions e.g. extent of training of who delivers the education, a healthcare professional, or specific educational training, whether feedback or re-inforcement were given (i.e. literature, audiovisual followup material).

- Method of structured educational delivery (one-to-one versus group versus combination).

- Theoretical versus no theoretical basis to educational intervention.

- Involvement of significant others (e.g. spouse, family member) in the education.

- Timing of the education following the index event.

- Length of the educational intervention.

- Follow-up period ( $\leq 12$ months versus $>12$ months).

For this update we also tested the following predictors of total mortality and withdrawal using univariate meta-regression:

- mean age of participants;

- percentage of male participants;

- type of cardiac rehabilitation (education only versus education plus e.g. exercise or psychological intervention);

- study location (continent); and

- setting (centre versus home).

Due to poor reporting, we were unable to examine the association of dose of education or timing following the index event, with the risk of total mortality or withdrawal.

\section{Sensitivity analysis}

We undertook a sensitivity analysis to examine the effect of risk of bias (low risk in $\geq$ five items versus < five items) and year of publication (before 2000 versus 2000 or later) of included studies on total mortality and withdrawal.

We decided it was appropriate to pool studies using random-effects modelling, due to the clinical heterogeneity seen in participant selection, interventions and comparators across studies. However, we undertook a sensitivity analysis to examine the effect on the pooled data of conducting a fixed-effect or a random-effects model. The results of the random-effects model are reported as default in the text, while the results from both models for all outcomes are reported in Table 1.

\section{RE S U L T S}

\section{Description of studies}

\section{Results of the search}

We identified 3918 records through our electronic database search. After de-duplication, 2749 titles and abstracts were screened for inclusion, of which 2639 were excluded. We identified two additional records from searching the citations of publications identified as meeting our inclusion criteria, and a further 10 studies listed on trial registries. We retrieved and assessed 122 full text reports for eligibility and subsequently excluded 84 publications. Sixteen studies were ongoing and five were determined as awaiting classification because the full text was not available and authors did not respond to repeated requests for study information. In total, we included an additional nine randomised controlled trials (RCTs) (17 publications) to the 13 RCTs (24 publications) from the 2011 review, totaling 22 RCTs (41 publications). Details of the exclusion process and reasons for exclusion are summarised in a PRISMA flow diagram (Figure 1 ) and in the Characteristics of excluded studies table.

\section{Included studies}

The previous version of this review (Brown 2011) included 13 RCTs (24 publications) (Clark 1997; Clark 2000; Clark 2009; Cupples 1994; Esposito 2008; Hanssen 2007; Lie 2009; Lisspers 1999; P.RE.COR Group 1991; Peikes 2009; Pogosova 2008; Southard 2003; Tingström 2005). We included an additional nine RCTs for this update (16 publications, 8215 participants) (Chow 2015; Cohen 2014; Dracup 2009; Furuya 2015; Jorstad 2013; Melamed 2014; Mooney 2014; Moreno-Palanco 2011; Park 2013). We included a total of 22 studies reporting data for a total of 76,864 participants in this update.

Details of included studies are listed in the Characteristics of included studies table. Seventeen studies compared educationonly interventions with a comparator and five studies reported on an education plus counselling or behaviour change intervention (Dracup 2009; Hanssen 2007; Lie 2009; Lisspers 1999; Peikes 2009). No studies included interventions which comprised exercise as a co-intervention.

Eleven studies were undertaken in Europe (Cohen 2014; Cupples 1994; Hanssen 2007; Jorstad 2013; Lie 2009; Lisspers 1999; Melamed 2014; Mooney 2014; Moreno-Palanco 2011; P.RE.COR Group 1991; Tingström 2005); six were performed in the USA (Clark 1997; Clark 2000; Clark 2009; Esposito 2008; Peikes 2009; Southard 2003); and one each in Russia (Pogosova 2008), Australia (Chow 2015), South America (Furuya 2015) and Asia (Park 2013) and one was undertaken in sites in USA, Australia and New Zealand (Dracup 2009). Fourteen studies were multicentre RCTs (Clark 1997; Clark 2000; Clark 2009; Cohen 2014; Cupples 1994; Dracup 2009; Esposito 2008; Jorstad 2013; Melamed 2014; Mooney 2014; P.RE.COR Group 1991; Peikes 2009; Southard 2003; Tingström 2005); and eight were single centre RCTs (Chow 2015; Furuya 2015; Hanssen 2007; Lie 2009; Lisspers 1999; Moreno-Palanco 2011; Park 2013; Pogosova 2008).

Sixteen studies reported sources of funding; six did not report funding sources (Clark 1997; Esposito 2008; Lie 2009; Melamed 2014; Moreno-Palanco 2011; Pogosova 2008). One study was funded by an industrial sponsor (Jorstad 2013), four by health insurance companies (Chow 2015; Cohen 2014; Lisspers 1999; Peikes 2009) and 11 by government or public sources (Clark 2000; Clark 2009; Cupples 1994; Dracup 2009; Furuya 2015; Hanssen 2007; Mooney 2014; P.RE.COR Group 1991; Park 2013; Southard 2003; Tingström 2005).

Most trials were relatively small in sample size (median 454 participants, range: 63 to 46,606). Two large trials (Esposito 2008; Peikes 2009) contributed $85 \%$ (65,008 participants) of all included participants. 
The median duration of trial intervention was six months (range 1 to 36 months) with median follow-up of 12 months (range 6 to 60 months).

The case mix of participants recruited to the included trials varied considerably; six studies recruited mixed populations of people with CHD (Chow 2015; Clark 1997; Clark 2000; Clark 2009; Melamed 2014; Pogosova 2008); four studies recruited participants with myocardial infarction (MI) or angina (Cohen 2014; Jorstad 2013; Mooney 2014; Park 2013); and the remaining studies recruited participants post-revascularisation (Furuya 2015; Lie 2009; Lisspers 1999); with coronary heart disease (CHD) or heart failure (Esposito 2008; Peikes 2009; Southard 2003); MI (Hanssen 2007; P.RE.COR Group 1991); acute coronary syndromes (ACS) (Dracup 2009; Moreno-Palanco 2011); angina (Cupples 1994); or MI or postrevascularisation (Tingström 2005).

The mean age of trial participants ranged from 51.0 to 72.8 years. Although all but two trials included women (20 studies, 91\%), only $25 \%$ of participants recruited were women.

The two largest studies (65,008 participants) (Esposito 2008; Peikes 2009) included some participants who were outside the scope of this review (i.e. trialists considered people with congestive cardiac failure and diabetes). However, participants with $\mathrm{CHD}$ contributed $69 \%$ and $61 \%$ respectively, to these studies. Both studies reported hospitalisation, health-related quality of life (HRQoL) and cost data. Only hospitalisation data from Esposito 2008 contributed to the meta-analysis, and these data were reported separately for participants with CHD (Esposito 2008). Southard 2003 included participants with cardiac failure as well as those with CHD.

Four studies involved group sessions (Clark 1997; Clark 2000; Pogosova 2008; Tingström 2005); 12 involved individual education sessions (Chow 2015; Cohen 2014; Cupples 1994; Dracup 2009; Esposito 2008; Hanssen 2007; Lie 2009; Melamed 2014; MorenoPalanco 2011; Mooney 2014; Park 2013; Peikes 2009); three used both group and individual sessions (Lisspers 1999; P.RE.COR Group 1991; Southard 2003); one study compared group and individual approaches (Clark 2009); and one study did not report on the mode of teaching (Jorstad 2013). Eighteen studies involved faceto-face sessions (Cohen 2014; Dracup 2009; Clark 1997; Clark 2000; Clark 2009; Cupples 1994; Esposito 2008; Furuya 2015; Jorstad 2013; Lie 2009; Lisspers 1999; Melamed 2014; Moreno-Palanco 2011; Mooney 2014; P.RE.COR Group 1991; Park 2013; Pogosova 2008; Tingström 2005); three were reliant on telephone contact (Esposito 2008; Hanssen 2007; Peikes 2009); three used face-to-face sessions as well as telephone follow-up (Furuya 2015; Mooney 2014; Park 2013); one involved interactive use of the Internet (Southard 2003); and one used text messages via a mobile phone (Chow 2015). The educational intervention was delivered by a wide variety of personnel, with nine interventions delivered by nurses (Cohen 2014; Dracup 2009; Esposito 2008; Furuya 2015; Hanssen 2007; Jorstad 2013; Lie 2009; Mooney 2014; Moreno-Palanco 2011); four by trained educators (Clark 1997; Clark 2000; Clark 2009; Tingström 2005); three by physicians (Melamed 2014; P.RE.COR Group 1991; Pogosova 2008), and one each by a care co0ordinator (Peikes 2009), case manager (Southard 2003), and a researcher (Furuya 2015). The person delivering the intervention was not described in one study (Park 2013). The intensity of the education programme varied substantially from just one 40 minute face-to-face session plus a 15 minute follow-up call (Dracup 2009) to a four-week residential stay reinforced with 11 months of nurse-led follow-up sessions (Lisspers 1999). Description of the educational content of the programmes was mostly brief and lacked detail. Table 2 summarises educational interventions.

\section{Excluded studies}

We excluded 84 full text publications because they did not meet the inclusion criteria for this review (see Characteristics of excluded studies). Seven studies were not RCTs, 13 studies had follow-up periods of less than six months, three studies included populations who were irrelevant for this Review, 36 studies investigated interventions that were not relevant to this Review, six included inappropriate comparators and 19 studies did not report outcomes that were relevant to this Review.

\section{Ongoing studies}

The details of 16 ongoing studies that appear to meet the inclusion criteria for this Review are presented in Characteristics of ongoing studies (ACTRN12613000395730; ACTRN12613000793718; ACTRN12616000426482; Brewer 2015; Dwinger 2013; IRCT201307162621N13; ISRCTN15839687; Kärner 2012; Lai 2016; Lynggaard 2014; NCT01028066; NCT01275716; NCT01925079; NCT02185391; NTR2388; Shah 2011).

\section{Studies awaiting classification}

The details of five studies that are awaiting classification are presented in Characteristics of studies awaiting classification.. One study was published in the IIOAB Journal, but we were not able to access any of this journal's web pages (Gao 2011). We were unable to find the full text or trace the authors of the remaining four studies ( Licina 2010; Soliman 2013; Vona 2009; Xiaolin 2012).

\section{Risk of bias in included studies}

Several studies did not report sufficient methodological detail to enable assessment of potential risk of bias. Details of random sequence generation, concealment of random allocation and blinding were the most frequent poorly reported parameters. Risk of bias results are summarised in Figure 2 and Figure 3. 
Figure 2. Risk of bias summary: review authors' judgements about each risk of bias item for each included study.

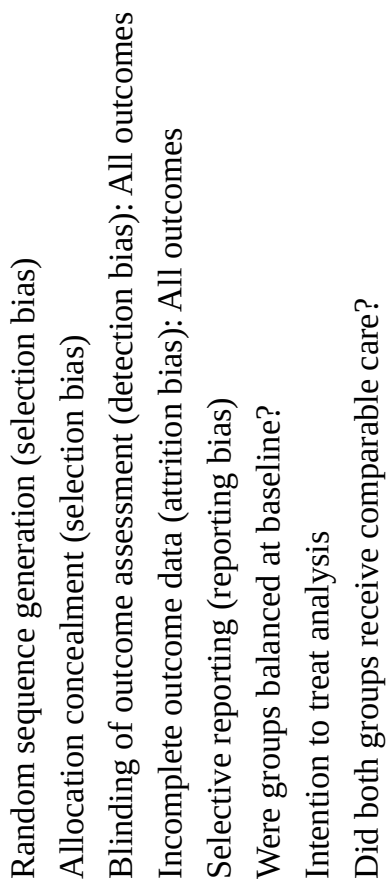

Chow 2015

Clark 1997

Clark 2000

Clark 2009

Cohen 2014

Cupples 1994

Dracup 2009

Esposito 2008

Furuya 2015

Hanssen 2007

Jorstad 2013

Lie 2009

Lisspers 1999

Melamed 2014

Mooney 2014

Moreno-Palanco 2011

P.RE.COR Group 1991

Park 2013

Peikes 2009

Pogosova 2008

Southard 2003

Tingström 2005
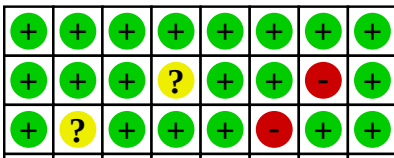
Figure 3. Risk of bias graph: review authors' judgements about each risk of bias item presented as percentages across all included studies

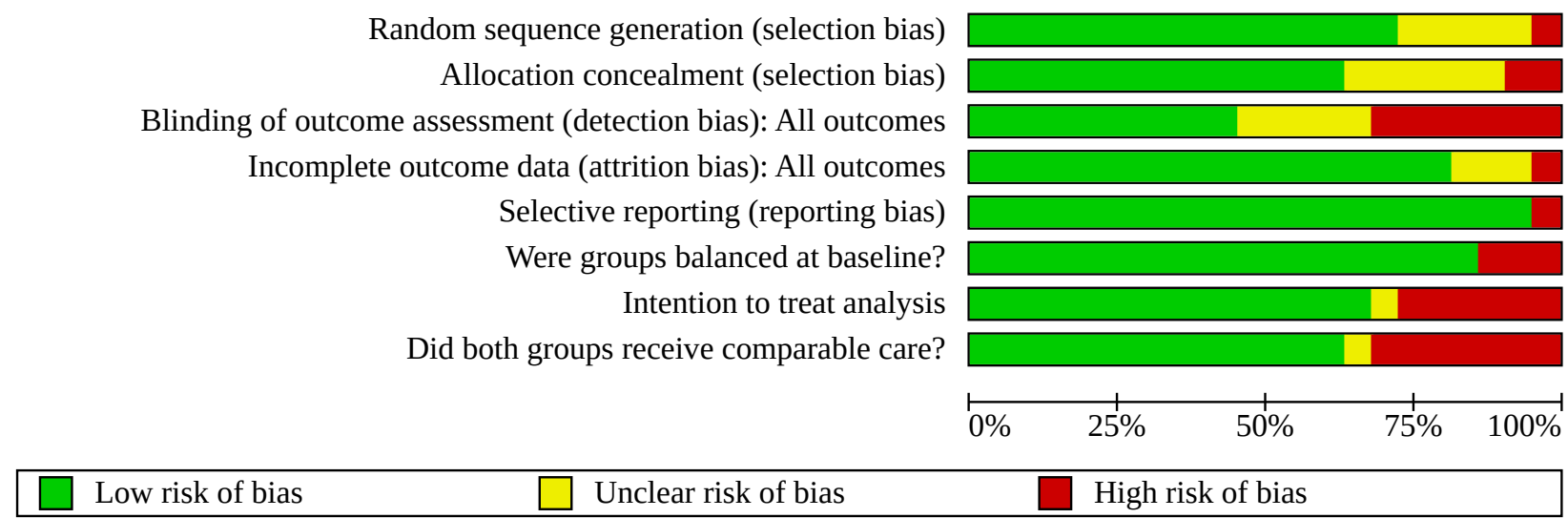

\section{Allocation}

Sixteen studies were judged to provide evidence of adequate random sequence generation (Chow 2015; Cohen 2014; Clark 1997; Clark 2000; Clark 2009; Cupples 1994; Furuya 2015; Hanssen 2007; Jorstad 2013; Lie 2009; Mooney 2014; Moreno-Palanco 2011; Park 2013; Peikes 2009; Southard 2003; Tingström 2005). Fourteen studies reported adequate concealment methods (Chow 2015; Clark 1997; Clark 2009; Cohen 2014; Cupples 1994; Furuya 2015; Hanssen 2007; Jorstad 2013; Lie 2009; Melamed 2014; Mooney 2014; Moreno-Palanco 2011; Peikes 2009; Tingström 2005).

\section{Blinding}

Due to the nature of the educational intervention, it was not possible to blind education providers or trial participants. We investigated evidence to ascertain if those collecting, assessing or analysing outcome data were blinded to group allocation. Blinding of this nature was confirmed in 10 studies (Chow 2015; Cohen 2014; Clark 1997; Clark 2000; Clark 2009; Cupples 1994; Dracup 2009; Furuya 2015; Jorstad 2013; Moreno-Palanco 2011).

\section{Incomplete outcome data}

Sixteen studies clearly stated withdrawal or numbers lost to followup (Table 3). Overall, $11.3 \%$ of participants in intervention groups and $11.5 \%$ of control group participants were lost to follow-up. Most authors failed to assess participants who were lost to follow-up for systematic differences when compared to those who completed the study.

\section{Selective reporting}

We compared the reported outcomes in the results sections to the outcomes described in the methods of published papers. No attempt was made to identify original study protocols and compare these to reported outcomes. Only one study demonstrated selective reporting by not reporting the results of a HRQoL measure (Southard 2003).

\section{Other potential sources of bias}

\section{Baseline balance}

Eighteen studies had a good balance of subject baseline characteristics between intervention and control groups. Four studies demonstrated a statistically significant imbalance between groups at baseline (Clark 2000; Dracup 2009; Mooney 2014; Peikes 2009). There were differences in baseline disease symptoms and weight in Clark 2000. Peikes 2009 highlighted 11 differences in 255 baseline characteristics compared between groups, which they qualified as "less than the expected number of statistical significant differences than would be observed by chance (Peikes 2009). In Dracup 2009, there were differences in baseline body mass index, gender (with more females in the experimental group than control, $P=0.02$ ), and insurance for ambulance use. In Mooney 2014, there were some significant differences between characteristics and prognostic factors of the two groups at baseline including age.

\section{Intention-to-treat analysis}

Fifteen studies analysed results on an intention-to-treat basis (Chow 2015; Cohen 2014; Clark 2000; Clark 2009; Cupples 1994; Esposito 2008; Hanssen 2007; Lie 2009; Lisspers 1999; Mooney 2014; Moreno-Palanco 2011; P.RE.COR Group 1991; Peikes 2009; Southard 2003; Tingström 2005). In most cases, this involved analysing those participants remaining at follow-up according to initial randomisation. Clark 1997 did not present intention-to-treat data, but presented data for participants who had attended at least one of the four intervention sessions.

\section{Comparative care}

We specifically sought to investigate the impact of education. However, in addition to education (the primary intervention), participants appeared to receive other co-interventions such as exercise or psychological therapy in a number of studies. It was unclear how much of these co-interventions were received by control group participants, posing potential for performance bias (Dracup 2009; Esposito 2008; Hanssen 2007; Lisspers 1999; Park 2013; Peikes 2009; Southard 2003). 


\section{Effects of interventions}

See: Summary of findings 1 Patient education for the management of coronary heart disease

\section{Primary outcomes}

\section{Total mortality}

Thirteen studies (10,075 participants) reported total mortality. Two studies reported deaths at six months (Chow 2015; Furuya 2015); five at 12 months (Clark 2000; Cohen 2014; Dracup 2009; Jorstad 2013; Mooney 2014); two at 18 months (Clark 2009; Hanssen 2007); four at 24 months (Clark 2000; Cupples 1994; Lisspers 1999; P.RE.COR Group 1991); one at 36 months (Moreno-Palanco 2011) and two at 60 months (Cupples 1994; Lisspers 1999). Only one study demonstrated a significant difference in total mortality between education and control, where the cumulative survival rate at three years was $97.4 \%$ in the intervention group and $85.5 \%$ in the control group $(P=0.003$ ) (Moreno-Palanco 2011). At the longest reported follow-up, there was no difference in effect of education-based interventions on total mortality (random effects RR $0.80,95 \% \mathrm{Cl}$ 0.60 to 1.05 ; participants $=10,075$; studies $=13$; Analysis 1.1 ) .

Quality of the evidence for this outcome was judged to be moderate (Summary of findings 1 ).

When data were stratified by length of follow-up, there was similar uncertainty of the effect of education-based interventions on total mortality for those studies with a mean length of follow-up of more than 12 months (random effects RR $0.78,95 \% \mathrm{Cl} 0.60$ to 1.02; participants $=6012$; studies $=7$ ). There was no evidence of a reduction in total mortality in studies with a mean length of followup of 12 or fewer months (random effects RR $0.78,95 \% \mathrm{Cl} 0.35$ to 1.78; participants $=4063$; studies $=6$ ).

\section{Cardiovascular mortality}

Individual causes of mortality were poorly or not reported across studies. We were therefore unable to report separate data for cardiovascular mortality.

\section{Non-cardiovascular mortality}

Individual causes of mortality were not reported across studies. We were therefore unable to report separate data for noncardiovascular mortality.

\section{Fatal and/or non-fatal myocardial infarction (MI)}

Two studies reported fatal and/or non-fatal MI (Lisspers 1999; P.RE.COR Group 1991). There was no evidence of a reduction in morbidity with education-based interventions for fatal and/or nonfatal MI (random effects RR $0.63,95 \% \mathrm{Cl} 0.26$ to 1.48; participants = 209; studies $=2$; Analysis 1.2)

Quality of the evidence for this outcome was judged to be very low (Summary of findings 1).

\section{Other fatal and/or non-fatal cardiovascular events}

Two studies reported other fatal or non-fatal cardiovascular events (Moreno-Palanco 2011; Park 2013, 310 participants). There was some evidence of a reduction in other fatal or nonfatal cardiovascular events with education-based interventions (random effects RR $0.36,95 \% \mathrm{Cl} 0.23$ to 0.56 ; participants $=310$; studies = 2; Analysis 1.3).
Quality of the evidence for this outcome was judged to be low (Summary of findings 1 ).

Southard 2003 reported a difference in "major cardiovascularrelated events"; fewer events occurred in the intervention group $(P=0.053)$. These were defined as events needing hospitalisation either as an inpatient or from the emergency department. As other cardiovascular events may have occurred that did not meet this definition, it was not appropriate to include these data in the pooled analysis.

\section{Secondary outcomes}

Total revascularisations (coronary artery bypass graft (CABG) or percutaneous coronary intervention (PCI))

Three studies (456 participants), reported subsequent revascularisation (CABG or PCI) (Lisspers 1999; Moreno-Palanco 2011; P.RE.COR Group 1991). There was no evidence of a reduction in morbidity with education for total revascularisations (random effects RR $0.58,95 \% \mathrm{Cl} 0.19$ to 1.71 ; participants $=456$; studies $=3$; Analysis 1.4).

Quality of the evidence for this outcome was judged to be very low (Summary of findings 1 ).

\section{Hospitalisations}

Seven studies reported cardiac-related hospitalisations (Clark 2000; Esposito 2008; Hanssen 2007; Lisspers 1999; Mooney 2014; Peikes 2009; Southard 2003).

We pooled the results of the five studies (14,849 participants) that reported numbers of participants who were hospitalised for cardiac-related events (Esposito 2008; Hanssen 2007; Lisspers 1999; Mooney 2014; Southard 2003). There was no evidence of a reduction in hospitalisation with education-based interventions (random effects RR $0.93,95 \% \mathrm{Cl} 0.71$ to 1.21 ; participants = 14,849; studies $=5$; Analysis 1.5 .

Quality of the evidence for this outcome was judged to be very low (Summary of findings 1).

Due to the method of reporting hospitalisations in four studies, it was not possible to include these in the pooled analysis (Clark 2000; Dracup 2009; Jorstad 2013; Peikes 2009).

Using intention-to-treat analysis Clark 2000 found no statistically significant difference in the total number of hospitalisations between intervention and control. Analysis of the "heart-related admissions" in those participants who attended at least one intervention session revealed statistically significant reductions in the intervention group: participants in the intervention group had $41 \%$ fewer "heart-related admissions" $(P=0.05)$ and $61 \%$ fewer "heart-related" inpatient days $(P=0.02)$ than in the control group (Clark 2000).

Dracup 2009 reported the number of participants who presented to the emergency department with symptoms of ACS ( 565 participants $(16.0 \%)$ and a total of 842 admissions). Of the 565 participants, 305 (54\%) were in the intervention group and 260 (46\%) were in the control group. Of the 842 emergency department admissions, $408(48 \%)$ were in the control group and $434(52 \%)$ were in the intervention group. 
Jorstad 2013 reported the cumulative number of re-admissions in 12 months. In total, there were 86 rehospitalisations in the intervention group and 132 in the control group $(P=0.023)$ (Jorstad 2013). This difference was driven by a $67 \%$ reduction in re-admissions for non-ACS chest pain (12 admissions versus 36 admissions, $\mathrm{P}<0.001$ ); re-admissions for ACS and elective interventions were comparable in both groups.

Peikes 2009 reported the rate of hospitalisations across 15 different USA study sites. Overall, there was no clear evidence of effect of intervention, with only two of 15 sites showing a significant difference in hospital admissions. One reported an increase in admissions in the intervention group and the other reported an increase in the control group. No between-group statistical difference was found in average annualised admission rates 0.91 (intervention) versus 0.95 (control) $(P=0.145)$.

\section{Withdrawals}

Studies varied in their reporting of participants who withdrew or dropped out of the study, the analysis or both. Most studies failed to report the number of participants who withdrew because they were unable to complete the intervention. Therefore, we reported withdrawals at follow-up (Table 3). There was no evidence of a difference in the number of withdrawals from the education-based intervention or control groups (random effects RR 1.04, 95\% Cl 0.88 to 1.22 ; participants $=10,972$; studies $=17$; Analysis 1.6 ) .

Results remained equivocal when data were stratified by length of follow-up (mean follow-up $\leq 12$ months: random effects RR 1.18 , $95 \% \mathrm{Cl} 0.93$ to 1.49; participants $=4960$; studies $=10$; mean followup > 12 months: random effects RR $0.98,95 \% \mathrm{Cl} 0.80$ to 1.20 ; participants $=6012$; studies $=7$ ).

Quality of the evidence for this outcome was judged to be low (Summary of findings 1).

Clark 1997 reported a combined withdrawal of 181 participants from both groups. A differential breakdown was not given, but there was "no appreciable differences in withdrawal rates between the intervention and control group" demonstrated (Clark 1997).

Numbers lost to follow-up were unclear in four studies (Esposito 2008; Lisspers 1999; Peikes 2009; Pogosova 2008).

\section{Health-related quality of life (HRQOL)}

Fifteen studies reported HRQoL (Cohen 2014; Clark 1997; Clark 2000; Clark 2009; Cupples 1994; Esposito 2008; Furuya 2015; Hanssen 2007; Lie 2009; Lisspers 1999; Melamed 2014; Park 2013; Pogosova 2008; Southard 2003; Tingström 2005). These studies used several generic HRQoL instruments, i.e. SF-12 (Cohen 2014; Furuya 2015), SF-36 (Furuya 2015; Hanssen 2007; Lie 2009; Pogosova 2008; Tingström 2005), Nottingham Health Profile (Cupples 1994), Sickness Impact Profile (Clark 1997; Clark 2000), a five-point patient assessment scale of quality of life (Cupples 1994) and two disease-specific HRQoL instruments i.e. Seattle Angina Questionnaire (Lie 2009; Park 2013), AP-QLQ (Angina PectorisQuality of Life Questionnaire) (Lisspers 1999) and the MacNew Heart Disease Quality of Life Questionnaire (Melamed 2014). The wide variation in $\mathrm{HRQ}$ oL outcomes and methods of reporting meant we were unable to meta-analyse results. Instead, we undertook a detailed tabulation of the overall and domain HRQoL scores from each of the trials with a particular focus on intervention- control differences at follow-up. To provide some level of overall synthesis, for each study we assessed whether total and domain HRQoL between-group differences were statistically different and, if so, the direction of effect (Table 4; Table 5; Table 6; Table 7; Table 8; Table 9; Table 10; Table 11; Table 12; Table 13; Table 14; Table 15; Table 16; Table 17 ).

Whilst overall we found no consistent difference in HRQoL total or domain score at follow-up between intervention and comparator, a number of studies reported statistically significant differences in HRQoL domains in favour of intervention (Clark 1997; Clark 2000; Cupples 1994; Park 2013). Pogosova 2008 demonstrated an improvement in all SF-36 domain scores and Lie 2009 an improvement in the overall mental score in the intervention groups. No studies reported HRQoL scores that favoured the comparator group.

Although Southard 2003 reported Dartmouth COOP Quality of Life scores at trial entry, there were no reports of this outcome at follow-up. Esposito 2008 reported on a HRQoL questionnaire undertaken in a randomly selected subgroup of patients from the overall trial. No significant differences were found between the intervention and control groups in a number of measures of mental and physical status, including: "Primary condition interfered a lot or somewhat with enjoyment of life in the last 4 weeks" (betweengroup difference $-3.6 \%$ (in favour of intervention) $P=0.379$ ); "Beneficiary felt primary condition placed a burden on family in the past 4 weeks" (between-group difference 0.5\% $P=0.897$ ); "Beneficiary felt depressed about living with primary condition in the past 4 weeks" (between-group difference 1.2\% (in favour of control) $\mathrm{P}=0.766$ ).

\section{Adverse events}

Few studies reported on adverse events other than mortality and cardiovascular-related morbidity and hospitalisations. Cohen 2014 reported numbers of participants in the intervention and usual care groups with arrhythmia (1.6\% and $2.8 \%$ respectively); coronary angiography $(7.3 \%$ and $8.9 \%)$; scheduled angioplasty $(4.9 \%$ and $3.2 \%)$; ACS, stent thrombosis, or chest pain (13.5\% and $12.6 \%)$; and dyspnoea, lung oedema, or congestive heart failure $(3.7 \%$ and $2.4 \%$ ). Esposito 2008 reported that there were no significant differences between the groups in the number of preventable events such as hospitalisations for pneumonia or exacerbations of heart failure, or lower-extremity amputations in patients with diabetes.

No study reported any intervention-related adverse events such as prohibitive time or travel demands which would prevent participation in the intervention.

\section{Healthcare costs and cost-effectiveness}

Five studies reported healthcare utilisation and costs (Clark 2000; Cupples 1994; Esposito 2008; Peikes 2009; Southard 2003). Given that cost results were presented in different currencies and incurred in different years, it was difficult to directly compare studies. Furthermore, although studies assessed healthcare costs, there was variation in the particular aspects of healthcare costs that were quantified. Components of costs considered included inpatient admissions, primary care visits, emergency attendances, use of drugs, investigations and subsequent procedures performed. To compare studies and gain an overall impression of the differences in healthcare between intervention and control, we undertook a 
detailed tabulation of the overall and component healthcare costs for each of the included studies (Table 18).

Reflecting the different education modalities and intensities of the interventions, the reported cost of provision per patient varied from GBP 49 (Cupples 1994) to USD 453 (Southard 2003). The largest trials, investigating the efficiency of the Medicare system in the USA (Esposito 2008; Peikes 2009), did not investigate the cost of providing the intervention but instead reported the charge associated with providing this service negotiated by the supplier (care co-ordination fee). Peikes reported a mean of USD 196 per month (Peikes 2009), while Esposito reported a mean of USD 162 per month (Esposito 2008).

Two studies reported an overall average net saving, after subtracting costs of intervention provision, of USD 965 per patient at six-months follow-up (Southard 2003) and USD 1420 per patient at 24-months follow up (Clark 2000). Peikes 2009 reported an increase in average net costs of USD 52 per patients; six of the 15 programmes investigated had higher costs for the intervention group. Two trials found no difference in between-group net costs (Cupples 1994; Esposito 2008).

\section{Meta-regression and stratified meta-analysis}

Predictors of total mortality and all-cause withdrawal were examined across the longest follow-up of each individual study using univariate meta-regression (Table 19; Table 20). We found no evidence that total mortality risk was associated with case mix, age of participants, percentage of male participants, type of cardiac rehabilitation, method of delivery, duration of intervention, theoretical basis of intervention, involvement of family members, study location, setting, or length of follow-up (Table 19). Similarly, we found no associations between predictors of withdrawal, with the exception of evidence of an increased risk of withdrawal in studies with shorter follow-up periods (Table 20). Due to poor reporting we were unable to examine the association of dose of education or timing following the index event with the risk of total mortality or withdrawal.

\section{Sensitivity analysis}

Sensitivity analysis found no evidence that total mortality risk was associated with year of publication (before 2000 versus 2000 or later), or risk of bias (Table 21). Similarly, we found no associations between risk of withdrawal and year of publication, but did see evidence of an increased risk of withdrawal in studies with higher risk of bias (low risk in $\geq$ five items versus $<$ five items) (Table 22).

Data for all outcomes were pooled using both random-effects and fixed-effect modelling (Table 1). With the exception of hospitalisations and withdrawals at the longest follow-up, the direction of effect of all outcomes was the same, regardless of the model used. Similarly, with the exception of total mortality, the choice of model used did not change whether or not the confidence intervals included the null hypothesis.

\section{Small study bias}

With the exception of total mortality and withdrawals, there were too few studies and outcome data to assess small study bias by means of funnel plots or Egger's test. There was no evidence of funnel plot asymmetry or statistically significant Egger's test for total mortality (Figure $4 \mathrm{P}=0.83$ ) or withdrawals (Figure $5 ; \mathrm{P}=0.10$ ). 
Figure 4. Funnel plot of comparison: 4 Education versus no education, outcome: 4.1 Total mortality at the end of the follow up period.

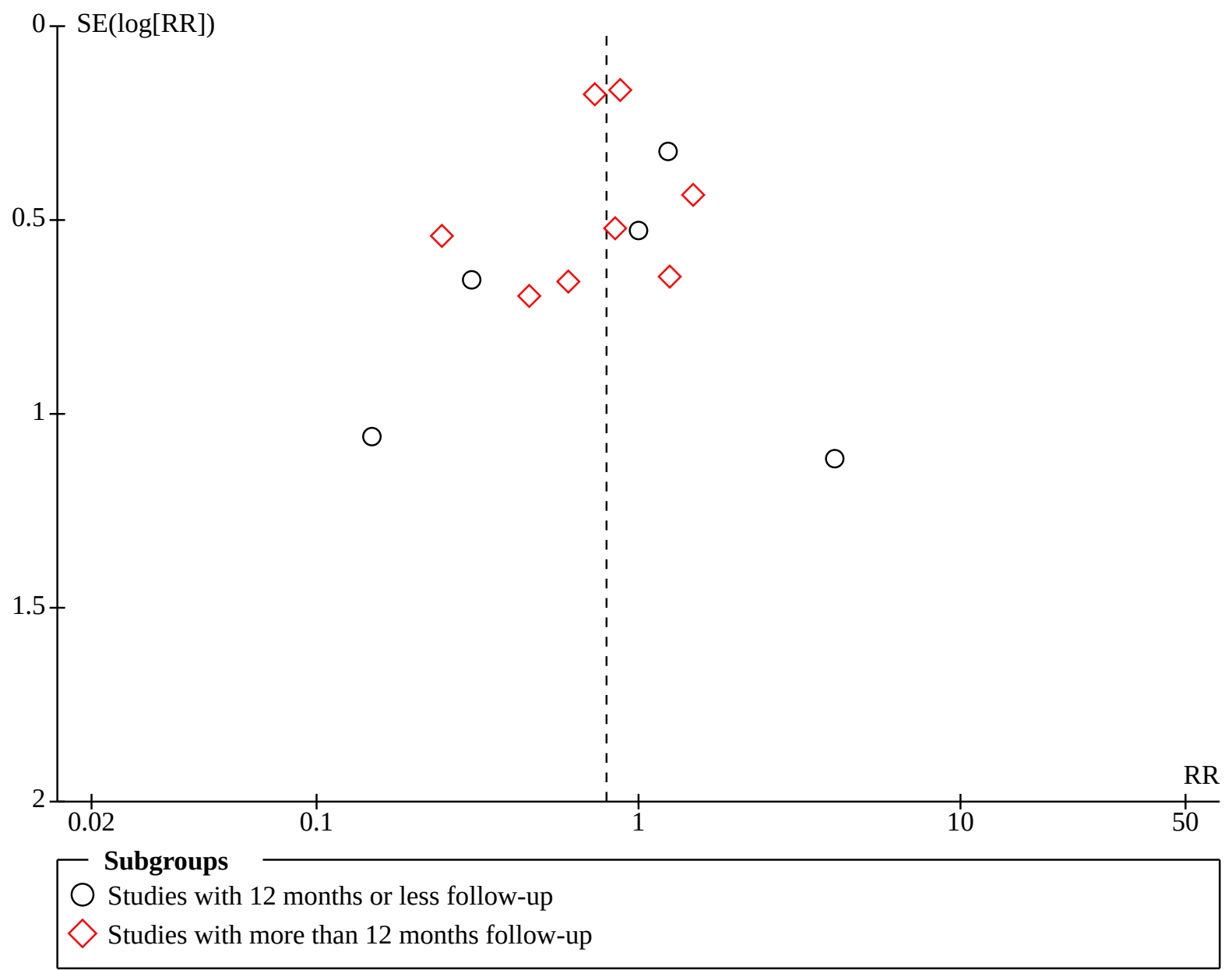


Figure 5. Funnel plot of comparison: 1 Education versus no education, outcome: 1.6 Withdrawals.

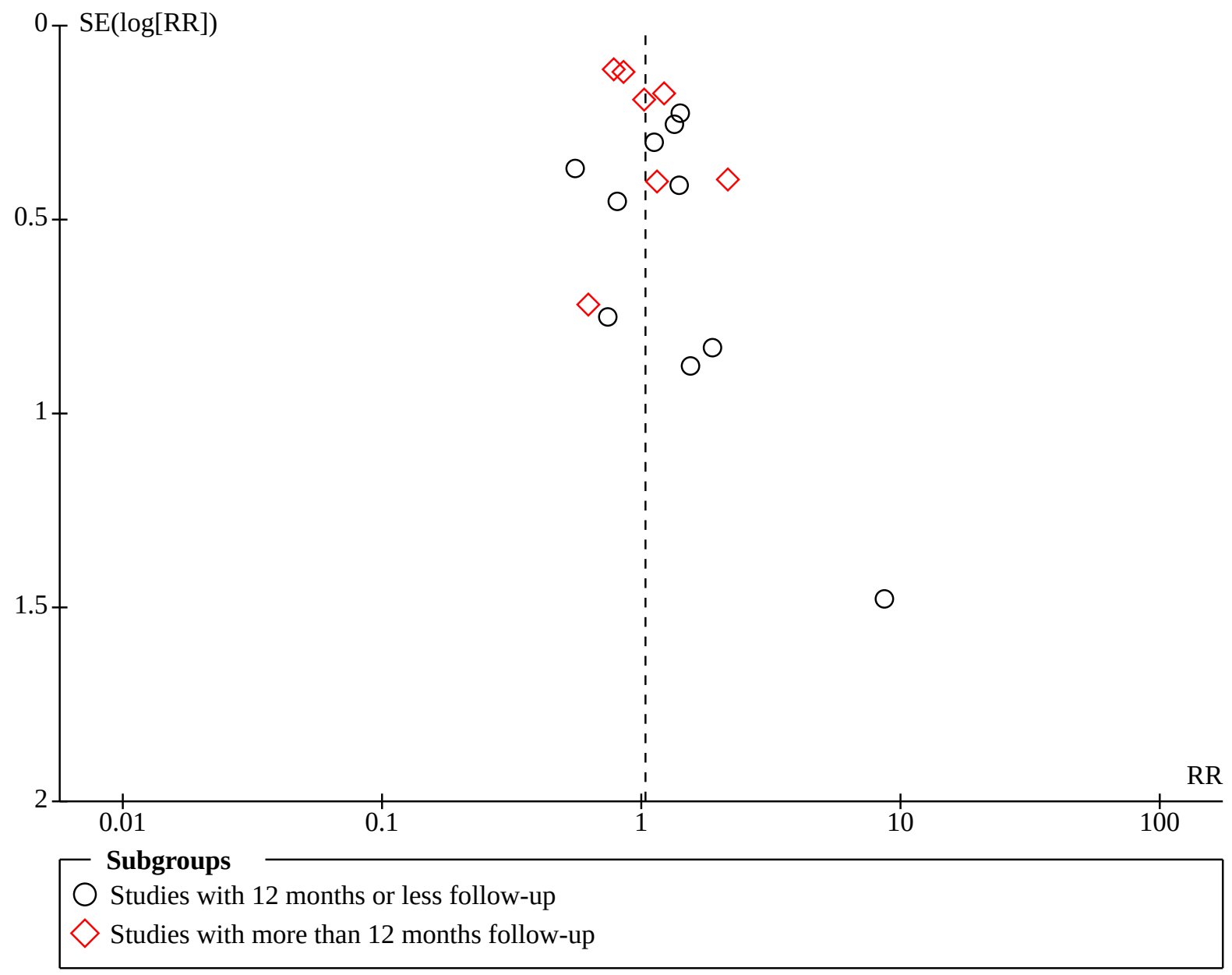

\section{Quality of evidence from randomised controlled trials}

The quality of the evidence for outcomes reported in the review was rated using the GRADE method (Schünemann 2011). The quality of the evidence varied widely by outcome and ranged from very low to moderate (see Summary of findings 1 ). The reasons for downgrading evidence of outcomes included poor reporting of blinding of outcome assessors in at least $50 \%$ of the studies which contributed data to the evidence, evidence of heterogeneity $\left(I^{2}>\right.$ $50 \%)$, or imprecision around the point of effect.

\section{DISCUSSION}

\section{Summary of main results}

We included 22 randomised controlled trials (RCTs) involving 76,864 participants with coronary heart disease (CHD) where education was the primary interventional intent of cardiac rehabilitation. The 'dose' of the education intervention varied substantially across studies from just one 40 minute face-to-face session plus a 15 minute follow-up call (Dracup 2009) to a four-week residential stay re-inforced with 11 months of nurse-led follow up sessions (Lisspers 1999). Control participants typically received usual medical care without a formalised cardiac rehabilitation or secondary prevention education programme.
We found no difference in effect of education on total mortality compared with control. Pooled data for total mortality translates to a possible reduction of 18 deaths per 1000 people, to an increase in two deaths per 1000 people, compared with the assumed risk in the control group of 46 deaths per 1000 (Summary of findings 1 ). As individual causes of mortality were not reported across studies, we were unable to report separate data for cardiovascular mortality or non cardiovascular mortality. We found no evidence that education reduced fatal and/or non-fatal myocardial infarction (MI). We found some evidence of a reduction with education in other fatal and/or non-fatal cardiovascular events, although this was based only on two studies (310 participants). We found no evidence that education reduced revascularisations, or hospitalisation, compared to control groups receiving no education.

Univariate meta-regression analysis shows that the impact of education on total mortality appears to be largely consistent across trials irrespective of case mix (percentage of post-MI participants), type of rehabilitation (exercise-only versus comprehensive), dose of education, duration of follow-up, study location, study setting or risk of bias. As most studies had a relatively short follow-up, these results were based on very few events, and therefore, our meta-analysis lacks sufficient statistical power to make definitive 
conclusions about the impact of educational interventions on events in people with CHD.

Although health-related quality of life (HRQoL) was reported by almost all included studies, we were unable to pool findings due to the heterogeneity of measures. Whilst there was some evidence of higher HRQoL in some domain scores, overall there was no consistent evidence of superior HRQoL following education compared to control. Many studies used generic HRQoL measures that are known to lack sensitivity with cardiac treatment, particularly in comparison with disease-specific measures (Cohen 2014; Furuya 2015; Oldridge 2003; Taylor 1998).

The intention of including analysis of withdrawal from the intervention was to use it as a surrogate for the adverse effects of the intervention, e.g. the educational intervention was so demanding that it could not be completed by participants. However, despite withdrawals being reported by most studies, the reasons for withdrawal were not always clearly described. We found no increase in withdrawals with education compared to control.

The search for this update identified no new studies that reported healthcare costs or cost-effectiveness data. As previously reported (Brown 2011), different currencies and the years in which studies were conducted, made it difficult to directly compare healthcare costs across studies. The cost of the educational intervention varied widely (between GBP 49 and USD 453 per patient) reflecting the differing intensity and requirements for provision of the interventions investigated. There was some evidence that when compared to usual care, patient education may be cost-saving as a result of a reduction in downstream healthcare utilisation.

\section{Overall completeness and applicability of evidence}

The scope of this review was limited in its design in three specific ways:

1. Inclusion only of studies published in 1990 or later;

2. Inclusion only of studies where the educational component was the primary intention of the intervention; and

3. Inclusion only of studies that reported event data (e.g. total mortality) as opposed to intermediate outcomes (e.g. blood pressure, exercise tolerance).

These limitations in scope were crucial in addressing the specific question of what is the 'added value' of patient education in the context of contemporary cardiovascular management. The interpretation of previous systematic reviews of patient education have been confounded by including multicomponent rehabilitation interventions, of which education was only an element, and reporting on studies using surrogate outcomes such as health knowledge or blood pressure. Indeed, many of the trials identified and considered in this review process only investigated outcomes such as cardiovascular risk factor reduction, or prehospital delay from time of symptom onset to hospital arrival, and have not been included in this review.

In spite of the focus of this review, there was considerable heterogeneity of participants and interventions. Several studies included CHD in combination with comorbidities such as diabetes, hypertension or a degree of heart failure (Esposito 2008; Peikes 2009; Southard 2003) and interventions varied substantially in content, mode of delivery and dose. It could be argued that a benefit of this heterogeneity is that the results are more likely to be applicable to the wider population of people with CHD and clinical practice. However, we must acknowledge that different components of the educational intervention may contribute to the composite effect of the education to varying extents. Similarly, fidelity (whether the intervention was delivered as intended) and dose (the quantity of intervention implemented) are important aspects of the delivery of a complex intervention such as cardiac rehabilitation, which were not reported by any included studies.

Previous reviews of patient education, and more broadly cardiac rehabilitation, have identified the paucity of research into outcomes in women and the elderly. However, this review includes several studies with a substantive proportion of women (Clark 2000) and older people (Clark 2009) specifically addressing this disparity. Nevertheless, ethnic minorities remain underrepresented, with a mean of $84 \%$ of participants described as Caucasian in studies that reported ethnicity.

\section{Quality of the evidence}

The general lack of reporting of methods in some of included RCTs made it difficult to assess methodological quality and thereby judge risk of bias. Details were often poorly reported and confirmation of methodology needed to be sought from some authors. Interestingly, reporting of methods was inferior in some of the more recent studies to many of the older studies, leading to a higher risk of selection and attrition bias than was reported in the previous version of this review (Brown 2011). The area of greatest potential risk of bias in this review was detection bias (lack of outcome assessment blinding), with less than half the studies providing sufficient details to judge if outcomes were assessed by researchers blinded or independent to the trial.

Due to this poor reporting, the quality of the evidence for outcomes was assessed as moderate at best. Other reasons for downgrading the quality of evidence included inconsistency (hospitalisations), and imprecision (total mortality, hospitalisations, subsequent $\mathrm{MI}$, revascularisations and withdrawal).

The other area of potential risk of bias was the imbalance of co-interventions received by intervention and control subjects, which made it difficult to investigate the specific impact of education on outcomes. We specifically selected studies on the basis of education being the primary intervention. However, a number of studies appeared to include additional elements (e.g. behaviour modification or psychological support) in the educational intervention arm, which led to a risk of performance bias. Whilst the decision to include studies was made independently by two review authors, the decision was ultimately one of judgement based on the description of the intervention provided by the authors. During correspondence, the lead author of one included study stated: "I would not define our program as 'patient education' (at least according to the way I define this term) - more as a 'behaviour change program'...we ...very much tried to develop active program components which actually and concretely supported the behaviour change process in the short term and for the long-term maintenance" (Lisspers 1999). We would argue that a key objective of patient education is to change behaviour, i.e. through education, patients learn to understand the reasoning for improved diet, exercise regime and compliance with medication and are, therefore, more likely to modify their behaviour. This objective is consistent with adult learning theory; 
learning is the outcome of education and can be defined as "a relatively permanent change in behaviour as a result of experience, training or practice" (Reece 2007).

\section{Potential biases in the review process}

We believe this is the most comprehensive systematic review to date of RCT-based evidence for the impact of education-based cardiac rehabilitation for people with CHD. However, our review has some limitations. Given the inconsistent reporting of outcomes, we were unable to judge the degree of publication bias for most outcomes, although there was no evidence of funnel plot asymmetry or statistically significant Egger's test for total mortality or all-cause withdrawal. Although a specific goal of this updated review was to clarify the impact of education programmes on clinical events, many of the included trials were relatively small and had short-term follow-up periods so that the number of deaths and hospitalisations reported by most trials was small. Indeed, in many studies, we located event data in the trial descriptions of losses to follow-up and exclusions, rather than as stated primary or secondary outcomes. We also acknowledge that the median outcome follow-up of 12 months is limited when assessing for impact on total mortality and morbidity outcome measures. However, reassuringly, our results were consistent when pooling was limited to RCTs with a follow-up more than 12 months.

In this updated review, we had hoped to categorise the CHD diagnoses of trial participants according to a more detailed framework based on Braunwald's classification of CHD (Braunwald 2011) and current clinical management of CHD. However, given the lack of details of trial participants, this more detailed assessment of diagnostic groups was not possible. All participants in the included studies had documented CHD; most had experienced MI or undergone revascularisation. As with the previous version of this review, we combined these different participant groups because there were insufficient data to stratify trials by CHD type. Finally, the mean age of participants in the included trials ranged from 51.0 years to 72.8 years. Elderly participants in clinical trials are underrepresented with only $14 \%$ of participants in clinical trials reported to be aged over 75 years (Dodd 2011). Yet, Myocardial Ischaemia National Audit Project registry data indicate that around $40 \%$ of people with ACS are in that age group (Zaman 2014). Clinical trial participants are therefore unlikely to be truly representative of, and are likely to have relatively fewer comorbidities than, the more frail, older population seen in clinical practice (Alexander 2007; Zaman 2014).

\section{Agreements and disagreements with other studies or reviews}

The findings of this updated review are largely in accord with the previous version (Brown 2011). In this update, we identified nine new RCTs looking at the effect of education on people with CHD. Disappointingly, few studies reported additional total mortality or event data, and consequently, the results of this update remain largely unchanged. While the previous version showed no evidence for the effect of education when delivered as part of cardiac rehabilitation on total mortality in people with CHD, this review found evidence of a reduced risk for this outcome (random effects RR $0.80,95 \% \mathrm{Cl} 0.60$ to 1.05 ; fixed effect RR 0.80 , $95 \% \mathrm{Cl} 0.66$ to 0.97 , moderate quality evidence). Similarly, early systematic reviews by Mullen 1992 and Dusseldorp 1999, reported a statistically significant reduction in mortality and morbidity in people with $\mathrm{CHD}$ following an educational intervention. These earlier reviews included studies with multidimensional interventions (e.g. education plus psychological interventions), non-randomised studies, and studies conducted before 1990 prior to the era of optimal medical therapy. Given the proven survival advantage of contemporary medical treatments, and the limited opportunity for mortality gain in this patient cohort, any incremental total mortality benefit with education is likely to be small.

A more recent systematic review that investigated the impact of education on patients' knowledge and health behaviour change in patients with CHD reported that educational interventions in cardiac care increased patients' knowledge and facilitated behaviour change (Ghisi 2014). Educational interventions were found to lead to increases in physical activity, healthier dietary habits and smoking cessation, but no associations between education and cardiac symptoms, medication adherence or psychosocial well-being were found (Ghisi 2014).

\section{AUTHORS' CONCLUSIONS}

\section{Implications for practice}

Our findings provide limited evidence in support of the use of educational interventions for people with coronary heart disease (CHD). Given the uncertainty of the evidence of effect and the moderate (at best) quality of evidence for all outcomes, educational interventions for people with CHD should only be considered as part of a comprehensive programme that includes exercise and psychological support. This is in accordance with current evidence and international guidelines for secondary prevention and cardiac rehabilitation (Anderson 2016; BACPR 2012; Balady 2007; NICE 2007; NICE 2013; Richards 2017).

\section{Implications for research}

Given the heterogeneity in educational interventions seen in the included studies, this review reflects current uncertainty about the optimal approach of offering education to people with CHD. Further studies with longer durations and follow-up periods are needed to compare the content and intent of individual educational interventions and their relative impact on reducing risk factors, changing patient behaviour and preventing unnecessary hospital re-admissions and emergency department visits by people with CHD. Studies also need to assess the relative costs and benefits of different methods and approaches of delivering the educational content by comparing group versus individual delivery, face-to-face versus self help manuals, as well as exploring new technologies for delivering educational content. Studies should also include under-represented groups (e.g. people aged over 65 years, ethnic minorities or people from lower socio-economic settings) to increase the generalisability of outcomes to the wider population of people with CHD.

Research methods should not only be well designed, but also include a parallel qualitative process evaluation to assess fidelity and quality of delivery and to better understand patients' expectations and needs. Such studies should be conducted in the context of a multi-interventional approach to secondary prevention and rehabilitation and report sufficient information to enable replication of the interventional approach. 
Improved reporting, including participant characteristics (e.g diagnoses), and the content, dose and mode of delivery of educational intervention, is needed. This would enable future reviews to stratify outcomes according to the range of CHD populations or types of cardiac rehabilitation interventions to help better understand the optimal approach for delivering education to these patient groups.

\section{ACKNOWLEDGEMENTS}

We are grateful to all authors of the previous version of this Cochrane Review (Brown 2011) for their contributions, in particular
Karen Welch, who was not involved in this update. We would also like to thank Nicole Martin of the Cochrane Heart Group for updating the search strategy and the following individuals for their assistance in translating papers from the original version of this review: Joey Kwong (Chinese), Nicole Martin (German), Marina Karanikolos (Russian), Rune Stensvold (Danish), and also to Jerong Yerong Ji (Mandarin) and Irena Tikhinova (Russian) for their translating assistance for this update.

Finally, we would like to thank all the authors who provided additional information about their trials. 
R E F E R E N C E S

\section{References to studies included in this review}

Chow 2015 \{published data only\}

* Chow CK, Redfern J, Hillis GS, Thakkar J, Santo K, Hackett ML, et al. Effect of lifestyle-focused text messaging on risk factor modification in patients with coronary heart disease: a randomized clinical trial. JAMA 2015;314(12):1255-63.

Thakkar J, Redfern J, De Keizer L, Thiagalingam A, Chow C. Patient perceptions of text message-based intervention for secondary prevention of cardiovascular events. Heart, Lung and Circulation 2013;22(Suppl 1):S264.

\section{Clark 1997 \{published and unpublished data\}}

Clark NM, Janz NK, Becker MH, Schork MA, wheeler J, Liang J, et al. Impact of self-management education on the functional health status of older adults with heart disease. Gerontologist 1992;32(4):438-43.

* Clark NM, Janz NK, Dodge JA, Schork MA, Wheeler JRC, Laing J, et al. Self-management of heart disease by older adults. Research on Aging 1997;19(3):362-82.

\section{Clark 2000 \{published and unpublished data\}}

* Clark NM, Janz NK, Dodge JA, Schork MA, Fingerlin TE, Wheeler JRC, et al. Changes in functional health status of older women with heart disease: evaluation of a program based on self-regulation. Journals of Gerontology. Series B, Psychological Sciences and Social Sciences 2000;55(2):S117-26.

Wheeler JR, Janz NK, Dodge JA. Can a disease self-management programme reduce health care costs: the case of older women with heart disease. Medical Care 2003;41(6):706-15.

Clark 2009 \{published and unpublished data\}

Clark NM, Janz NK, Dodge JA, Lin X, Trabert BL, Kaciroti N, et al. Heart disease management by women: Does intervention format matter? Health Education \& Behavior 2009;36:394-409. [DOI: 10.1177/1090198107309458.]

\section{Cohen 2014 \{published data only\}}

Cohen A, Assyag P, Boyer-Chatenet L, Cohen-Solal A, Perdrix C, Dalichampt $M$, et al Réseau Insuffisance Cardiaque (RESICARD) PREVENTION Investigators. An education program for risk factor management after an acute coronary syndrome: a randomized clinical trial. JAMA Internal Medicine 2014;174(1):40-8.

\section{Cupples 1994 \{published data only (unpublished sought but not used)\}}

Cupples ME, McKnight A, O'Neill C, Normand C. The effect of personal health education on the quality of life of patients with angina in general practice. Health Education Journal 1996;55(4):75-83.

Cupples ME, McKnight A. Five year follow up of patients at high cardiovascular risk who took part in randomised controlled trial of health promotion. British Medical Journal 1999;319(7211):687-8.
* Cupples ME, McKnight A. Randomised controlled trial of health promotion in general practice for patients at high cardiovascular risk. British Medical Journal 1994;309(6960):993-6.

O'Neill C, Normand C, Cupples M, McKnight A. Cost effectiveness of personal health education in primary care for people with angina in the greater Belfast area of Northern Ireland. Journal of Epidemiology and Community Health 1996;50(5):538-40.

Dracup 2009 \{published data only\}

Dracup K, McKinley S, Riegel B, Moser DK, Meischke H, Doering LV, et al. A randomized clinical trial to reduce patient prehospital delay to treatment in acute coronary syndrome. Circulation. Cardiovascular Quality and Outcomes 2009;2(6):524-32.

Esposito 2008 \{published data only (unpublished sought but not used)\}

Esposito D, Brown R, Chen A, Schore J, Shapiro R. Impacts of a disease management program for dually eligible beneficiaries. Health Care Financing Review 2008;30(1):27-45.

Furuya 2015 \{published data only\}

Furuya RK, Arantes EC, Dessotte CA, Ciol MA, Hoffman JM, Schmidt $A$, et al. A randomized controlled trial of an educational programme to improve self care in Brazilian patients following percutaneous coronary intervention. Journal of Advanced Nursing 2015;71(4):895-908.

Hanssen 2007 \{published data only (unpublished sought but not used)\}

* Hanssen TA, Nordrehaug JE, Eide BE, Hanestad BR. Improving outcomes after myocardial infarction: a randomized controlled trial evaluating effects of a telephone follow-up intervention. European Journal of Cardiovascular Prevention and Rehabilitation 2007;14(3):429-37.

Hanssen TA, Nordrehaug JE, Eide GE, Hanestad BR. Can telephone follow-up after discharge improve life style factors after a myocardial infarction? A randomized controlled trial. European Journal of Cardiovascular Nursing 2007;6:S43-4.

Hanssen TA, Nordrehaug JE, Eide GE, Hanestad BR. Does a telephone follow-up intervention for patients discharges with acute myocardial infarction have long-term effects on healthrelated quality of life? A randomised controlled trial. Journal of Clinical Nursing 2009;18(9):1334-45.

Hanssen TA, Nordrehaug JE, Eide GE, Hanestad BR. Evaluating the effect of a combined reactive and proactive telephone follow-up intervention after acute myocardial infarction. A randomized controlled trial. European Journal of Cardiovascular Nursing 2006;5(1):S46.

\section{Jorstad 2013 \{published data only\}}

Jorstad HT, von Birgelen C, Alings AM, Liem A, van Dantzig JM, Jaarsma W, et al. Effect of a nurse-coordinated prevention programme on cardiovascular risk after an acute coronary 
syndrome: main results of the RESPONSE randomised trial. Heart 2013;99(19):1421-30.

Jorstad HT, von Birgelen C, Alings M, Liem A, van Dantzig JM, Jaarsma W, et al. Improvement of risk factor control after an acute coronary syndrome by a nurse coordinated prevention program: results from a randomized trial. Journal of the American College of Cardiology 2011;57(14):E549.

Lie 2009 \{published data only (unpublished sought but not used)\} Lie I, Arnesen H, Sandvik L, Hamilton G, Bunch EH. Healthrelated quality of life after coronary artery bypass grafting. The impact of a randomised controlled home-based intervention program. Quality of Life Research 2009;18(2):201-7.

\section{Lisspers 1999 \{published and unpublished data\}}

Hofman-Bang C, Lisspers J, Nordlander R, Nygren A, Sundin O, Ohman A, et al. Two-year results of a controlled study of residential rehabilitation for patients treated with percutaneous transluminal coronary angioplasty. A randomized study of a multifactorial programme. European Heart Journal 1999;20(20):1465-74.

* Lisspers J, Sundin O, Hofman-Bang C, Norlander R, Nygren A, Rydén $\mathrm{L}$, et al. Behavioral effects of a comprehensive, mutifactorial program for lifestyle change after percutaneous transluminal coronary angioplasty: a prospective, randomized, controlled study. Journal of Psychosomatic Research 1999;46(2):143-54.

Lisspers J, Sundin O, Ohman A, Hofman-Bang C, Rydén L, Nygren A. Long-term effects of lifestyle behavior change in coronary artery disease: effects on recurrent coronary events after percutaneous coronary intervention. Health Psychology 2005;24(1):41-8

\section{Melamed 2014 \{published data only\}}

Melamed RJ, Tillmann A, Kufleitner HE, Thürmer U, Dursch M. Evaluating the efficacy of an education and treatment program for patients with coronary heart disease. Deutsches Arzteblatt International 2014;111(47):802-8.

\section{Mooney 2014 \{published data only\}}

McKee G, Mooney M, O'Brien F, O'Donnell S, Moser D. A randomised controlled trial to reduce prehospital delay time in patients with acute coronary syndrome. Irish Journal of Medical Science 2014;183 Suppl 8:389-435.

* Mooney M, McKee G, Fealy G, O'Brien F, O'Donnell S, Moser D. A randomized controlled trial to reduce prehospital delay time in patients with acute coronary syndrome (ACS). Journal of Emergency Medicine 2014;46(4):495-506.

Mooney M, McKee G, O'Brien F, O'Donnell S, Moser D. A randomized controlled trial to test an intervention to reduce pre-hospital delay time in patients diagnosed with acute coronary syndrome (ACS). European Heart Journal 2011;32(8):229-30

Mooney M, O'Brien F, McKee G, O'Donnell S, Moser D. An intervention to alter help-seeking behaviour and reduce prehospital delay time in patients diagnosed with acute coronary syndrome (ACS). Heart 2012;98:A69.
O'Brien F, McKee G, Mooney M, O'Donnell S, Moser D. Improving knowledge, attitudes and beliefs about acute coronary syndrome through an individualized educational intervention: a randomized controlled trial. Patient Education and Counseling 2014;96(2):179-87.

O'Brien F, McKee G, O'Donnell S, Mooney M, Moser D. Improving ACS patients' knowledge, attitudes and beliefs about heart disease through education: a randomised controlled trial. European Heart Journal 2011;96(2):179-87.

\section{Moreno-Palanco 2011 \{published data only\}}

Moreno-Palanco MA, Ibáñez-Sanz P, Ciria-de Pablo C, PizarroPortillo A, Rodríguez-Salvanés F, Suárez-Fernández C. Impact of comprehensive and intensive treatment of risk factors concerning cardiovascular mortality in secondary prevention: MIRVAS study [Impacto de un tratamiento integral e intensivo de factores de riesgo sobre la mortalidad cardiovascular en prevencion secundaria: estudio MIRVAS]. Revista Espanola de Cardiologia 2011;64(3):179-85.

P.RE.COR Group 1991 \{published data only (unpublished sought but not used)\}

PRECOR Group. Comparison of a rehabilitation programme, a counselling programme and usual care after an acute myocardial infarction: results of a long-term randomized trial. European Heart Journal 1991;12(5):612-6.

\section{Park 2013 \{published data only\}}

Park JH, Tahk SJ, Bae SH, Son YJ. Effects of a psychoeducational intervention for secondary prevention in Korean patients with coronary artery disease: a pilot study. International Journal of Nursing Practice 2013;19(3):295-305.

Peikes 2009 \{published data only (unpublished sought but not used)\}

Brown R, Peikes D, Chen A, Schore J. 15-site randomized trial of coordinated care in Medicare FFS. Health Care Financing Review 2008;30(1):5-25.

* Peikes D, Chen A, Schore J, Brown R. Effects of care coordination on hospitalization, quality of care, and health care expenditures among medicare beneficiaries 15 randomized trials. Journal of the American Medical Association 2009;301(6):603-18.

Pogosova 2008 \{published data only (unpublished sought but not used)\}

Pogosova GV, Kalinina AM, Spivak EI, Nazarkina VA. Efficacy of an educational preventive technology in patients with stable angina in ambulatory conditions. Kardiologiia 2008;48(7):4-9.

Southard 2003 \{published data only (unpublished sought but not used)\}

Southard BH, Southard DR, Nuckolls J. Clinical trial of an Internet-based case management system for secondary prevention of heart disease. Journal of Cardiopulmonary Rehabilitation 2003;23(5):341-8.

Tingström 2005 \{published and unpublished data\}

Tingström PR, Kamwendo K, Bergdahl B. Effects of a problembased learning rehabilitation programme on quality of life in 
patients with coronary artery disease. European Journal of Cardiovascular Nursing 2005;4(4):324-30.

\section{References to studies excluded from this review}

Abbaszadeh 2011 \{published data only\}

Abbaszadeh A, Borhani F, Asadi N. Effects of health belief model-based video training about risk factors on knowledge and attitude of myocardial infarction patients after discharge. Journal of Research in Medical Sciences 2011;16(2):195-9.

\section{Abbaszadeh 2012 \{published data only\}}

Abbaszadeh A, Borhanib F, Asadi N. Effects of face-to-face health-belief oriented education about risk factors on knowledge and attitude of myocardial infarction patients after discharge. Iranian Journal of Medical Education 2012;12(9):638-46.

\section{Ades 2001 \{published data only\}}

Ades PA. Cardiac rehabilitation and secondary prevention of coronary heart disease. New England Journal of Medicine 2001;345(12):892-902.

\section{Allen 2010 \{published data only\}}

Allen JK, Dennison CR. Randomized trials of nursing interventions for secondary prevention in patients with coronary artery disease and heart failure: systematic review. Journal of Cardiovascular Nursing 2010;25(3):207-20.

\section{Allison 2000 \{published data only\}}

Allison TG, Farkouh ME, Smars PA, Evans RW, Squires RW, Gabriel SE, et al. Management of coronary risk factors by registered nurses versus usual care in patients with unstable angina pectoris (a chest pain evaluation in the emergency room [CHEER] substudy). American Journal of Cardiology 2000;86(2):133-8.

\section{Ammenwerth 2015 \{published data only\}}

Ammenwerth E, Woess S, Baumgartner C, Fetz B, van der Heidt A, Kastner P, et al. Evaluation of an integrated telemonitoring surveillance system in patients with coronary heart disease. Methods of Information in Medicine 2015;54(5):388-97.

\section{Arthur 2000 \{published data only\}}

Arthur HM, Daniels C, McKelvie R, Hirsh J, Rush B. Effect of a preoperative intervention on preoperative and postoperative outcomes in low-risk patients awaiting elective coronary artery bypass graft surgery. A randomized, controlled trial. Annals of Internal Medicine 2000;133(4):253-62.

\section{Bagheri 2007 \{published data only\}}

Bagheri $\mathrm{H}$, Memarian R, Alhani F. Evaluation of the effect of group counselling on post myocardial infarction patients: determined by an analysis of quality of life. Journal of Clinical Nursing 2007;16(2):402-6.

\section{Balasch 2011 \{published data only\}}

Balasch iBM, López B, Rodríguez de SG, Dueñas M. Effects of a phase III cardiac rehabilitation program on the risk factors of arterial hypertension and obesity in the elderly over 60 with cardiovascular disease. Fisioterapia 2011;33:56-63.

Barley 2014 \{published data only\}

Barley EA, Walters P, Haddad M, Phillips R, Achilla E, McCrone P, et al. The UPBEAT nurse-delivered personalized care intervention for people with coronary heart disease who report current chest pain and depression: a randomised controlled pilot study. PLoS One 2014;9(6):e98704.

Barnason 1995 \{published data only\}

Barnason S, Zimmerman L. A comparison of patient teaching outcomes among postoperative coronary artery bypass graft (CABG) patients. Progress in Cardiovascular Nursing 1995;10(4):11-20.

\section{Barnason 2006 \{published data only\}}

Barnason S, Zimmerman L, Nieveen J, Hertzog M. Impact of a telehealth intervention to augment home health care on functional and recovery outcomes of elderly patients undergoing coronary artery bypass grafting. Heart \& Lung 2006;35(4):225-33.

\section{Barnason 2009 \{published data only\}}

Barnason S, Zimmerman L, Nieveen J, Schulz P, Miller C, Hertzog M, et al. Influence of a symptom management telehealth intervention on older adults' early recovery outcomes after coronary artery bypass surgery. Heart \& Lung 2009;38(5):364-76.

\section{Barnason 2009a \{published data only\}}

Barnason S, Zimmerman L, Schulz P, Tu C. Influence of an early recovery telehealth intervention on physical activity and functioning after coronary artery bypass surgery among older adults with high disease burden. Heart \& Lung 2009;38(6):459-68.

\section{Barnes 2012 \{published data only\}}

Barnes BK, Kramer JB, Howard P, Ababneh B, Muehlebach G, Daon $\mathrm{E}$, et al. Secondary prevention following coronary artery bypass surgery: The need for a continuum of care. Circulation: Cardiovascular Quality and Outcomes 2012;5(3 (Suppl)):A288.

\section{Bell 1998 \{published data only\}}

Bell JM. A comparison of a multi-disciplinary home based cardiac rehabilitation programme with comprehensive conventional rehabilitation in post-myocardial infarction patients [PhD thesis]. London (UK): University of London, 1998.

\section{Benson 2000 \{published data only\}}

Benson G. Commentary. Psychoeducational programmes reduce long term mortality and recurrence of myocardial infarction in cardiac patients. Evidence-Based Nursing 2000;3(3):80.

\section{Beranova 2007 \{published data only\}}

Beranova E, Sykes C. A systematic review of computer-based software for educating patients with coronary heart disease. Patient Education and Counseling 2007;66(1):21-8. 
Bethell 1990 \{published data only\}

Bethell HJ, Mullee MA. A controlled trial of community based coronary rehabilitation. British Heart Journal 1990;64(6):370-5.

\section{Bettencourt 2005 \{published data only\}}

Bettencourt N, Dias C, Mateus P, Sampaio F, Santos L, Adão L, et al. Impact of cardiac rehabilitation on quality of life and depression after acute coronary syndrome. Revista Portuguesa de Cardiologia 2005;24(5):687-96.

\section{Bitzer 2002 \{published data only\}}

Bitzer EM, Aster-Schenck IU, Klosterhuis H, Dorning H, Rose S. Developing evidence based guidelines on cardiac rehabilitation - phase 1: a qualitative review. Rehabilitation 2002;41(4):226-36.

\section{Bjørnnes 2015 \{published data only\}}

Bjørnnes AK, Lie I, Rustøen T, Stubhaug A, Leegaard M. A RCT of the effectiveness of an intervention to enhance pain management after discharge from cardiac surgery. European Journal of Cardiovascular Nursing 2015;14:S95-6.

\section{Boulay 2004 \{published data only\}}

Boulay P, Prud'homme D. Health-care consumption and recurrent myocardial infarction after 1 year of conventional treatment versus short- and long-term cardiac rehabilitation. Preventive Medicine 2004;38(5):586-93.

Brand 1998 \{published data only\}

Brand M. Commentary. Coronary care programme improved food habits but not physical activity or smoking status after acute myocardial infarction. Evidence-Based Nursing 1998;1(1):14.

\section{Brügemann 2007 \{published data only\}}

Brügemann J, Poels BJ, Oosterwijk MH, van der Schans CP, Postema K, van Veldhuisen DJ. A randomised controlled trial of cardiac rehabilitation after revascularisation. International Journal of Cardiology 2007;119(1):59-64.

\section{Campbell 1998 \{published data only\}}

Campbell NC, Ritchie LD, Thain J, Deans HG, Rawles JM, Squair JL. Secondary prevention in coronary heart disease: a randomised trial of nurse led clinics in primary care. Heart 1998;80(5):447-52.

\section{Campbell 1998a \{published data only\}}

Campbell NC, Thain J, Deans HG, Ritchie LD, Rawles JM, Squair JL. Secondary prevention clinics for coronary heart disease: randomised trial of effect on health. British Medical Journal 1998;316(7142):1434-7.

\section{Cannon 2002 \{published data only\}}

Cannon CP, Hand MH, Bahr R, Boden WE, Christenson R, Gibler WB, et al National Heart Attack Alert Program (NHAAP) Coordinating Committee Critical Pathways Writing Group. Critical pathways for management of patients with acute coronary syndromes: an assessment by the National Heart Attack Alert Program. American Heart Journal 2002;143(5):777-89.

\section{Carrington 2013 \{published data only\}}

Carrington MJ, Chan YK, Calderone A, Scuffham PA, Esterman A, Goldstein $\mathrm{S}$, et al Young at Heart Investigators. A multicenter, randomized trial of a nurse-led, home-based intervention for optimal secondary cardiac prevention suggests some benefits for men but not for women: the Young at Heart Study. Circulation. Cardiovascular Quality and Outcomes 2013;6(4):379-89

\section{Cebeci 2008 \{published data only\}}

Cebeci F, Celik SS. Discharge training and counselling increase self-care ability and reduce postdischarge problems in CABG patients. Journal of Clinical Nursing 2008;17(3):412-20.

\section{Chan 2005 \{published data only\}}

Chan DS, Chau JP, Chang AM. Acute coronary syndromes: cardiac rehabilitation programmes and quality of life. Journal of Advanced Nursing 2005;49(6):591-9.

\section{Chan 2012 \{published data only\}}

Chan YK, Stewart S, Calderone A, Scuffham P, Goldstein S, Carrington MJ Young @ Heart Investigators. Exploring the potential to remain "Young @ Heart": initial findings of a multi-centre, randomised study of nurse-led, home-based intervention in a hybrid health care system. International Journal of Cardiology 2012;154(1):52-8.

\section{Chen 2005 \{published data only\}}

Chen W, Guo LH, Li YW, Guo SQ, Li Z. Effect of cognitive education on the physical and psychological rehabilitation of patients with coronary heart disease after interventional therapy. Chinese Journal of Clinical Rehabilitation 2005;9(7):1-3.

Cho 2010 \{published data only\}

Cho HY, Kim HS. Effects of individualized cardiac health education on self care behavior and serum cholesterol in patients with coronary artery disease. Journal of Korean Academic Society of Adult Nursing 2010;22(3):322-8.

\section{Cingözbay 2011 \{published data only\}}

Cingözbay BY, Isilak Z, Tokatli A, Uzun M. Effects of patient education and counseling about life style on quality of life in patients with coronary artery disease. Anatolian Journal of Cardiology 2011;11(2):107-13.

\section{Clark 2005 \{published data only\}}

Clark AM, Hartling L, Vandermeer B, McAlister FA. Meta-analysis: Secondary prevention programs for patients with coronary artery. Annals of Internal Medicine 2005;143(9):659-72.

\section{Clark 2007 \{published data only\}}

Clark AM, Hartling L, Vandermeer B, Lissel SL, McAlister FA. Secondary prevention programmes for coronary heart disease: a meta-regression showing the merits of shorter, generalist, primary care-based interventions. European Journal of Cardiovascular Prevention and Rehabilitation 2007;14(4):538-46.

Cobb 2006 \{published data only\}

Cobb SL, Brown DJ, Davis LL. Effective interventions for lifestyle change after myocardial infarction or coronary artery 
revascularization. Journal of the American Academy of Nurse Practitioners 2006;18(1):31-9.

\section{Coburn 2012 \{published data only\}}

Coburn KD, Marcantonio S, Lazansky R, Keller M, Davis N. Effect of a community-based nursing intervention on mortality in chronically ill older adults: a randomized controlled trial. PLoS Medicine 2012;9(7):e1001265.

\section{Costa e Silva 2008 \{published data only\}}

Costa e Silva R, Pellanda L, Portal V, Maciel P, Furquim A, Schaan B. Transdisciplinary approach to the follow-up of patients after myocardial infarction. Clinics 2008;63(4):489-96.

\section{Coull 2004 \{published data only\}}

Coull AJ, Taylor VH, Elton R, Murdoch PS, Hargreaves AD. A randomised controlled trial of senior Lay Health Mentoring in older people with ischaemic heart disease: The Braveheart Project. Age and Ageing 2004;33(4):348-54.

Crumlish 2011 \{published data only\}

Crumlish CM, Magel CT. Patient education on heart attack response: is rehearsal the critical factor in knowledge retention? Medsurg Nursing 2011;20(6):310-7.

\section{Cundey 1995 \{published data only\}}

Cundey PE 3rd, Frank MJ. Cardiac rehabilitation and secondary prevention after a myocardial event. Clinical Cardiology 1995;18(10):547-53.

\section{Dankner 2011 \{published data only\}}

Dankner R, Geulayov G, Ziv A, Novikov I, Goldbourt U, Drory Y. The effect of an educational intervention on coronary artery bypass graft surgery patients' participation rate in cardiac rehabilitation programs: a controlled health care trial. $B M C$ Cardiovascular Disorders 2011;11:60.

\section{DeBusk 1994 \{published data only\}}

DeBusk RF, Miller NH, Superko HR, Dennis CA, Thomas RJ, Lew HT, et al. A case-management system for coronary risk factor modification after acute myocardial infarction. Annals of Internal Medicine 1994;120(9):721-9.

\section{Delaney 2008 \{published data only\}}

Delaney EK, Murchie P, Lee AJ, Ritchie LD, Campbell NC. Secondary prevention clinics for coronary heart disease: a 10year follow-up of a randomised controlled trial in primary care. Heart 2008;94(11):1419-23.

\section{Devi 2014 \{published data only\}}

Devi R, Powell J, Singh S. A web-based program improves physical activity outcomes in a primary care angina population: randomized controlled trial. Journal of Medical Internet Research 2014;16(9):e186.

\section{Divison 2014 \{published data only\}}

Divison JA, Escobar Cervantes C, Segui Diaz M. Multifactorial intervention to improve therapeutic compliance and secondary prevention measures after acute coronary syndrome. Semergen Sociedad Espanola de Medicina Rural y Generalista 2014;40(5):274-5.

\section{Dusseldorp 1999 \{published data only\}}

Dusseldorp E, van Elderen T, Maes S, Meulman J, Kraaij V. A meta-analysis of psychoeduational programs for coronary heart disease patients. Health Psychology 1999;18(5):506-19.

Dusseldorp 2000 \{published data only\}

Dusseldorf E, van Elderen T, Maes S. Commentary: Psychoeducational programmes reduce $\mathrm{MI}$ recurrence and improve some physical health outcome. Evidence-Based Medicine 2000;5:83.

\section{Eckman 2012 \{published data only\}}

Eckman MH, Wise R, Leonard AC, Dixon E, Burrows C, Khan F, et al. Impact of health literacy on outcomes and effectiveness of an educational intervention in patients with chronic diseases. Patient Education \& Counseling 2012;87:143-51.

Engblom 1992 \{published data only\}

Engblom E, Hämäläinen H, Lind J, Mattlar CE, Ollila S, Kallio V, et al. Quality of life during rehabilitation after coronary artery bypass surgery. Quality of Life Research 1992;1(3):167-75.

Engblom 1994 \{published data only\}

Engblom E, Hämäläinen H, Rönnemaa T, Vänttinen E, Kallio V, Knuts LR. Cardiac rehabilitation and return to work after coronary artery bypass surgery. Quality of Life Research 1994;3(3):207-13.

\section{Engblom 1996 \{published data only\}}

Engblom E, Korpilahti K, Hämäläinen H, Puukka P, Rönnemaa T. Effects of five years of cardiac rehabilitation after coronary artery bypass grafting on coronary risk factors. American Journal of Cardiology 1996;78(12):1428-31.

\section{Engblom 1997 \{published data only\}}

Engblom E, Korpilahti K, Hämäläinen H, Rönnemaa T, Puukka P. Quality of life and return to work 5 years after coronary artery bypass surgery. Long-term results of cardiac rehabilitation. Journal of Cardiopulmonary Rehabilitation 1997;17(1):29-36.

Enzenhofer 2004 \{published data only\}

Enzenhofer M, Bludau HB, Komm N, Wild B, Mueller K, Herzog W, et al. Improvement of the educational process by computer-based visualization of procedures: randomized controlled trial. Journal of Medical Internet Research 2004;6(2):e16.

\section{Eshah 2009 \{published data only\}}

Eshah NF, Bond AE. Cardiac rehabilitation programme for coronary heart disease patients: an integrative literature review. International Journal of Nursing Practice 2009;15(3):131-9.

\section{Eshah 2010 \{published data only\}}

Eshah NF, Bond AE, Froelicher ES. The effects of a cardiovascular disease prevention program on knowledge and adoption of a heart healthy lifestyle in Jordanian working adults. European Journal of Cardiovascular Nursing 2010;9(4):244-53. 


\section{Eshah 2013 \{published data only\}}

Eshah NF. Predischarge education improves adherence to a healthy lifestyle among Jordanian patients with acute coronary syndrome. Nursing \& Health Sciences 2013;15(3):273-9.

\section{Eshah 2014 \{published data only\}}

Eshah NF. Predischarge education improves adherence to a healthy lifestyle among Jordanian patients with acute coronary syndrome. European Journal of Cardiovascular Nursing 2014;13:S6-7

\section{Espinosa Caliani 2004 \{published data only\}}

Espinosa Caliani S, Bravo Navas JC, Gómez-Doblas JJ, Collantes Rivera R, González Jiménez B, Martínez Lao M, et al. Postmyocardial infarction cardial rehabilitation in low risk patients. Results with a coordinated program of cardiological and primary care. Revista Espanola de Cardiologia 2004;57(1):53-9.

\section{Fang 2015 \{published data only\}}

Fang R, Li X. Electronic messaging support service programs improve adherence to lipid-lowering therapy among outpatients with coronary artery disease: an exploratory randomised control study. Journal of Clinical Nursing 2015;25(5-6):664-71.

\section{Fattirolli 1998 \{published data only\}}

Fattirolli F, Cartei A, Burgisser C, Mottino G, Del Lungo F, Oldridge $\mathrm{N}$, et al. Aims, design and enrolment rate of the Cardiac Rehabilitation in Advanced Age (CR-AGE) randomized, controlled trial. Aging 1998;10(5):368-76.

\section{Fernandez 2009 \{published data only\}}

Fernandez RS, Davidson P, Griffiths R, Juergens C, Stafford B, Salamonson Y. A pilot randomised controlled trial comparing a health-related lifestyle self-management intervention with standard cardiac rehabilitation following an acute cardiac event: implications for a larger clinical trial. Australian Critical Care 2009;22(1):17-27.

\section{Frasure-Smith 1997 \{published data only\}}

Frasure-Smith N, Lespérance F, Prince RH, Verrier P, Garber RA, Juneau M, et al. Randomised trial of home-based psychosocial nursing intervention for patients recovering from myocardial infarction. Lancet 1997;350(9076):473-9.

\section{Fredericks 2009 \{published data only\}}

Fredericks S. Timing for delivering individualized patient education intervention to coronary artery bypass graft patients: an RCT. European Journal of Cardiovascular Nursing 2009;8(2):144-50.

\section{Fredericks 2009a \{published data only\}}

Fredericks S, Ibrahim S, Puri R. Coronary artery bypass graft surgery patient education: a systematic review. Progress in Cardiovascular Nursing 2009;24(4):162-8.

\section{Fredericks 2013 \{published data only\}}

Fredericks S, Yau T. Educational intervention reduces complications and rehospitalizations after heart surgery. Western Journal of Nursing Research 2013;35(10):1251-65.

\section{Frederix 2015 \{published data only\}}

Frederix I, Hansen D, Van Driessche N, Coninx K, Vandervoort P, Vrints C, et al. Do we keep cardiac patients out of hospital by adding telerehabilitation to standard rehabilitation? Cardiology 2015;131:183.

\section{Froelicher 1994 \{published data only\}}

Froelicher ES, Kee LL, Newton KM, Lindskog B, Livingston M. Return to work, sexual activity, and other activities after acute myocardial infarction. Heart \& Lung 1994;23(5):423-35.

\section{Furze 2012 \{published data only\}}

Furze G, Cox H, Morton V, Chuang LH, Lewin RJP, Nelson P, et al. Randomized controlled trial of a lay-facilitated angina management programme. Journal of Advanced Nursing 2012;68(10):2267-79.

\section{Gao 2007 \{published data only\}}

Gao WG, Hu DY, Ma WL, Tang CZ, Li J, Hasimu B, et al. Effect of health management on the rehabilitation of patients undergoing coronary artery bypass graft. Journal of Clinical Rehabilitative Tissue Engineering Research 2007;11(25):4874-8.

\section{Ghali 2004 \{published data only\}}

Ghali JK. A community-based disease management program for post-myocardial infarction reduces hospital readmissions compared with usual care. Evidence-Based Healthcare 2004;8:119-21.

\section{Goodman 2008 \{published data only\}}

Goodman H, Parsons A, Davison J, Preedy M, Peters E, Shuldham $\mathrm{C}$. A randomised controlled trial to evaluate a nurse led programme of support and lifestyle management for patients awaiting cardiac surgery: ' Fit for surgery: Fit for life' Study. European Journal of Cardiovascular Nursing 2008;7(3):189-95

\section{Han 2011 \{published data only\}}

Han WZ, Zhang M, Wang J, Sun YM, Fang WY. Effects of standardized secondary prevention on lifestyle of patients with acute coronary syndrome. Journal of Shanghai Jiaotong University (Medical Science) 2011;31(3):302-4.

\section{Harbman 2006 \{published data only\}}

Harbman P. Review: secondary prevention programmes with and without exercise reduced all cause mortality and recurrent myocardial infarction. Evidence-Based Nursing 2006;9(3):77.

\section{Haskell 1994 \{published data only\}}

Haskell W, Alderman E, Fair J, Maron D, Mackey S, Superko R, et al. Effects of intensive multiple risk factor reduction on coronary atherosclerosis and clinical cardiac events in men and women with coronary artery disease. The Stanford Coronary Risk Intervention Project (SCRIP). Circulation 1994;89(3):975-90.

\section{Hawkes 2009 \{published data only\}}

Hawkes AL, Atherton J, Taylor CB, Scuffham P, Eadie K, Miller $\mathrm{NH}$, et al. Randomised controlled trial of a secondary prevention program for myocardial infarction patients ('ProActive Heart'): study protocol. Secondary prevention 
program for myocardial infarction patients. BMC Cardiovascular Disorders 2009;9:16. [DOI: 10.1186/1471-2261-9-16]

\section{Hazavei 2012 \{published data only\}}

Hazavei SMM, Sabzmakan L, Hasanzadeh A, Rabiei K, Roohafza $\mathrm{H}$. The effects of an educational program based on PRECEDE model on depression levels in patients with coronary artery bypass grafting. ARYA Atherosclerosis 2012;8(1):36-42.

\section{He 2012 \{published data only\}}

He YP, Lu ZG, Gu YW, Pan JW, Gao MF, Wei M. Impact of multifactor intensive intervention on self management, risk factor control and outcome of post percutaneous transluminal coronary intervention patients. Zhonghua Xin Xue Guan Bing Za Zhi 2012;40(12):1037-40.

\section{Hedback 1993 \{published data only\}}

Hedback B, Perk J, Wodlin P. Long-term reduction of cardiac mortality after myocardial infarction: 10 -year results of a comprehensive rehabilitation programme. European Heart Journal 1993;14(6):831-5.

\section{Hedback 2001 \{published data only\}}

Hedback B, Perk J, Hornblad M, Ohlsson U. Cardiac rehabilitation after coronary artery bypass surgery: 10-year results on mortality, morbidity and readmissions to hospital. Journal of Cardiovascular Risk 2001;8:153-8.

\section{Heidarnia 2005 \{published data only\}}

Heidarnia A, Dehdari T, Ghofranipour F, Kazemnejad A, Heidarnia M. The effect of health education on health related quality of life in patients with coronary artery bypass surgery. Medical Journal of the Islamic Republic of Iran 2005;18(4):319-26.

\section{Heilmann 2014 \{published data only\}}

Heilmann C, Fritzsche K, Beyersdorf F, Leonhart R, Imbery C, Starke $S$, et al. Short-term intervention to reduce anxiety before artery coronary bypass surgery-A randomised controlled study. Thoracic and Cardiovascular Surgeon 2014;62:OP7. [DOI: DOI:10.1055/s-0034-1367087]

\section{Hobbs 2002 \{published data only\}}

Hobbs FD. Does pre-operative education of patients improve outcomes? The impact of pre-operative education on recovery following coronary artery bypass surgery: a randomized controlled clinical trial. European Heart Journal 2002;23(8):600-1.

\section{Hoseini 2013 \{published data only\}}

Hoseini S, Soltani F, Babaee Beygi M, Zarifsanaee N. The effect of educational audiotape programme on anxiety and depression in patients undergoing coronary artery bypass graft. Journal of Clinical Nursing 2013;22(11-12):1613-9.

\section{Huang 2014 \{published data only\}}

Huang Y, Chen J, Zeng Y, Liu D, He G. Community nursing intervention in population with high-risk coronary heart disease in Hengyang. Zhong Nan da Xue Xue Bao. Yi Xue Ban (Journal of Central South University. Medical Sciences) 2014;39(10):1061-6.

\section{Huber 2016 \{published data only\}}

Huber D, Henriksson R, Jakobsson S, Stenfors N, Mooe T. Implementation of a telephone-based secondary preventive intervention after acute coronary syndrome (ACS): Participation rate, reasons for non-participation and 1-year survival. Trials 2016;17(1):85.

\section{Jackson 2009 \{published data only\}}

Jackson AM, Gregory S, McKinstry B. Self-help groups for patients with coronary heart disease as a resource for rehabilitation and secondary prevention - what is the evidence? Heart \& Lung 2009;38(3):192-200.

\section{Jamshidi 2013 \{published data only\}}

Jamshidi N, Abbaszadeh A, Kalyani MN, Sharif F. Effectiveness of video information on coronary angiography patients' outcomes. Collegian 2013;20(3):153-9.

\section{Janz 1999 \{published data only\}}

Janz NK, Clark NM, Dodge JA, Schork MA, Mosca L, Fingerlin TE. The impact of a disease management program in the symptom experiences of older women with heart disease. Women \& Health 1999;30(2):1-24.

\section{Jenny 2001 \{published data only\}}

Jenny NYY, Fai TS. Evaluating the effectiveness of an interactive multimedia computer-based patient education program in cardiac rehabilitation. Occupational Therapy Journal of Research 2001;21(4):260-75.

\section{Johansen 2003 \{published data only\}}

Johansen S, Baumbach LA, Jørgensen T, Willaing I. The effect of psychosocial rehabilitation after acute myocardial infarction. A randomized controlled trial. Ugeskrift for Laeger 2003;165(34):3229-33.

\section{Kamal 2014 \{published data only\}}

Kamal K, Nader A. The effect of written material and verbal method education on anxiety and depression in myocardial infarction patients in educational hospitals. European Heart Journal: Acute Cardiovascular Care 2014;3(S2):124.

\section{Khunti 2007 \{published data only\}}

Khunti K, Stone M, Paul S, Baines J, Gisborne L, Farooqi A, et al. Disease management programme for secondary prevention of coronary heart disease and heart failure in primary care: $\mathrm{A}$ cluster randomised controlled trial. Heart 2007;93(11):1398-405.

Klainin-Yobas 2015 \{published data only\}

Klainin-Yobas P, Koh KWL, Ambhore AA, Chai P, Chan SW$\mathrm{C}, \mathrm{He} \mathrm{HG}$. A study protocol of a randomized controlled trial examining the efficacy of a symptom self-management programme for people with acute myocardial infarction. Journal of Advanced Nursing 2015;71(6):1299-309.

\section{Koertge 2003 \{published data only\}}

Koertge J, Weidner G, Elliott-Eller M, Scherwitz L, MerrittWorden TA, Marlin R, et al. Improvement in medical risk factors and quality of life in women and man with coronary artery disease in the Multicentre Lifestyle Demonstration Project. American Journal of Cardiology 2003;91(11):1316-22. 
La Sala 2015 \{published data only\}

La Sala R, Foà C, Paoli G, Mattioli M, Solinas E, Artioli G, et al. Multi-dimensional nursing form: a novel means of approaching nurse-led secondary cardiology prevention. Acta Bio-medica 2015;86(Suppl 3):174-82.

\section{Leemrijse 2012 \{published data only\}}

Leemrijse CJ, van Dijk L, Jørstad HT, Peters RJG, Veenhof C. The effects of Hartcoach, a life style intervention provided by telephone on the reduction of coronary risk factors: a randomised trial. BMC Cardiovascular Disorders 2012;12:47.

Levine 2011 \{published data only\}

Levine DA, Funkhouser EM, Houston TK, Gerald JK, JohnsonRoe N, Allison JJ, et al. Improving care after myocardial infarction using a 2-year internet-delivered intervention: the Department of Veterans Affairs myocardial infarctionplus cluster-randomized trial. Archives of Internal Medicine 2011;171(21):1910-7.

\section{Lindsay 2009 \{published data only\}}

Lindsay S, Smith S, Bellaby P, Baker R. The health impact of an online heart disease support group: a comparison of moderated versus unmoderated support. Health Education Research 2009;24(4):646-54.

\section{Luisi 2015 \{published data only\}}

Luisi MLE, Biffi B, Gheri CF, Sarli E, Rafanelli E, Graziano E, et al. Efficacy of a nutritional education program to improve diet in patients attending a cardiac rehabilitation program: outcomes of a one-year follow-up. Internal and Emergency Medicine 2015;10(6):671-676.

\section{Ma 2012 \{published data only\}}

Tsai ST, Chou FH. The effectiveness of multimedia nursing education on reducing illness-related anxiety in myocardial infarction patients after percutaneous coronary intervention. Hu Li Za Zhi 2012;59(4):43-53.

\section{Mayou 2002 \{published data only\}}

Mayou RA, Thompson DR, Clements A, Davies CH, Goodwin SJ, Normington K, et al. Guideline-based early rehabilitation after myocardial infarction. A pragmatic randomised controlled trial. Journal of Psychosomatic Research 2002;52(2):89-95.

\section{McGillion 2004 \{published data only\}}

McGillion M, Watt-Watson J, Kim J, Yamada J. A systematic review of psychoeducational intervention trials for the management of chronic stable angina. Journal of Nursing Management 2004;12(3):174-82.

\section{McGillion 2006 \{published data only\}}

McGillion MH. A clinical trial of a self-management education program for people with chronic stable angina. http:// clinicaltrials.gov/show/nct00350922.

\section{McGillion 2008 \{published data only\}}

McGillion MH, Watt-Watson J, Stevens B, LeFort SM, Coyte P, Graham A. Randomized controlled trial of a psychoeducation program for the self-management of chronic cardiac pain. Journal of Pain and Symptom Management 2008;36(2):126-40.
McGillion 2008a \{published data only\}

McGillion MH, Croxford R, Watt-Watson WJ, Lefort S, Stevens B, Coyte P. Cost of illness for chronic stable angina patients enrolled in a self-management education trial. Canadian Journal of Cardiology 2008;24(10):759-64.

Meisinger 2013 \{published data only\}

Meisinger C, Stollenwerk B, Kirchberger I, Seidl H, Wende R, Kuch B, et al. Effects of a nurse-based case management compared to usual care among aged patients with myocardial infarction: results from the randomized controlled KORINNA study. BMC Geriatrics 2013;13:115. [DOI: 10.1186/1471-2318-13-115]

\section{Meng 2014 \{published data only\}}

Meng K, Seekatz B, Haug G, Mosler G, Schwaab B, Worringen U, et al. Evaluation of a standardized patient education program for inpatient cardiac rehabilitation: impact on illness knowledge and self-management behaviors up to 1 year. Health Education Research 2014;29(2):235-46.

\section{Mirkamali 2014 \{published data only\}}

Mirkamali SM, Javanak LM, Yeganeh MR. Correlation between organizational culture with clinical governance in public hospitals in Rasht. Hayat 2014;20(1):15-25.

\section{Mohammadpour 2015 \{published data only\}}

Mohammadpour A, Rahmati SN, Khosravan S, Alami A, Akhond M. The effect of a supportive educational intervention developed based on the Orem's self-care theory on the self-care ability of patients with myocardial infarction: a randomised controlled trial. Journal of Clinical Nursing 2015;24(11-12):1686-92.

\section{Mohammady 2010 \{published data only\}}

Mohammady M, Memari A, Shaban M, Mehran A, Yavari P, Far M Salari. Comparing computer-assisted vs. face to face education on dietary adherence among patients with myocardial infarction. Hayat 2010;16(3-4):109.

\section{Moore 2001 \{published data only\}}

Moore SM, Dolansky MA. Randomized trial of a home recovery intervention following coronary artery bypass surgery. Research in Nursing and Health 2001;24:93-104.

\section{Mosca 2010 \{published data only\}}

Mosca L, Christian AH, Mochari-Greenberger H, Kligfield P, Smith SC Jr. A randomized clinical trial of secondary prevention among women hospitalized with coronary heart disease. Journal of Women's Health 2010;19(2):195-202.

\section{Moser 2012 \{published data only\}}

Moser DK, McKinley S, Riegel B, Doering LV, Meischke H, Pelter M, et al. The impact on anxiety and perceived control of a short one-on-one nursing intervention designed to decrease treatment seeking delay in people with coronary heart disease. European Journal of Cardiovascular Nursing 2012;11(2):160-7. 
Mullen 1992 \{published data only\}

Mullen PD, Mains DA, Velez R. A meta-analysis of controlled trials of cardiac patient education. Patient Education and Counseling 1992;19(2):143-62.

\section{Muñiz 2010 \{published data only\}}

Muñiz J, Gómez-Doblas JJ, Santiago-Pérez MI, Lekuona-Goya I, Murga-Eizagaetxebarría N, Teresa-Galván SE, et al CAM2 Project working group. The effect of post-discharge educational intervention on patients in achieving objectives in modifiable risk factors six months after discharge following an episode of acute coronary syndrome, (CAM-2 Project): a randomized controlled trial. Health and Quality of Life Outcomes 2010;8:137.

Murchie 2003 \{published data only\}

Murchie P, Campbell NC, Ritchie LD, Simpson JA, Thain J. Secondary prevention clinics for coronary heart disease: four year follow up of a randomised controlled trial in primary care. British Medical Journal 2003;326(7380):84.

Murchie 2004 \{published data only\}

Murchie P, Campbell NC, Ritchie LD, Deans HG, Thain J. Effects of secondary prevention clinics on health status in patients with coronary heart disease: 4 year follow-up of a randomized trial in primary care. Family Practice 2004;21(5):567-74.

\section{NCT00683813 \{published data only\}}

NCT00683813. Randomized trial of a cardiac rehabilitation program delivered remotely through the internet. clinicaltrials.gov/ct2/show/NCT00683813 (first received 21 May 2008).

\section{Nelson 2013 \{published data only\}}

Nelson P, Cox H, Furze G, Lewin RJP, Morton V, Norris H, et al. Participants' experiences of care during a randomized controlled trial comparing a lay-facilitated angina management programme with usual care: a qualitative study using focus groups. Journal of Advanced Nursing 2013;69(4):840-50.

\section{Nematian 2015 \{published data only\}}

Nematian Jelodar H, Jannati Y, Ghafari R, Yazdani Charati J, Gholami Gorzini M, Esmaeili R. The impact of peer education on stress level in patients undergoing coronary artery bypass grafting. Journal of Babol University of Medical Sciences 2015;17(11):7-13.

\section{Neubeck 2009 \{published data only\}}

Neubeck L, Redfern J, Fernandez R, Briffa T, Bauman A, Freedman SB. Telehealth interventions for the secondary prevention of coronary heart disease: a systematic review. European Journal of Cardiovascular Prevention \& Rehabilitation 2009;16(3):281-9.

\section{Niebauer 1997 \{published data only\}}

Niebauer J, Hambrecht R, Velich T, Hauer K, Marburger C, Kaulberer $\mathrm{B}$, et al. Attenuated progression of coronary artery disease after 6 years of multifactorial risk intervention: role of physical exercise. Circulation 1997;96(8):2534-41.

\section{Nisbeth 2000 \{published data only\}}

Nisbeth O, Klausen K, Andersen LB. Effectiveness of counselling over 1 year on changes in lifestyle and coronary heart disease risk factors. Patient Education and Counseling 2000;40(2):121-31.

\section{Nolan 2011 \{published data only\}}

Nolan RP, Upshur RE, Lynn H, Crichton T, Rukholm E, Stewart DE, et al. Therapeutic benefit of preventive telehealth counseling in the community outreach heart health and risk reduction trial. American Journal of Cardiology 2011;107(5):690-6.

\section{Nordmann 2001 \{published data only\}}

Nordmann A, Heilmbauer I, Walker T, Martina B, Battegay E. A case-management program of medium intensity does not improve cardiovascular risk factor control in coronary artery disease patients: the Heartcare I trial. American Journal of Medicine 2001;110(7):543-50.

\section{O'Neil 2011 \{published data only\}}

O'Neil A, Hawkes AL, Chan B, Sanderson K, Forbes A, Hollingsworth $B$, et al. A randomised, feasibility trial of a telehealth intervention for acute coronary syndrome patients with depression ('MoodCare'): study protocol. BMC Cardiovascular Disorders 2011;11:8. [DOI: 10.1186/1471-2261-11-8]

\section{O'Neil 2014 \{published data only\}}

O'Neil A, Hawkes AL, Atherton JJ, Patrao TA, Sanderson K, Wolfe R, et al. Telephone-delivered health coaching improves anxiety outcomes after myocardial infarction: the 'ProActive Heart' trial. European Journal of Preventive Cardiology 2014;21:30-8

\section{O'Neil 2014a \{published data only\}}

O'Neil A, Taylor B, Sanderson K, Cyril S, Chan B, Hawkes AL, et al. Efficacy and feasibility of a tele-health intervention for acute coronary syndrome patients with depression: Results of the "MoodCare" randomized controlled trial. Annals of Behavioral Medicine 2014;48(2):163-74.

\section{Oldenburg 1995 \{published data only\}}

Oldenburg B, Martin A, Greenwood J, Bernstein L, Allan R. A controlled trial of a behavioral and educational intervention following coronary artery bypass surgery. Journal of Cardiopulmonary Rehabilitation 1995;15(1):39-46.

\section{Oranta 2012 \{published data only\}}

Oranta O, Luutonen S, Salokangas RKR, Vahlberg T, LeinoKilpi H. Depression-focused interpersonal counseling and the use of healthcare services after myocardial infarction. Perspectives in Psychiatric Care 2012;48(1):47-55.

Ornish 1990 \{published data only\}

Ornish D, Scherwitz LW, Billings JH, Armstrong WT, Ports TA, et al. Can life style changes revere coronary heart disease? The Lifestyle Heart Trial. Lancet 1990;336(8708):129-33.

Ornish 1998 \{published data only\}

Ornish D, Scherwitz LW, Billings JH, Brown SE, Gould KL, Merritt TA, et al. Intensive lifestyle changes for reversal of 
coronary heart disease. Journal of American Medical Association 1998;280(23):2001-7.

\section{Paez 2006 \{published data only\}}

Paez KA, Allen JK. Cost-effectiveness of nurse practitioner management of hypercholesterolemia following coronary revascularization. Journal of the American Academy of Nurse Practitioners 2006;18(9):436-44.

\section{Palacio 2015 \{published data only\}}

Palacio AM, Uribe C, Hazel-Fernandez L, Li H, Tamariz Leonardo J, Garay Sylvia D, et al. Can phone-based motivational interviewing improve medication adherence to antiplatelet medications after a coronary stent among racial minorities? A randomized trial. Journal of General Internal Medicine 2015;30(4):469-75.

\section{Parry 2009 \{published data only\}}

Parry MJ, Watt-Watson J, Hodnett E, Tranmer J, Dennis CL, Brooks D. Cardiac Home Education and Support Trial (CHEST): A Pilot Study. Canadian Journal of Cardiology 2009;25(12):e393-8.

\section{Peterson 2012 \{published data only\}}

Peterson JC, Charlson ME, Hoffman Z, Wells MT, Wong SC, Hollenberg JP, et al. A randomized controlled trial of positive-affect induction to promote physical activity after percutaneous coronary intervention. Archives of Internal Medicine 2012;172(4):329-36.

\section{Raftery 2005 \{published data only\}}

Raftery JP, Yao GL, Murchie P, Campbell NC, Ritchie LD. Cost effectiveness of nurse led secondary prevention clinics for coronary heart disease in primary care: follow up of a randomised controlled trial. British Medical Journal 2005;330(7493):707.

\section{Redaelli 2010 \{published data only\}}

Redaelli M, Mayer-Berger W, Simic D, Kohlmeyer M, Schwitalla B. Randomized controlled trial on the effect of a long-term secondary prevention program over 3 years in a high-risk low-education cohort. European Journal of Cardiovascular Prevention and Rehabilitation 2010;17:S68.

\section{Redfern 2009 \{published data only\}}

Redfern J, Briffa T, Ellis E, Freedman SB. Choice of secondary prevention improves risk factors after acute coronary syndrome: 1-year follow-up of the CHOICE (Choice of Health Options in prevention of Cardiovascular Events) randomised controlled trial. Heart 2009;95(6):468-75.

\section{Robertson 2003 \{published data only\}}

Robertson K, Kayhko K, Kekki P. A supportive-education home follow-up programme for post MI patients. Journal of Community Nursing 2003;17(6):4-13.

\section{Rubenfire 2008 \{published data only\}}

Rubenfire M. Efficacy of in-hospital multidimensional interventions of secondary prevention after acute coronary syndrome: a systematic review and meta-analysis (Commentary). ACC Cardiosource Review Journal 2008;17:17-8.

\section{Saffi 2014 \{published data only\}}

Saffi MAL, Polanczyk CA, Rabelo-Silva ER. Lifestyle interventions reduce cardiovascular risk in patients with coronary artery disease: a randomized clinical trial. European Journal of Cardiovascular Nursing 2014;13(5):436-43.

Saki 2014 \{published data only\}

Saki A, Hooshmand BA, Asadi NAA, Mehran A. Comparison of face-to-face and electronic education methods on anxiety in patients with acute myocardial infarction. Hayat 2014;20(1):6-14.

\section{Schneider 2012 \{published data only\}}

Schneider RH, Grim CE, Rainforth MV, Kotchen T, Nidich SI, Gaylord-King C, et al. Stress reduction in the secondary prevention of cardiovascular disease: randomized, controlled trial of transcendental meditation and health education in Blacks. Circulation. Cardiovascular Quality and Outcomes 2012;5(6):750-8.

\section{Schwalm 2015 \{published data only\}}

Schwalm JD, Ivers NM, Natarajan MK, Taljaard M, RaoMelacini P, Witteman $\mathrm{HO}$, et al. Cluster randomized controlled trial of delayed educational reminders for long-term medication adherence in ST-elevation myocardial infarction (DERLA-STEMI). American Heart Journal 2015;170(5):903-13.

\section{Seekatz 2013 \{published data only\}}

Seekatz B, Haug G, Mosler G, Schwaab B, Altstidl R, Worringen $U$, et al. Development and short-term effects of a standardized patient education program for in-patient cardiologic rehabilitation. Rehabilitation 2013;52(5):344-51.

\section{Shahamfar 2010 \{published data only\}}

Shahamfar J, Aslanabadi N, Gupta VK, Daga MK, Zolfaghari R, Shahamfar M. Reduction of risk factors following lifestyle modification programme in patients with coronary heart disease. Journal of International Medical Sciences Academy 2010;23(2):73-4.

\section{Sherrard 2000 \{published data only\}}

Sherrard H. Counselling after a myocardial infarction improved mood for patients and their partners and decreased patient functional limitations [commentary on Johnston M, Foulkes J, Johnston DW, et al. Impact on patients and partners of inpatient and extended cardiac counselling and rehabilitation: a controlled trial. PSYCHOSOM MED 1999 Mar/Apr;61:255-33]. Evidence-Based Nursing 2000;3:21.

\section{Shui 2014 \{published data only\}}

Shui Y, Ling S, Letian L, Zeyu Q, Xiaosu Z. The effect of diversified health education on myocardial infarction patients with anxiety and depression. Journal of the American College of Cardiology 2014;64(Suppl C):C244.

\section{Shuldham 2001 \{published data only\}}

Shuldham CM. Pre-operative education for the patient having coronary artery bypass surgery. Patient Education and Counseling 2001;43(2):129-37. 
Shuldham 2002 \{published data only\}

Shuldham CM, Fleming S, Goodman H. The impact of preoperative education on recovery following coronary artery bypass surgery. A randomized controlled clinical trial. European Heart Journal 2002;23(8):666-74.

Sinclair 2005 \{published data only\}

Sinclair AJ, Conroy SP, Davies M, Bayer AJ. Post-discharge home-based support for older cardiac patients: a randomised controlled trial. Age and Ageing 2005;34(4):338-43.

\section{Stewart 2012 \{published data only\}}

Stewart S, Carrington MJ, Chan YK, Calderone A, Goldstein S, Scuffham P. Long-term impact of a nurse-led, home-based, prevention program for hospitalised cardiac patients on risk of secondary events: The multicentre young @ heart randomised controlled trial. European Heart Journal 2012;33(Suppl):443-4.

\section{Stewart 2013 \{published data only\}}

Stewart S, Carrington MJ, Goldstein S, Scuffham P. Differential impact of a nurse-led, home-based intervention for optimal secondary cardiac prevention on recurrent hospitalization in men and women: The Young @ Heart multicentre, randomized trial. European Heart Journal 2013;34(Suppl 1):P3359.

\section{Stewart 2014 \{published data only\}}

Stewart S, Carrington M, Chan YK, Jennings G, Wong C. Impact of a hybrid nurse-led home and clinic-based intervention on hospitalization and related hospital stay: Results from a pragmatic, randomized trial (the NIL-CHF study). Circulation 2014;130:A12157.

\section{Thompson 2000 \{published data only\}}

Thompson DR, Lewin RJ. Coronary disease: management of the post-myocardial infarction patient: rehabilitation and cardiac necrosis. Heart 2000;84(1):101-5.

\section{Thompson 2002 \{published data only\}}

Thompson DR, Quinn T, Stewart S. Effective nurse-led interventions in heart disease. International Journal of Cardiology 2002;83(3):233-7.

\section{Tranmer 2004 \{published data only\}}

Tranmer JE, Parry MJ. Enhancing postoperative recovery of cardiac surgery patients: a randomized clinical trial of an advanced practice nursing intervention. Western Journal of Nursing Research 2004;26(5):515-32.

\section{Turner 2008 \{published data only\}}

Turner DA, Paul S, Stone MA, Juarez-Garcia A, Squire I, Khunti K. Cost-effectiveness of a disease management programme for secondary prevention of coronary heart disease and heart failure in primary care. Heart 2008;94(12):1601-6.

\section{Uysal 2012 \{published data only\}}

Uysal H, Özcan Ş. The effect of individual training and counselling programme for patients with myocardial infarction over patients' quality of life. International Journal of Nursing Practice 2012;18(5):445-53.

\section{Uysal 2015 \{published data only\}}

Uysal H, Ozcan Ş. The effect of individual education on patients' physical activity capacity after myocardial infarction. International Journal of Nursing Practice 2015;21:18-28.

\section{Vale 2003 \{published data only\}}

Vale MJ, Jelinek MV, Best JD, Dart AM, Grigg LE, Hare DL, et al. Coaching patients On Achieving Cardiovascular Health (COACH): a multicenter randomized trial in patients with coronary heart disease. Archives of Internal Medicine 2003;163(22):2775-83.

\section{Van Elderen 1994 \{published data only\}}

Van Elderen T, Maes S, Seegers G. Effects of a posthospitalization group health education programme for patients with coronary heart disease. British Journal of Clinical Psychology 1994;9(4):317-30.

\section{Van Elderen 2001 \{published data only\}}

Van Elderen T, Dusseldorp E. Lifestyle effects of group health education for patients with coronary heart disease. Psychology and Health 2001;16(3):327-41.

\section{Vida 2011 \{published data only\}}

SadeghZadeh V, Moshtagh Eshgh Z. Effect of cardiac rehabilitation on quality of life in myocardial infarction patients in Zanjan. Faculty of Nursing of Midwifery Quarterly 2011;21(72):8-13.

\section{Volpe 2012 \{published data only\}}

Volpe R, Sotis G, Gavita R, Urbinati S, Valle S, Grazia MM. Healthy diet to prevent cardiovascular diseases and osteoporosis: the experience of the 'ProSa' project. High Blood Pressure \& Cardiovascular Prevention 2012;19(2):65-71.

\section{Vonder Muhll 2002 \{published data only\}}

Vonder Muhll I, Daub B, Black B, Warburton D, Haykowsky M. Benefits of cardiac rehabilitation in the ninth decade of life in patients with coronary heart disease. American Journal of Cardiology 2002;90(6):645-8.

\section{Wallner 1999 \{published data only\}}

Wallner S, Watzinger N, Lindschinger M, Smolle KH, Toplak H, Eber B, et al. Effects of intensified lifestyle modification on the need for further revascularization after coronary angioplasty. European Journal of Clinical Investigation 1999;29(5):372-9.

\section{Wang 2010 \{published data only\}}

Wang N, Zhong Y, Li H, Guo S, Zhou Z. Evaluation of the effect on the management of patients suffering from coronary atherosclerotic heart disease combined with chronic heart failure. Heart 2010;96:A114.

\section{Wang 2012 \{published data only\}}

Wang W, Chair SY, Thompson DR, Twinn SF. Effects of homebased rehabilitation on health-related quality of life and psychological status in Chinese patients recovering from acute myocardial infarction. Heart \& Lung 2012;41(1):15-25.

\section{Wang 2015 \{published data only\}}

Wang W, Liu J, Wang Y, Sun J, Zhao D. Effect of different intervening models in improving medication adherence of ACS 
patients: Results from the bridging the gap on CHD secondary prevention in china (BRIG) project. Journal of the American College of Cardiology 2015;66(16):C152.

\section{Weibel 2016 \{published data only\}}

Weibel L, Massarotto P, Hediger H, Mahrer-Imhof R. Early education and counselling of patients with acute coronary syndrome. A pilot study for a randomized controlled trial. European Journal of Cardiovascular Nursing 2016;15(4):213-22.

Williams 2009 \{published data only\}

Williams B, Pace AE. Problem based learning in chronic disease management: a review of the research. Patient Education and Counseling 2009;77(1):14-9.

\section{Williamson 2008 \{published data only\}}

Williamson K. An individualized telephone educational intervention for patients following coronary artery bypass graft surgery during the first three weeks after discharge: using Orem's Self-Care Deficit Nursing Theory in Interventional Research. Self-Care \& Dependent-Care Nursing 2008;16(1):54-5.

\section{Wolkanin 2010 \{published data only\}}

Wolkanin BJ, Pogorzelska $\mathrm{H}$. The effect of patient education on home-based rehabilitation on physical fitness in patients over 60 after acute myocardial infarction. European Heart Journal 2010;31:377.

\section{Wolkanin-Bartnik 2011 \{published data only\}}

Wolkanin-Bartnik J, Pogorzelska H, Bartnik A. Patient education and quality of home-based rehabilitation in patients older than 60 years after acute myocardial infarction. Journal of Cardiopulmonary Rehabilitation and Prevention 2011;31(4):249-53.

\section{Yavarikia 2011 \{published data only\}}

Yavarikia M, Shahamfar J, Amidfar H. Assessment of the role of education in changing lifestyle in patients with coronary heart diseases. Journal of Cardiovascular and Thoracic Research 2011;3(2):63-6.

\section{Yildiz 2014 \{published data only\}}

Yildiz T, Gürkan S, Gür Ö, Ünsal C, Göktaş SB, Özen Y. Effect of standard versus patient-targeted in-patient education on patients' anxiety about self-care after discharge from cardiovascular surgery clinics. Cardiovascular Journal of Africa 2014;25(6):259-64

\section{Zalesskaya 2005 \{published data only\}}

Zalesskaya JV, Noruzbaeva AM, Lunegova OS, Mirrakhimov EM. Evaluation of the economic efficiency of educational programs for patients with coronary heart disease and dyslipidemia. Prevention and Control 2005;1(4):297-304.

\section{Zhao 2009 \{published data only\}}

Zhao Y, Wong FK. Effects of a postdischarge transitional care programme for patients with coronary heart disease in China: a randomised controlled trial. Journal of Clinical Nursing 2009;18(17):2444-55.
Zhao 2015 \{published data only\}

Zhao SJ, Zhao HW, Du S, Qin YH. The impact of clinical pharmacist support on patients receiving multi-drug therapy for coronary heart disease in China. Indian Journal of Pharmaceutical Sciences 2015;77(3):306-11.

Zhou 2014 \{published data only\}

Zhou H, Feng X, Liu Y, Yu L, Li J. The application of health education path in patients with acute myocardial infarction in PCI. Cardiology 2014;129:138.

\section{Zutz 2007 \{published data only\}}

Zutz A, Ignaszewski A, Bates J, Lear SA. Utilization of the internet to deliver cardiac rehabilitation at a distance: a pilot study. Telemedicine Journal and e-Health 2007;13(3):323-30.

\section{References to studies awaiting assessment}

Gao 2011 \{published data only\}

Gao Y, Li Y, Zheng J, Wang R, Meng H, Zhang L. The effects of a comprehensive health education program in Chinese patients after percutaneous coronary intervention. IIOAB Journal 2011;2(7):23-30.

\section{Licina 2010 \{published data only\}}

Licina M, Giga V, Beleslin B, Djordjevic-Dikic A, Stepanovic J, Ostojic MM, et al. Effects of lifestyle interventions on high risk patients after percutaneous coronary intervention-single center experience. European Heart Journal 2010;31:379.

\section{Soliman 2013 \{published data only\}}

Soliman SM, Selim G. Motivational interviewing as educational program in improving cardiac risk factors control in patients post myocardial infarction. European Heart Journal 2013;P3361:629

\section{Vona 2009 \{published data only\}}

Vona M, Chapuis L, Iannino T, Ferrari E, Von Segesser LK. Efficacy of two long-term intervention strategies to promote long-term adherence to lifestyle changes and to reduce cardiovascular events in patients with coronary artery disease. European Heart Journal 2009;30:474.

\section{Xiaolin 2012 \{published data only\}}

Xiaolin Hu, Guiying You, Jiping Li. Analysis on health education demand of patients with coronary heart disease accepting interventual procedures. Chinese Nursing Research 2012;26:1751.

\section{References to ongoing studies \\ ACTRN12613000395730 \{unpublished data only\}}

ACTRN12613000395730. Evaluation of an educational resource for cardiac secondary prevention: a randomised controlled trial. https://anzctr.org.au/Trial/Registration/TrialReview.aspx? id=364009 First received 8 April 2013.

\section{ACTRN12613000793718 \{unpublished data only\}}

ACTRN12613000793718. TEXT messages to improve MEDication adherence \& Secondary prevention - TEXTMEDS. https:// 
www.anzctr.org.au/Trial/Registration/TrialReview.aspx? id=364448 First received 18 June 2013.

ACTRN12616000426482 \{unpublished data only\}

ACTRN12616000426482. SMARTphone-based, early cardiac REHABilitation in patients with acute coronary syndromes: A Randomized Controlled Trial Protocol [SMART-REHAB Trial]. https://www.anzctr.org.au/Trial/Registration/TrialReview.aspx? id=370434 First received 30 March 2016.

Brewer 2015 \{published data only\}

Brewer LC, Kaihoi B, Zarling KK, Squires RW, Thomas R, Kopecky S. The use of virtual world-based cardiac rehabilitation to encourage healthy lifestyle choices among cardiac patients: intervention development and pilot study protocol. JMIR Research Protocols 2015;4(2):e39.

Dwinger 2013 \{published data only\}

Dwinger S, Dirmaier J, Herbarth L, Konig HH, Eckardt M, Kriston L, et al. Telephone-based health coaching for chronically ill patients: study protocol for a randomized controlled trial. Trials [Electronic Resource] 2013;14:337.

IRCT201307162621N13 \{unpublished data only\} IRCT201307162621N13. The effects of application of Prochaska's stages of change model in education of coronary artery bypass grafting patients on quality of life, lipid profile \& some psychological complications of CABG, Shiraz 2012. http:// en.search.irct.ir/view/14373 First receive 17 January 2014.

\section{ISRCTN15839687 \{unpublished data only\}}

ISRCTN15839687. Examining the effectiveness of a self-help psychoeducation programme on outcomes of outpatients with coronary heart disease (CHD). http://www.isrctn.com/ISRCTN15839687? q=ISRCTN15839687\&filters=\&sort=\&offset=1\&totalResults=1\&page=1\& search First receive 21 January 2014.

\section{Kärner 2012 \{published data only\}}

Kärner A, Nilsson S, Jaarsma T, Andersson A, Wiréhn AB, Wodlin $\mathrm{P}$, et al. The effect of problem-based learning in patient education after an event of CORONARY heart disease-a randomised study in PRIMARY health care: design and methodology of the COR-PRIM study. BMC Family Practice 2012; Volume:110.

Karner A, Nilsson S, Jaarsma T, Tingstrom P, Abrandt Dahlgren M, Dahl L, et al. COR-PRIM: Patient education after coronary disease - Long-term evaluation in primary care. Scandinavian Cardiovascular Journal 2010;44:39-40.

Karner A, Tingstrom P, Nilsson S, Jaarsma T. COR-PRIM: Longitudinal study on PBL in self-care after CVD - Preliminary results from a pilot study. European Journal of Cardiovascular Nursing 2011;10:S23-4.

\section{Lai 2016 \{published data only\}}

Lai, VKW, Lee A, Leung P, et al. Patient and family satisfaction levels in the intensive care unit after elective cardiac surgery: study protocol for a randomised controlled trial of a preoperative patient education intervention. BMJ Open 2016;6:e011341.

\section{Lynggaard 2014 \{published data only\}}

Lynggaard V, May O, Beauchamp A, Nielsen C V, Wittrup I. LCREHAB: randomised trial assessing the effect of a new patient education method--learning and coping strategies--in cardiac rehabilitation. BMC Cardiovasc Disord 2014;14:186.

NCT01028066 \{unpublished data only\}

NCT01028066. Feeding Education in Patients Submitted to Coronary Angioplasty (PTCA-Nutri). https://clinicaltrials.gov/ ct2/show/NCT01028066 First received December 82009.

\section{NCT01275716 \{unpublished data only\}}

NCT01275716. Impact of Coronary Images Used During Patient Education on Coronary Artery Disease and Subsequent Lifestyle Modifications. Is a Picture Really Worth a Thousand Words? https://clinicaltrials.gov/ct2/show/NCT01275716 First received January 102011.

\section{NCT01925079 \{unpublished data only\}}

NCT01925079. Intensive Education on Lipid Management. https://clinicaltrials.gov/ct2/show/NCT01925079 First received August 152013

NCT02185391 \{unpublished data only\}

NCT02185391. Interactive Education of Patients With Coronary Heart Disease (INSERT). https://clinicaltrials.gov/ct2/show/ NCT02185391 First received June 232014.

NTR2388 \{unpublished data only\}

NTR2388. Evaluation Program "Coaching patients On Achieving Cardiovascular Health" (COACH). http://www.trialregister.nl/ trialreg/admin/rctview.asp?TC=2388 First received 21June 2010.

Shah 2011 \{published data only\}

Shah B R, Adams M, Peterson E D, Powers B, Oddone E Z,

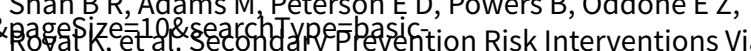
Telemedicine and Tailored Patient Education (SPRITE): A Randomized Trial to Improve Postmyocardial Infarction Management. Circulation: Cardiovascular Quality \& Outcomes 2011;4:235-42.

\section{Additional references}

\section{Alexander 2007}

Alexander KP, Newby LK, Cannon CP, Armstrong PW, Gibler WB, Rich MW, et al. Acute coronary care in the elderly, Part I. Non-ST-segment-elevation acute coronary syndromes: A scientific statement for healthcare professionals from the American Heart Association Council on Clinical Cardiology: In Collaboration With the Society of Geriatric Cardiology. Circulation 2007;115(19):2549-69.

\section{Amsterdam 2014}

Amsterdam EA, Wenger NK, Brindis RG, Casey DE, Ganiats TG, Holmes DR, et al. AHA/ACC guideline for the management of patients with non-ST-elevation acute coronary syndromes: a report of the American College of Cardiology/American Heart Association Task Force on Practice Guidelines. Journal of the American College of Cardiology 2014;64(24):e139-e228. 


\section{Anderson 2016}

Anderson L, Thompson DR, Oldridge N, Zwisler AD, Rees K, Martin N, et al. Exercise-based cardiac rehabilitation for coronary heart disease. Cochrane Database of Systematic Reviews 2016, Issue 1. Art. No: CD001800. [DOI: 10.1002/14651858.CD001800]

\section{BACPR 2012}

British Association for Cardiovascular Prevention and Rehabilitation. The BACPR standards and core components for cardiovascular disease prevention and rehabilitation, 2nd edition. www.bacpr.com/resources/46C_BACPR_Standards and_Core_Components_2012.pdf (accessed 12 April 2016).

\section{Balady 2007}

Balady GJ, Williams MA, Ades PA, Bittner V, Comoss P, Foody JM, et al. AHA/AACVPR Scientific Statement; Core Components of Cardiac Rehabilitation/Secondary Prevention Programs: 2007 Update. Circulation 2007;115:2675-82.

\section{Balady 2011}

Balady GJ, Ades PA, Bittner VA, Franklin BA, Gordon NF, Thomas RJ, et al. Referral, enrollment, and delivery of cardiac rehabilitation/secondary prevention programs at clinical centers and beyond: a presidential advisory from the American Heart Association. Circulation 2011;124:2951-60.

\section{BHF 2015}

British Heart Foundation. Cardiovascular disease statistics 2015. www.bhf.org.uk/publications/statistics/cvd-stats-2015 (accessed April 2016).

\section{Braunwald 2011}

Bonow RO, Mann DL, Zipes DP, Libby P. Braunwald's heart disease: a textbook of cardiovascular medicine. 9th edition. Philadelphia: Elsevier Saunders, 2011.

\section{Deeks 2011}

Deeks JJ, Higgins JPT, Altman DG (editors). Chapter 9: Analysing data and undertaking meta-analyses. In: Higgins JPT, Green S (editors). Cochrane Handbook for Systematic Reviews of Interventions Version 5.1.0 (updated March 2011). The Cochrane Collaboration, 2011. Available from www.cochranehandbook.org.

\section{Dodd 2011}

Dodd KS, Saczynski JS, Zhao Y, Goldberg RJ, Gurwitz JH. Exclusion of older adults and women from recent trials of acute coronary syndromes. Journal of the American Geriatrics Society 2011;59(3):506-11.

\section{Egger 1997}

Egger M, Davey Smith G, Schneider M, Minder C. Bias in metaanalysis detected by a simple graphical test. British Medical Journal 1997;315(7109):629-34.

\section{ESC 2012}

Task Force on the management of ST-segment elevation acute myocardial infarction of the European Society of Cardiology (ESC), Steg PG, James SK, Atar D, Badano LP, Blömstrom-Lundqvist C, Borger MA, et al. ESC Guidelines for the management of acute myocardial infarction in patients presenting with ST-segment elevation. European Heart Journal 2012;33(20):2569-619.

\section{ESC 2016}

Roffi M, Patrono C, Collet JP, Mueller C, Valgimigli M, Andreotti F, et al. 2015 ESC Guidelines for the management of acute coronary syndromes in patients presenting without persistent ST-segment elevation: Task Force for the Management of Acute Coronary Syndromes in Patients Presenting without Persistent ST-Segment Elevation of the European Society of Cardiology (ESC). European Heart Journal 2016;37(3):267-315.

\section{Ferri 2007}

Ferri SMN, Pereira MJB, Mishima SM, Caccia-Bava MCG, Almeida MCP. Soft technologies as generating satisfaction in users of a family health unit. Interface-Comunicacao, Saude, Educacao 2007;11(23):515-29.

\section{Foster 2007}

Foster G, Taylor SJC, Eldridge S, Ramsay J, Griffiths CJ. Self-management education programmes by lay leaders for people with chronic conditions. Cochrane Database of Systematic Reviews 2007, Issue 4. Art. No: CD005108. [DOI: 10.1002/14651858.CD005108.pub2]

\section{Ghisi 2014}

Ghisi GL, Abdallah F, Grace SL, Thomas S, Oh P. A systematic review of patient education in cardiac patients: Do they increase knowledge and promote health behavior change? Patient Education and Counseling 2014;95(2):160-74.

\section{GRADEpro GDT 2014 [Computer program]}

GRADE Working Group, McMaster University GRADEpro GDT. Version (accessed prior to 6 June 2017). Hamilton (ON): GRADE Working Group, McMaster University, 2014.

\section{Higgins 2011}

Higgins JPT, Altman DG, Sterne JAC (editors). Chapter 8: Assessing risk of bias in included studies Higgins JPT, Green $\mathrm{S}$ (editors). Cochrane Handbook for Systematic Reviews of Interventions Version 5.1.0 (updated March 2011). The Cochrane Collaboration, 2011. Available from www.cochranehandbook.org 2011.

\section{Koongstvedt 2001}

Koongstvedt PR. The Managed Health Care Handbook. 4th edition. Gaithersburg (MD): Aspen Publishers, 2001.

\section{Kulik 2015}

Kulik A, Ruel M, Jneid H, Ferguson TB, Hiratzka LF, Ikonomidis JS, et al. Secondary prevention after coronary artery bypass graft surgery: a scientific statement from the American Heart Association. Circulation 2015;131(10):927-64.

\section{Lefebvre 2011}

Lefebvre C, Manheimer E, Glanville JC. Chapter 6: Searching for studies. In: Cochrane Handbook for Systematic Reviews of Interventions Version 5.1.0 (updated March 2011). Available from www.cochrane-handbook.org. The Cochrane Collaboration, 2011. 


\section{MECIR 2016}

Higgins JPT, Lasserson T, Chandler J, Tovey D, Churchill R. Methodological Expectations of Cochrane Intervention Reviews (MECIR). methods.cochrane.org/sites/default/files/public/ uploads/mecir_printed_booklet_final.pdf (accessed prior to 6 June 2017).

\section{Moher 2009}

Moher D, Liberati A, Tetzlaff J, Altman DG. Preferred reporting items for systematic reviews and meta-analyses: The PRISMA Statement. PLOS Medicine 2009;6(7):e1000097.

\section{NICE 2007}

National Institute for Health and Clinical Excellence. Secondary prevention in primary and secondary care for patients following a myocardial infarction. www.nice.org.uk/CG48 (accessed prior to 6 June 2017).

\section{NICE 2013}

National Institute for Health and Clinical Excellence. Commissioning guides: Cardiac rehabilitation services. www.nice.org.uk/guidance/cmg40 (accessed 18 April 2016).

\section{Oldridge 2003}

Oldridge N. Assessing health-related quality of life: it is important when evaluating the effectiveness of cardiac rehabilitation? Journal of Cardiopulmonary Rehabilitation 2003;23:26-8.

\section{Perk 2012}

Perk J, De Backer G, Gohlke H, Graham I, Reiner Ž, Verschuren M, et al. European Guidelines on cardiovascular disease prevention in clinical practice. European Heart Journal 2012;33(13):1635-701.

\section{Phillips 2014}

Phillips P. Telephone follow-up for patients eligible for cardiac rehab: A systematic review. British Journal of Cardiac Nursing 2014;9(4):186-97.

\section{Rahe 1979}

Rahe RH, Ward HW, Hayes V. Brief group therapy in myocardial infarction rehabilitation: Three to four year follow-up of a controlled trial. Psychosomatic Medicine 1979;41(3):229-42.

\section{Reece 2007}

Reece I, Walker S. Teaching, Training and Learning. A Practical Guide. 6th edition. Tyne and Wear: Business Education Publishers, 2007.

\section{RevMan 2014 [Computer program]}

Copenhagen: The Nordic Cochrane Centre, The Cochrane Collaboration Review Manager (RevMan) Version 5.3. Copenhagen: The Nordic Cochrane Centre, The Cochrane Collaboration, 2014.

\section{Richards 2017}

Richards SH, Anderson L, Jenkinson CE, Whalley B, Rees K, Davies P, Bennett P, Liu Z, West R, Thompson DR, Taylor RS. Psychological interventions for coronary heart disease.
Cochrane Database of Systematic Reviews 2017, Issue 4. Art. No: CD002902. [DOI: 10.1002/14651858.CD002902.pub4]

\section{Schünemann 2011}

Schünemann HJ, Oxman AD, Vist GE, Higgins JPT, Deeks JJ, Glasziou P, et al. Chapter 12: Interpreting results and drawing conclusions. In: Higgins JPT, Green S (editors), Cochrane Handbook for Systematic Reviews of Interventions Version 5.1.0 (updated March 2011). The Cochrane Collaboration, 2011. Available from www.cochrane-handbook.org.

\section{Smith 2011}

Smith SC, Benjamin EJ, Bonow RO, Braun LT, Creager MA, Franklin BA, et al. AHA/ACCF secondary prevention and risk reduction therapy for patients with coronary and other atherosclerotic vascular disease: 2011 update: a guideline from the American Heart Association and American College of Cardiology Foundation endorsed by the World Heart Federation and the Preventive Cardiovascular Nurses Association. Journal of the American College of Cardiology 2011;58(23):2432-46.

\section{Taylor 1998}

Taylor RS, Kirby BJ, Burdon D, Caves R. The assessment of recovery in post-myocardial infarction patients using three generic quality of life measures. Journal of Cardiopulmonary Rehabilitation 1998;18(2):139-44.

\section{Walker 2003}

Walker C, Swerissen H, Belfrage J. Self-management: its place in the management of chronic illnesses. Australian Health Review 2003;26(2):34-42.

\section{WHO 2017}

World Health Organization. Global Health Observatory (GHO) data. http://www.who.int/gho/mortality_burden_disease/en/ (accessed 15 June 2017).

\section{Zaman 2014}

Zaman MJ, Stirling S, Shepstone L, Ryding A, Flather M, Bachmann $\mathrm{M}$, et al. The association between older age and receipt of care and outcomes in patients with acute coronary syndromes: a cohort study of the Myocardial Ischaemia National Audit Project (MINAP). European Heart Journal 2014;35(23):1551-8.

\section{References to other published versions of this review \\ Brown 2010}

Brown JP, Clark AM, Dalal H, Welch K, Taylor RS. Patient education in the contemporary management of coronary heart disease. Cochrane Database of Systematic Reviews 2010, Issue 12. Art. No: CD008895. [DOI: 10.1002/14651858.CD008895]

\section{Brown 2011}

Brown JPR, Clark AM, Dalal H, Welch K, Taylor RS. Patient education in the management of coronary heart disease. Cochrane Database of Systematic Reviews 2011, Issue 12. Art. No: CD008895. [DOI: 10.1002/14651858.CD008895]

* Indicates the major publication for the study 


\section{CHARACTERISTICS OF STUDIES}

Characteristics of included studies [ordered by study ID]

Chow 2015

\section{Study characteristics}

$\begin{array}{ll}\text { Methods } & \text { Study design: Single centre RCT } \\ \text { Country: Australia } & \\ \text { Dates patients recruited: September } 2011 \text { to November } 2013 \\ \text { When randomised: After hospital discharge } \\ \text { Maximum follow up: } 6 \text { months }\end{array}$

Interventions

Description of intervention: The text message-based prevention programme involved delivery of regular semi-personalised text messages providing advice, motivation, and information that aimed to improve diet, increase physical activity, and encourage smoking cessation (if relevant). Content for each participant was selected using a prespecified algorithm dependent on key baseline characteristics. Each message was sent on 4 of 5 randomly selected weekdays and arrived at random times of the day during working hours. The general module of messages included information generally provided by secondary prevention programs, e.g. on chest pain action plans, guidelines and risk factor targets, and medications and adherence.

Components: Education

Delivered by: Text messages (A bank of messages was developed with input from investigators, clinicians, academics, and patients)

Setting (home/centre): Home

Teaching modalities: Individual

Involvement of family: No

Time of start after event: After discharge

Dose:

Length of session: NR

Frequency/number of sessions: 4 messages per week

Total duration: 24 weeks.

Follow-up further re-inforcement: NR

Theoretical basis for intervention: NR

Co-interventions: Both groups received 3 study management text messages providing allocation assignment, study contact details, and a reminder before the follow-up appointment 
Chow 2015 (Continued)

Comparator: Control participants received usual care, which generally included community follow-up with most referred to inpatient cardiac rehabilitation, as determined by their usual physicians.

Co-interventions: Both groups received 3 study management text messages providing allocation assignment, study contact details, and a reminder before the follow-up appointment

\begin{tabular}{ll}
\hline Outcomes & $\begin{array}{l}\text { Total mortality } \\
\text { Withdrawals }\end{array}$ \\
\hline Source of funding & National Heart Foundation of Australia Grant-in-Aid and a BUPA Foundation Grant \\
\hline Conflicts of interest & $\begin{array}{l}\text { All authors completed and submitted the ICMJE Form for Disclosure of Potential Conflicts of Interest. } \\
\text { No conflicts were reported }\end{array}$ \\
\hline Notes & NA
\end{tabular}

\section{Risk of bias}

\begin{tabular}{|c|c|c|}
\hline Bias & Authors' judgement & Support for judgement \\
\hline $\begin{array}{l}\text { Random sequence genera- } \\
\text { tion (selection bias) }\end{array}$ & Low risk & $\begin{array}{l}\text { Randomisation occurred via a computerised randomisation program accessed } \\
\text { through a secure web interface }\end{array}$ \\
\hline $\begin{array}{l}\text { Allocation concealment } \\
\text { (selection bias) }\end{array}$ & Low risk & $\begin{array}{l}\text { Randomisation occurred via a computerised randomisation program accessed } \\
\text { through a secure web interface }\end{array}$ \\
\hline $\begin{array}{l}\text { Blinding of outcome as- } \\
\text { sessment (detection bias) } \\
\text { All outcomes }\end{array}$ & Low risk & $\begin{array}{l}\text { "...minimizing unblinding at follow-up by sending a message to participants } \\
\text { asking them not to disclose their group allocation" }\end{array}$ \\
\hline $\begin{array}{l}\text { Incomplete outcome data } \\
\text { (attrition bias) } \\
\text { All outcomes }\end{array}$ & Low risk & $\begin{array}{l}\text { Intervention: } 33 / 352(9.4 \%) \text { lost to follow-up } \\
\text { Control: } 25 / 358(7.0 \%) \text { lost to follow-up }\end{array}$ \\
\hline $\begin{array}{l}\text { Selective reporting (re- } \\
\text { porting bias) }\end{array}$ & Low risk & All outcomes described in the methods were reported \\
\hline $\begin{array}{l}\text { Were groups balanced at } \\
\text { baseline? }\end{array}$ & Low risk & "Baseline characteristics were similar between the groups (Table 1)" \\
\hline Intention to treat analysis & Low risk & $\begin{array}{l}\text { "...and all intervention evaluations were performed on the principle of inten- } \\
\text { tion to treat." }\end{array}$ \\
\hline $\begin{array}{l}\text { Did both groups receive } \\
\text { comparable care? }\end{array}$ & Low risk & Co-interventions were the same in both groups \\
\hline
\end{tabular}

\section{Clark 1997}

\section{Study characteristics}

\begin{tabular}{ll}
\hline Methods & Study design: Multicentre RCT (4 sites) \\
Country: USA \\
Dates participants recruited: NR \\
When randomised: NR \\
\end{tabular}


Clark 1997 (Continued)

Maximum follow up: 18 months

Participants

Inclusion criteria: Aged > 60 years; diagnosed cardiac disease (arrhythmia, angina, MI, valvular disease); treated daily by at least one heart medication; seen by a physician at least once every six months.

Exclusion criteria: "If physicians felt that they wouldn't be able to benefit fully for the program due to medical reasons (e.g. terminal illness, memory loss, significant hearing loss)"

Recruitment from: Review of outpatient cardiology clinics in four hospitals in Southern Eastern Michigan

$\mathrm{N}$ randomised: total: 636 ; intervention: $\mathrm{NR}$; comparator: $\mathrm{NR}$ Diagnosis (\% of pts):

Post MI: $45 \%$

Angina: $57 \%$

Post CABG: $32 \%$

Post PCI: $25 \%$

These groups were not mutually exclusive.

Age: mean (range): total: 69.6 years (60 to 93 years); intervention: NR; comparator: NR

Percentage male: total: 59\%; intervention: 59;comparator: 59

Ethnicity: $88 \%$ white

Description of intervention: The "Take PRIDE" programme introduces participants to a process for identifying and resolving problems they encounter in managing their heart disease. Participants are asked to follow the following steps: Problem selecting, Researching one's daily routine, Identifying a behavioural goal, Developing a plan to reach one's goal, and Establishing a reward for making progress. Basing decisions on the medical regimens recommended by their physicians, participants select a heart disease management problem to resolve using the PRIDE steps. The common target across subjects is the PRIDE problem-solving process. The intervention aims to enable participants to apply this process to whichever management problem they confront.

Components: Education

Delivered by: Health educator

Setting (home/centre): Centre

Teaching modalities: Videotape, guidebook, interactive group teaching

Involvement of family: NR

Time of start after event: Six months to 20 years after initial diagnosis

Dose:

Length of session: 2 hours

Frequency/number of sessions: 4

Total duration: 4 weeks

Follow-up further re-inforcement: NR

Theoretical basis for intervention: Based on social cognitive theory, particularly the principles of selfregulation (Bandura 1986; Clark and Zimmerman 1990), problem identification, researching one's routine, Identifying a management goal, developing a plan to reach it, expressing one's reactions and establishing rewards for making progress

Co-interventions: NR 
Clark 1997 (Continued)

Comparator: Usual care consisted of: "Seeing their physicians at the intervals specified by the particular physician and receiving any information or communications that would be provided as part of routine care in that setting".

\section{Co-interventions: NR}

\begin{tabular}{ll}
\hline Outcomes & HRQoL - Sickness Impact Profile \\
& Withdrawal from intervention and control group \\
\hline Source of funding & NR \\
\hline Conflicts of interest & NR \\
\hline Notes & NA \\
\hline
\end{tabular}

\section{Risk of bias}

\begin{tabular}{|c|c|c|}
\hline Bias & Authors' judgement & Support for judgement \\
\hline $\begin{array}{l}\text { Random sequence genera- } \\
\text { tion (selection bias) }\end{array}$ & Low risk & "Use of random number table" \\
\hline $\begin{array}{l}\text { Allocation concealment } \\
\text { (selection bias) }\end{array}$ & Low risk & $\begin{array}{l}\text { "As the numbers were generated, each was placed in a sealed envelope. They } \\
\text { were stored in a locked drawer in my office. As participants completed their } \\
\text { baseline interview I was given their names and opened the next envelope in } \\
\text { the numerical sequence." Dodge JA (email communication) }\end{array}$ \\
\hline $\begin{array}{l}\text { Blinding of outcome as- } \\
\text { sessment (detection bias) } \\
\text { All outcomes }\end{array}$ & Low risk & $\begin{array}{l}\text { "Data collectors and data analysts were blinded. The health educators who } \\
\text { delivered the intervention obviously knew who had been randomised to the } \\
\text { intervention, but had no involvement with the collection of quantitative evalu- } \\
\text { ation data at baseline or follow-up." Dodge JA (email communication) }\end{array}$ \\
\hline $\begin{array}{l}\text { Incomplete outcome data } \\
\text { (attrition bias) } \\
\text { All outcomes }\end{array}$ & Unclear risk & $\begin{array}{l}455 / 636 \text { had complete data at } 18 / 12 \text {. "No appreciable difference in dropout } \\
\text { rates between the intervention and control groups were found." Similarity of } \\
\text { demographic details of those loss to follow up not discussed }\end{array}$ \\
\hline $\begin{array}{l}\text { Selective reporting (re- } \\
\text { porting bias) }\end{array}$ & Low risk & All outcomes listed in the methods are reported in the results \\
\hline $\begin{array}{l}\text { Were groups balanced at } \\
\text { baseline? }\end{array}$ & Low risk & $\begin{array}{l}\text { "There were no baseline differences between the experimental and control } \\
\text { groups". }\end{array}$ \\
\hline Intention to treat analysis & High risk & $\begin{array}{l}\text { "Data analyses reported...participants who attended at least one of the four } \\
\text { sessions." }\end{array}$ \\
\hline $\begin{array}{l}\text { Did both groups receive } \\
\text { comparable care? }\end{array}$ & Low risk & $\begin{array}{l}\text { Other than the stated intervention both groups appeared to have been treated } \\
\text { similarly }\end{array}$ \\
\hline
\end{tabular}

\section{Clark 2000}

\section{Study characteristics}

\begin{tabular}{ll}
\hline Methods & Study design: Multicentre RCT (6 sites) \\
& Country: USA \\
& Dates patients recruited: NR
\end{tabular}


Clark 2000 (Continued)

When randomised: At consent. Median of 13 years since initial cardiac diagnosis (range 6 months to 20 years)

Maximum follow up: 24 months

Participants

Inclusion criteria: > 60 years; female; cardiac disease treated daily with at least one medication; cardiac disease can be arrhythmia, angina, MI or valvular disease

Exclusion criteria: "If physicians felt they could not benefit fully from the program due to medical reason (e.g. terminal illness or significant hearing loss)"

Recruitment from: Physician practices affiliated with six medical centres in Southeastern Michigan

N randomised: total: 570 ; intervention: 309 ; comparator: 261

Diagnosis (\% of pts):

Post MI: 39\%

Angina: $45 \%$

Post CABG: $26 \%$

Post PCI: $29 \%$

These groups are not mutually exclusive.

Age: mean (range): total: 71.9 years (range 60 to 93 years); intervention: NR; comparator: NR

Percentage male: total: $0 \%$; intervention: $0 \%$;comparator: $0 \%$

Ethnicity: $87 \%$ white

Description of intervention: The goal was to enhance overall management of the heart condition by helping older women to be more self-regulating. Adapted from "Take PRIDE" (Clark, Janz, Becker, et al, 1992; Clark et al,1997), participants selected an area of management that was problematic (e.g. exercise, medicine taking, diet). The program recommended a comprehensive approach to managing the heart condition, i.e. using medicines, following dietary recommendations, and exercising. Participants were provided information and assistance to be more self-evaluating and active; e.g. each used a pedometer to log physical activity. During the intervening days, women used a workbook at home as a guide to carrying out the PRIDE steps

Components: Education

Delivered by: Trained health educators and peer leaders (selected graduates from the program that received extra training)

Setting (home/centre): Centre (and home on intervening days)

Teaching modalities: Class room group sessions (groups of 6 to 8 women). Workbook for use at home on the intervening days. Handouts summarising classroom sessions, daily self-monitoring logs. Weekly telephone call during program period

Involvement of family: NR

Time of start after event: NR

Dose:

Length of session: 2 to 2.5 hours

Frequency/number of sessions: weekly (4)

Total duration: 4 weeks

Follow-up further re-inforcement: A letter 3 months after program and a telephone call 6 months after 
Clark 2000 (Continued)

Theoretical basis for intervention: Yes - PRIDE: Problem identification, Researching one's routine, Identifying a management goal, Developing a plan to reach it, Expressing one's reactions and Establishing rewards for making progress.

\section{Co-interventions: NR}

Comparator: "Usual care": Control group members saw their physicians at the intervals specified by the particular physician and received any information or communications that would be provided as part of routine care in that setting

\begin{tabular}{ll}
\hline Outcomes & Total mortality \\
& HRQoL - Sickness Impact Profile \\
& Adverse events (Withdrawal from intervention group) \\
& Hospitalisations (numbers of admissions, inpatient days, hospital inpatient charges) (Wheeler 2003) \\
& Cost-effectiveness (Wheeler 2003) \\
\hline Source of funding & National Heart, Lung, and Blood Institute \\
\hline Conflicts of interest & NR \\
\hline Notes & $\begin{array}{l}\text { The following paper produced from the results of the same trial were used to inform the data collected: } \\
\text { Wheeler } 2003\end{array}$
\end{tabular}

\section{Risk of bias}

\begin{tabular}{|c|c|c|}
\hline Bias & Authors' judgement & Support for judgement \\
\hline $\begin{array}{l}\text { Random sequence genera- } \\
\text { tion (selection bias) }\end{array}$ & Low risk & "...women were assigned, by use of random number tables" (Clark 2000) \\
\hline $\begin{array}{l}\text { Allocation concealment } \\
\text { (selection bias) }\end{array}$ & Unclear risk & NR \\
\hline $\begin{array}{l}\text { Blinding of outcome as- } \\
\text { sessment (detection bias) } \\
\text { All outcomes }\end{array}$ & Low risk & $\begin{array}{l}\text { "Interviewers were blind to women's participation in the program" (Clark } \\
\text { 2000) }\end{array}$ \\
\hline $\begin{array}{l}\text { Incomplete outcome data } \\
\text { (attrition bias) } \\
\text { All outcomes }\end{array}$ & Low risk & Table detailing withdrawals \\
\hline $\begin{array}{l}\text { Selective reporting (re- } \\
\text { porting bias) }\end{array}$ & Low risk & Outcomes in methods reported in results \\
\hline $\begin{array}{l}\text { Were groups balanced at } \\
\text { baseline? }\end{array}$ & High risk & $\begin{array}{l}\text { Demographically similar but statistically significant differences in baseline dis- } \\
\text { ease symptoms and weight. }\end{array}$ \\
\hline Intention to treat analysis & Low risk & $\begin{array}{l}\text { Data was analysed in two different phases, one "an analysis of all women ran- } \\
\text { domised" the other "all program women who attended one or more program } \\
\text { sessions" (Clark 2000) }\end{array}$ \\
\hline $\begin{array}{l}\text { Did both groups receive } \\
\text { comparable care? }\end{array}$ & Low risk & $\begin{array}{l}\text { "In an effort to assure similar care to both the program and the control groups, } \\
\text { no feedback about individual participants was provided to medical or nursing } \\
\text { staff. The clinical staff had no knowledge of which patients had agreed to par- } \\
\text { ticipate in research" (Clark 2000) }\end{array}$ \\
\hline
\end{tabular}




$\begin{array}{ll}\text { Methods } & \text { Study design: Multicentre RCT - } 3 \text { groups } \\ & \text { Country: USA } \\ & \text { Dates patients recruited: N/A - list compiled from physicians patient rota }\end{array}$

When randomised: After collecting baseline data

Maximum follow up: 18 months

Participants
Inclusion criteria: Aged > 60 years; diagnosed cardiac condition (arrhythmia, angina, MI, congestive heart failure, valvular disease); treated by daily heart medication; seen by a physician in the last year; living within 1 hour drive of the study site

Exclusion criteria: If not able to fully participate because of medical reasons

Recruitment from: Five hospital sites in Southeastern Michigan

N randomised: total: 575; intervention: Self Directed: 201; Group Format:190; comparator: 184 Diagnosis (\% of pts):

Post MI: $42 \%$

Angina: $38 \%$

Post CABG: NR

Post PCI: NR

These groups are not mutually exclusive.

Age: mean (range): total: 72.8 years (60 to 90 years); Group: 73.1 years (61 to 87 years); Self-directed: 72.7 years (61 to 88 years);comparator: 72.5 years (60 to 90 years)

Percentage male: total: $0 \%$

Ethnicity: $82.8 \%$ white

Description of intervention: Comparison of a "Take PRIDE" - based intervention, delivered in (i) selfdirected and (ii) group formats. The content of and the materials used with the two formats were the same. Both formats consisted of six units. Both groups received weekly telephone calls from a heath educator during the study period. The self directed group also had an instructional video tape that gave examples of group discussions.

The content (instructor's manual,videotape, workbook and logs) was tailored to the unique roles, responsibilities and settings in which older women manage their heart disease. In the self-directed format, women engage in the same self regulatory process at home in their own timeframe, while the group format women meet for 2-2 1/2 hours on a weekly basis. In the self-directed version, motivation and support that are part of the social environment in the group format are provided via an instructional videotape that presents examples of group discussions. Weekly telephone calls from a health educator or a peer leader are also provided.

Components: Education

Delivered by: Trained health educators and peer leaders

Setting (home/centre): Single orientation session at centre then home

Teaching modalities: Groups of 6 to 8 women

Involvement of family: NR

Time of start after event: NR

Dose: 
Clark 2009 (Continued)

\section{Length of session: 2 to 2.5 hours}

Frequency/number of sessions: 6 weekly sessions

Total duration: 6 weeks

Follow-up further re-inforcement: Participants in both formats received a monthly newsletter for three months following completion of their program. At six months, the group format women wee invited to attend a reunion and the self-directed participants received an in-depth motivational telephone call from the health educator

Theoretical basis for intervention: Yes, described in separate paper

\section{Co-interventions: NR}

Comparator: Usual care: "see their physician on the routine schedule and receive any information that would normally be provided as part of regular care in the practice."

\section{Co-interventions: NR}

\begin{tabular}{ll}
\hline Outcomes & Total mortality \\
& HRQoL - Sickness Impact Profile (SIP) \\
& Withdrawal from treatment \\
\hline Source of funding & Heart Division of the National Heart, Lung, and Blood Institute \\
\hline Conflicts of interest & NR \\
\hline Notes & NA
\end{tabular}

\section{Risk of bias}

\begin{tabular}{lll}
\hline Bias & Authors' judgement & Support for judgement \\
\hline $\begin{array}{l}\text { Random sequence genera- } \\
\text { tion (selection bias) }\end{array}$ & Low risk & "...complied using...book of random numbers." \\
\hline $\begin{array}{l}\text { Allocation concealment } \\
\text { (selection bias) }\end{array}$ & Low risk & "Sealed opaque and sequentially numbered envelopes." \\
\hline $\begin{array}{l}\text { Blinding of outcome as- } \\
\text { sessment (detection bias) } \\
\text { All outcomes }\end{array}$ & Low risk & $\begin{array}{l}\text { "Those assessing outcomes were blinded to the group allocation unless the } \\
\text { participant happened to reference program participation during the follow-up } \\
\text { telephone interviews or at the physical assessment visit." Correspondence } \\
\text { with author, J Dodge }\end{array}$ \\
\hline
\end{tabular}

\begin{tabular}{lll}
\hline $\begin{array}{l}\text { Incomplete outcome data } \\
\text { (attrition bias) } \\
\text { All outcomes }\end{array}$ & Low risk & Clear description of withdrawals from trial given \\
\hline $\begin{array}{l}\text { Selective reporting (re- } \\
\text { porting bias) }\end{array}$ & Low risk & $\begin{array}{l}\text { Sickness Impact Profile numerical scores were not individually reported as } \\
\text { no significant difference was found. These were subsequently made available } \\
\text { through correspondence with author, J Dodge }\end{array}$ \\
\hline $\begin{array}{l}\text { Were groups balanced at } \\
\text { baseline? }\end{array}$ & Low risk & "no significant differences among study conditions..." (Table 1) \\
\hline $\begin{array}{l}\text { Intention to treat analysis } \\
\text { Low risk }\end{array}$ & $\begin{array}{l}\text { "Analyses were carried out using the women as they were randomised to each } \\
\text { of the three study conditions" }\end{array}$
\end{tabular}


Clark 2009 (Continued)

Did both groups receive Low risk comparable care?
"In an effort to ensure similar care to all participants, no feedback about individual study participants was provided to health care personnel at the study sites."

Cohen 2014

Study characteristics

$\begin{array}{ll}\text { Methods } & \text { Study design: Multicentre RCT ( } 6 \text { sites) } \\ \text { Country: France } \\ \text { Dates patients recruited: June } 212006 \text { to July } 302008 \\ \text { When randomised: During their hospitalisation } \\ \text { Maximum follow up: } 1 \text { year }\end{array}$

Participants

Inclusion criteria: At least 18 years of age, were hospitalised in a cardiac intensive care unit for an ACS (unstable angina, ST-segment elevation MI, or non-ST-segment elevation MI), and had at least 1 of the following education modifiable risk factors: current smoking (for $\geq 12$ months), sedentary lifestyle ( $<3$ hours of physical activity per week), or overweight or obesity (body mass index $\geq 25$ for overweight or $\geq 30$ for obesity, calculated as weight in kilograms divided by height in meters squared). Patients also had to be willing and able to attend regular visits at an outpatient program.

Exclusion criteria: NR

N Randomised: total: 502; intervention: 251; comparator: 251

Diagnosis (\% of pts):

ST elevation MI: intervention: $48.8 \%$; comparator: $47.0 \%$

Non-ST-elevation MI: intervention: 35.2\%; comparator: $32.9 \%$

Unstable angina: intervention:16.0\%; comparator:20.1\%

Age (mean \pm SD): total: NR; intervention: 58.0 years ( \pm 10.9 years); comparator: 55.7 years $( \pm 10.9$ years)

Percentage male: total: NR; intervention: $80.9 \%$;comparator: $87.6 \%$

Ethnicity: NR

Interventions

Description of intervention: Patients attended the House of Education at least 6 times: within the first month after discharge and then at months 2, 3, 6, 9, and 12. Patients could attend additional consultations at any time up to 12 months after the index event. The content of the consultations was individualised according to a patient's risk factors. Current smokers attended a consultation with the nurse specialised in the management of smoking cessation. The consultation with the dietician comprised an evaluation of the patient's diet, followed by an explanation of the general principles for an adequately balanced diet.

\section{Components: Education}

Delivered by: Nurse who was specialised in smoking cessation counselling, and a dietician who had received training in physical activity counselling

\section{Setting (home/centre): Centre}

Teaching modalities: Individual

Involvement of family: A consultation with the patient's partner could be organised to improve the patient's diet

Time of start after event: Within a month after discharge 
Cohen 2014 (Continued)

Dose:

Length of session: NR

Frequency/number of sessions: At least 6 times

Total duration: 12 months

Follow-up further re-inforcement: Information related to the hospitalisation period, the patient's risk factors, and objectives for risk factor management was recorded via the Internet system. An e-mail was automatically sent to the staff at the House of Education and to the primary care physicians (general practice and cardiologists). The staff and the primary care physicians could log into the system using a secure access to see all patient information

\section{Theoretical basis for intervention: NR}

Co-interventions: Information was recorded on the prescription of co-interventions (e.g. nicotine supplements, hospitalisation in a rehabilitation centre, and others). The administration was left to the discretion of the care provider

Comparator: Patients in the control group attended appointments with their primary care physician and primary care cardiologist within 1 month of discharge

Co-interventions: Information was recorded on the prescription of co-interventions (e.g. nicotine supplements, hospitalisation in a rehabilitation centre, and others). The administration was left to the discretion of the care provider

\begin{tabular}{ll}
\hline Outcomes & Total mortality \\
& Withdrawals \\
& HRQoL \\
\hline Source of funding & The study was funded by grant 960110211 from the Unions Régionales des Caisses d'Assurance Mal- \\
adie & Dr Cohen has received a research grant for research nurses (RESICARD) and consultant and lecture fees \\
from AstraZeneca, Bayer Pharma, Bohringer-Ingelheim, Daiichi Sankyo, GlaxoSmithKline, and sanofi- \\
aventis. Dr Solol has received grants and honorarium from Servier, Roche, Pfizer, Bayer Pharma, Novar- \\
tis, Alere, Thermofischer, sanofi-aventis, Ipsen, and Vifor. Dr Montalescot has received research grants \\
to the institution or consultant and lecture fees from Bayer Pharma, Bristol-Myers Squibb, Boehri- \\
inger-Ingelheim, Duke Institute, Europa, GlaxoSmithKline, Iroko, Lead-Up, Novartis, Springer, TIMI \\
group, WebMD, Wolters, AstraZeneca, Biotronik, Eli Lilly, The Medicines Company, Medtronic, Menar- \\
ini, Roche, sanofi-aventis, Pfizer, Accumetrics, Abbott Vascular, Daiichi Sankyo, Fédération Française \\
de Cardiologie, Fondation de France, INSERM, Institut de France, Nanosphere, Stentys, and Société \\
$\begin{array}{l}\text { Française de Cardiologie. Dr Steg has received research grants from New York University School of Med- } \\
\text { icine, Servier, and sanofi-aventis. He has served as a speaker or consultant to Ablynx, Amarin, Amgen, } \\
\text { Astellas, AstraZeneca, Bayer Pharma, Boehringer-Ingelheim, Bristol-Myers Squibb, Daiichi Sankyo, Ei- } \\
\text { sai, GlaxoSmithKline, Eli Lilly, Medtronic, Merck-Sharpe Dohme, Novartis, Otsuka, Pfizer, Roche, sanofi- } \\
\text { aventis, Servier, The Medicines Company, and Vivus. He has equity ownership in Aterovax. No other dis- } \\
\text { closures were reported }\end{array}$
\end{tabular}

Notes NA

\section{Risk of bias}

\begin{tabular}{lll}
\hline Bias & Authors' judgement & Support for judgement \\
\hline $\begin{array}{l}\text { Random sequence genera- } \\
\text { tion (selection bias) }\end{array}$ & Low risk & $\begin{array}{l}\text { "Patients were randomised according to a computer-generated list with } \\
\text { blocks of varying size stratified on centers" }\end{array}$ \\
\hline
\end{tabular}


Cohen 2014 (Continued)

$\begin{array}{ll}\begin{array}{l}\text { Allocation concealment } \quad \text { Low risk } \\ \text { (selection bias) }\end{array} & \begin{array}{l}\text { "The list was prepared and maintained by an independent statistician at the } \\ \text { clinical trial unit. Allocation was concealed in sequentially numbered, sealed } \\ \text { opaque envelopes." }\end{array}\end{array}$

\begin{tabular}{|c|c|c|}
\hline $\begin{array}{l}\text { Blinding of outcome as- } \\
\text { sessment (detection bias) } \\
\text { All outcomes }\end{array}$ & Low risk & $\begin{array}{l}\text { "independent research staff rather than the treating physician performed out- } \\
\text { come assessments." }\end{array}$ \\
\hline $\begin{array}{l}\text { Incomplete outcome data } \\
\text { (attrition bias) } \\
\text { All outcomes }\end{array}$ & Low risk & $\begin{array}{l}\text { Intervention: } 48 / 251(19.1 \%) \text { lost to follow-up } \\
\text { Control: } 36 / 251(14.3 \%) \text { lost to follow-up }\end{array}$ \\
\hline $\begin{array}{l}\text { Selective reporting (re- } \\
\text { porting bias) }\end{array}$ & Low risk & All outcomes described in methods are reported \\
\hline $\begin{array}{l}\text { Were groups balanced at } \\
\text { baseline? }\end{array}$ & Low risk & $\begin{array}{l}\text { Baseline characteristics for patients in the } 2 \text { treatment groups were well bal- } \\
\text { anced (Table 1) }\end{array}$ \\
\hline Intention to treat analysis & Low risk & $\begin{array}{l}\text { "The primary end point was analysed according to the intent-to-treat princi- } \\
\text { ple." }\end{array}$ \\
\hline $\begin{array}{l}\text { Did both groups receive } \\
\text { comparable care? }\end{array}$ & Low risk & $\begin{array}{l}\text { Co-interventions received by the two groups were similar (e.g. nicotine supple- } \\
\text { ments, hospitalisation in a rehabilitation centre, and others) }\end{array}$ \\
\hline
\end{tabular}

Cupples 1994

\section{Study characteristics}

\begin{tabular}{|c|c|}
\hline Methods & $\begin{array}{l}\text { Study design: Multicentre RCT (18 sites) } \\
\text { Country: Northern Ireland, UK } \\
\text { Dates patients recruited: between } 1990 \text { and } 1993 \\
\text { When randomised: NR } \\
\text { Maximum follow up: } 5 \text { years }\end{array}$ \\
\hline Participants & $\begin{array}{l}\text { Inclusion criteria: } \geq 6 \text { month history of angina diagnosed by classical history } \\
\text { Exclusion criteria: No other severe illness } \\
\text { Recruitment from: } 18 \text { general practices in Greater Belfast } \\
\text { N randomised: total: } 688 \text {; intervention: } 342 \text {; comparator: } 346 \\
\text { Diagnosis (\% of pts): } \\
\text { Angina: } 100 \% \\
\text { Previous MI: } 45 \% \\
\text { Age (mean } \pm \text { SD): total: NR; intervention: } 62.7 \text { years }(7.1) \text {; comparator: } 63.6 \text { years }(6.8) \\
\text { Percentage male: total: } 59.3 \% \text {; intervention: } 59.4 \% \text {; comparator: } 59.2 \% \\
\text { Ethnicity: NR }\end{array}$ \\
\hline Interventions & $\begin{array}{l}\text { Description of intervention: "Patients in the intervention group were given practical relevant advice } \\
\text { regarding cardiovascular risk factors. They were reviewed at four monthly intervals and given appropri- } \\
\text { ate health education (Cupples 1994)." } \\
\text { "Visited by a health visitor, whose brief was to discuss ways of living more easily with their disease and } \\
\text { ways in which risks of further events might be reduced (O'Neill 1996)." } \\
\text { "The education involved giving information which was tailored to the individuals' coronary risk factors } \\
\text { and the use of medication (Cupples 1996)" }\end{array}$ \\
\hline
\end{tabular}




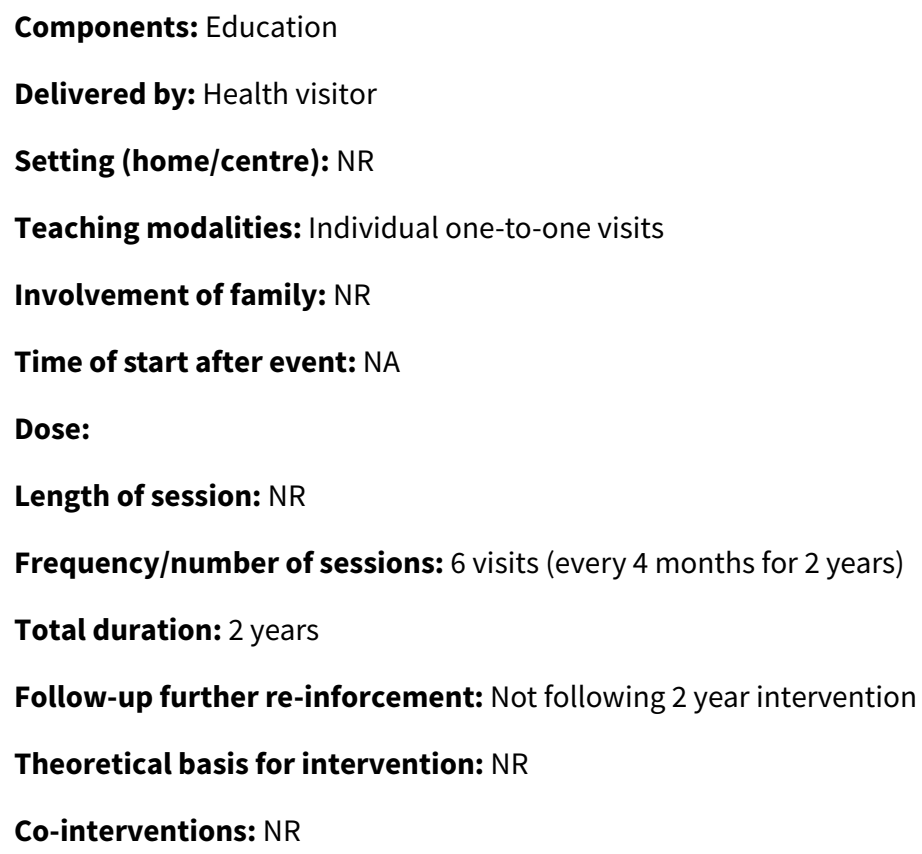

Comparator: Patients in the usual care group received the same screening interview as the intervention group but once randomised to control had no further intervention.

Co-interventions: NR

\begin{tabular}{ll}
\hline Outcomes & Total mortality \\
& Cardiovascular related mortality \\
& Hospitalisations recorded as part of cost analysis (not independently reported) (O'Neill 1996) \\
& HRQoL (Nottingham Health Profile Questionnaire) (Cupples 1996) \\
& Adverse events (withdrawal from intervention group) \\
& Cost Analysis (O'Neill 1996) \\
\hline Source of funding & The Medical Research Council \\
\hline Conflicts of interest & NR \\
\hline Notes & The following papers produced from the results of the same trial were used to inform the data collect- \\
& ed: Cupples 1996; Cupples 1999; O'Neill 1996
\end{tabular}

\section{Risk of bias}

\begin{tabular}{lll}
\hline Bias & Authors' judgement & Support for judgement \\
\hline $\begin{array}{l}\text { Random sequence genera- } \\
\text { tion (selection bias) }\end{array}$ & Low risk & "generated by a computer program using permuted blocks (Cupples 1996)." \\
\hline $\begin{array}{l}\text { Allocation concealment } \\
\text { (selection bias) }\end{array}$ & Low risk & $\begin{array}{l}\text { "The health visitor opened an opaque, sealed, and numbered envelope con- } \\
\text { taining the allocation" (Cupples 1994) }\end{array}$ \\
\hline $\begin{array}{l}\text { Blinding of outcome as- } \\
\text { sessment (detection bias) } \\
\text { All outcomes }\end{array}$ & Low risk & $\begin{array}{l}\text { "After 2 years both groups were reviewed by a research worker who had not } \\
\text { previously been involved with the subjects" (Cupples 1994) }\end{array}$ \\
\hline
\end{tabular}


Cupples 1994 (Continued)

At five year follow-up: "nurse (performing interview) was blind to trial group allocation" (Cupples 1999)

\begin{tabular}{|c|c|c|}
\hline $\begin{array}{l}\text { Incomplete outcome data } \\
\text { (attrition bias) } \\
\text { All outcomes }\end{array}$ & Low risk & $\begin{array}{l}\text { Detailed report of withdrawals and losses to follow up reported. } \\
\text { Cupples } 1994 \text { Yes; Cupples } 1996 \text { No; O'Neill } 1996 \text { No; Cupples } 1999 \text { No }\end{array}$ \\
\hline $\begin{array}{l}\text { Selective reporting (re- } \\
\text { porting bias) }\end{array}$ & Low risk & All relevant outcomes listed in methods were reported in methods \\
\hline $\begin{array}{l}\text { Were groups balanced at } \\
\text { baseline? }\end{array}$ & Low risk & $\begin{array}{l}\text { "No significant differences were found between the two groups at base- } \\
\text { line" (Cupples 1994) }\end{array}$ \\
\hline Intention to treat analysis & Low risk & $\begin{array}{l}\text { "We also analysed the data in an intention to treat basis, with baseline or adjust- } \\
\text { ed values being substituted for missing data, but this did not alter the conclu- } \\
\text { sions (Cupples 1999)." }\end{array}$ \\
\hline $\begin{array}{l}\text { Did both groups receive } \\
\text { comparable care? }\end{array}$ & Low risk & $\begin{array}{l}\text { Both groups received same usual care and only difference between groups } \\
\text { was the educational intervention }\end{array}$ \\
\hline
\end{tabular}

Dracup 2009

\section{Study characteristics}

$\begin{array}{ll}\text { Methods } & \begin{array}{l}\text { Study design: Multicentre RCT (18 sites) } \\ \text { Country: USA, Australia and New Zealand } \\ \text { Dates patients recruited: Between } 2002 \text { and } 2004 \\ \text { When randomised: Following collection of baseline data } \\ \text { Maximum follow up: } 2 \text { years }\end{array}\end{array}$

Participants

Inclusion criteria: Diagnosis of ischemic heart disease, confirmed by their physician or hospital medical record, and if they lived independently (i.e. not in an institutional setting)

Exclusion criteria: Patients were excluded if they had any of the following: complicating serious comorbidity such as a psychiatric illness or untreated malignancy, neurological disorder with impaired cognition, or inability to read or understand English

N Randomised: total: 3522; intervention: 1777; comparator: 1745 Diagnosis (\% of pts):

ACS (100\%)

Age (mean \pm SD): total: $67 \pm 11$ years; intervention: NR; comparator: NR Percentage male: total: $68.0 \%$; intervention: $66.2 \%$;comparator: $69.7 \%$ Ethnicity: $91.1 \%$ white ticipated emotional issues and social factors that could affect delay. Patients were given standardised information about typical and atypical symptoms of ACS and possible variability in symptom presentation. Patients were told that they might experience chest pressure or discomfort that was intermittent rather than constant, and that diaphoresis, shortness of breath, and pain radiation to parts of the body other than the left arm (e.g. neck or back) were also possible symptoms of ACS. They were advised to call emergency medical services immediately. Patients were asked to anticipate the emotional responses to ACS symptoms that might lead to delay, as well as to discuss their previous experiences accessing the medical system. The rewards of seeking treatment immediately were emphasised and emotional issues were addressed through role playing scenarios that were standardised across inter- 
vention group patients. The potential reaction of the family member was discussed (e.g. denial, fear, ambivalence, etc.) and the importance of and rewards for quick action were underscored

Components: Education and counselling

Delivered by: A nurse with expertise in cardiology

Setting (home/centre): Home or centre

Teaching modalities: Individual

Involvement of family: Patients were asked to bring their spouse, another family member or friend to the intervention session whenever possible. These individuals were "deputised" to act as the decision maker if the patient hesitated to call emergency medical services

\section{Time of start after event: NR}

Dose:

Length of session: 40 minutes

Frequency/number of sessions: 1

Total duration: 55 minutes (40 min plus 15 min follow-up call)

Follow-up further re-inforcement: One month following the initial intervention session, the nurse who had provided the intervention called each patient and reviewed the main points from the initial session. The average length of the phone call was 15 minutes

Theoretical basis for intervention: Based on Leventhal's self regulatory model of illness behaviour

Co-interventions: At the time of the development of the educational intervention, patients who had no contraindications were encouraged to take one non-enteric coated aspirin prior to arrival at the hospital as well as nitroglycerin (if prescribed), and this instruction was included

Comparator: Usual care

Co-interventions: NR

\begin{tabular}{ll}
\hline Outcomes & Total mortality \\
& Hospitalisations \\
& Withdrawals \\
\hline Source of funding & National Institutes of Health, National Institute of Nursing Research \\
\hline Conflicts of interest & No real or perceived conflicts of interest exist for any of the authors of this manuscript. \\
\hline Notes & NA \\
\hline
\end{tabular}

\section{Risk of bias}

\begin{tabular}{lll}
\hline Bias & Authors' judgement & Support for judgement \\
\hline $\begin{array}{l}\text { Random sequence genera- } \\
\text { tion (selection bias) }\end{array}$ & High risk & Method of randomisation not described \\
\hline $\begin{array}{l}\text { Allocation concealment } \\
\text { (selection bias) }\end{array}$ & High risk & Method of allocation concealment not described \\
\hline $\begin{array}{l}\text { Blinding of outcome as- } \\
\text { sessment (detection bias) }\end{array}$ & Low risk & $\begin{array}{l}\text { "Physicians caring for patients and nurses collecting follow-up data were } \\
\text { blinded to study assignment." }\end{array}$ \\
\hline
\end{tabular}


Dracup 2009 (Continued)

All outcomes

\begin{tabular}{|c|c|c|}
\hline $\begin{array}{l}\text { Incomplete outcome data } \\
\text { (attrition bias) } \\
\text { All outcomes }\end{array}$ & Low risk & $\begin{array}{l}\text { Intervention: } 197 / 1777(11.1 \%) \text { lost to follow-up } \\
\text { Control: } 238 / 1745 \text { (13.6\%) lost to follow-up }\end{array}$ \\
\hline
\end{tabular}

Selective reporting (re- Low risk All outcomes described in the methods are described in the results
porting bias)

\begin{tabular}{|c|c|c|}
\hline $\begin{array}{l}\text { Were groups balanced at } \\
\text { baseline? }\end{array}$ & High risk & $\begin{array}{l}\text { "A check on randomisation revealed no significant differences between groups } \\
\text { on a variety of demographic and clinical variables except for body mass index } \\
(P=0.048) \text {, gender (with more females in the experimental group than control, } \\
P=0.02 \text { ), and insurance for ambulance use (with more patients with insurance } \\
\text { in the control group compared to the experimental group, } P=0.04 \text { ) (Table } 1 \text { )." }\end{array}$ \\
\hline
\end{tabular}

$\begin{array}{ll}\text { Intention to treat analysis } \quad \text { High risk } & \begin{array}{l}\text { ITT analysis is not described and data from patients lost to follow-up are not } \\ \text { included in analyses }\end{array}\end{array}$

Did both groups receive High risk Intervention included counselling

comparable care?

\section{Study characteristics}

\begin{tabular}{|c|c|}
\hline Methods & $\begin{array}{l}\text { Study design: Multicentre RCT } \\
\text { Country: USA } \\
\text { Dates patients recruited: All Florida Medicare beneficiaries enrolled in Medicaid as of March } 2006 \text { who } \\
\text { met eligibility criteria. } \\
\text { When randomised: "When eligible beneficiaries are identified." } \\
\text { Maximum follow up: } 18 \text { months }\end{array}$ \\
\hline Participants & $\begin{array}{l}\text { Inclusion criteria: Enrolled in Medicare and receiving Medicard benefits; have congestive cardiac fail- } \\
\text { ure, diabetes or CAD } \\
\text { Exclusion criteria: Psychiatric inpatient therapy of more than } 14 \text { consecutive days in the prior } 12 \\
\text { months; long term nursing home residence } \\
\text { Recruitment from: Medicare database } \\
\text { N Randomised: total: } 46,606 \text {; intervention: } 33,267 \text {; comparator: } 13,339 \\
\text { Diagnosis ( } \% \text { of pts): } \\
\text { CAD (Not further defined): } 69 \% \\
\text { In combination with heart failure: } 10 \% \\
\text { In combination with diabetes: } 19 \% \\
\text { With all three diagnoses: } 12 \% \\
\text { Age (mean): total: } 68.4 \text { years; intervention: } 68.4 \text { years; comparator: } 68.4 \text { years } \\
\text { Percentage male: total: } 34 \% \text {; intervention: } 34 \% \text {; comparator: } 34 \% \\
\text { Ethnicity: } 55 \% \text { white }\end{array}$ \\
\hline Interventions & $\begin{array}{l}\text { Description of intervention: "Nurse case managers provided education to patients on the recognition } \\
\text { of signs and symptoms of their disease; how to monitor vital signs; the cause of diseases; how to better } \\
\text { adhere to diet, exercise, and medication regimes; and strategies to cope with chronic illness. When pro- } \\
\text { viding education to patients, nurses use pre-designed scripts. Geared towards educating patients on } \\
\text { how to attain clinical goals." }\end{array}$ \\
\hline
\end{tabular}




\section{Components: Education}

Delivered by: Individually assigned nurse care manager

Setting (home/centre): Home (telephone)

Teaching modalities: "The intervention is primarily telephonic, but also had an in-person component."

Involvement of family: NR

Time of start after event: NA

Dose: Patients received 1.1 contacts per active month, on average

\section{Length of session: NR}

Frequency/number of sessions: NR

Total duration: 18 months

Follow-up further re-inforcement: Intervention continued until end of follow up period

Theoretical basis for intervention: NR

Co-interventions: Patient assessment, care planning, routine nurse monitoring, patient self-monitoring, care co-ordination, and service arrangement

Comparator: Not described

Co-interventions: NR

\begin{tabular}{ll}
\hline Outcomes & Hospitalisations - Emergency and inpatient use \\
HRQoL (survey of selected 613 enrollees only and claims based quality of care measures) \\
Cost analysis
\end{tabular}

\begin{tabular}{ll}
\hline Source of funding & NR \\
\hline Conflicts of interest & $\begin{array}{l}\text { "The authors are with Mathematica Policy Research, Inc. The statements expressed in this article are } \\
\text { those of the authors and do not necessarily reflect the views or policies of Mathematica Policy Re- } \\
\text { search, Inc., or the Centers for Medicare \& Medicaid Services (CMS)." }\end{array}$ \\
\hline Notes & $\begin{array}{l}\text { Analysed first and second } 6 \text { month periods, first year and } 18 \text { months. } \\
\text { Population based study that only a relatively small proportion of those assigned to the intervention } \\
\text { group actually actively continued to participate in. Therefore treatment effect may be difficult to statis- } \\
\text { tically demonstrate }\end{array}$
\end{tabular}

\section{Risk of bias}

\begin{tabular}{lll}
\hline Bias & Authors' judgement & Support for judgement \\
\hline $\begin{array}{l}\text { Random sequence genera- } \\
\text { tion (selection bias) }\end{array}$ & Unclear risk & NR \\
\hline $\begin{array}{l}\text { Allocation concealment } \\
\text { (selection bias) }\end{array}$ & Unclear risk & NR \\
\hline
\end{tabular}

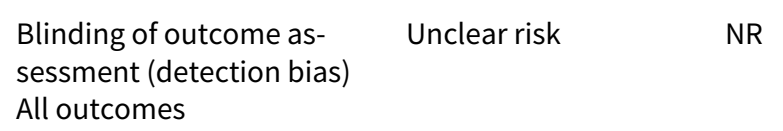


Esposito 2008 (Continued)

Incomplete outcome data Low risk Divided patients in to mediated - those that fully engaged with the interven(attrition bias) tion and instructional - those that were less that fully engaged but did not opt All outcomes out. Breakdown of mediated patients demonstrated in a table.

Selective reporting (re- Low risk Primary outcomes stated in methods were reported in the results. porting bias)

$\begin{array}{ll}\begin{array}{l}\text { Were groups balanced at } \quad \text { Low risk } \\ \text { baseline? }\end{array} & \begin{array}{l}\text { Detailed table (Table 4) of pre-enrolment characteristics showed no statistical- } \\ \text { ly significant differences seen. Authors reported that there was a difference in } \\ \text { that the treatment group utilised health services } 5 \% \text { more in } 2 \text { year run up pe- } \\ \text { riod to the trial (not statistically significant) }\end{array}\end{array}$

\begin{tabular}{lll}
\hline Intention to treat analysis & Low risk & "intention to treat study design." \\
\hline $\begin{array}{l}\text { Did both groups receive } \\
\text { comparable care? }\end{array}$ & High risk & $\begin{array}{l}\text { Education only part of the intervention: "intervention components include pa- } \\
\text { tient assessment, care planning, routine nurse monitoring, patient self-mon- } \\
\text { itoring, education, care co-ordination, and service arrangement." Physicians } \\
\text { were alerted to "important changes in patients' health." }\end{array}$ \\
\hline
\end{tabular}

Furuya 2015

\section{Study characteristics}

\begin{tabular}{|c|c|}
\hline \multirow[t]{2}{*}{ Methods } & $\begin{array}{l}\text { Study design: Single centre RCT } \\
\text { Country: Brazil } \\
\text { Dates patients recruited: August } 2011 \text { to June } 2012\end{array}$ \\
\hline & $\begin{array}{l}\text { When randomised: After collecting baseline data } \\
\text { Maximum follow up: } 6 \text { months }\end{array}$ \\
\hline
\end{tabular}

Participants

Inclusion criteria: Aged 18 years or older, undergoing first $\mathrm{PCl}$ and had access to a telephone Exclusion criteria: Exclusion criteria included: being clinically unable to answer questions or talk on the telephone (e.g. patients with dyspnea, confusion or unable to hear); having sequelae affecting daily activities (e.g. amputation or paresis); being already enrolled in another educational programme; or having cognitive impairment as assessed by the Mini-Mental State Examination (MMSE) adapted to the Brazilian population (Brucki et al. 2003)

N randomised: total: *66; intervention: 34 ; comparator: 32

Diagnosis (\% of pts):

PCl: $100 \%$

Age (mean \pm SD): total: NR; intervention: 63.3 years $( \pm 12.4)$; comparator: 60.6 years $( \pm 8.7)$

Percentage male: total: $\%$; intervention: $60.0 \%$;comparator: $53.3 \%$

Ethnicity: NR

Interventions

Description of intervention: The educational programme consisted of three booklets and three telephone follow-up calls. The first booklet was discussed with participants before undergoing $\mathrm{PCI}$ procedure. The objective was to help the patient to understand his cardiac condition, the $\mathrm{PCl}$ procedure and how to cope with CAD in general. The other two booklets focused on self-care related to the $\mathrm{PCl}$ itself and to day-to-day management of the disease, which were discussed with participants after $\mathrm{PCl}$, on the day of procedure or on the following day. Three telephone calls were made (in the first, eighth and sixteenth week after hospital discharge), focusing on lifestyle changes. The telephone script contained questions on self-care including: care of arm and leg used for the $\mathrm{PCI}$ procedure, changes in risk factors for $C A D$ and correct use of medication. Each participant was asked whether s/he was successfully executing changes in physical activity, eating and smoking habits and verifying blood pressure. Then the investigator attempted to motivate the participant to make behavioural changes and discussed barriers to changing habits. 
Furuya 2015 (Continued)

\author{
Components: Education \\ Delivered by: Two researchers \\ Setting (home/centre): Centre \\ Teaching modalities: Individual \\ Involvement of family: NR
}

Time of start after event: Programme commenced prior to $\mathrm{PCl}$ procedure

Dose:

Length of session: NR

Frequency/number of sessions: 2 face-to-face sessions and 3 telephone calls

Total duration: 16 weeks

Follow-up further re-inforcement: Each participant was instructed to make a telephone call to the investigator for further questions or support for secondary prevention for CAD

Theoretical basis for intervention: Based on the construct of self-efficacy according to Albert Bandura's Social Cognitive Theory (Bandura 2004)

Co-interventions: NR

Comparator: Control group participants received the usual instructions given by healthcare providers at the hospital

\title{
Co-interventions: NR
}

\begin{tabular}{ll}
\hline Outcomes & HRQoL \\
& Withdrawals \\
\hline Source of funding & Grants 2010/19761-3 and 2010/10006-8, São Paulo Research Foundation (FAPESP) \\
\hline Conflicts of interest & $\begin{array}{l}\text { The authors state that there are no financial and personal relationships with people or organisations } \\
\text { that could inappropriately influence this work }\end{array}$ \\
\hline Notes & $\begin{array}{l}\text { *90 Patients were originally randomised but 24 were excluded after randomisation for the following } \\
\text { reasons: further medical assessment indicated need for surgical revascularisation or clinical treatment } \\
(\mathrm{N}=20), \text { or participant was enrolled in another educational programme (N }=4)\end{array}$
\end{tabular}

\section{Risk of bias}

\begin{tabular}{|c|c|c|}
\hline Bias & Authors' judgement & Support for judgement \\
\hline $\begin{array}{l}\text { Random sequence genera- } \\
\text { tion (selection bias) }\end{array}$ & Low risk & $\begin{array}{l}\text { "A research staff member...generated the random allocation in Graphpad soft- } \\
\text { ware" }\end{array}$ \\
\hline $\begin{array}{l}\text { Allocation concealment } \\
\text { (selection bias) }\end{array}$ & Low risk & $\begin{array}{l}\text { A research staff member...generated the random allocation in Graphpad soft- } \\
\text { ware...concealing it from the investigators in sequentially numbered, sealed, } \\
\text { opaque envelopes." }\end{array}$ \\
\hline $\begin{array}{l}\text { Blinding of outcome as- } \\
\text { sessment (detection bias) } \\
\text { All outcomes }\end{array}$ & Low risk & $\begin{array}{l}\text { "Therefore, investigators who were un-blinded to participant allocation } \\
\text { helped with the data collection." }\end{array}$ \\
\hline $\begin{array}{l}\text { Incomplete outcome data } \\
\text { (attrition bias) }\end{array}$ & Low risk & Intervention: $4 / 34$ (11.8\%) lost to follow-up \\
\hline
\end{tabular}


Furuya 2015 (Continued) All outcomes
Control: 2/32 (6.3\%) lost to follow-up

(90 participants were originally randomised (45 in each group), but 24 participants were excluded immediately after randomisation as they were indicated for surgery or enrolled in another study)

Selective reporting (re- Low risk All outcomes described in the methods are reported
porting bias)

Were groups balanced at Low risk baseline?

"The intervention and control groups did not differ significantly in socio-demographic and clinical characteristics at baseline ( $P>0.12$ for all variables)."

Intention to treat analysis High risk

No ITT analysis is described and data from patients lost to follow-up are not included in the analyses

Hanssen 2007

\section{Study characteristics}

\begin{tabular}{|c|c|}
\hline Methods & $\begin{array}{l}\text { Study design: Single centre RCT } \\
\text { Country: Norway } \\
\text { Dates patients recruited: Sept } 2001 \text { to Sept } 2005 \\
\text { When randomised: After hospitalisation of at least } 2 \text { days } \\
\text { Maximum follow up: } 18 \text { months }\end{array}$ \\
\hline Participants & $\begin{array}{l}\text { Inclusion criteria: All patients with confirmed AMI and admitted to the hospital. } \\
\text { Exclusion criteria: Severe co-existing chronic disabling disease; nursing home resident; unable to re- } \\
\text { ceive telephone calls; unable to fill in questionnaires; if expected to have CABG in that admission; In the } \\
\text { first year of the study > } 80 \text { year olds were excluded, after the first year they were included } \\
\text { Recruitment from: Haukeland University Hospital, Bergen, Norway } \\
\text { N randomised: total: } 288 \text {; intervention: } 156 \text {; comparator: } 132 \\
\text { Diagnosis (\% of pts): } \\
\text { Post MI: } 100 \% \\
\text { Age (mean } \pm \text { SD): intervention: } 59.5 \text { years (12.9); comparator: } 60.9 \text { years }(10.8) \\
\text { Percentage male: total: } 81 \% \text {; intervention: } 84.6 \% \text {;comparator: } 76.5 \% \\
\text { Ethnicity: NR }\end{array}$ \\
\hline
\end{tabular}

Interventions

Description of intervention: "Structured intervention encompassing telephone follow up and an open telephone line" "to provide patients with information, education and support on the basis of individual needs. To provide patients with information about what are common questions after AMI and encourage elaboration on the issues if desired. One issue was addressed in each call."

Components: Education and counselling

Delivered by: Nurses with interests and experience in counselling and providing information to patients with ischaemic heart disease

Setting (home/centre): Home (telephone)

Teaching modalities: Telephone follow up

Involvement of family: (telephone) "Lines were open to patients and relatives/relations" 
Time of start after event: On discharge following the event

Dose:

Length of session: As long as required (mean telephone call $6.88 \mathrm{~min}$ (SD 3.89))

Frequency/number of sessions: 8 (weekly first 4 weeks, then weeks 6, 8, 12 and 24).

Total duration: 6 months (could stop earlier if requested) but encouraged to have at least the first 5 months intervention

\section{Follow-up further re-inforcement: None}

Theoretical basis for intervention: Intervention was developed on the basis of the Lazarus and Folkmans theory on stress, appraisal and copy, principles about patient education, findings from previous research and according to guideline recommendations.

Co-interventions: Counselling

Comparator: Managed in accordance with current clinical practice. Included one visit to a physician at the outpatient clinic 6 to 8 weeks after discharge, and subsequent visits to the patient's general practitioner

\section{Co-interventions: NR}

\begin{tabular}{ll}
\hline Outcomes & HRQoL (SF-36) \\
& Re-admission to hospital \\
& Mortality \\
\hline Source of funding & $\begin{array}{l}\text { Haukeland University Hospital, the Norwegian Nurse Association, the Meltzer Foundation for grants, } \\
\text { and the Norwegian Lung and Heart Foundation }\end{array}$ \\
\hline Conflicts of interest & "None" \\
\hline Notes & $\begin{array}{l}\text { The following paper produced from the results of the same trial were used to inform the data collected: } \\
\text { Hanssen } 2009\end{array}$
\end{tabular}

\section{Risk of bias}

\begin{tabular}{lll}
\hline Bias & Authors' judgement & Support for judgement \\
\hline $\begin{array}{l}\text { Random sequence genera- } \\
\text { tion (selection bias) }\end{array}$ & Low risk & $\begin{array}{l}\text { "A simple randomisation procedure using a computer-generated list of ran- } \\
\text { dom numbers" }\end{array}$ \\
\hline $\begin{array}{l}\text { Allocation concealment } \\
\text { (selection bias) }\end{array}$ & Low risk & "...group allocation in sealed opaque envelopes prepared by the researcher." \\
\hline
\end{tabular}

\begin{tabular}{lll}
$\begin{array}{l}\text { Blinding of outcome as- } \\
\text { sessment (detection bias) } \\
\text { All outcomes }\end{array}$ & Unclear risk & Not clear if researchers were blinded to group allocations \\
\hline $\begin{array}{l}\text { Incomplete outcome data } \\
\text { (attrition bias) }\end{array}$ & Low risk & $\begin{array}{l}\text { CONSORT diagram of trial flow reported with details of withdrawals and loss } \\
\text { to follow up }\end{array}$
\end{tabular}

All outcomes

Selective reporting (re- Low risk Outcomes in methods reported in results.
porting bias)


Hanssen 2007 (Continued)

Were groups balanced at Low risk "No statistically differences were found" in baseline characteristics baseline?

Intention to treat analysis Low risk

Although intention to treat analysis not explicitly stated, the groups were analysed according to original random allocation

Did both groups receive High risk

comparable care?

Intervention included both education and counselling - psychological based intervention. "Providing emotional support and alternative coping strategies" which was not received by control group

Jorstad 2013

\section{Study characteristics}

$\begin{array}{ll}\text { Methods } & \begin{array}{l}\text { Study design: Multicentre RCT (11 sites) } \\ \text { Country: Netherlands } \\ \text { Dates patients recruited: June } 2006 \text { to July } 2009\end{array} \\ \text { When randomised: Shortly after hospitalisation } \\ \text { Maximum follow up: } 12 \text { months }\end{array}$

Participants

Inclusion criteria: Patients aged 18 to 80 years were eligible if they had been diagnosed with an ACS (STEMI, non-STEMI or unstable angina pectoris), within 8 weeks prior to entry into the study

Exclusion criteria: Visits to the nurse coordinated prevention programmes not feasible; not available for follow-up; surgery, percutaneous coronary intervention or other interventions expected within 8 weeks after inclusion; limited life expectancy ( $\leq 2$ years); previously enrolled in the nurse coordinated prevention programme; New York Heart Association class III or class IV heart failure

N randomised: total: 754 ; intervention: 375 ; comparator: 379

Diagnosis (\% of pts):

STEMI: intervention: 50\%; comparator: $48 \%$

NSTEMI: intervention: 33\%; comparator:33\%

Unstable angina pectoris: intervention: 17\%; comparator: 19\%

Age (mean \pm SD): total: NR; intervention: $57.5 \pm 9.9$; comparator: $57.8 \pm 10.4$

Percentage male: total: $80 \%$; intervention: $80 \%$;comparator: $80 \%$

Ethnicity: NR

Description of intervention: The programme included four outpatient clinic visits to a cardiovascular nurse during the first 6 months: at weeks 2, 7, 12 and 17 after baseline. The nurse-coordinated prevention programme followed a protocol based on national and international guidelines, focusing on (1) healthy lifestyles, (2) biometric risk factors and (3) medication adherence. During each visit, smoking status, dietary status, level of physical exercise, weight, waist circumference, blood pressure, total cholesterol, high-density lipoprotein (HDL) cholesterol, low density lipoprotein (LDL) cholesterol, triglycerides, glucose and $\mathrm{HbAlc}$ were reviewed. Nurses provided general lifestyle advice, including dietary advice. Nurses provided specific educational material and individual counselling to achieve smoking cessation, adequate physical exercise and healthy weight/fat distribution. There were no visits to the nurse-coordinated prevention programme between 6 and 12 months

Components: Education

Delivered by: Registered nurses with a 4-year bachelor's degree and experience in the care of cardiac patients. All nurses were given a 3-day course in motivational interviewing

Setting (home/centre): Centre 


\section{Teaching modalities: NR}

Involvement of family: NR

Time of start after event: 2 weeks

Dose:

Length of session: NR

Frequency/number of sessions: 4 sessions

Total duration: 6 months

Follow-up further re-inforcement: NR

\section{Theoretical basis for intervention: NR}

Co-interventions: Adherence to prescribed medication was encouraged at each visit, including antithrombotic therapy and a statin. If discontinued, reasons for discontinuation were documented, and if possible the therapy was restarted

Comparator: Usual care included outpatient clinic visits to treating cardiologists and other relevant specialists. This included referral to cardiovascular rehabilitation according to the national guidelines on cardiovascular rehabilitation. In short, cardiovascular rehabilitation typically consisted of a 12 week programme of evaluation of physical, psychological and social functioning, of providing education, physical exercise, and interventions to improve physical and social functioning and to improve cardiovascular risk factors and/or risk behaviour. Cardiologists were encouraged, in all patients, to adhere to current national and international guidelines for secondary prevention of cardiovascular disease

Co-interventions: As above

\begin{tabular}{|c|c|c|}
\hline \multirow[t]{3}{*}{ Outcomes } & \multicolumn{2}{|l|}{ Total mortality } \\
\hline & \multicolumn{2}{|l|}{ Hospitalisations } \\
\hline & \multicolumn{2}{|l|}{ Withdrawals } \\
\hline Source of funding & \multicolumn{2}{|c|}{$\begin{array}{l}\text { The study was sponsored by an unrestricted grant from AstraZeneca, The Netherlands. The sponsor } \\
\text { had no role in the design, data collection, data analysis, data interpretation and writing of this report }\end{array}$} \\
\hline Conflicts of interest & \multicolumn{2}{|l|}{ None } \\
\hline Notes & \multicolumn{2}{|l|}{ NA } \\
\hline \multicolumn{3}{|l|}{ Risk of bias } \\
\hline Bias & Authors' judgement & Support for judgement \\
\hline $\begin{array}{l}\text { Random sequence genera- } \\
\text { tion (selection bias) }\end{array}$ & Low risk & $\begin{array}{l}\text { "The online randomisation protocol consisted of a pre-generated block-strati- } \\
\text { fied randomisation protocol" }\end{array}$ \\
\hline $\begin{array}{l}\text { Allocation concealment } \\
\text { (selection bias) }\end{array}$ & Low risk & $\begin{array}{l}\text { "Study personnel entered patient's initials, date of birth and gender, and par- } \\
\text { ticipating individuals were assigned a study identification number along with } \\
\text { their allocation to either the intervention group or control group." }\end{array}$ \\
\hline $\begin{array}{l}\text { Blinding of outcome as- } \\
\text { sessment (detection bias) } \\
\text { All outcomes }\end{array}$ & Low risk & $\begin{array}{l}\text { "The randomly assigned treatment of patients was not disclosed to treating } \\
\text { cardiologists or general practitioners." }\end{array}$ \\
\hline $\begin{array}{l}\text { Incomplete outcome data } \\
\text { (attrition bias) }\end{array}$ & Low risk & Intervention: $23 / 375$ (6.1\%) lost to follow-up \\
\hline
\end{tabular}


Jorstad 2013 (Continued)
All outcomes
Control: 35/379 (9.2\%) lost to follow-up

\begin{tabular}{|c|c|c|}
\hline $\begin{array}{l}\text { Selective reporting (re- } \\
\text { porting bias) }\end{array}$ & Low risk & All outcomes described in the methods are reported \\
\hline
\end{tabular}

\begin{tabular}{lll}
\hline $\begin{array}{l}\text { Were groups balanced at } \\
\text { baseline? }\end{array}$ & Low risk & $\begin{array}{l}\text { All characteristics and prognostic factors were similar in both groups at base- } \\
\text { line }\end{array}$ \\
\hline Intention to treat analysis & High risk & $\begin{array}{l}\text { ITT analysis is not described, and data from patients lost to follow up are not } \\
\text { included in the analyses }\end{array}$ \\
\hline $\begin{array}{l}\text { Did both groups receive } \\
\text { comparable care? }\end{array}$ & Low risk & $\begin{array}{l}\text { "Patients were randomised to either the nurse-coordinated prevention pro- } \\
\text { gramme in addition to usual care (intervention group) or usual care alone } \\
\text { (control group)." }\end{array}$ \\
\hline
\end{tabular}

Lie 2009

\section{Study characteristics}

\begin{tabular}{|c|c|}
\hline Methods & $\begin{array}{l}\text { Study design: Single centre RCT } \\
\text { Country: Norway } \\
\text { Dates patients recruited: August } 2003 \text { to } 2004 \\
\text { When randomised: NR } \\
\text { Maximum follow up: } 6 \text { months }\end{array}$ \\
\hline Participants & $\begin{array}{l}\text { Inclusion criteria: All elective CABG patients aged } 18 \text { to } 80 \text { years } \\
\text { Exclusion criteria: More than } 3 \text { hours driving distance } \\
\text { Recruitment from: Hospital } \\
\text { N randomised: total: } 203 \text {; intervention: } 101 \text {; comparator: } 102 \\
\text { Diagnosis (\% of pts): } \\
\text { Post CABG: } 100 \% \\
\text { Previous AMI: intervention: } 40 \% \text {; comparator: } 31 \% \\
\text { Age mean (range): total: } 62 \text { years; intervention: } 62 \text { years ( } 39 \text { to } 77 \text { years); comparator: } 62 \text { years ( } 42 \text { to } \\
78 \text { years) } \\
\text { Percentage male: total: } 89.5 \% \text {; intervention: } 90 \% \text {;comparator: } 89 \% \\
\text { Ethnicity: NR }\end{array}$ \\
\hline
\end{tabular}

Interventions

Description of intervention: Structured information and psychological support for the topics of angina symptoms, medications, sexuality, anxiety, and depression. Material developed for the study

Components: "A psycho-educative intervention"

Delivered by: Masters prepared critical care nurse with 12 years' experience

Setting (home/centre): Home

Teaching modalities: Home visits

Involvement of family: NR

Time of start after event: 2 weeks post CABG

Dose:

Length of session: 1 hour 
Lie 2009 (Continued)

\section{Frequency/number of sessions: 2}

Total duration: 4 weeks

Follow-up further re-inforcement: No

Theoretical basis for intervention: NR

Co-interventions: Psychological support

Comparator: Patients in the intervention group and the control group received standard discharge care that involved a non-standardised short talk with the nurse/doctor

\section{Co-interventions: NR}

\begin{tabular}{ll}
\hline Outcomes & HRQoL - SF36 and Seattle Angina Questoinnaire (SAQ) \\
\hline Source of funding & NR \\
\hline Conflicts of interest & NR \\
\hline Notes & NA \\
\hline
\end{tabular}

\section{Risk of bias}

\begin{tabular}{|c|c|c|}
\hline Bias & Authors' judgement & Support for judgement \\
\hline $\begin{array}{l}\text { Random sequence genera- } \\
\text { tion (selection bias) }\end{array}$ & Low risk & "Statistician made the randomisation codes by using a computer program." \\
\hline $\begin{array}{l}\text { Allocation concealment } \\
\text { (selection bias) }\end{array}$ & Low risk & $\begin{array}{l}\text { "...a secretary created sealed opaque envelopes containing individual codes } \\
\text { with sequential numbers." }\end{array}$ \\
\hline $\begin{array}{l}\text { Blinding of outcome as- } \\
\text { sessment (detection bias) } \\
\text { All outcomes }\end{array}$ & Unclear risk & Blinding not described \\
\hline $\begin{array}{l}\text { Incomplete outcome data } \\
\text { (attrition bias) } \\
\text { All outcomes }\end{array}$ & Low risk & $\begin{array}{l}\text { Clear table demonstrating patients excluded and the attrition. All accounted } \\
\text { for at the end of the trial. } \\
\text { Minimal incomplete data from responses in each group in both questionnaires } \\
\text { e.g. "number of respondents for each subscale and each measurement point } \\
\text { ranged between } 74 \text { and } 92 \text { for each group" }\end{array}$ \\
\hline $\begin{array}{l}\text { Selective reporting (re- } \\
\text { porting bias) }\end{array}$ & Low risk & All stated outcomes SAQ and SF-36 at 6 months reported \\
\hline $\begin{array}{l}\text { Were groups balanced at } \\
\text { baseline? }\end{array}$ & Low risk & Baseline characteristics "did not differ significantly between groups". \\
\hline Intention to treat analysis & Low risk & $\begin{array}{l}\text { ITT not explicitly stated. Reported patient flow chart suggests that groups } \\
\text { analysed according to original random allocation. }\end{array}$ \\
\hline $\begin{array}{l}\text { Did both groups receive } \\
\text { comparable care? }\end{array}$ & High risk & $\begin{array}{l}\text { "Patients in the intervention group and the control group received standard } \\
\text { discharge care that involved a non-standardised short talk with the nurse/doc- } \\
\text { tor." However, the intervention contained psychological support which was } \\
\text { not delivered to the control group }\end{array}$ \\
\hline
\end{tabular}




\section{Study characteristics}

\begin{tabular}{ll}
\hline Methods & Study design: Single centre RCT \\
Country: Sweden \\
Dates patients recruited: Feb 1993 and Dec 1995 \\
When randomised: NR \\
Maximum follow up: 60 months \\
\hline Inclusion criteria: At least one coronary stenosis suitable for PCl and at least one additional clinically \\
insignificant coronary artherosclerotic lesion that could be evaluated by quantitative computerised an- \\
giography; employed; able to perform bike test \\
Exclusion criteria: Absence of other disease that would prevent completion of programme; age $>65$ \\
years; unemployed \\
Recruitment from: Consecutive referrals to cardiology outpatients of 1 hospital \\
N randomised: total: 87 ; intervention: $46 ;$ comparator: 41 \\
Diagnosis (\% of pts): \\
Post PCl: $100 \%$ \\
Previous MI: intervention: $43 \%$; comparator: $32 \%$ \\
Congestive heart failure: intervention: $9 \%$; comparator: $5 \%$ \\
Age (mean \pm SD): total: $53 \pm 7$ years; intervention: $53 \pm 7$ years; comparator: $53 \pm 7$ years \\
Percentage male: total: $83.9 \%$ intervention: $80.4 \% ;$ comparator: $87.8 \%$ \\
Ethnicity: NR
\end{tabular}

Description of intervention: Intervention had a duration of 12 months, and started with a 4-week residential stay at the intervention unit. This first phase consisted of intense health education and behaviour-change activities, including lectures and discussions, but focusing mainly on practical skills training and habit rehearsal directed toward stress management and diet, exercise, and smoking habits. Much of the education, discussions, and introductory skills training in the different lifestyle areas were performed. The curriculum included regular group-based practical skills training sessions in all areas; e.g. physical exercise,food preparation, biofeedback, and training in applied relaxation. The participants were also assigned daily "homework," to be performed individually (or sometimes in groups) between the group sessions.

Components: Education and behaviour change

Delivered by: Trained nurse ("personal coach")

Setting (home/centre): Residential stay in a centre

Teaching modalities: A combination of group (5 to 8 ) and individually oriented intervention formats was used.

Involvement of family: NR

Time of start after event: NR

Dose:

Length of session: 4 weeks, then NR

Frequency/number of sessions: NR

Total duration: 12 months

Follow-up further re-inforcement: yes for 1 year ("regular follow-up contacts between the patient and his/her personal coach for verbal feedback, problem-solving, and replanning discussions when needed (Lisspers 1999)"). 


\section{Theoretical basis for intervention: No}

Co-interventions: Stress management, exercise, smoking habits and dietary advice

Comparator: One outpatient visit, then referral to family physician.

Co-interventions: NR

\begin{tabular}{ll}
\hline Outcomes & Total mortality \\
& Total cardiovascular events, non fatal MI \\
& Total revascularisations (both CABG and PCI) \\
& Hospitalisations \\
& HRQoL: Angina Pectoris Quality of Life Questionnaire (AP-QLQ) \\
\hline Source of funding & MF Insurance Co, the SPP Insurance Co, and The Swedish Heart and Lung Foundation \\
\hline Conflicts of interest & NR \\
\hline Notes & $\begin{array}{l}\text { In direct communication with the author he described the program as a "behaviour change program" } \\
\text { primarily and he viewed patient education as "secondary and supportive to behaviour change proce- }\end{array}$ \\
The following papers produced from the results of the same trial were used to inform the data collect- \\
ed: Hofman-Bang 1999; Lisspers 2005
\end{tabular}

\section{Risk of bias}

\begin{tabular}{|c|c|c|}
\hline Bias & Authors' judgement & Support for judgement \\
\hline $\begin{array}{l}\text { Random sequence genera- } \\
\text { tion (selection bias) }\end{array}$ & Unclear risk & NR \\
\hline $\begin{array}{l}\text { Allocation concealment } \\
\text { (selection bias) }\end{array}$ & Unclear risk & NR \\
\hline $\begin{array}{l}\text { Blinding of outcome as- } \\
\text { sessment (detection bias) } \\
\text { All outcomes }\end{array}$ & High risk & $\begin{array}{l}\text { Not reported in the paper but from direct communication with the author it } \\
\text { was confirmed that those analysing the results were not blinded to the group } \\
\text { allocation. }\end{array}$ \\
\hline $\begin{array}{l}\text { Incomplete outcome data } \\
\text { (attrition bias) } \\
\text { All outcomes }\end{array}$ & Low risk & $\begin{array}{l}\text { "Two patients in the intervention and four in the control group were excluded } \\
\text { soon after randomisation at their own request leaving } 87 \text { subjects as the final } \\
\text { patient population" (Hofman-Bang 1999) }\end{array}$ \\
\hline $\begin{array}{l}\text { Selective reporting (re- } \\
\text { porting bias) }\end{array}$ & Low risk & $\begin{array}{l}\text { All stated rehabilitation and secondary prevention endpoints in methods doc- } \\
\text { umented in results }\end{array}$ \\
\hline $\begin{array}{l}\text { Were groups balanced at } \\
\text { baseline? }\end{array}$ & Low risk & $\begin{array}{l}\text { Patient characteristics table and statistical comparison included. Apart from } \\
\text { beta-blocker usage, groups not different }\end{array}$ \\
\hline Intention to treat analysis & Low risk & $\begin{array}{l}\text { Intention to treat (ITT) not stated in the test but calculations stated in the re- } \\
\text { sults appear to be analysed according to original allocation worked out on an } \\
\text { ITT basis }\end{array}$ \\
\hline $\begin{array}{l}\text { Did both groups receive } \\
\text { comparable care? }\end{array}$ & High risk & $\begin{array}{l}\text { As well as education: intervention group received stress management, exer- } \\
\text { cise, smoking habits and dietary advice }\end{array}$ \\
\hline
\end{tabular}




\begin{tabular}{ll}
\hline Study design: Multicentre RCT (13 sites) \\
Country: Germany \\
Dates patients recruited: February 2010 to September 2011 \\
When randomised: Immediately after recruitment and anonymous completion of the baseline ques- \\
tionnaire \\
Maximum follow up: 220 days \\
Inclusion criteria: Patients with CHD and aged 18 to 89 years. Patients with confirmed coronary heart \\
disease in whom an ergometric assessment had been carried out in the 12 weeks preceding the start- \\
ing date of the study, and who had achieved a level of at least 2 minutes at 75 watts \\
Exclusion criteria: NR \\
N randomised: total: $407 ;$ intervention: $202 ;$ comparator: 205 \\
Diagnosis (\% of pts): \\
CHD 100\% \\
Age (mean \pm SD): total: NR; intervention: 65.7 years; comparator: 65.8 years \\
Percentage male: total: $79.2 \%$; intervention: $79.1 \%$; comparator: $79.4 \%$ \\
Ethnicity: NR
\end{tabular}

The lesson materials consisted of:

- A patient brochure

- Teaching cards

- A curriculum

- A poster/wall chart set.

The patient brochure was intended for patients' own independent study and for the purpose of repeating the previous module. Patients were able to enter comments and responses to questions, as in a workbook. Additionally, patients were given an exercise diary to enable them to document their daily physical activity.

\section{Components: Education}

Delivered by: Physicians and medical assistants

Setting (home/centre): Centre

Teaching modalities: individual

Involvement of family: NR

Time of start after event: NR

Dose:

Length of session: NR

Frequency/number of sessions: NR

Total duration: NR

Follow-up further re-inforcement: NR

Theoretical basis for intervention: NR 
Melamed 2014 (Continued)

\section{Co-interventions: NR}

Comparator: Patients in the control group continued to receive usual care from their primary care physicians/cardiologists

Co-interventions: NR

\begin{tabular}{ll}
\hline Outcomes & HRQoL (MacNew) \\
\hline Source of funding & NR \\
\hline Conflicts of interest & "The authors declare that no conflict of interest exists" \\
\hline Notes & NA \\
\hline
\end{tabular}

\section{Risk of bias}

\begin{tabular}{|c|c|c|}
\hline Bias & Authors' judgement & Support for judgement \\
\hline $\begin{array}{l}\text { Random sequence genera- } \\
\text { tion (selection bias) }\end{array}$ & Unclear risk & Random sequence generation was not described \\
\hline $\begin{array}{l}\text { Allocation concealment } \\
\text { (selection bias) }\end{array}$ & Low risk & $\begin{array}{l}\text { "The study centre was located at the Bürgerhospital, Frankfurt am Main, and } \\
\text { functioned as a central coordinating centre (headed by Ms Kufleitner). She } \\
\text { randomised patients dynamically and communicated to the study practices } \\
\text { whether a patient had been allocated to the intervention group or the control } \\
\text { group" }\end{array}$ \\
\hline $\begin{array}{l}\text { Blinding of outcome as- } \\
\text { sessment (detection bias) } \\
\text { All outcomes }\end{array}$ & High risk & $\begin{array}{l}\text { "The study was designed as a randomised controlled and open intervention } \\
\text { study" }\end{array}$ \\
\hline $\begin{array}{l}\text { Incomplete outcome data } \\
\text { (attrition bias) } \\
\text { All outcomes }\end{array}$ & Low risk & $\begin{array}{l}\text { Intervention group: } 21 / 202(3.0 \%) \text { lost to follow-up } \\
\text { Control group: } 19 / 205 \text { (3.2\%) lost to follow-up }\end{array}$ \\
\hline $\begin{array}{l}\text { Selective reporting (re- } \\
\text { porting bias) }\end{array}$ & Low risk & $\begin{array}{l}\text { All outcomes described in the methods section were reported for all time } \\
\text { points }\end{array}$ \\
\hline $\begin{array}{l}\text { Were groups balanced at } \\
\text { baseline? }\end{array}$ & Low risk & Table 1 shows there to be no differences between the groups at baseline \\
\hline \multirow[t]{2}{*}{ Intention to treat analysis } & High risk & $\begin{array}{l}\text { "The primary end points were evaluated on the basis of an intention-to-treat } \\
\text { analysis according to the LOCF (last observation carried forward) principle (Ta- } \\
\text { ble 2)." }\end{array}$ \\
\hline & & $\begin{array}{l}\text { This explanation is contradictory and implies that an intention-to-treat analy- } \\
\text { sis was not actually conducted }\end{array}$ \\
\hline $\begin{array}{l}\text { Did both groups receive } \\
\text { comparable care? }\end{array}$ & Low risk & No co-interventions are described for either group \\
\hline
\end{tabular}

Mooney 2014

\section{Study characteristics}

Methods Study design: Multicentre RCT (5 sites)

Patient education in the management of coronary heart disease (Review) 
Mooney 2014 (Continued)

Country: Ireland

Dates patients recruited: October 2007 to October 2009

When randomised: Within 2 to 4 days of hospital admission

Maximum follow up: 1 year

Participants

Inclusion criteria: 1) provisional ACS diagnosis; 2) clinically stable at time of enrolment; 3) access to a telephone; and 4) ability to read, understand, and communicate in English. In all cases, the diagnosis of ACS was based on the European Society of Cardiology Guidelines (2). The criteria included electrocardiograms, biochemical markers, and a physical examination.

Exclusion criteria: Patients were excluded if they had any condition that prohibited them from understanding the intervention or decision-making process, such as a major or uncorrected hearing loss, a profound learning disability, or any neurological disorder that impaired cognition. Those who lived in an institutional setting and those with serious complicating co-morbidities or untreated malignancies were also excluded from the trial.

N randomised: total: $1944^{\star}$; intervention: 972 ; comparator: 972

Diagnosis (\% of pts):

STEMI: total: 28.2 ; intervention:28.8; comparator: 27.6

NSTEMI: total: 36.3 ; intervention:38.5; comparator: 34.1

Unstable angina: total: 35.5 ; intervention:32.7; comparator: 38.4

Age (mean \pm SD): total: $63.19 \pm 11.68$ years; intervention: $62.55 \pm 11.71$ years; comparator: $63.83 \pm$ 11.62 years

Percentage male: total: $72.1 \%$; intervention: $72.9 \%$;comparator: $71.2 \%$

Ethnicity: NR

Interventions

Description of intervention: The intervention was aimed at reducing total pre-hospital delay time. The education was focused on pre-hospital delay and included decision delay, physician delay, and transport delay. The research nurses used preprinted flip charts and prescriptive scripts as educational aids. The educational intervention was individualised to the patient's specific needs and illness experiences, and sought to address the range of potential cognitive and emotional effects that the person with ACS symptoms may have experienced. Positive messages were reinforced and the ways that people tend to respond to symptoms were discussed together with the benefits of prompt reactions to symptoms

Components: Education

Delivered by: Research nurse

Setting (home/centre): Centre

Teaching modalities: Indiviudal

Involvement of family: It was agreed that a nominated person would act as a confidant In the presence of symptoms and as a decision-maker, if the patient themselves hesitated to contact the ambulance in the face of unresolved symptoms. If the nominated person was available, $s /$ he was invited to be present during the delivery of the intervention

Time of start after event: 2 to 4 days

Dose:

Length of session: $40 \mathrm{~min}$

Frequency/number of sessions: 1

Total duration: 6 months 
Follow-up further re-inforcement: At the end of the intervention, patients completed an action plan, which they were given to take home as a reminder of what to do if symptoms arose. Patients were telephoned 1 month after the intervention was delivered to reinforce the motivation to adhere to the components of the educational intervention. Six months later, those in the intervention group received a letter by post, which again reinforced the educational intervention and included a written reminder about the main intervention messages

Theoretical basis for intervention: Leventhal's Self-Regulatory Model of Health and Illness

Co-interventions: Usual care - which included patient education

Comparator: Usual care was not completely standardised between the research sites, but broadly comprised pre-discharge patient education with respect to ACS symptoms, medications, modifiable risk factors, and advice about lifestyle adjustments. None of the sites delivered extensive information that focused solely on pre-hospital delay or the factors that influence it

\section{Co-interventions: NR}

\begin{tabular}{|c|c|c|}
\hline \multirow[t]{2}{*}{ Outcomes } & \multicolumn{2}{|l|}{ Total mortality } \\
\hline & \multicolumn{2}{|l|}{ Withdrawals } \\
\hline Source of funding & \multicolumn{2}{|c|}{ This study was funded by the Health Research Board, Ireland } \\
\hline Conflicts of interest & \multicolumn{2}{|l|}{ NR } \\
\hline Notes & \multicolumn{2}{|c|}{ *2041 initially randomised, but 94 final diagnosis was not ACS and 3 had no baseline data available } \\
\hline \multicolumn{3}{|l|}{ Risk of bias } \\
\hline Bias & Authors' judgement & Support for judgement \\
\hline $\begin{array}{l}\text { Random sequence genera- } \\
\text { tion (selection bias) }\end{array}$ & Low risk & $\begin{array}{l}\text { A computerised random number generator was used to devise random se- } \\
\text { quences for the five tertiary hospitals }\end{array}$ \\
\hline $\begin{array}{l}\text { Allocation concealment } \\
\text { (selection bias) }\end{array}$ & Low risk & $\begin{array}{l}\text { The study numbers were allocated sequentially and group assignment was } \\
\text { concealed until after baseline data were collected }\end{array}$ \\
\hline $\begin{array}{l}\text { Blinding of outcome as- } \\
\text { sessment (detection bias) } \\
\text { All outcomes }\end{array}$ & High risk & Blinding of outcome assessors is not described \\
\hline $\begin{array}{l}\text { Incomplete outcome data } \\
\text { (attrition bias) } \\
\text { All outcomes }\end{array}$ & Low risk & $\begin{array}{l}\text { Intervention: } 35 / 972(3.6 \%) \text { lost to follow-up } \\
\text { Control: } 27 / 972(2.8 \%) \text { lost to follow-up }\end{array}$ \\
\hline $\begin{array}{l}\text { Selective reporting (re- } \\
\text { porting bias) }\end{array}$ & Low risk & All outcomes described in the methods are reported \\
\hline $\begin{array}{l}\text { Were groups balanced at } \\
\text { baseline? }\end{array}$ & High risk & $\begin{array}{l}\text { There were some significant differences between characteristics and prognos- } \\
\text { tic factors of the two groups at baseline e.g. age }\end{array}$ \\
\hline Intention to treat analysis & Low risk & $\begin{array}{l}\text { Although ITT analysis is not described, data from patients lost to follow-up } \\
\text { were included in the analyses }\end{array}$ \\
\hline $\begin{array}{l}\text { Did both groups receive } \\
\text { comparable care? }\end{array}$ & Low risk & Both control and intervention groups received usual in-hospital care \\
\hline
\end{tabular}


Moreno-Palanco 2011

\section{Study characteristics}

\begin{tabular}{ll}
\hline Methods & Study design: Single centre RCT \\
Country: Spain \\
Dates patients recruited: September 2002 to February 2004 \\
When randomised: Before hospital discharge \\
Maximum follow up: 3 years
\end{tabular}

Participants

Inclusion criteria: Patients aged 18 to 80 years admitted for ACS (with or without ST segment elevation) or for ischemic stroke

Exclusion criteria: Refusal or impossibility of participating in the follow-up (patients who moved or had reduced mobility), life expectancy of $<12$ months and severe cognitive deterioration

N randomised: total: 247 ; intervention: 121 ; comparator: 126

Diagnosis (\% of pts):

Ischemic Cardiopathy: intervention: $64.5 \%$; comparator: $66.7 \%$

Stroke: intervention: $35.5 \%$; comparator: $33.3 \%$

Age (mean \pm SD): total: NR; intervention: $64.89 \pm 11.53$ years; comparator: $65.60 \pm 14.3$ years

Percentage male: total: NR\%; intervention: $79.3 \%$;comparator: $69.8 \%$

Ethnicity: NR

Description of intervention: The patients received health education informing them of their disease and the importance of carrying out correct treatment. Subsequently, visits were programmed at 2, 5, 12,24 , and 36 months after the acute episode, with the possibility of more visits if considered appropriate. Patients could consult with other specialists related to their cardiovascular disease. Each visit consisted of a nursing intervention (health education, lifestyle modifications, evaluation of adherence to treatment) and a medical assessment (clinical evaluation and modification of treatment, if appropriate)

Components: Education

Delivered by: Trained nurse

Setting (home/centre): Centre

Teaching modalities: Individual

Involvement of family: NR

Time of start after event: NR

Dose:

Length of session: NR

Frequency/number of sessions: At least 5 sessions

Total duration: 3 years

Follow-up further re-inforcement: NR

Theoretical basis for intervention: NR

Co-interventions: NR

Comparator: Usual follow-up in cardiology or neurology and/or primary care consulting offices

Co-interventions: NR

Outcomes Total mortality


Moreno-Palanco 2011 (Continued)

$$
\begin{aligned}
& \text { Cardiovascular mortality } \\
& \text { Non-cardiovascular mortality } \\
& \text { Total cardiovascular events } \\
& \text { Fatal and/or non-fatal MI } \\
& \text { Other fatal and/or non-fatal cardiovascular events }
\end{aligned}
$$

\begin{tabular}{|c|c|c|}
\hline Source of funding & NR & \\
\hline Conflicts of interest & "None declared" & \\
\hline Notes & NA & \\
\hline \multicolumn{3}{|l|}{ Risk of bias } \\
\hline Bias & Authors' judgement & Support for judgement \\
\hline $\begin{array}{l}\text { Random sequence genera- } \\
\text { tion (selection bias) }\end{array}$ & Low risk & $\begin{array}{l}\text { "randomisation by blocks... assigned each patient to either the intervention } \\
\text { group or the control group using a computer generated list" }\end{array}$ \\
\hline $\begin{array}{l}\text { Allocation concealment } \\
\text { (selection bias) }\end{array}$ & Low risk & $\begin{array}{l}\text { "...using a computer generated list, with a different person in charge of this } \\
\text { task than of the previous tasks" }\end{array}$ \\
\hline $\begin{array}{l}\text { Blinding of outcome as- } \\
\text { sessment (detection bias) } \\
\text { All outcomes }\end{array}$ & Low risk & $\begin{array}{l}\text { "The evaluation was carried out by a non-blinded member of the research } \\
\text { team" }\end{array}$ \\
\hline $\begin{array}{l}\text { Incomplete outcome data } \\
\text { (attrition bias) } \\
\text { All outcomes }\end{array}$ & High risk & $\begin{array}{l}\text { Intervention: } 3 / 121(2.5 \%) \text { lost to follow-up } \\
\text { Control: } 5 / 126(4.0 \%) \text { lost to follow-up }\end{array}$ \\
\hline $\begin{array}{l}\text { Selective reporting (re- } \\
\text { porting bias) }\end{array}$ & Low risk & All outcomes described in methods are reported \\
\hline $\begin{array}{l}\text { Were groups balanced at } \\
\text { baseline? }\end{array}$ & Low risk & $\begin{array}{l}\text { There were no significant differences between characteristics or prognostic } \\
\text { factors }\end{array}$ \\
\hline Intention to treat analysis & Low risk & "Data analysis was carried out based on intention to treat" \\
\hline $\begin{array}{l}\text { Did both groups receive } \\
\text { comparable care? }\end{array}$ & Low risk & Neither group received any co-interventions \\
\hline
\end{tabular}

\section{P.RE.COR Group 1991}

\section{Study characteristics}

\begin{tabular}{ll}
\hline Methods & Study design: Multicentre RCT (4 sites); 3 groups \\
Country: France \\
Dates patients recruited: Feb 1981 to May 1984 \\
$\begin{array}{ll}\text { When randomised: } 30 \text { to } 60 \text { days post MI } \\
\text { Maximum follow up: } 24 \text { months }\end{array}$ \\
\hline Participants & Inclusion criteria: MI < 65 years \\
\hline
\end{tabular}


Exclusion criteria: Contraindicaton to exercise: recent stroke, disability lower limbs, uncontrolled heart failure, severe rhythm disturbances, systolic blood pressure $>250 \mathrm{~mm} \mathrm{Hg}$, severe angina pectoris, severe hypotension, chest pain or low heart rate on exercise

Recruitment from: Coronary Care Unit of the four participating hospitals

N randomised: total: 182; intervention: 60; comparator I "Counselling programme": 61; comparator II "Usual care": 61

Diagnosis (\% of pts):

Post MI: $100 \%$

Age (mean): total: 50.3 years; intervention: 51 years; comparator I: 51 years; comparator II: 49 years Percentage male: total: $100 \%$; intervention: $100 \%$;comparator: $100 \%$

Ethnicity: NR

Interventions
Description of intervention: Recommendations were given about control of cardiovascular risk factors and physical standardised exercise. Patients were also seen privately by the cardiologist in charge of the programme for a full medical examination and personal adjustment of the recommendations

Components: Education

Delivered by: Cardiologist

Setting (home/centre): Centre

Teaching modalities: One group session, plus individual session with Cardiologist

Involvement of family: Spouse/partner encouraged to attend

Time of start after event: NR

Dose:

Length of session: NR

Frequency/number of sessions: One

Total duration: NR

Follow-up further re-inforcement: No

Theoretical basis for intervention: No

Co-interventions: There was no restriction or recommendation in the three groups for any other concomitant therapies

Comparator: Patients randomised to a counselling programme attended a group session with a cardiologist, a psychiatrist, a nutritionist and a physiotherapist whenever possible.

Patients in the usual care group were just referred to their usual private practitioner and/or cardiologist.

Co-interventions: There was no restriction or recommendation in the three groups for any other concomitant therapies

$\begin{array}{ll}\text { Outcomes } & \text { Mortality } \\ \text { Cardiovascular events }\end{array}$

Source of funding Institut National de la Santé et de la Recherche Médicale, by the Hospices Civils de Lyon and by the Association pour la Promotion et la Réalisation d'Essais Thérapeutiques 
P.RE.COR Group 1991 (Continued)
Notes
NA

\section{Risk of bias}

\begin{tabular}{|c|c|c|}
\hline Bias & Authors' judgement & Support for judgement \\
\hline $\begin{array}{l}\text { Random sequence genera- } \\
\text { tion (selection bias) }\end{array}$ & Unclear risk & NR \\
\hline $\begin{array}{l}\text { Allocation concealment } \\
\text { (selection bias) }\end{array}$ & Unclear risk & NR \\
\hline $\begin{array}{l}\text { Blinding of outcome as- } \\
\text { sessment (detection bias) } \\
\text { All outcomes }\end{array}$ & Unclear risk & NR \\
\hline $\begin{array}{l}\text { Incomplete outcome data } \\
\text { (attrition bias) } \\
\text { All outcomes }\end{array}$ & Low risk & $\begin{array}{l}\text { Reasons for exclusions pre-randomisation given. "Exclusion of women and } \\
\text { men above the age of } 65 \text { alone contributed to almost } 60 \% \text { of all reasons for } \\
\text { non-eligibility...the reasons for non-inclusion in the other patients were either } \\
\text { inability to perform the exercise test or major ECG abnormalities." } \\
\text { "No patient was lost to follow-up" but number actually completing interven- } \\
\text { tions not reported. Results for all those randomised, reported for non-fatal } \\
\text { events and mortality outcomes }\end{array}$ \\
\hline
\end{tabular}

Selective reporting (re- Low risk All outcomes listed in methods reported in results
porting bias)

\begin{tabular}{lll}
$\begin{array}{l}\text { Were groups balanced at } \\
\text { baseline? }\end{array}$ & Low risk & $\begin{array}{l}\text { "No statistically significant differences were observed among the treatment } \\
\text { groups for any of the tested variable" }\end{array}$ \\
\hline Intention to treat analysis & Low risk & $\begin{array}{l}\text { "The analysis followed the intention-to-treat principle; patients were counted in } \\
\text { the groups in which they were allocated" }\end{array}$ \\
\hline $\begin{array}{l}\text { Did both groups receive } \\
\text { comparable care? }\end{array}$ & Low risk & $\begin{array}{l}\text { Intervention and control group received identical care other than the interven- } \\
\text { tion stated }\end{array}$ \\
\hline
\end{tabular}

Park 2013

\section{Study characteristics}

\begin{tabular}{|c|c|}
\hline \multirow[t]{2}{*}{ Methods } & $\begin{array}{l}\text { Study design: Single centre RCT } \\
\text { Country: South Korea } \\
\text { Dates patients recruited: March } 2010 \text { to November } 2010\end{array}$ \\
\hline & $\begin{array}{l}\text { When randomised: After baseline measures } \\
\text { Maximum follow up: } 6 \text { months }\end{array}$ \\
\hline
\end{tabular}

Participants

Inclusion criteria: (i) Patients from 18 to 70 years of age with first hospitalisation diagnosed with either angina pectoris or $\mathrm{MI}$ and who had scheduled $\mathrm{PCl}$; (ii) Willing to participate in this study; and (ii) Able to speak, read and write Korean.

Exclusion criteria: (i) Planning for surgical treatment; (ii) Previous revascularisation; (iii) Aged < 18 years or > 70 years; (iv) diagnosis of psychosis or currently on antipsychotic medications; and (v) diagnosed with a terminal illness.

N randomised: total: 63 ; intervention: 31 ; comparator: 32

Diagnosis (\% of pts): 
Park 2013 (Continued)

Angina:intervention: 20.0 comparator: 3228.6

Myocardial:intervention: infarction 80.0 comparator: 3271.4

Age (mean \pm SD): total: NR; intervention: $57.89 \pm 7.96$ years; comparator: $58.27 \pm 8.56$ years

Percentage male: total: NR; intervention: $82.1 \%$;comparator: $83.2 \%$

Ethnicity: NR

Interventions

Description of intervention: The 12-week psycho-educational intervention consisted of individual face-to-face education using a tailored resource package and telephone-delivered health coaching. It began with a risk factor assessment, focusing on lifestyle changes related to the risk factors and some biological risk indicators for CAD and was performed using individual face-to-face education. Next, the patients made guided choices about which risk factors they wanted to lower and participated in goal setting informed by current national targets for the chosen risk factors. They selected the management options they would use to lower the risks and were provided with a tailored resource package that was developed in consultation with clinical experts.

In addition, patients in the intervention group received up to six telephone delivered health coaching (every other week) throughout the 12-week period. This biweekly telephone delivered health coaching helped patients to develop management plans that included giving advice and information for specific concerns or problems, reinforced education, and for counselling/support.

Components: Education

Delivered by: NR

Setting (home/centre): Centre then home (telephone call)

Teaching modalities: Individual

Involvement of family: NR

Time of start after event: NR

Dose: Initial face-to face meeting plus telephone-delivered health coaching:

Length of session: 10 to 40 minutes

Frequency/number of sessions: Every other week ( 6 sessions)

Total duration: 12 weeks

Follow-up further re-inforcement: NR

Theoretical basis for intervention: NR

\section{Co-interventions: NR}

Comparator: Standard care from the medical team. Patients were provided with a short booklet on general guidelines related to CAD and were instructed to contact their medical team to continue with follow-up care

\section{Co-interventions: NR}

Outcomes

Total cardiovascular events

Withdrawals

Source of funding

Basic Science Research Program through the National Research Foundation of Korea (NRF) funded by the Ministry of Education, Science and Technology 
Park 2013 (Continued)
Notes
NA

\section{Risk of bias}

\begin{tabular}{lll}
\hline Bias & Authors' judgement & Support for judgement \\
\hline $\begin{array}{ll}\text { Random sequence genera- } \\
\text { tion (selection bias) }\end{array}$ & Low risk & $\begin{array}{l}\text { "Random assignment was based on the last digit of the patient's identification } \\
\text { number, with even numbers assigned to the intervention group and odd num- } \\
\text { bers assigned to the control group." }\end{array}$
\end{tabular}

\begin{tabular}{|c|c|c|}
\hline $\begin{array}{l}\text { Allocation concealment } \\
\text { (selection bias) }\end{array}$ & High risk & Allocation concealment not described \\
\hline $\begin{array}{l}\text { Blinding of outcome as- } \\
\text { sessment (detection bias) } \\
\text { All outcomes }\end{array}$ & High risk & Blinding of outcome assessors is not described \\
\hline $\begin{array}{l}\text { Incomplete outcome data } \\
\text { (attrition bias) } \\
\text { All outcomes }\end{array}$ & Low risk & $\begin{array}{l}\text { Intervention: } 3 / 31(9.7 \%) \text { lost to follow-up } \\
\text { Control: } 2 / 32(6.3 \%) \text { lost to follow-up }\end{array}$ \\
\hline $\begin{array}{l}\text { Selective reporting (re- } \\
\text { porting bias) }\end{array}$ & Low risk & All outcomes described in the methods are reported \\
\hline $\begin{array}{l}\text { Were groups balanced at } \\
\text { baseline? }\end{array}$ & Low risk & $\begin{array}{l}\text { "There were no significant differences in the sociodemographic and dis- } \\
\text { ease/treatment-related characteristics between the two groups." }\end{array}$ \\
\hline Intention to treat analysis & High risk & $\begin{array}{l}\text { ITT analysis is not described and data from patients lost to follow-up were not } \\
\text { included in the analyses }\end{array}$ \\
\hline $\begin{array}{l}\text { Did both groups receive } \\
\text { comparable care? }\end{array}$ & High risk & Intervention includes psychological support and counselling \\
\hline
\end{tabular}

Peikes 2009

\section{Study characteristics}

\begin{tabular}{ll}
\hline Methods & Study design: Multicentre RCT (15 sites) \\
Country: USA \\
Dates patients recruited: April 2002 and June 2005 \\
When randomised: NR \\
Maximum follow up: At least 1 year. Mean follow-up 51 months.
\end{tabular}

Participants

Inclusion and exclusion criteria: "Each program was allowed to define within broad boundaries its own target population and exclusion criteria, and designed its intervention accordingly."

$10 / 15$ sites required a hospital admission within the previous year, $4 / 15$ sites excluded $<65$ years old and $14 / 15$ excluded "terminal illness and conditions that affected their ability to learn self management"

Recruitment from: Eligible-fee for service Medicare patients from 15 care co-ordination programs

N randomised: total: 18,402 ; intervention: 9,427 ; comparator: 8,975

Diagnosis (\% of pts):

CHD: $61 \%$ 
Peikes 2009 (Continued)

Congestive heart failure: $48 \%$

Age (mean \pm SD): total: NR; intervention: NR; comparator: NR

Percentage male: total: $45 \%$; intervention: NR;comparator: NR

Ethnicity: $85 \%$ white

Interventions

Description of intervention: The care coordination interventions of the 15 programs differed widely. All of the programs assigned patients to a care coordinator.Nurses provided patient education and monitoring. All but one of the programs educated patients to improve adherence to medication, diet, exercise, and self-care regimens, mostly through the nurses conveying factual information. Seven programs also used behaviour change models such as the transtheoretical approach or techniques such as motivational interviewing.

Components: Education and behaviour change

Delivered by: Care co-ordinator. Licensed or registered nurses (4 programs required a BSc level qualification in nursing studies)

\section{Setting (home/centre): NR}

Teaching modalities: All programs contacted patients primarily by telephone; however, 4 programs contacted patients in person nearly once a month as well.

Involvement of family: NR

Time of start after event: NR

Dose:

Length of session: NR

Frequency/number of sessions: 11 programs: 1 to 2.5 times/month: 3 programs 4 to 8 times/month. Other programs did not record contact frequency

Total duration: On average 30 months eligibility (range 18 to 31 months)

Follow-up further re-inforcement: NR

Theoretical basis for intervention: NR

Co-interventions: Seven programs also used behaviour change models such as the transtheoretical approach or techniques such as motivational interviewing

Comparator: Not described

Co-interventions: NR

\begin{tabular}{ll}
\hline Outcomes & Hospitalisations \\
& Cost analysis - monthly Medicare expenditure \\
\hline Source of funding & $\begin{array}{l}\text { Centers for Medicare \& Medicaid Services. There were no industry sponsors of this study. The writing of } \\
\text { the manuscript was funded solely by Mathematica Policy Research Inc }\end{array}$ \\
\hline Conflicts of interest & $\begin{array}{l}\text { The authors are all salaried employees of Mathematica Policy Research Inc and receive no compensa- } \\
\text { tion from any other source. They do not own stock in any of the programs being evaluated or stand to } \\
\text { profit in any way, directly or indirectly, from particular findings in this article }\end{array}$ \\
\hline Notes & $\begin{array}{l}\text { The following paper produced from the results of the same trial were used to inform the data collected: } \\
\text { Brown } 2008\end{array}$ \\
\hline
\end{tabular}


Peikes 2009 (Continued)

Risk of bias

\begin{tabular}{|c|c|c|}
\hline Bias & Authors' judgement & Support for judgement \\
\hline $\begin{array}{l}\text { Random sequence genera- } \\
\text { tion (selection bias) }\end{array}$ & Low risk & Randomly generated concealed 4-digit "strings" \\
\hline $\begin{array}{l}\text { Allocation concealment } \\
\text { (selection bias) }\end{array}$ & Low risk & Randomised assignment was returned via the trial web site \\
\hline $\begin{array}{l}\text { Blinding of outcome as- } \\
\text { sessment (detection bias) } \\
\text { All outcomes }\end{array}$ & High risk & $\begin{array}{l}\text { "Because of the nature of the intervention, no individuals were blinded to } \\
\text { which group participants were randomised." Peikes } 2009\end{array}$ \\
\hline $\begin{array}{l}\text { Incomplete outcome data } \\
\text { (attrition bias) } \\
\text { All outcomes }\end{array}$ & Unclear risk & $\begin{array}{l}\text { "Observations are weighted by the number of months in the follow-up peri- } \\
\text { od that the same member meets eligibility requirements." Peikes 2009. A full } \\
\text { breakdown of periods that patients were eligible is not given }\end{array}$ \\
\hline $\begin{array}{l}\text { Selective reporting (re- } \\
\text { porting bias) }\end{array}$ & Low risk & All outcomes stated in the methods are reported in the results \\
\hline $\begin{array}{l}\text { Were groups balanced at } \\
\text { baseline? }\end{array}$ & Low risk & $\begin{array}{l}\text { "Across all of the } 15 \text { programs and the baseline characteristics the treatment } \\
\text { and control groups differed significantly on only } 11 \text { of the } 255 \text { comparisons at } \\
\text { the } p<0.05 \text { level, less than the expected number of statistical significant differ- } \\
\text { ences that would be observed by chance." Peikes } 2009\end{array}$ \\
\hline Intention to treat analysis & Low risk & "Effects were calculated using....an intention to treat design." Peikes 2009 \\
\hline $\begin{array}{l}\text { Did both groups receive } \\
\text { comparable care? }\end{array}$ & High risk & $\begin{array}{l}\text { "7 of the programs used behaviour change models. } 14 \text { programs attempted to } \\
\text { improve communication between patients and physicians." Peikes } 2009\end{array}$ \\
\hline & & Education was not the only intervention that the treatment groups received \\
\hline
\end{tabular}

Pogosova 2008

\section{Study characteristics}

Study design: Single centre RCT
Country: Russia
Dates patients recruited: NR (total study period: March 2004 to January 2006)
When randomised: NR
Maximum follow up: 12 months

Participants

Inclusion criteria: Diagnosis of CHD, stable angina, age $<65$ years

Exclusion criteria: ACS and acute cerebrovascular disorders in 6 months before selection; patients with severe somatic disorders (life-threatening arrhythmia, heart failure (3 to 4 functional class), kidney or liver failure; decompensated diabetes, severe bronchial asthma), psychiatric disorders and alcoholic, narcotic and prescription drug addictions

Recruitment from: Ambulatory patients of the Moscow polyclinic

N randomised: total: 100; intervention: 50; comparator: 50 Diagnosis (\% of pts):

Angina: $100 \%$

Post MI: intervention: $52 \%$; comparator: $48 \%$ 
Pogosova 2008 (Continued)

Post CABG: intervention: $14 \%$; comparator: $8 \%$

Post PCl: intervention: $18 \%$; comparator: $14 \%$

Age (mean \pm SD): total: $59.9 \pm 0.4$ years; intervention: $59.3 \pm 0.69$ years; comparator: $60.5 \pm 0.48$ years Percentage male: total: $59 \%$; intervention: $60 \%$;comparator: $58 \%$

Ethnicity: NR

Interventions

Description of intervention: A course at the "Health school for CHD patients"; Structured programme of 6 sessions ( 90 min each, twice a week), during which 1 or 2 risk factors were discussed. Evaluation of knowledge about the disease and risk factors after the course.

Components: Education

Delivered by: Outpatient doctors

Setting (home/centre): Centre

Teaching modalities: Group

Involvement of family: NR

Time of start after event: NR

Dose:

Length of session: 90 minutes

Frequency/number of sessions: twice a week (6 sessions total)

Total duration: 3 weeks

Follow-up further re-inforcement: NR

Theoretical basis for intervention: Organisation of Health Schools for CHD patients in practical health-care setting. Organisational-methodical letter. Appendix 2. M 2003

Co-interventions: NR

Comparator: Usual care (for all patients) consisted of three visits during a 12 months follow-up. First visit - evaluating inclusion criteria, giving informed consent, randomisation, evaluation of knowledge about the disorder and risk factors; clinical examination; blood test for lipids and glucose; psychological survey. Second and third visits - 6 and 12 months after the start of the study; consisted of clinical examination (blood test for lipids and glucose), evaluation of knowledge and psychological survey

Co-interventions: NR

Outcomes HRQoL: SF36

Source of funding NR

Conflicts of interest NR

Notes NA

\section{Risk of bias}

\begin{tabular}{lll}
\hline Bias & Authors' judgement & Support for judgement \\
\hline $\begin{array}{l}\text { Random sequence genera- } \\
\text { tion (selection bias) }\end{array}$ & Unclear risk & NR \\
\hline
\end{tabular}


Pogosova 2008 (Continued)

\begin{tabular}{l}
$\begin{array}{l}\text { Allocation concealment } \\
\text { (selection bias) }\end{array}$ \\
\hline
\end{tabular}

\begin{tabular}{|c|c|}
\hline $\begin{array}{l}\text { Blinding of outcome as- } \\
\text { sessment (detection bias) } \\
\text { All outcomes }\end{array}$ & Unclear risk \\
\hline
\end{tabular}

\begin{tabular}{lll}
\hline $\begin{array}{l}\text { Incomplete outcome data } \\
\text { (attrition bias) } \\
\text { All outcomes }\end{array}$ & Unclear risk & $\begin{array}{l}\text { Likely, description of the results in text indicates missing data but no break- } \\
\text { down given }\end{array}$ \\
\hline $\begin{array}{l}\text { Selective reporting (re- } \\
\text { porting bias) }\end{array}$ & Low risk & $\begin{array}{l}\text { All outcomes are accounted for in the results in either table, graphical or text } \\
\text { format }\end{array}$ \\
\hline $\begin{array}{l}\text { Were groups balanced at } \\
\text { baseline? }\end{array}$ & Low risk & Groups at baseline were comparable \\
\hline $\begin{array}{l}\text { Intention to treat analysis } \\
\text { Did both groups receive }\end{array}$ & Unclear risk & Low risk \\
\hline \begin{tabular}{l} 
comparable care? \\
\hline
\end{tabular}
\end{tabular}

Southard 2003

\section{Study characteristics}

\begin{tabular}{ll}
\hline Methods & Study design: Multicentre RCT \\
Country: USA \\
Dates patients recruited: NR (10 month period) \\
When randomised: NR \\
Maximum follow up: 6 months \\
\hline
\end{tabular}

Participants Inclusion criteria: Diagnosis of CHD or CHF or both. Approval of either primary care physician or cardiologist. Need access to the Internet

\section{Exclusion criteria: NR}

Recruitment from: 46 outpatient facilities throughout SW Virginia or through newspaper adverts

N randomised: total: 104; intervention: 53; comparator: 51

Diagnosis (\% of pts):

$\mathrm{CHD}$, or congestive heart failure or both

Breakdown not reported.

Age (mean \pm SD): total: $61.8 \pm 10.6$ years; intervention: $62.8 \pm 10.6$ years; comparator: $62.3 \pm 10.6$ years

Percentage male: total: $75 \%$; intervention: $67 \%$;comparator: $72 \%$

Ethnicity: $97 \%$ white case manager through a secure form of e-mail, completing education modules assigned by the case manager, and entering data into progress graphs. Participants had the opportunity to use an on-line discussion group. There were material incentives for active participation. Also dietary input

Components: Education 
Delivered by: "Case Managers" and dieticians

Setting (home/centre): Home

Teaching modalities: Interactive, multiple choice, self tests followed by feedback

Involvement of family: NR

Time of start after event: NA

Dose:

Length of session: at least $30 \mathrm{~min}$

Frequency/number of sessions: one/week

Total duration: 6 months

Follow-up further re-inforcement: No

Theoretical basis for intervention: NR

Co-interventions: NR

Comparator: Usual care (details not explicitly stated)

Co-interventions: NR

\begin{tabular}{|c|c|c|}
\hline \multirow[t]{5}{*}{ Outcomes } & \multicolumn{2}{|c|}{ Total cardiovascular Events (fatal/nonfatal MI and other fatal/nonfatal cardiovascular event) } \\
\hline & \multicolumn{2}{|c|}{ Total revascularisations $(\mathrm{PCl})$} \\
\hline & \multicolumn{2}{|l|}{ Hospitalisations } \\
\hline & \multicolumn{2}{|c|}{ HRQoL - Dartmouth COOP QoL } \\
\hline & \multicolumn{2}{|l|}{ Cost analysis } \\
\hline Source of funding & \multicolumn{2}{|c|}{ The Agency for Healthcare Research and Quality } \\
\hline Conflicts of interest & \multicolumn{2}{|l|}{ NR } \\
\hline Notes & \multicolumn{2}{|c|}{$\begin{array}{l}\text { NB. Included heart failure not just CHD patients; percentage with just heart failure not clear; the break- } \\
\text { down table shows "multiple diagnoses". }\end{array}$} \\
\hline & \multicolumn{2}{|c|}{ Included a proportion of patients who had previously received cardiac rehabilitation } \\
\hline \multicolumn{3}{|l|}{ Risk of bias } \\
\hline Bias & Authors' judgement & Support for judgement \\
\hline $\begin{array}{l}\text { Random sequence genera- } \\
\text { tion (selection bias) }\end{array}$ & Low risk & $\begin{array}{l}\text { "Randomly assigned to SI or UC on the basis of a computer-generated random } \\
\text { number." "study population was stratified on the basis of minority status, par- } \\
\text { ticipation in cardiac rehabilitation, and acute status (time since event)" }\end{array}$ \\
\hline $\begin{array}{l}\text { Allocation concealment } \\
\text { (selection bias) }\end{array}$ & Unclear risk & NR \\
\hline $\begin{array}{l}\text { Blinding of outcome as- } \\
\text { sessment (detection bias) } \\
\text { All outcomes }\end{array}$ & High risk & $\begin{array}{l}\text { Case managers collected number of outcomes (height, weight, blood pres- } \\
\text { sure) at follow up and were not blind to intervention or control. }\end{array}$ \\
\hline
\end{tabular}


Southard 2003 (Continued)

Incomplete outcome data Low risk "Of the 104 subjects randomised to the study, 6-month follow-up data was ob(attrition bias) tained on 100. Four subjects were lost to follow up evaluation." Details of withAll outcomes drawals/loss to follow up reported.

\begin{tabular}{|c|c|c|}
\hline $\begin{array}{l}\text { Selective reporting (re- } \\
\text { porting bias) }\end{array}$ & High risk & $\begin{array}{l}\text { Dartmouth COOP QoL taken at entry and exit. Results reported on entry but } \\
\text { not at exit }\end{array}$ \\
\hline
\end{tabular}

\begin{tabular}{ll}
\hline $\begin{array}{l}\text { Were groups balanced at } \\
\text { baseline? }\end{array}$ & Low risk
\end{tabular}

\begin{tabular}{lll}
\hline Intention to treat analysis & Low risk & $\begin{array}{l}\text { Although not explicitly stated, there groups appear to have been analysed ac- } \\
\text { cording to initial random allocation }\end{array}$ \\
\hline $\begin{array}{l}\text { Did both groups receive } \\
\text { comparable care? }\end{array}$ & Unclear risk & Not clear if intervention group received same usual care as control arm \\
\hline
\end{tabular}

Tingström 2005

\section{Study characteristics}

\begin{tabular}{|c|c|}
\hline Methods & $\begin{array}{l}\text { Study design: Multicentre RCT ( } 2 \text { sites) } \\
\text { Country: Sweden } \\
\text { Dates patients recruited: NR } \\
\text { When randomised: NR } \\
\text { Maximum follow up: } 12 \text { months }\end{array}$ \\
\hline Participants & $\begin{array}{l}\text { Inclusion criteria: Recent CAD; MI and/or PCI and/or CABG } \\
\text { Exclusion criteria: Planned CABG; senility; psychiatric medication; expected poor prognosis within a } \\
\text { year; deficient in Swedish; participation in other studies. } \\
\text { Recruitment from: consecutive patients from } 2 \text { participating hospitals } \\
\text { N randomised: total: } 207 \text {; intervention: } 104 \text {; comparator: } 103 \\
\text { Diagnosis (\% of pts): } \\
\text { Post MI: } 40.5 \% \\
\text { MI and/or post CABG: } 22 \% \\
\text { MI and/or post PCI: } 37 \% \\
\text { Age (mean } \pm \text { SD): total: } 59 \pm 7 \text { years; intervention: } 59 \pm 7 \text { years; comparator: } 59 \pm 7 \text { years } \\
\text { Percentage male: total: } 74 \% \text {; intervention: } 72 \% \text {;comparator: } 76 \% \\
\text { Ethnicity: NR }\end{array}$ \\
\hline Interventions & $\begin{array}{l}\text { Description of intervention: The PBL programme was run within CR at the two participating hospi- } \\
\text { tals. The first meeting focused on information about the pedagogic model of learning, the content of } \\
\text { the programme, and the role of the tutor. Real-life situations or scenarios were presented, consisting of } \\
\text { pictures, press cuttings, or short texts about exercise, food, drugs, smoking, and cholesterol. They were } \\
\text { produced in accordance with the planned curriculum for the programme, which included manifesta- } \\
\text { tions of CAD and its symptoms, psychological reactions to the disease, psychosocial factors, stress, } \\
\text { smoking, metabolic factors, food and alcohol, physical exercise, sex life, revascularisation procedures, } \\
\text { and drug treatment. During the second group meeting, the participants were presented with a scenario } \\
\text { chosen to illustrate the whole life situation for patients with CAD. They then decided which particu- } \\
\text { lar aspects they would choose to focus on, and a priority list of problem areas was made. A structured } \\
\text { problem solving process was used to facilitate the work in tutorial groups and to stimulate self-directed } \\
\text { learning. Every group member was given a diary in which to write down goals for learning and for own } \\
\text { lifestyle changes. }\end{array}$ \\
\hline
\end{tabular}


Components: Education

Delivered by: Tutor - member of rehabilitation team, trained to take the role of the facilitator

Setting (home/centre): Centre

Teaching modalities: Groups of 6 to 8 people

Involvement of family: NR

Time of start after event: NR

Dose:

Length of session: 1.5 hours

Frequency/number of sessions: 13 group sessions (weekly for the first month, every other week for the next month and the spread over the year)

Total duration: 1 year

Follow-up further re-inforcement: NR

Theoretical basis for intervention: Schmidt seven step model of problem solving

Co-interventions: Participants were offered standard treatment by the rehabilitation team, including visits to a nurse and physician. All patients were also offered the possibility of taking part in physical exercise groups, smoking cessation groups, and individual counselling by a dietician

Comparator: Standard treatment by the rehabilitation team, including visits to a nurse and physician

Co-interventions: All patients were also offered the possibility of taking part in physical exercise groups, smoking cessation groups and individual counselling by a dietician

\section{Outcomes} HRQoL - Ladder of Life, Self-Rated Health, SF-36, Cardiac Health Profile Withdrawal from intervention group

\begin{tabular}{ll}
\hline Source of funding & Vardal Foundation, the Swedish Heart- and Lung Association and the Swedish Heart- and Lung Founda- \\
tion
\end{tabular}

Conflicts of interest NR

\begin{tabular}{|c|c|c|}
\hline Notes & High attendance rate & the educational sessions. Mean 9.4 (median 11) out of 13 sessions \\
\hline \multicolumn{3}{|l|}{ Risk of bias } \\
\hline Bias & Authors' judgement & Support for judgement \\
\hline $\begin{array}{l}\text { Random sequence genera- } \\
\text { tion (selection bias) }\end{array}$ & Low risk & $\begin{array}{l}\text { Not reported in the study itself but from communication with the author it was } \\
\text { confirmed that sealed envelopes were randomly organised by a person out- } \\
\text { side of the research team }\end{array}$ \\
\hline $\begin{array}{l}\text { Allocation concealment } \\
\text { (selection bias) }\end{array}$ & Low risk & $\begin{array}{l}\text { Not reported in the study. However, from communication with the author a } \\
\text { sealed envelope method was used }\end{array}$ \\
\hline $\begin{array}{l}\text { Blinding of outcome as- } \\
\text { sessment (detection bias) } \\
\text { All outcomes }\end{array}$ & High risk & Not reported in the study. Confirmed by communication with author \\
\hline $\begin{array}{l}\text { Incomplete outcome data } \\
\text { (attrition bias) }\end{array}$ & Low risk & $\begin{array}{l}\text { QUORUM trial flow diagram reported with exclusions and attrition document- } \\
\text { ed and reasons given }\end{array}$ \\
\hline
\end{tabular}


Tingström 2005 (Continued)

All outcomes

\begin{tabular}{|c|c|c|}
\hline $\begin{array}{l}\text { Selective reporting (re- } \\
\text { porting bias) }\end{array}$ & Low risk & $\begin{array}{l}\text { All stated outcomes in methods are reported in results at pre and post tests. } \\
\text { Although the self rated health score was not reported in detail }\end{array}$ \\
\hline
\end{tabular}

\begin{tabular}{lll}
\hline $\begin{array}{l}\text { Were groups balanced at } \\
\text { baseline? }\end{array}$ & Low risk & Table of baseline characteristics showed no statistically differences \\
\hline $\begin{array}{l}\text { Intention to treat analysis } \\
\text { Lid both groups receive }\end{array}$ & Low risk & $\begin{array}{l}\text { Confirmed by communication with the author. "For all analyses intention to } \\
\text { treat was used." }\end{array}$ \\
\hline \begin{tabular}{l} 
comparable care? \\
\hline
\end{tabular}
\end{tabular}

Abbreviations:

ACS: acute coronary syndrome; AMI: acute myocardial infarction; CABG: coronary artery bypass graft; CAD: coronary artery disease; CHD: coronary heart disease; CR: cardiac rehabilitation; HRQoL: health related quality of life; ITT: intention to treat; MI: myocardial infarction; NR: not reported; PCl: percutaneous coronary intervention; pts: participants; RCT: randomised controlled trial; SD: standard deviation; SF-36: Short Form 36; STEMI: ST segment elevation myocardial infarction; USA: United States of America

\section{Characteristics of excluded studies [ordered by study ID]}

\begin{tabular}{|c|c|}
\hline Study & Reason for exclusion \\
\hline Abbaszadeh 2011 & No outcomes of interest \\
\hline Abbaszadeh 2012 & No outcomes of interest \\
\hline Ades 2001 & Identifed from Lie 2009. Review not a RCT \\
\hline Allen 2010 & $\begin{array}{l}\text { Systematic Review: } 21 \text { references identified and reviewed as being of potential interest to this re- } \\
\text { view }\end{array}$ \\
\hline Allison 2000 & Education not primary aim of intervention. (Risk Factor intervention clinic) \\
\hline Ammenwerth 2015 & Follow-up less than 6 months \\
\hline Arthur 2000 & Performance bias, intervention included exercise as well as education. \\
\hline Bagheri 2007 & Education not primary aim of intervention. (Psychological Counselling) \\
\hline Balasch 2011 & An observational retrospective study \\
\hline Barley 2014 & Education not primary aim of intervention \\
\hline Barnason 1995 & "quasi-experimental" investigating patient satisfaction with teaching. \\
\hline Barnason 2006 & Performance bias: education only part of the intervention. \\
\hline Barnason 2009 & $\begin{array}{l}\text { Education not primary aim of intervention: symptom management intervention (pain manage- } \\
\text { ment / incremental physical exercise.) }\end{array}$ \\
\hline Barnason 2009a & Performance bias: education only part of the intervention. \\
\hline Barnes 2012 & No outcomes of interest \\
\hline
\end{tabular}




\begin{tabular}{|c|c|}
\hline Study & Reason for exclusion \\
\hline Bell 1998 & Identified from Clark 2007. Not RCT. \\
\hline Benson 2000 & A review of a meta-analysis Dusseldorp 1999 \\
\hline Beranova 2007 & $\begin{array}{l}\text { Systematic Review: } 2 \text { references identified and reviewed as being of potential interest to this re- } \\
\text { view }\end{array}$ \\
\hline Bethell 1990 & $\begin{array}{l}\text { Identified from Clark 2005. Education not primary aim of intervention (Exercise based interven- } \\
\text { tion). }\end{array}$ \\
\hline Bettencourt 2005 & Not education: exercise intervention. \\
\hline Bitzer 2002 & Not a RCT. \\
\hline Bjørnnes 2015 & No outcomes of interest \\
\hline Boulay 2004 & $\begin{array}{l}\text { Performance bias, intervention included exercise as well as education. Not a RCT compared with } \\
\text { historical controls. }\end{array}$ \\
\hline Brand 1998 & Performance bias, intervention included exercise as well as education. \\
\hline Brügemann 2007 & Education not primary aim of intervention. Psychological - "Rational Emotive behavioural therapy". \\
\hline Campbell 1998 & Education not primary aim of intervention (nurse intervention clinic). \\
\hline Campbell 1998a & Education not primary aim of intervention (nurse intervention clinic). \\
\hline Cannon 2002 & Review of implementation of Acute Coronary Syndrome patient pathway. Not an intervention. \\
\hline Carrington 2013 & Education not primary aim of intervention \\
\hline Cebeci 2008 & No relevant outcomes - self care questionnaires. \\
\hline Chan 2005 & Identified from Eshah 2009. Not RCT: Prospective pre-test / post-test design. \\
\hline Chan 2012 & Education not primary aim of intervention \\
\hline Chen 2005 & No specified follow-up period. \\
\hline Cho 2010 & Follow-up was "two weeks after discharge. " \\
\hline Cingözbay 2011 & Comment paper \\
\hline Clark 2005 & $\begin{array}{l}\text { Systematic Review: } 45 \text { references identified and reviewed as being of potential interest to this re- } \\
\text { view }\end{array}$ \\
\hline Clark 2007 & $\begin{array}{l}\text { Systematic Review: } 35 \text { references identified and reviewed as being of potential interest to this re- } \\
\text { view }\end{array}$ \\
\hline Cobb 2006 & $\begin{array}{l}\text { Systematic Review: } 3 \text { references identified and reviewed as being of potential interest to this re- } \\
\text { view }\end{array}$ \\
\hline Coburn 2012 & Education not primary aim of intervention \\
\hline Costa e Silva 2008 & Education not primary aim of intervention - multidisciplinary interventional clinic. \\
\hline
\end{tabular}




\begin{tabular}{|c|c|}
\hline Study & Reason for exclusion \\
\hline Coull 2004 & Entrance into study after cardiac rehabilitation. \\
\hline Crumlish 2011 & Population doesn't have CHD \\
\hline Cundey 1995 & Identifed from Hanssen 2007. Review not an RCT \\
\hline Dankner 2011 & Not an RCT design \\
\hline DeBusk 1994 & Education not primary aim of intervention. Nurse led intervention. \\
\hline Delaney 2008 & Education not primary aim of intervention - a nurse led intervention clinic. \\
\hline Devi 2014 & Education not primary aim of intervention \\
\hline Divison 2014 & Comment article \\
\hline Dusseldorp 1999 & $\begin{array}{l}\text { Systematic Review: } 12 \text { references identified and reviewed as being of potential interest to this re- } \\
\text { view }\end{array}$ \\
\hline Dusseldorp 2000 & Commentary on a meta-analysis: Dusseldorp 1999 \\
\hline Eckman 2012 & Comparator group received education \\
\hline Engblom 1992 & Performance bias: Intervention multifactorial involves exercise and psychological therapy. \\
\hline Engblom 1994 & Performance bias: Intervention multifactorial involves exercise and psychological therapy. \\
\hline Engblom 1996 & Performance bias: Intervention multifactorial involves exercise and psychological therapy. \\
\hline Engblom 1997 & Performance bias: Intervention multifactorial involves exercise and psychological therapy. \\
\hline Enzenhofer 2004 & Identified from Beranova 2007. Not relevant outcomes. \\
\hline Eshah 2009 & $\begin{array}{l}\text { Systematic Review: } 8 \text { references identified and reviewed as being of potential interest to this re- } \\
\text { view }\end{array}$ \\
\hline Eshah 2010 & Population doesn't have CHD \\
\hline Eshah 2013 & A non-equivalent control group pretest-post-test design was used. \\
\hline Eshah 2014 & A non-equivalent control group pretest-post-test design was used. \\
\hline Espinosa Caliani 2004 & Education not primary aim of intervention- Performance bias \\
\hline Fang 2015 & No outcomes of interest \\
\hline Fattirolli 1998 & Education not primary aim of intervention: Exercise intervention \\
\hline Fernandez 2009 & $\begin{array}{l}\text { Intervention cognitive behavioural therapy compared with standard cardiac rehabilitation (includ- } \\
\text { ing education). }\end{array}$ \\
\hline
\end{tabular}

\begin{tabular}{ll}
\hline Frasure-Smith 1997 & Education not primary aim of intervention: Individualised psychological intervention. \\
\hline Fredericks 2009 & $\begin{array}{l}\text { Individualised educational intervention in CABG patients: Study designed to investigate the time of } \\
\text { delivery of education - both groups received the same intervention }\end{array}$
\end{tabular}




\begin{tabular}{|c|c|}
\hline Study & Reason for exclusion \\
\hline Fredericks 2009a & $\begin{array}{l}\text { Systematic Review: } 7 \text { references identified and reviewed as being of potential interest to this re- } \\
\text { view }\end{array}$ \\
\hline Fredericks 2013 & Comparator group received education \\
\hline Frederix 2015 & Education not primary aim of intervention \\
\hline Froelicher 1994 & Not relevant outcomes (patients recruited between 1977 and 79). \\
\hline Furze 2012 & Education not primary aim of intervention \\
\hline Gao 2007 & Not education, exercise is the primary focus post CABG. \\
\hline Ghali 2004 & Commentary: paper excluded education not primary intervention. \\
\hline Goodman 2008 & Follow-up period only 3 months post discharge from CABG. \\
\hline Han 2011 & Education not primary aim of intervention \\
\hline \multirow[t]{2}{*}{ Harbman 2006} & Commentary on meta-analysis \\
\hline & $\begin{array}{l}\text { Clark, A.M., et al., Meta-analysis: Secondary prevention programs for patients with coronary artery. } \\
\text { Annals of Internal Medicine, 2005. 143(9): p. 659-672+187. }\end{array}$ \\
\hline Haskell 1994 & Identified from Clark 2007. Education not primary aim of intervention \\
\hline Hawkes 2009 & ID from 2011 update: No outcomes of interest \\
\hline Hazavei 2012 & Follow up less than 6 months and no outcomes of interest \\
\hline He 2012 & Education not primary aim of intervention \\
\hline Hedback 1993 & Education not primary aim of intervention - Performance bias. \\
\hline Hedback 2001 & Education not primary aim of intervention - Performance bias. \\
\hline Heidarnia 2005 & Not RCT "experimental design" \\
\hline Heilmann 2014 & Follow-up only 5 days after intervention \\
\hline Hobbs 2002 & Editorial referring to Shuldham 2002, Pre-CABG education. No relevant outcomes investigated. \\
\hline Hoseini 2013 & Follow-up only 6 weeks \\
\hline Huang 2014 & No outcomes of interest \\
\hline Huber 2016 & No outcomes of interest \\
\hline Jackson 2009 & Systematic Review: 0 references identified \\
\hline Jamshidi 2013 & Comparator group received education \\
\hline Janz 1999 & Identified from Clark 2009. No relevant outcomes. \\
\hline
\end{tabular}




\begin{tabular}{|c|c|}
\hline Study & Reason for exclusion \\
\hline Jenny 2001 & $\begin{array}{l}\text { Identifed from Beranova 2007. Outcomes; Effectiveness of education package in promoting learn- } \\
\text { ing only. }\end{array}$ \\
\hline Johansen 2003 & Not education, psycho-social intervention, post MI. \\
\hline Kamal 2014 & No outcomes of interest \\
\hline Khunti 2007 & Education not primary aim of intervention. Nurse led clinic. \\
\hline Klainin-Yobas 2015 & Education not primary aim of intervention \\
\hline Koertge 2003 & $\begin{array}{l}\text { Identified from Eshah 2009. Education not primary aim of intervention (diet and stress manage- } \\
\text { ment and social support). }\end{array}$ \\
\hline La Sala 2015 & Education not primary aim of intervention \\
\hline Leemrijse 2012 & Education not primary aim of intervention \\
\hline Levine 2011 & No outcomes of interest \\
\hline Lindsay 2009 & $\begin{array}{l}\text { Education not primary aim of intervention: computer support group - comparison of moderated } \\
\text { and unmoderated access. }\end{array}$ \\
\hline Luisi 2015 & No outcomes of interest \\
\hline Ma 2012 & Comparator group received education \\
\hline Mayou 2002 & Education not primary aim of intervention \\
\hline McGillion 2004 & Systematic Review: 0 references identified \\
\hline McGillion 2006 & ID from 2011 update: Follow-up only 3 months \\
\hline McGillion 2008 & $\begin{array}{l}\text { Education not primary aim of intervention: Psychological intervention - cognitive behavioural ther- } \\
\text { apy. }\end{array}$ \\
\hline McGillion 2008a & Education not primary aim of intervention-Psychological intervention \\
\hline Meisinger 2013 & Education not primary aim of intervention \\
\hline Meng 2014 & Quasi-experimental, sequential cohort design study \\
\hline Mirkamali 2014 & No outcomes of interest \\
\hline Mohammadpour 2015 & Intervention included counseling and no outcomes of interest and \\
\hline Mohammady 2010 & Follow-up only 3 months and no outcomes of interest \\
\hline Moore 2001 & $\begin{array}{l}\text { Identified from Fredericks 2009. Education not primary aim of intervention. Symptom manage- } \\
\text { ment program using audiotapes. }\end{array}$ \\
\hline Mosca 2010 & No outcomes of interest \\
\hline Moser 2012 & Intervention included counseling and no outcomes of interest and \\
\hline
\end{tabular}




\begin{tabular}{|c|c|}
\hline Study & Reason for exclusion \\
\hline Mullen 1992 & Duplicate of Dolan 1992; Systematic Review: 0 references identified (all pre1990) \\
\hline Muñiz 2010 & Education not primary aim of intervention \\
\hline Murchie 2003 & Education not primary aim of intervention: secondary prevention clinic. \\
\hline Murchie 2004 & Education not primary aim of intervention: secondary prevention clinic. \\
\hline NCT00683813 & ID from 2011 update: Education not primary aim of intervention \\
\hline Nelson 2013 & Education not primary aim of intervention \\
\hline Nematian 2015 & Follow-up less than 6 months \\
\hline Neubeck 2009 & $\begin{array}{l}\text { Systematic Review: } 11 \text { references identified and reviewed as being of potential interest to this re- } \\
\text { view }\end{array}$ \\
\hline Niebauer 1997 & Identified from Clark 2007. Education not primary aim of intervention (exercise and low fat diet) \\
\hline Nisbeth 2000 & Education not primary aim of intervention: psychological intervention \\
\hline Nolan 2011 & No outcomes of interest \\
\hline Nordmann 2001 & $\begin{array}{l}\text { Education not primary aim of intervention: case management - not relevant outcomes (only risk } \\
\text { factor modification). }\end{array}$ \\
\hline O'Neil 2011 & Education not primary aim of intervention; no outcomes of interest (protocol) \\
\hline O'Neil 2014 & Education not primary aim of intervention; no outcomes of interest \\
\hline O'Neil 2014a & No outcomes of interest \\
\hline Oldenburg 1995 & Education not primary aim of intervention: psychological intervention. \\
\hline Oranta 2012 & Education not primary aim of intervention \\
\hline Ornish 1990 & Identified from Clark 2007. Education not primary aim of intervention \\
\hline Ornish 1998 & Education not primary aim of intervention: lifestyle regime \\
\hline Paez 2006 & Education not primary aim of intervention: nurse managed cholesterol control program. \\
\hline Palacio 2015 & Education not primary aim of intervention \\
\hline Parry 2009 & No relevant outcomes \\
\hline Peterson 2012 & Education not primary aim of intervention \\
\hline Raftery 2005 & Education not primary aim of intervention \\
\hline Redaelli 2010 & Education not primary aim of intervention \\
\hline Redfern 2009 & Non-standard RCT design with non-randomised control group. \\
\hline
\end{tabular}




\begin{tabular}{|c|c|}
\hline Study & Reason for exclusion \\
\hline Robertson 2003 & $\begin{array}{l}\text { Not RCT. "True experimental post-test only, control group design, including the process of randomisa- } \\
\text { tion." }\end{array}$ \\
\hline Rubenfire 2008 & $\begin{array}{l}\text { Commentary on a Systematic Review, subsequently reviewed and demonstrated: } 9 \text { references } \\
\text { identified and reviewed as being of potential interest to this review }\end{array}$ \\
\hline Saffi 2014 & Education not primary aim of intervention \\
\hline Saki 2014 & Follow up less than 6 months \\
\hline Schneider 2012 & Transcendental Meditation Intervention vs health education (control) \\
\hline Schwalm 2015 & Education not primary aim of intervention \\
\hline Seekatz 2013 & Comparator group received education \\
\hline Shahamfar 2010 & No outcomes of interest \\
\hline Sherrard 2000 & $\begin{array}{l}\text { Education not primary aim of intervention, combined with psychological counselling and no rele- } \\
\text { vant outcomes. }\end{array}$ \\
\hline Shui 2014 & Follow-up only 30 days after leaving hospital. \\
\hline Shuldham 2001 & Systematic Review: 0 references identified \\
\hline Shuldham 2002 & pre-CABG education. No relevant outcomes investigated. \\
\hline Sinclair 2005 & Follow-up only 100 days. \\
\hline Stewart 2012 & Education not primary aim of intervention \\
\hline Stewart 2013 & Education not primary aim of intervention \\
\hline Stewart 2014 & Education not primary aim of intervention \\
\hline Thompson 2000 & Identified from Hanssen 2007. Review not an RCT \\
\hline Thompson 2002 & Identified from Hanssen 2007. Review not an RCT \\
\hline Tranmer 2004 & Education not primary aim of intervention, telephone nurse management. \\
\hline Turner 2008 & Cost analysis of Khunti 2007; Education not primary aim of intervention \\
\hline Uysal 2012 & Follow-up only 3 months \\
\hline Uysal 2015 & Not an RCT; follow-up only 3 months post-discharge \\
\hline Vale 2003 & $\begin{array}{l}\text { Education not primary aim of intervention: Program is a risk factor targeted prompting of treat- } \\
\text { ment. }\end{array}$ \\
\hline Van Elderen 1994 & No relevant outcomes. \\
\hline Van Elderen 2001 & Not RCT -" quasi-experimental pre-test / post test control group design." \\
\hline Vida 2011 & Follow-up only 8 weeks \\
\hline
\end{tabular}




\begin{tabular}{|c|c|}
\hline Study & Reason for exclusion \\
\hline Volpe 2012 & Population doesn't have CHD \\
\hline Vonder Muhll 2002 & Identified from Eshah 2009. Not RCT: Retrospective Study \\
\hline Wallner 1999 & Dietary intervention, Education not primary aim of intervention. \\
\hline Wang 2010 & Education not primary aim of intervention \\
\hline Wang 2012 & Education not primary aim of intervention \\
\hline Wang 2015 & No outcomes of interest \\
\hline Weibel 2016 & No outcomes of interest \\
\hline Williams 2009 & Systematic Review: 0 references identified. \\
\hline Williamson 2008 & Listed under "Studies awaiting assessment" in 2011 update: Unable to find full publication \\
\hline Wolkanin 2010 & Follow-up only 3 months and no outcomes of interest \\
\hline Wolkanin-Bartnik 2011 & No outcomes of interest \\
\hline Yavarikia 2011 & No outcomes of interest \\
\hline Yildiz 2014 & Comparator group received education \\
\hline Zalesskaya 2005 & No relevant outcomes. \\
\hline Zhao 2009 & Education not primary aim of intervention-Performance bias \\
\hline Zhao 2015 & No outcomes of interest \\
\hline Zhou 2014 & Comparator group received education \\
\hline Zutz 2007 & Identified from Neubeck 2009. No relevant outcome measures \\
\hline
\end{tabular}

Characteristics of studies awaiting classification [ordered by study ID]

Gao 2011

\begin{tabular}{ll}
\hline Methods & Not available \\
\hline Participants & Not available \\
\hline Interventions & Not available \\
\hline Outcomes & Not available \\
\hline Notes & Published in IIOAB but cannot access any of this journal's web pages \\
\hline
\end{tabular}


Licina 2010

\begin{tabular}{ll}
\hline Methods & RCT \\
\hline Participants & $\begin{array}{l}355 \text { patients (mean age } 59 \pm 9 \text { years; } 258 \text { male) consecutively admitted for control exercise stress } \\
\text { test after PCI }\end{array}$ \\
\hline Interventions & $\begin{array}{l}\text { Education on lifestyle modification regarding dietary habits, physical activity, stress management, } \\
\text { smoking status, lipid status, fasting blood glucose, blood pressure and adherence to treatment }\end{array}$ \\
\hline Outcomes & Primary outcome was a change in risk factor management \\
\hline Notes & Unable to find full text or trace authors \\
\hline
\end{tabular}

\section{Soliman 2013}

\begin{tabular}{ll}
\hline Methods & RCT \\
\hline Participants & 1850 post MI patients \\
\hline Interventions & $\begin{array}{l}\text { Ml educational program: Patients participated in a } 30 \text { min weekly education session for eight } \\
\text { weeks. Follow up telephone calls after another } 4 \text { weeks. }\end{array}$ \\
\hline Outcomes & Smoking cessation; overweight; diet modifications; physical activity \\
\hline Notes & Unable to find full text or trace authors \\
\hline
\end{tabular}

Vona 2009

Methods $\quad$ RCT; 3 groups: usual care (G1, 214 patients); phone follow-up group (G2, 193 patients), intensive
long-term intervention group (G3, 204 patients).

\begin{tabular}{ll}
\hline Participants & 611 patients ( $57 \pm 9$ year), following an acute coronary event \\
\hline Interventions & $\begin{array}{l}\text { The G2 patients were called every month by a nurse to reinforce adherence to medical treatment } \\
\text { and physical activity recommended and to check progress regarding lifestyle and other risk factors } \\
\text { changes; the G3 patients underwent, every } 3 \text { months, } 2 \text { hours of a risk factors - education coun- } \\
\text { selling session managed by nurse }\end{array}$ \\
\hline Outcomes & $\begin{array}{l}\text { Total and cardiovascular mortality; MI; hospitalisations; LDL cholesterol; adherence to medical } \\
\text { treatment; adherence to physical activity; blood pressure }\end{array}$ \\
\hline Notes & Unable to find full text or trace authors \\
\hline
\end{tabular}

\section{Xiaolin 2012}

\begin{tabular}{ll}
\hline Methods & Not available \\
\hline Participants & Not available \\
\hline Interventions & Not available \\
\hline
\end{tabular}


Xiaolin 2012 (Continued)

Outcomes Not available

Notes Unable to find full text or abstract, or trace authors

Characteristics of ongoing studies [ordered by study ID]

ACTRN12613000395730

\begin{tabular}{|c|c|}
\hline Study name & $\begin{array}{l}\text { Investigating whether patients with ACS who receive a secondary-prevention educational resource } \\
\text { have greater attendance at cardiac rehabilitation compared to patients who receive usual inpa- } \\
\text { tient education }\end{array}$ \\
\hline Methods & $\mathrm{RCT}$ \\
\hline Participants & Patients aged over 18 years with a diagnosis of ACS and eligible for cardiac rehabilitation. \\
\hline Interventions & $\begin{array}{l}\text { Patients will receive an educational booklet produced by the Heart Foundation Australia. The re- } \\
\text { source aims to support patients with coronary heart disease to understand and better manage } \\
\text { their cardiac condition. }\end{array}$ \\
\hline Outcomes & Hospital admissions \\
\hline Starting date & May 2013 \\
\hline Contact information & $\begin{array}{l}\text { Dr Alison Beauchamp, Faculty of Health Deakin University Melbourne Burwood Campus, } 221 \text { Bur- } \\
\text { wood Highway, Burwood, VIC 3125, Australia, alison.beauchamp@deakin.edu.au }\end{array}$ \\
\hline Notes & http://www.anzctr.org.au/ACTRN12613000395730.aspx \\
\hline
\end{tabular}

\section{ACTRN12613000793718}

\section{Study name}

Methods

\begin{tabular}{ll}
\hline Participants & $\begin{array}{l}\text { Acute coronary syndrome, a planned return to the community, ability to provide informed consent, } \\
\text { own an operational mobile telephone and sufficient skill in English language to read and send text } \\
\text { messages. }\end{array}$ \\
\hline
\end{tabular}

Interventions

The intervention group will receive secondary prevention support program delivered via mobile phone text message and an opportunity to communicate with a health counsellor over a 12 month period. The messages will provide education, support, motivation and reminders with respect to medications and lifestyle.

\begin{tabular}{ll}
\hline Outcomes & $\begin{array}{l}\text { Major vascular event (cardiovascular death, non-fatal AMI, stroke or hospital admission with un- } \\
\text { stable angina or congestive heart failure), coronary revascularisation (coronary artery bypass graft } \\
\text { surgery or percutaneous coronary intervention), Death, hospital readmission }\end{array}$ \\
\hline Starting date & July 2013 \\
\hline Contact information & $\begin{array}{l}\text { Assoc Prof Clara Chow, The George Institute for Global Health PO Box M201 Missenden Road NSW } \\
\text { 2050, Australia, cchow@georgeinstitute.org.au }\end{array}$ \\
\hline
\end{tabular}

TEXT messages to improve MEDication adherence \& Secondary prevention in patients with acute coronary syndrome - TEXTMEDS 
ACTRN12613000793718 (Continued)

Notes $\quad$ http://www.anzctr.org.au/ACTRN12613000793718.aspx

ACTRN12616000426482

\begin{tabular}{ll}
\hline Study name & $\begin{array}{l}\text { SMARTphone-based, early cardiac REHABilitation in patients with acute coronary syndromes: A } \\
\text { Randomised Controlled Trial Protocol (SMART-REHAB Trial) }\end{array}$ \\
\hline Methods & RCT \\
\hline Participants & Adults with acute coronary syndromes with documented coronary artery disease \\
\hline Interventions & $\begin{array}{l}\text { The smartphone-based secondary prevention program delivered over } 8 \text { weeks starting at time of } \\
\text { discharge from hospital through a smartphone application (App). This is a multi-faceted interven- } \\
\text { tion with particular emphasis on early mobilisation. The app provides a platform to deliver a com- } \\
\text { prehensive secondary prevention program. }\end{array}$
\end{tabular}

\section{Outcomes}

Major adverse cardiovascular events (combination of death, mortality, stroke and unplanned revascularisation), HRQOL, hospital readmissions

\begin{tabular}{ll}
\hline Starting date & 04/04/2016 \\
\hline Contact information & $\begin{array}{l}\text { Dr Matias Yudi, Austin Health Cardiology Department } 145 \text { Studley Road PO BOX } 5555 \text { Heidelberg, } \\
\text { VIC 3084, Australia; matias.yudi@austin.org.au }\end{array}$ \\
\hline Notes & $\begin{array}{l}\text { Multi-faceted intervention, and not clear if the follow-up will extend beyond the duration of the } 8 \\
\text { week intervention }\end{array}$ \\
\hline
\end{tabular}

Brewer 2015

\begin{tabular}{ll} 
Study name & $\begin{array}{l}\text { The Use of Virtual World-Based Cardiac Rehabilitation to Encourage Healthy Lifestyle Choices } \\
\text { Among Cardiac Patients: Intervention Development and Pilot Study Protocol }\end{array}$ \\
\hline Methods & $\begin{array}{l}\text { In Phase 1: Patients will participate in a 12-week, virtual world health education program which } \\
\text { will provide feedback on the feasibility, usability, and design of the intervention. }\end{array}$ \\
& $\begin{array}{l}\text { During Phase 2: A 2-arm, parallel group, single-centre, randomised controlled trial (RCT). Patients } \\
\text { will be randomised at a 1:1 ratio to adjunct virtual world-based CR with conventional CR or conven- } \\
\text { tional CR only. }\end{array}$
\end{tabular}

$\begin{array}{ll}\text { Participants } & \text { Patients recently hospitalised for an ACS (unstable angina, ST-segment elevation MI, non-ST-seg- } \\ & \text { ment elevation MI) or who recently underwent elective PCI at Mayo Clinic Hospital, Rochester Cam- } \\ \text { pus in Rochester, Minnesota with at least one modifiable, lifestyle risk factor target (sedentary } \\ \text { lifestyle, unhealthy diet, and current smoking) }\end{array}$

\begin{tabular}{ll}
\hline Interventions & Adjunct virtual world-based CR with conventional CR or conventional CR only. \\
\hline Outcomes & $\begin{array}{l}\text { The primary outcome is a composite including at least one of the following (1) at least 150 minutes } \\
\text { of physical activity per week, (2) daily consumption of five or more fruits and vegetables, and (3) } \\
\text { smoking cessation. Patients will be assessed at 3, 6, and } 12 \text { months. }\end{array}$ \\
\hline Starting date & NR \\
\hline
\end{tabular}


Brewer 2015 (Continued)

Contact information
Stephen Kopecky, Mayo Clinic College of Medicine, Department of Medicine, 200 First Street SW, Rochester, MN, 55905, United States, Phone: 1507284 9601, Fax: 1507266 0228, Email: ude.oyam@nehpets.ykcepok.

Notes

Dwinger 2013

\begin{tabular}{ll} 
Study name & Telephone-based health coaching for chronically ill patients \\
\hline Methods & The study is a prospective randomised controlled trial comparing the effects of telephone-based \\
health coaching with usual care during a 4-year time period. Data are collected at baseline and af- & ter 12,24 and 36 months. Patients are selected based on one of the following chronic conditions: \\
diabetes, coronary artery disease, asthma, hypertension, heart failure, COPD, chronic depression \\
or schizophrenia. The statistical analyses includes intention-to-treat and as-treated principles
\end{tabular}

\begin{tabular}{ll}
\hline Participants & Approximately 12,000 insurants will be enrolled \\
\hline Interventions & $\begin{array}{l}\text { The health coaching intervention is carried out by trained nurses employed by a German statuto- } \\
\text { ry health insurance. The frequency and the topics of the health coaching are manual-based but tai- } \\
\text { lored to the patients' needs and medical condition, following the concepts of motivational inter- } \\
\text { viewing, shared decision-making and evidence-based-medicine }\end{array}$ \\
\hline
\end{tabular}

Outcomes Primary outcome is the time until hospital readmission within two years after enrolling in the health coaching, assessed by routine data. Secondary outcomes are patient-reported outcomes like changes in quality of life, depression and anxiety and clinical values assessed with questionnaires. Additional secondary outcomes are further economic evaluations like health service use as well as costs and hospital readmission rates

\begin{tabular}{ll}
\hline Starting date & The recruitment will be completed in September 2014 \\
\hline Contact information & $\begin{array}{l}\text { Sarah Dwinger. Department of Medical Psychology, University Medical Center Hamburg-Eppendorf, } \\
\text { Martinistr 52, Hamburg 20246, Germany. s.dwinger@uke.de }\end{array}$ \\
\hline
\end{tabular}

Notes

\section{IRCT201307162621N13}

\begin{tabular}{ll}
\hline Study name & $\begin{array}{l}\text { The effects of application of Prochaska's stages of change model in education of coronary artery } \\
\text { bypass grafting patients on quality of life, lipid profile \& some psychological complications of CABG }\end{array}$ \\
\hline Methods & RCT \\
\hline Participants & Patients aged 40 to 75 who have received CABG \\
\hline Interventions & $\begin{array}{l}\text { Intervention group receive education based on stages of change model of Prochaska, for } 8 \text { weeks, } \\
\text { immediately after discharge. Control group received "routine education" }\end{array}$ \\
\hline Outcomes & Quality of life \\
\hline Starting date & February 2013 \\
\hline
\end{tabular}


IRCT201307162621N13 (Continued)

Contact information

Dr Marzieh Moattari, Faculty of Nursing and Midwifery, Namazi Square, Shiraz, Islamic Republic of Iran, moattarm@sums.ac.ir

Notes

\section{ISRCTN15839687}

\begin{tabular}{ll}
\hline Study name & $\begin{array}{l}\text { A randomised controlled trial of the effectiveness of a self-help psycho-education programme on } \\
\text { outcomes of outpatients with coronary heart disease }\end{array}$ \\
\hline Methods & Single centre RCT \\
\hline Participants & $\begin{array}{l}\text { Patients aged } 21 \text { or more with a diagnosis of CHD, lives at home and does not intend to attend hos- } \\
\text { pital-based rehabilitation programme }\end{array}$ \\
\hline Interventions & $\begin{array}{l}\text { Intervention group will receive a self-help psycho-education programme, which includes an edu- } \\
\text { cation booklet, an accompanying DVD and an education session conducted by a mem of the re- } \\
\text { search team. Control group will receive usual care }\end{array}$ \\
\hline Outcomes & $\begin{array}{l}\text { Hospital admissions, HRQoL } \\
\text { Starting date }\end{array}$ \\
\hline January 2015 \\
$\begin{array}{l}\text { Wenru Wang, Alice Lee Centre for Nursing Studies Yong Loo Lin School of Medicine National Univer- } \\
\text { sity of Singapore 10, Medical Drive, Block MD11 Clinical Research Centre, Level } 2117597 \text { Singapore } \\
\text { Singaporewenru_wang@nuhs.edu.sg }\end{array}$
\end{tabular}

Notes

Kärner 2012

\begin{tabular}{ll}
\hline Study name & COR-PRIM study \\
& NCT01462799 \\
\hline Methods & RCT \\
\hline Participants & 165 patients with CHD \\
\hline Interventions & $\begin{array}{l}\text { All patients will receive conventional care from their general practitioner and other care providers. } \\
\text { The intervention consists of a patient education program in PHC by trained district nurses (tutors) } \\
\text { who will apply PBL to groups of 6-9 patients meeting on } 13 \text { occasions for two hours over one year. } \\
\text { Patients in the control group will not attend a PBL group but will receive home-sent patient infor- } \\
\text { mation on } 11 \text { occasions during the year }\end{array}$
\end{tabular}

\section{Outcomes}

The primary outcome is empowerment to reach self-care goals. Data collection will be performed at baseline at hospital and after one, three and five years in PHC using quantitative and qualitative methodologies involving questionnaires, medical assessments, interviews, diaries and observations

Starting date September 2011


Kärner 2012 (Continued)

Contact information

Notes anita.karner@liu.se; Department of Social and Welfare studies (HAV), Linköping University, Linköping, Sweden

"The first finding of the COR-PRIM study will become available in 2014, and the first results of the main study around 2015"

Lai 2016

\begin{tabular}{ll}
\hline Study name & $\begin{array}{l}\text { Patient and family satisfaction levels in the intensive care unit after elective cardiac surgery: study } \\
\text { protocol for a randomised controlled trial of a preoperative patient education intervention }\end{array}$ \\
\hline Methods & 2-group, parallel, superiority, double-blinded randomised controlled trial \\
\hline Participants & $\begin{array}{l}100 \text { patients undergoing elective coronary artery bypass graft, with or without valve replacement } \\
\text { surgery }\end{array}$ \\
\hline Interventions & $\begin{array}{l}\text { Participants will be randomised to either preoperative patient education comprising of a video and } \\
\text { ICU tour with standard care (intervention) or standard education (control) }\end{array}$ \\
\hline Outcomes & $\begin{array}{l}\text { The primary outcome measures are the satisfaction levels of patients and family members with ICU } \\
\text { care and decision-making in the ICU. The secondary outcome measures are patient anxiety and de- } \\
\text { pression levels before and after surgery. }\end{array}$
\end{tabular}

\begin{tabular}{ll}
\hline Starting date & First received 26 Augst 2015 \\
\hline Contact information & Veronica Lai Ka Wai, veronicalai@link.cuhk.edu.hk \\
\hline
\end{tabular}

Notes

\section{Lynggaard 2014}

Study name LC-REHAB

NCT01668394

\begin{tabular}{ll}
\hline Methods & Open parallel randomised controlled trial conducted in three hospital units in Denmark \\
\hline Participants & Patients recently discharged with ischemic heart disease or heart failure \\
\hline Interventions & $\begin{array}{l}\text { Patients are allocated to either the intervention group with learning and coping strategies incor- } \\
\text { porated into standard care in cardiac rehabilitation or the control group who receive the usual car- } \\
\text { diac rehabilitation program. Learning and coping consists of two individual clarifying interviews, } \\
\text { participation of experienced patients as educators together with health professionals and theo- } \\
\text { ry based, situated and inductive teaching. Usual care is characterised by a structured deductive } \\
\text { teaching style with use of identical pre-written slides in all hospital units. In both groups, cardiac } \\
\text { rehabilitation consists of training three times a week and education once a week over eight weeks. }\end{array}$ \\
\hline Outcomes & $\begin{array}{l}\text { Adherence to cardiac rehabilitation, morbidity and mortality,quality of life (SF-12, Health educa- } \\
\text { tion impact questionnaire and Major Depression Inventory) and lifestyle and risk factors (Body } \\
\text { Mass Index, waist circumference, blood pressure, exercise work capacity, lipid profile and DXA- } \\
\text { scan). }\end{array}$ \\
\hline Starting date & 30th of November 2010 \\
\hline
\end{tabular}


Lynggaard 2014 (Continued)

Contact information

viblyn@rm.dk; Regional Hospital West Jutland, Cardiovascular Research Unit, Herning, Denmark

\section{Notes}

\section{NCT01028066}

\begin{tabular}{ll}
\hline Study name & Feeding Education in Patients Submitted to Coronary Angioplasty (PTCA-Nutri) \\
\hline Methods & Open label RCT \\
\hline Participants & Patients submitted for PTCA \\
\hline Interventions & $\begin{array}{l}\text { The intervention group will receive 4x } 1 \text { hour group meetings of food education, including Inves- } \\
\text { tigation, Contextualisation, Awareness and Strengthening the nutritional concepts. The control } \\
\text { group will have access to the nutritionist }\end{array}$ \\
\hline Outcomes & $\begin{array}{l}\text { Cardiovascular event (new PTCA, CABG, ischemic acute syndrome, MI) and mortality (all causes) at } \\
1 \text { and 3 years }\end{array}$ \\
\hline Starting date & April 2008 \\
\hline Contact information & $\begin{array}{l}\text { Moacyr Roberto Cucê Nobre, Heart Institute, São Paulo University } \\
\text { São Paulo, Brazil, 05403000 }\end{array}$
\end{tabular}

Notes

\section{NCT01275716}

\begin{tabular}{ll}
\hline Study name & $\begin{array}{l}\text { Impact of Coronary Images Used During Patient Education on Coronary Artery Disease and Subse- } \\
\text { quent Lifestyle Modifications. Is a Picture Really Worth a Thousand Words? }\end{array}$ \\
\hline Methods & RCT \\
\hline Participants & $\begin{array}{l}\text { The investigators will show half of the patients their before and after images of their heart arter- } \\
\text { ies where the narrowing occurred and was treated. The other half of the patients will not be shown } \\
\text { these images. }\end{array}$ \\
\hline Interventions & Occurrence of major adverse cardiovascular events \\
\hline Outcomes & December 2010 \\
\hline Starting date & Janet Karol jkarol@uchicago.edu \\
\hline Contact information &
\end{tabular}

\section{NCT01925079}




\begin{tabular}{ll}
$\begin{array}{l}\text { NCT01925079 (Continued) } \\
\text { Methods }\end{array}$ & RCT \\
\hline Participants & Patients $\geq 18$ years, admitted with a diagnosis of ACS \\
\hline Interventions & Multi-channel intensive patient education versus usual care \\
\hline Outcomes & August 2013 \\
\hline Starting date & Bingqing Huang huang.bingqing@zs-hospital.sh.cn \\
\hline Contact information & \\
\hline Notes & \\
\hline
\end{tabular}

NCT02185391

\begin{tabular}{ll}
\hline Study name & Interactive Education of Patients With Coronary Heart Disease (INSERT) \\
\hline Methods & RCT \\
\hline Participants & Patients $\geq 18$ years with cardiovascular disease \\
\hline Interventions & $\begin{array}{l}\text { Using an Audience Response System (ARS) during oral presentations in rehabilitation centers to } \\
\text { improve the learning effect of patients. Patients will receive motivating telephone calls in the fol- } \\
\text { low-up. }\end{array}$ \\
\hline Outcomes & HRQoL, MI \\
\hline Starting date & May 2014 \\
\hline Contact information & Paracelsus Harz Clinic Bad Suderode, Quedlinburg, Saxony-Anhalt, Germany, 06485 \\
\hline Notes &
\end{tabular}

\section{NTR2388}

\begin{tabular}{ll}
\hline Study name & Evaluation Program “Coaching patients On Achieving Cardiovascular Health" (COACH) \\
\hline Methods & Single site RCT \\
\hline Participants & $\begin{array}{l}\text { Patients with CHD (AMI or chronic/unstable angina), treated with a CABG, PCl or with medication } \\
\text { and have finished the hospital's rehabilitation programme }\end{array}$ \\
\hline Interventions & $\begin{array}{l}\text { Trained professionals coach patients achieving targets of the influential risk factors, while focusing } \\
\text { on lifestyle factors and drug use. Each session contains education, assertiveness training and goal } \\
\text { setting. }\end{array}$ \\
\hline Outcomes & HRQoL \\
\hline Starting date & June 2010 \\
\hline Contact information & Chantal Leemrijse, Postbus 15683500 BN Utrecht The Netherlands, C.Leemrijse@nivel.nl
\end{tabular}


NTR2388 (Continued)

Notes http://www.trialregister.nl/trialreg/admin/rctview.asp?TC $=2388$

Shah 2011

\begin{tabular}{|c|c|}
\hline Study name & $\begin{array}{l}\text { SPRITE } \\
\text { NCT00901277 }\end{array}$ \\
\hline Methods & 3-arm RCT \\
\hline Participants & 450 patients with a recent $\mathrm{MI}$ and hypertension \\
\hline Interventions & $\begin{array}{l}\text { Telephone-based, nurse-administered disease management program. The first arm ( } \mathrm{N}=150) \text { will } \\
\text { receive home blood pressure }(\mathrm{BP}) \text { monitors plus a nurse-delivered, telephone-based tailored pa- } \\
\text { tient education intervention and will be enrolled into HealthVault, a Microsoft electronic health } \\
\text { record platform. The second arm }(\mathrm{N}=150) \text { will also receive } \mathrm{BP} \text { monitors plus a tailored patient ed- } \\
\text { ucation intervention and be enrolled in HeartVault. However, the patient education intervention } \\
\text { will be delivered by a Web-based program and will cover topics identical to those in the nurse-de- } \\
\text { livered intervention. Both arms will be compared with a control group receiving standard care }(\mathrm{N}= \\
\text { 150) }\end{array}$ \\
\hline
\end{tabular}

Outcomes

BP, LDL cholesterol, body weight, and glycosylated haemoglobin (in diabetic subjects), adherence to evidence-based therapies and improvement in health behaviours

\begin{tabular}{ll}
\hline Starting date & NR \\
\hline Contact information & $\begin{array}{l}\text { Bimal R. Shah, MD, MBA, Duke Clinical Research Institute, 2400 Pratt St, Durham, NC 27705; bi- } \\
\text { mal.shah@duke.edu }\end{array}$ \\
\hline
\end{tabular}

Notes

\section{DATA AND ANALYSES}

\section{Comparison 1. Education versus no education}

\begin{tabular}{lllll}
\hline Outcome or subgroup title & No. of studies & $\begin{array}{l}\text { No. of partici- } \\
\text { pants }\end{array}$ & Statistical method & Effect size \\
\hline $\begin{array}{l}\text { 1.1 Total mortality at the end of the } \\
\text { follow up period }\end{array}$ & 13 & 10075 & $\begin{array}{l}\text { Risk Ratio (M-H, Random, } \\
95 \% \mathrm{Cl})\end{array}$ & $0.80[0.60,1.05]$ \\
\hline $\begin{array}{l}1.1 .1 \text { Studies with 12 months or less } \\
\text { follow-up }\end{array}$ & 6 & 4063 & $\begin{array}{l}\text { Risk Ratio (M-H, Random, } \\
95 \% \mathrm{Cl})\end{array}$ & $0.78[0.35,1.78]$ \\
\hline $\begin{array}{l}1.1 .2 \text { Studies with more than 12 } \\
\text { months follow-up }\end{array}$ & 7 & 6012 & $\begin{array}{l}\text { Risk Ratio (M-H, Random, } \\
95 \% \mathrm{Cl})\end{array}$ & $0.78[0.60,1.02]$ \\
\hline $\begin{array}{l}1.2 \text { Fatal and/or non-fatal MI } \\
\text { nisk Ratio (M-H, Random, }\end{array}$ & $0.63[0.26,1.48]$ \\
\hline
\end{tabular}




\begin{tabular}{|c|c|c|c|c|}
\hline Outcome or subgroup title & No. of studies & $\begin{array}{l}\text { No. of partici- } \\
\text { pants }\end{array}$ & Statistical method & Effect size \\
\hline $\begin{array}{l}\text { 1.3 Other fatal and/or non-fatal car- } \\
\text { diovascular events }\end{array}$ & 2 & 310 & $\begin{array}{l}\text { Risk Ratio (M-H, Random, } \\
95 \% \mathrm{Cl})\end{array}$ & $0.36[0.23,0.56]$ \\
\hline $\begin{array}{l}\text { 1.4 Total revascularisations (includ- } \\
\text { ing } C A B G \text { and } P C I \text { ) }\end{array}$ & 3 & 456 & $\begin{array}{l}\text { Risk Ratio (M-H, Random, } \\
95 \% \mathrm{Cl})\end{array}$ & $0.58[0.19,1.71]$ \\
\hline 1.5 Hospitalisations & 5 & 14849 & $\begin{array}{l}\text { Risk Ratio (M-H, Random, } \\
95 \% \mathrm{Cl})\end{array}$ & $0.93[0.71,1.21]$ \\
\hline 1.6 Withdrawals & 17 & 10972 & $\begin{array}{l}\text { Risk Ratio (M-H, Random, } \\
95 \% \mathrm{Cl})\end{array}$ & $1.04[0.88,1.22]$ \\
\hline $\begin{array}{l}\text { 1.6.1 Studies with } 12 \text { months or less } \\
\text { follow-up }\end{array}$ & 10 & 4960 & $\begin{array}{l}\text { Risk Ratio (M-H, Random, } \\
95 \% \mathrm{Cl} \text { ) }\end{array}$ & $1.18[0.93,1.49]$ \\
\hline $\begin{array}{l}\text { 1.6.2 Studies with more than } 12 \\
\text { months follow-up }\end{array}$ & 7 & 6012 & $\begin{array}{l}\text { Risk Ratio (M-H, Random, } \\
95 \% \mathrm{Cl} \text { ) }\end{array}$ & $0.98[0.80,1.20]$ \\
\hline
\end{tabular}




\section{Analysis 1.1. Comparison 1: Education versus no education,} Outcome 1: Total mortality at the end of the follow up period

\begin{tabular}{lccccccc} 
& \multicolumn{2}{c}{ Intervention } & \multicolumn{2}{c}{ Control } & \multicolumn{2}{c}{ Risk Ratio } & \multicolumn{2}{c}{ Risk Ratio } \\
Study or Subgroup & Events & Total & Events & Total & Weight & M-H, Random, 95\% CI & M-H, Random, 95\% CI
\end{tabular}

1.1.1 Studies with 12 months or less follow-up Chow 2015

Cohen 2014

Furuya 2015

Jorstad 2013

Lisspers 1999

Mooney 2014

Subtotal (95\% CI)

Total events:

Heterogeneity: $\mathrm{Tau}^{2}=0.42 ; \mathrm{Chi}^{2}=8.54, \mathrm{df}=4(\mathrm{P}=0.07) ; \mathrm{I}^{2}=53 \%$

Test for overall effect: $\mathrm{Z}=0.58(\mathrm{P}=0.56)$

1.1.2 Studies with more than 12 months follow-up

$\begin{array}{lrrrrr}\text { Clark 2000 } & 14 & 309 & 8 & 261 & 8.0 \% \\ \text { Clark 2009 } & 4 & 201 & 4 & 92 & 3.7 \% \\ \text { Clark 2009 } & 5 & 190 & 4 & 92 & 4.1 \% \\ \text { Cupples 1994 } & 47 & 342 & 65 & 346 & 20.9 \% \\ \text { P.RE.COR Group 1991 } & 5 & 61 & 4 & 61 & 4.3 \% \\ \text { Hanssen 2007 } & 7 & 156 & 7 & 132 & 6.1 \% \\ \text { Dracup 2009 } & 67 & 1777 & 75 & 1745 & 21.7 \% \\ \text { Moreno-Palanco 2011 } & 4 & 121 & 17 & 126 & 5.7 \% \\ \text { Subtotal (95\% CI) } & & \mathbf{3 1 5 7} & & \mathbf{2 8 5 5} & \mathbf{7 4 . 6 \%} \\ \text { Total events: } & 153 & & 184 & & \end{array}$

Total events: $153 \quad 184$

Heterogeneity: $\mathrm{Tau}^{2}=0.03 ; \mathrm{Chi}^{2}=8.66, \mathrm{df}=7(\mathrm{P}=0.28) ; \mathrm{I}^{2}=19 \%$

Test for overall effect: $\mathrm{Z}=1.79(\mathrm{P}=0.07)$

Total (95\% CI)

5187

5187

Total events:

189 225

Heterogeneity: Tau$^{2}=0.07 ; \mathrm{Chi}^{2}=17.50, \mathrm{df}=12(\mathrm{P}=0.13) ; \mathrm{I}^{2}=31 \%$

Test for overall effect: $\mathrm{Z}=1.59(\mathrm{P}=0.11)$

Test for subgroup differences: $\mathrm{Chi}^{2}=0.00, \mathrm{df}=1(\mathrm{P}=0.99), \mathrm{I}^{2}=0 \%$
$4.07[0.46,36.22]$

$1.00[0.36,2.81]$

Not estimable

$0.30[0.08,1.09]$

$0.15[0.02,1.18]$

$1.24[0.66,2.33]$

$0.78[0.35,1.78]$

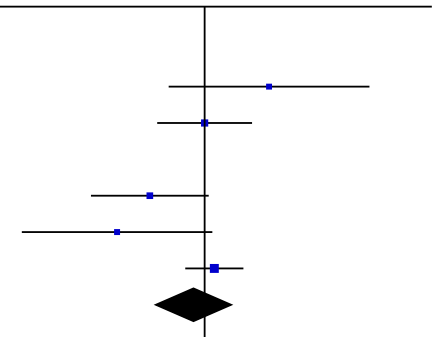

$1.48[0.63,3.47]$

$0.46[0.12,1.79]$

$0.61[0.17,2.20]$

$0.73[0.52,1.03]$

$1.25[0.35,4.43]$

$0.85[0.30,2.35]$

$0.88[0.64,1.21]$

$0.25[0.08,0.71]$

$0.78[0.60,1.02]$

$0.80[0.60,1.05]$

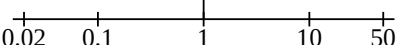

Favours education $\quad$ Favours no education

Analysis 1.2. Comparison 1: Education versus no education, Outcome 2: Fatal and/or non-fatal MI

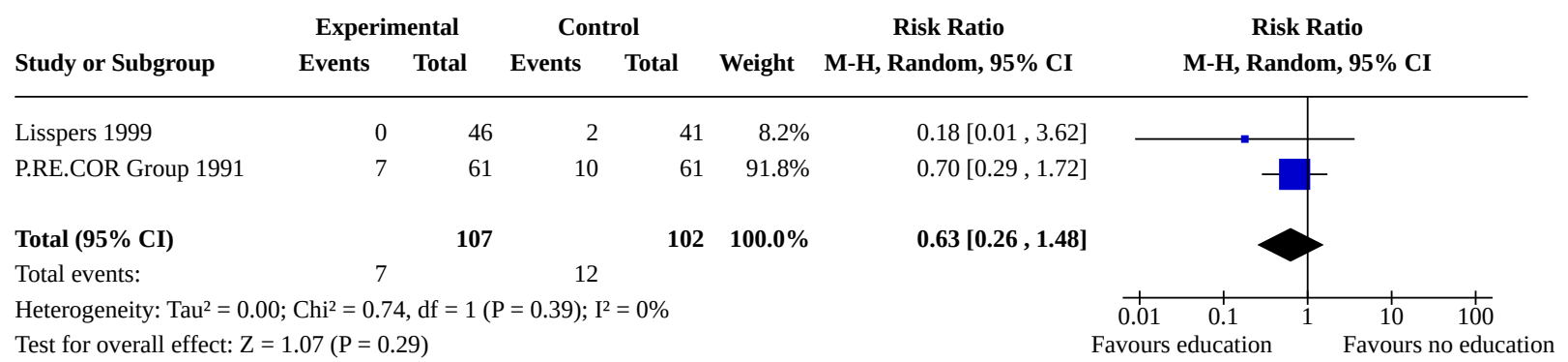

Test for subgroup differences: Not applicable 
Analysis 1.3. Comparison 1: Education versus no education, Outcome 3: Other fatal and/or non-fatal cardiovascular events

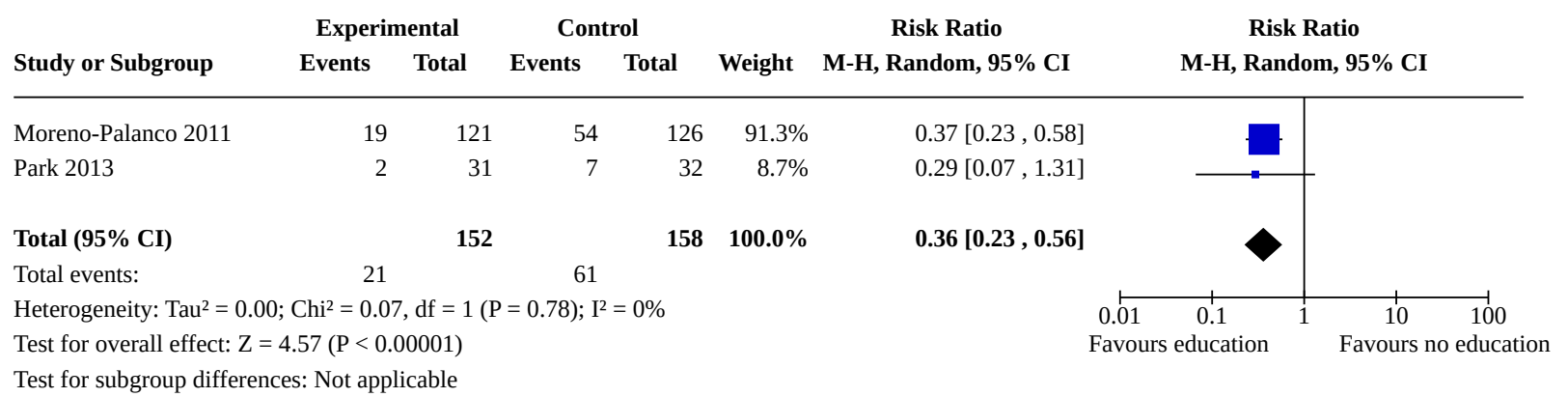
Analysis 1.4. Comparison 1: Education versus no education,
Outcome 4: Total revascularisations (including CABG and PCI)

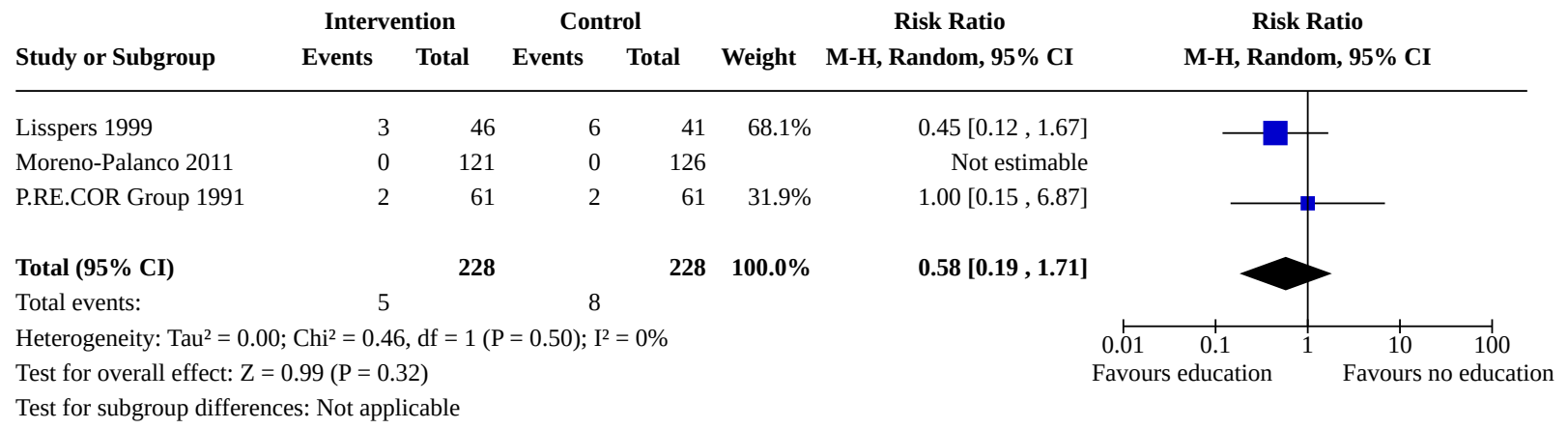

Analysis 1.5. Comparison 1: Education versus no education, Outcome 5: Hospitalisations

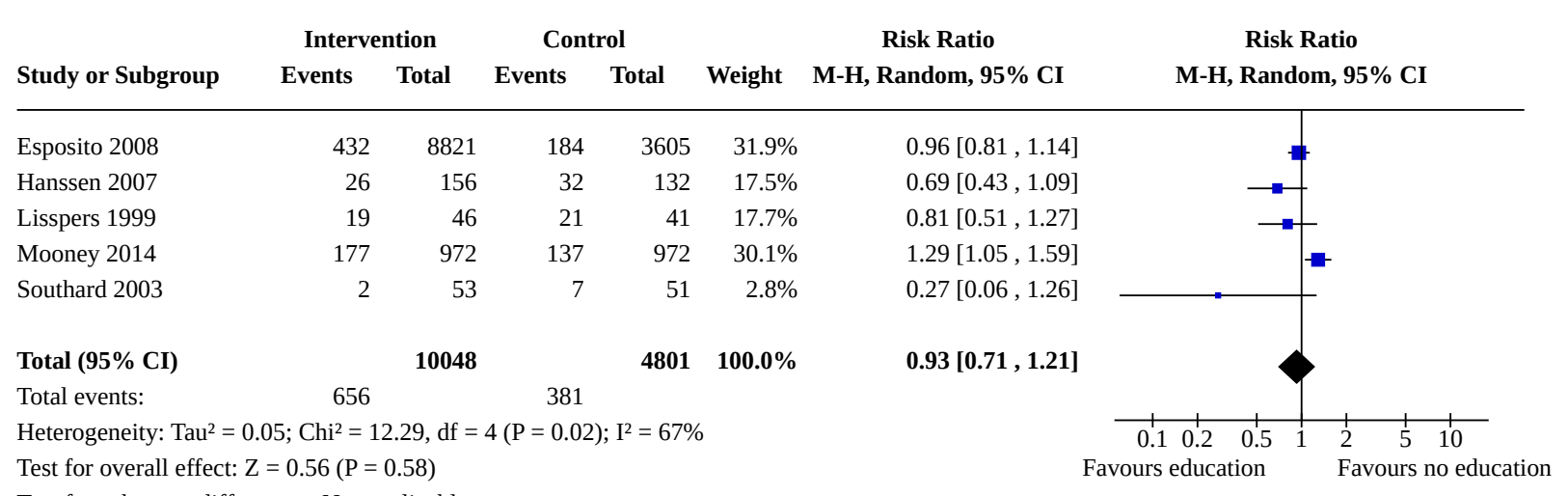


Analysis 1.6. Comparison 1: Education versus no education, Outcome 6: Withdrawals

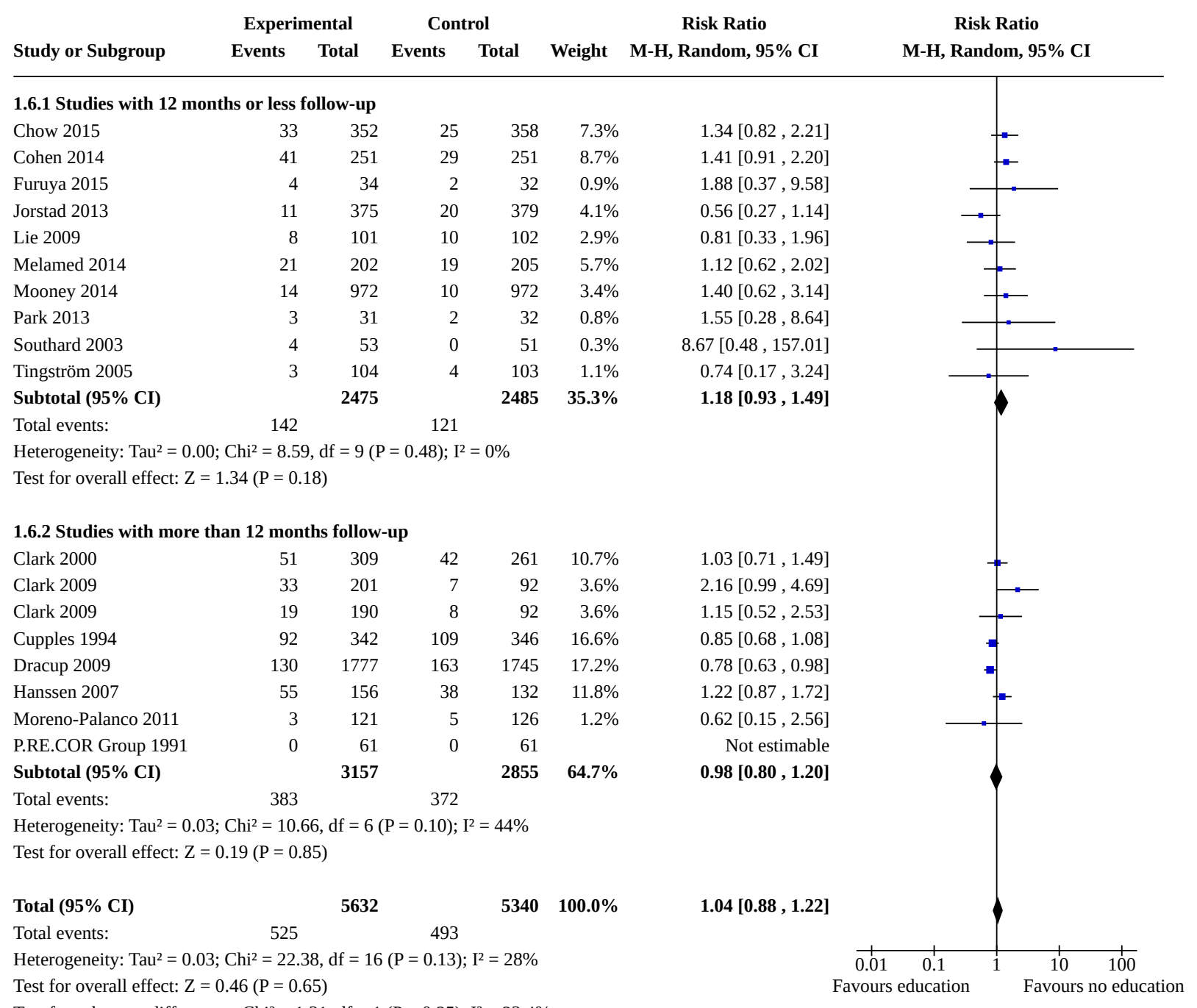

\section{ADDITIONAL TABLES}

Table 1. Results of sensitivity analysis for fixed-effect versus random-effects models

\begin{tabular}{lllll}
\hline Outcome or subgroup & Studies & Participants & $\begin{array}{l}\text { Effect estimate } \\
\text { (random-effect) RR } \\
\text { (M-H, random, 95\% } \\
\text { Cl) }\end{array}$ & $\begin{array}{l}\text { Effect estimate } \\
\text { (fixed-effect) RR (M- } \\
\text { H, fixed, 95\% CI) }\end{array}$ \\
\hline $\begin{array}{l}1.1 \text { Total mortality at the end of the follow } \\
\text { up period }\end{array}$ & 13 & 10,075 & $0.80[0.60,1.05]$ & $0.80[0.66,0.97]$ \\
\hline $\begin{array}{l}1.1 .1 \text { Studies with } 12 \text { months or less fol- } \\
\text { low-up }\end{array}$ & 6 & 4063 & $0.78[0.35,1.78]$ & $0.87[0.56,1.36]$ \\
\hline $\begin{array}{l}1.1 .2 \text { Studies with more than 12 months } \\
\text { follow-up }\end{array}$ & 7 & 6012 & $0.78[0.60,1.02]$ & $0.79[0.64,0.97]$ \\
\hline
\end{tabular}


Table 1. Results of sensitivity analysis for fixed-effect versus random-effects models (Continued)

\begin{tabular}{|c|c|c|c|c|}
\hline $\begin{array}{l}2.1 \text { Myocardial Infarction at the end of the } \\
\text { follow-up period }\end{array}$ & 2 & 209 & $0.63[0.26,1.48]$ & $0.59[0.25,1.38]$ \\
\hline 2.2 Total revascularisations & 3 & 456 & $0.58[0.19,1.71]$ & $0.58[0.20,1.69]$ \\
\hline $\begin{array}{l}2.3 \text { Other fatal and/or non-fatal cardiovas- } \\
\text { cular events }\end{array}$ & 2 & 310 & $0.36[0.23,0.56]$ & $0.36[0.23,0.56]$ \\
\hline $\begin{array}{l}\text { 3.1 Cardiac hospitalisations at end of fol- } \\
\text { low-up period }\end{array}$ & 5 & 14,849 & $0.93[0.71,1.21]$ & $1.02[0.90,1.15]$ \\
\hline $\begin{array}{l}\text { 4.1 All cause withdrawal or drop-out at fol- } \\
\text { low-up }\end{array}$ & 17 & 10,972 & $1.04[0.88,1.22]$ & $0.98[0.88,1.10]$ \\
\hline $\begin{array}{l}\text { 4.1.1 Studies with } 12 \text { months or less fol- } \\
\text { low-up }\end{array}$ & 10 & 4960 & $1.18[0.93,1.49]$ & $1.18[0.94,1.49]$ \\
\hline $\begin{array}{l}\text { 4.1.2 Studies with more than } 12 \text { months } \\
\text { follow-up }\end{array}$ & 7 & 6012 & $0.98[0.80,1.20]$ & $0.92[0.81,1.05]$ \\
\hline
\end{tabular}




\begin{tabular}{|c|c|c|c|c|c|c|c|c|c|c|}
\hline Study ID & $\begin{array}{l}\text { Description of Inter- } \\
\text { vention }\end{array}$ & $\begin{array}{l}\text { Theoreti- } \\
\text { cal basis }\end{array}$ & Tailored & Duration & $\begin{array}{l}\text { One-to- } \\
\text { one }\end{array}$ & Group & $\begin{array}{l}\text { Face- to- } \\
\text { face }\end{array}$ & $\begin{array}{l}\text { Tele- } \\
\text { phone }\end{array}$ & Internet & Notes \\
\hline $\begin{array}{l}\text { Chow } \\
2015\end{array}$ & $\begin{array}{l}\text { Text message-based } \\
\text { prevention program } \\
\text { delivering regular se- } \\
\text { mi-personalised mes- } \\
\text { sages providing ad- } \\
\text { vice, motivation, and } \\
\text { information to im- } \\
\text { prove diet, increase } \\
\text { physical activity, and } \\
\text { encourage smoking } \\
\text { cessation }\end{array}$ & NR & $Y$ & $\begin{array}{l}4 \text { messages } \\
\text { per week for } \\
24 \text { weeks }\end{array}$ & $\mathrm{Y}$ & $\mathrm{N}$ & $\mathrm{N}$ & $\begin{array}{l}\mathrm{Y} \text { (text } \\
\text { messages) }\end{array}$ & $\mathrm{N}$ & $\begin{array}{l}\text { Content for each } \\
\text { participant was } \\
\text { selected using a } \\
\text { prespecified al- } \\
\text { gorithm depen- } \\
\text { dent on key base- } \\
\text { line characteris- } \\
\text { tics }\end{array}$ \\
\hline $\begin{array}{l}\text { Clark } \\
1997\end{array}$ & ${ }^{*} \mathrm{PRIDE}$ & $Y$ & $Y$ & $\begin{array}{l}\text { Once weekly } \\
\text { for } 4 \text { weeks }\end{array}$ & & $Y$ & $Y$ & & & $\begin{array}{l}\text { Taught by health } \\
\text { educator. Video- } \\
\text { tape and work- } \\
\text { book aids }\end{array}$ \\
\hline $\begin{array}{l}\text { Clark } \\
2000\end{array}$ & ${ }^{*} \mathrm{PRIDE}$ & $Y$ & $Y$ & $\begin{array}{l}\text { Once weekly } \\
\text { for } 4 \text { weeks }\end{array}$ & & $Y$ & $Y$ & & & $\begin{array}{l}\text { Taught by health } \\
\text { educator. Video- } \\
\text { tape and work- } \\
\text { book aids }\end{array}$ \\
\hline $\begin{array}{l}\text { Clark } \\
2009\end{array}$ & ${ }^{*} \mathrm{PRIDE}$ & $Y$ & $Y$ & $\begin{array}{l}\text { Once weekly } \\
\text { for } 6 \text { weeks }\end{array}$ & $Y$ & $Y$ & $Y$ & & & $\begin{array}{l}3 \text { groups (self-di- } \\
\text { rected and group } \\
\text { intervention and } \\
\text { a control) }\end{array}$ \\
\hline $\begin{array}{l}\text { Cohen } \\
2014\end{array}$ & $\begin{array}{l}\text { "House of Education" } \\
\text { with individualised } \\
\text { consultations with e.g. } \\
\text { smoking cessation } \\
\text { nurse }\end{array}$ & NR & $Y$ & $\begin{array}{l}\text { At least } 6 \\
\text { sessions in } \\
12 \text { months }\end{array}$ & $\mathrm{Y}$ & $N$ & Y & $\mathrm{N}$ & $\mathrm{N}$ & $\begin{array}{l}\text { Consultations } \\
\text { content was in- } \\
\text { dividualised ac- } \\
\text { cording to a pa- } \\
\text { tient's risk factors }\end{array}$ \\
\hline $\begin{array}{l}\text { Cupples } \\
1994\end{array}$ & $\begin{array}{l}\text { Practical tailored ad- } \\
\text { vice on cardiovascu- } \\
\text { lar risk factors and ap- } \\
\text { propriate health edu- } \\
\text { cation }\end{array}$ & NR & $Y$ & $\begin{array}{l}3 \text { times a } \\
\text { year for } 2 \\
\text { years }\end{array}$ & $Y$ & & Y & & & $\begin{array}{l}\text { Delivered at } \\
\text { home by health } \\
\text { visitor }\end{array}$ \\
\hline
\end{tabular}




\begin{tabular}{|c|c|c|c|c|c|c|c|c|c|c|}
\hline $\begin{array}{l}\text { Dracup } \\
2009\end{array}$ & $\begin{array}{l}\text { Patients received ed- } \\
\text { ucation on ACS, antic- } \\
\text { ipated emotional is- } \\
\text { sues and social factors } \\
\text { that could affect delay }\end{array}$ & $Y$ & $Y$ & $\begin{array}{l}55 \text { mins ( } 40 \\
\text { min face- } \\
\text { to-face plus } \\
15 \text { min fol- } \\
\text { low-up call) }\end{array}$ & $Y$ & $\mathrm{~N}$ & $Y$ & $N$ & $\mathrm{~N}$ & $\begin{array}{l}\text { Delivered by a } \\
\text { nurse with exper- } \\
\text { tise in cardiology }\end{array}$ \\
\hline $\begin{array}{l}\text { Esposito } \\
2008\end{array}$ & $\begin{array}{l}\text { Predesigned scripts } \\
\text { to provide education } \\
\text { on various aspects of } \\
\text { care, geared to person- } \\
\text { alised clinical goals }\end{array}$ & NR & $Y$ & $\begin{array}{l}\text { Average } 1.1 \\
\text { contacts per } \\
\text { month for } \\
18 \text { months }\end{array}$ & $Y$ & & $Y$ & $Y$ & & $\begin{array}{l}\text { Nurse case man- } \\
\text { ager, primarily by } \\
\text { telephone but al- } \\
\text { so face-to-face }\end{array}$ \\
\hline $\begin{array}{l}\text { Furuya } \\
2015\end{array}$ & $\begin{array}{l}\text { Three booklets and } \\
\text { three telephone fol- } \\
\text { low-up calls aimed at } \\
\text { helping patient under- } \\
\text { stand his cardiac con- } \\
\text { dition, PCI and how to } \\
\text { cope with CAD }\end{array}$ & $Y$ & $\mathrm{~N}$ & $\begin{array}{l}2 \text { face to } \\
\text { face ses- } \\
\text { sions and } 3 \\
\text { telephone } \\
\text { calls over } 16 \\
\text { weeks }\end{array}$ & $\mathrm{Y}$ & $\mathrm{N}$ & $Y$ & $Y$ & $\mathrm{~N}$ & $\begin{array}{l}\text { The first booklet } \\
\text { was discussed } \\
\text { with participants } \\
\text { before undergo- } \\
\text { ing PCI procedure }\end{array}$ \\
\hline $\begin{array}{l}\text { Hanssen } \\
2007\end{array}$ & $\begin{array}{l}\text { Individualised educa- } \\
\text { tion from a menu of } \\
\text { topics to be covered }\end{array}$ & $Y$ & $Y$ & $\begin{array}{l}6 \text { months ( } 8 \\
\text { sessions in } \\
\text { total) }\end{array}$ & $Y$ & & & $Y$ & & $\begin{array}{l}\text { Structured ele- } \\
\text { ment and an on- } \\
\text { call element }\end{array}$ \\
\hline $\begin{array}{l}\text { Jorstad } \\
2013\end{array}$ & $\begin{array}{l}\text { Outpatient clinic vis- } \\
\text { its to a cardiovascular } \\
\text { nurse }\end{array}$ & NR & $Y$ & $\begin{array}{l}6 \text { months (4 } \\
\text { sessions) }\end{array}$ & NR & NR & Y & $\mathrm{N}$ & $N$ & $\begin{array}{l}\text { Nurse-coordinat- } \\
\text { ed: } \\
\text { provided general } \\
\text { lifestyle advice, } \\
\text { and individual } \\
\text { counselling }\end{array}$ \\
\hline Lie 2009 & $\begin{array}{l}\text { A psycho-educative in- } \\
\text { tervention. Structured } \\
\text { information and psy- } \\
\text { chological support }\end{array}$ & NR & $\mathrm{N} / \mathrm{S}$ & $\begin{array}{l}2 \text { visits (1 } \\
\text { hour each) }\end{array}$ & $Y$ & & $Y$ & & & $\begin{array}{l}\text { Critical care } \\
\text { nurse, home } \\
\text { based }\end{array}$ \\
\hline $\begin{array}{l}\text { Lisspers } \\
1999\end{array}$ & $\begin{array}{l}\text { Health education and } \\
\text { achievement of behav- } \\
\text { ioural change }\end{array}$ & NR & $Y$ & $\begin{array}{l}4 \text { week resi- } \\
\text { dential then } \\
11 \text { month } \\
\text { one-to-one } \\
\text { individual } \\
\text { sessions }\end{array}$ & $Y$ & $Y$ & $Y$ & & & $\begin{array}{l}\text { Trained nurses } \\
\text { (personal coach- } \\
\text { es). Seminars, } \\
\text { lectures, discus- } \\
\text { sion and skills } \\
\text { sessions }\end{array}$ \\
\hline
\end{tabular}




\begin{tabular}{|c|c|c|c|c|c|c|c|c|c|c|}
\hline $\begin{array}{l}\text { Melamed } \\
2014\end{array}$ & $\begin{array}{l}\text { Lesson materials con- } \\
\text { sisted of a patient } \\
\text { brochure, teaching } \\
\text { cards and curriculum } \\
\text { poster/wall chart set }\end{array}$ & NR & $\mathrm{N}$ & NR & Y & $\mathrm{N}$ & $\mathrm{Y}$ & $\mathrm{N}$ & $\mathrm{N}$ & $\begin{array}{l}\text { Patients were giv- } \\
\text { en an exercise } \\
\text { diary to enable } \\
\text { them to docu- } \\
\text { ment their daily } \\
\text { physical activity }\end{array}$ \\
\hline $\begin{array}{l}\text { Mooney } \\
2014\end{array}$ & $\begin{array}{l}\text { Education intervention } \\
\text { aimed at reducing to- } \\
\text { tal prehospital delay } \\
\text { time }\end{array}$ & Y & $Y$ & $\begin{array}{l}6 \text { months (1 } \\
\text { face-to-face } \\
\text { session, } 1 \\
\text { telephone } \\
\text { call and one } \\
\text { reinforce- } \\
\text { ment letter } \\
\text { at } 6 \text { months) }\end{array}$ & $Y$ & $\mathrm{~N}$ & $Y$ & Y & $\mathrm{N}$ & $\begin{array}{l}\text { Research nurs- } \\
\text { es used preprint- } \\
\text { ed flip charts } \\
\text { and prescriptive } \\
\text { scripts as educa- } \\
\text { tional aids }\end{array}$ \\
\hline $\begin{array}{l}\text { Moreno- } \\
\text { Palanco } \\
2011\end{array}$ & $\begin{array}{l}\text { Health education on } \\
\text { the meaning of pa- } \\
\text { tients' disease and the } \\
\text { importance of treat- } \\
\text { ment }\end{array}$ & NR & NR & $\begin{array}{l}3 \text { years (at } \\
\text { least } 5 \text { ses- } \\
\text { sions) }\end{array}$ & $Y$ & $\mathrm{~N}$ & $\mathrm{Y}$ & $\mathrm{N}$ & $\mathrm{N}$ & $\begin{array}{l}\text { Each visit consist- } \\
\text { ed of a nursing in- } \\
\text { tervention and a } \\
\text { medical assess- } \\
\text { ment }\end{array}$ \\
\hline $\begin{array}{l}\text { P.RE.COR } \\
\text { Group } \\
1991\end{array}$ & $\begin{array}{l}\text { Education and coun- } \\
\text { selling on manage- } \\
\text { ment of cardiovascu- } \\
\text { lar risk factors and ex- } \\
\text { ercise }\end{array}$ & NR & $Y$ & $\begin{array}{l}1 \text { group ses- } \\
\text { sion, } 1 \text { indi- } \\
\text { vidual ses- } \\
\text { sion with } \\
\text { cardiologist }\end{array}$ & $Y$ & $Y$ & $Y$ & & & $\begin{array}{l}\text { Multidisciplinary } \\
\text { input to group. } \\
\text { Cardiologist tai- } \\
\text { lors therapy }\end{array}$ \\
\hline Park 2013 & $\begin{array}{l}\text { Psycho-educational } \\
\text { intervention compris- } \\
\text { ing tailored face-to- } \\
\text { face education and } \\
\text { telephone-delivered } \\
\text { health coaching }\end{array}$ & NR & $Y$ & $\begin{array}{l}12 \text { weeks ( } 6 \\
\text { sessions) }\end{array}$ & $Y$ & $\mathrm{~N}$ & $Y$ & Y & $\mathrm{N}$ & $\begin{array}{l}\text { Patients made } \\
\text { choices about } \\
\text { risk factors they } \\
\text { wanted to lower } \\
\text { and participated } \\
\text { in goal setting }\end{array}$ \\
\hline $\begin{array}{l}\text { Peikes } \\
2009\end{array}$ & $\begin{array}{l}\text { Variable - nurse provi- } \\
\text { sion of patient educa- } \\
\text { tion }\end{array}$ & NR & NR & $\begin{array}{l}1 \text { to } 2.5 \\
\text { times a } \\
\text { month for } \\
\text { an aver- } \\
\text { age of } 30 \\
\text { months }\end{array}$ & $Y$ & & & $Y$ & & $\begin{array}{l}15 \text { different pro- } \\
\text { grams, majority } \\
\text { telephone, one- } \\
\text { to-one }\end{array}$ \\
\hline
\end{tabular}




\begin{tabular}{|c|c|c|c|c|c|c|c|c|c|}
\hline $\begin{array}{l}\text { Pogosova } \\
2008\end{array}$ & $\begin{array}{l}\text { Structured program } \\
\text { addressing different } \\
\text { risk factors in each ses- } \\
\text { sion }\end{array}$ & $\mathrm{Y}$ & NR & $\begin{array}{l}6 \text { sessions } \\
\text { (twice week- } \\
\text { ly, } 90 \text { min) }\end{array}$ & & $\mathrm{Y}$ & $\mathrm{Y}$ & & \\
\hline $\begin{array}{l}\text { Southard } \\
2003\end{array}$ & $\begin{array}{l}\text { Modular internet ses- } \\
\text { sions, Interactive mul- } \\
\text { tiple choice and self } \\
\text { tests followed by feed- } \\
\text { back }\end{array}$ & NR & NR & $\begin{array}{l}\text { Once weekly } \\
\text { for } 6 \text { months } \\
\text { (at least } 30 \\
\text { min) }\end{array}$ & $\mathrm{Y}$ & $\mathrm{Y}$ & & $\mathrm{Y}$ & $\begin{array}{l}\text { Communication } \\
\text { with case manag- } \\
\text { er and online dis- } \\
\text { cussion group }\end{array}$ \\
\hline $\begin{array}{l}\text { Tingström } \\
2005\end{array}$ & $\begin{array}{l}\text { Problem based reha- } \\
\text { bilitation to teach a } \\
\text { planned curriculum }\end{array}$ & Y & NR & $\begin{array}{l}13 \text { sessions } \\
\text { over } 1 \text { year }\end{array}$ & & Y & $\mathrm{Y}$ & & Trained facilitator \\
\hline
\end{tabular}

PRIDE = Problem Identification, Researching one's routine, Identifying a management goal, Developing a plan to reach it, Expressing one's reactions and Establishing rewards for making progress.

$\mathrm{Y}=\mathrm{Yes} ; \mathrm{N}=\mathrm{No} ; \mathrm{NR}=$ not reported 
Table 3. All-cause withdrawal or drop-out at follow-up

\begin{tabular}{|c|c|c|c|c|}
\hline Study ID & & $\begin{array}{l}\text { Number ran- } \\
\text { domised }\end{array}$ & $\begin{array}{l}\text { Number lost at } \\
\text { follow-up* }\end{array}$ & Notes \\
\hline \multirow[t]{2}{*}{ Chow 2015} & Intervention & 352 & 33 & $\begin{array}{l}20 \text { excluded from analysis, } 9 \text { unable to contact, } 4 \\
\text { died }\end{array}$ \\
\hline & Control & 358 & 25 & $\begin{array}{l}21 \text { excluded from analysis, } 3 \text { unable to contact, } 1 \\
\text { died }\end{array}$ \\
\hline \multirow[t]{2}{*}{ Clark 2000} & Intervention & 309 & 51 & 36 withdrew, 14 died, 1 data missing \\
\hline & Control & 262 & 42 & 33 withdrew, 8 died, 1 data missing \\
\hline \multirow[t]{3}{*}{ Clark 2009} & Intervention & 201 & 37 & Self-directed program; 33 withdrew, 4 died \\
\hline & Intervention & 190 & 24 & Group format; 19 withdrew, 5 died \\
\hline & Control & 184 & 23 & 15 withdrew, 8 died \\
\hline \multirow[t]{2}{*}{ Cohen 2014} & Intervention & 251 & 48 & $\begin{array}{l}6 \text { did not meet inclusion criteria, } 7 \text { died, } 23 \text { fol- } \\
\text { low-up refusal, } 10 \text { lost to follow-up, } 2 \text { in another } \\
\text { protocol }\end{array}$ \\
\hline & Control & 251 & 36 & $\begin{array}{l}4 \text { did not meet inclusion criteria, } 7 \text { died, } 13 \text { fol- } \\
\text { low-up refusal, } 12 \text { lost to follow-up }\end{array}$ \\
\hline \multirow[t]{2}{*}{ Cupples 1994} & Intervention & 342 & 92 & 45 defaulted, 47 died; 21 defaulted at 2 years \\
\hline & Control & 346 & 109 & 44 defaulted, 65 died; 25 defaulted at 2 years \\
\hline \multirow[t]{2}{*}{ Dracup 2009} & Intervention & 1777 & 197 & 89 lost to follow-up, 41 withdrawn, 67 died \\
\hline & Control & 1745 & 238 & 94 lost to follow-up, 69 withdrawn, 75 died \\
\hline \multirow[t]{2}{*}{ Furuya 2015} & Intervention & 34 & 4 & $\begin{array}{l}4 \text { unable to contact by telephone at follow-up } \\
\text { (90 participants were originally randomised ( } 45 \text { in } \\
\text { each group), but } 24 \text { participants were excluded im- } \\
\text { mediately after randomisation as they were indi- } \\
\text { cated for surgery or enrolled in another study) }\end{array}$ \\
\hline & Control & 32 & 2 & 2 did not return for 6 month follow-up \\
\hline \multirow[t]{2}{*}{ Hanssen 2007} & Intervention & 156 & 55 & 40 withdrew, 7 died, 8 missing data \\
\hline & Control & 132 & 38 & 21 withdrew, 7 died, 10 missing data \\
\hline \multirow[t]{2}{*}{ Jorstad 2013} & Intervention & 375 & 23 & $\begin{array}{l}9 \text { did not receive intervention, } 3 \text { died, } 2 \text { had early } \\
\text { discontinuation of intervention, } 9 \text { had incomplete } \\
\text { data }\end{array}$ \\
\hline & Control & 379 & 35 & $\begin{array}{l}12 \text { were excluded from the study, } 10 \text { died, } 1 \text { lost to } \\
\text { follow-up, } 7 \text { didn't attend } 12 \text { month follow-up, } 5 \\
\text { had incomplete data }\end{array}$ \\
\hline Lie 2009 & Intervention & 101 & 8 & 6 withdrew, 2 medical exclusions \\
\hline
\end{tabular}


Table 3. All-cause withdrawal or drop-out at follow-up (Continued)

\begin{tabular}{|c|c|c|c|c|}
\hline & Control & 102 & 10 & 5 withdrew, 5 medical exclusions \\
\hline \multirow[t]{2}{*}{ Melamed 2014} & Intervention & 202 & 21 & $\begin{array}{l}\text { "patients were exclude (for example, because of } \\
\text { missed training appointments)" }\end{array}$ \\
\hline & Control & 205 & 19 & $\begin{array}{l}\text { "patients were excluded (for example, because of } \\
\text { missed training appointments)" }\end{array}$ \\
\hline \multirow[t]{2}{*}{ Mooney 2014} & Intervention & 972 & 35 & 14 withdrew, 21 died \\
\hline & Control & 972 & 27 & 10 withdrew, 17 died \\
\hline \multirow{2}{*}{$\begin{array}{l}\text { Moreno-Palanco } \\
2011\end{array}$} & Intervention & 121 & 3 & 3 lost to follow-up, 0 died \\
\hline & Control & 126 & 5 & 5 lost to follow-up, 0 died \\
\hline \multirow{3}{*}{$\begin{array}{l}\text { P.RE.COR Group } \\
1991\end{array}$} & Intervention & 60 & 0 & Counseling program without exercise \\
\hline & Intervention & 61 & 0 & Comprehensive cardiac rehabilitation \\
\hline & Control & 61 & 0 & Usual care \\
\hline \multirow[t]{2}{*}{ Park 2013} & Intervention & 31 & 3 & 3 withdrew, 0 died \\
\hline & Control & 32 & 2 & 2 withdrew, 0 died \\
\hline \multirow[t]{2}{*}{ Southard 2003} & Intervention & 53 & 4 & \multirow{2}{*}{$\begin{array}{l}\text { Reasons for drop-out stated: relocation, dietary in- } \\
\text { tervention instead, psychiatric diagnosis, loss of in- } \\
\text { terest }\end{array}$} \\
\hline & Control & 51 & 0 & \\
\hline \multirow[t]{2}{*}{ Tingström 2005} & Intervention & 104 & 3 & 7 lost to follow-up: 2 died, 5 did not attend \\
\hline & Control & 103 & 4 & \\
\hline \multirow{2}{*}{$\begin{array}{l}\text { Combined re- } \\
\text { sults }\end{array}$} & Intervention & 5692 & 641 & $11.3 \%$ \\
\hline & Control & 5341 & 615 & $11.5 \%$ \\
\hline
\end{tabular}

* All causes of drop out from follow0up included (including mortality)

Table 4. Summary of HRQoL scores at follow-up: Clark 1997

\section{Sickness Impact Profile+++ at 12 months}

Absolute mean outcome values at follow-up++

Education Comparator Between group $\mathbf{P}$

value

value

\section{Comparison}

\section{Comparison}

\section{Clark 1997(12 months)}

\begin{tabular}{lllll}
\hline Total score & 7.26 & 8.09 & NS & Education = comparator \\
\hline Psychosocial dimension & 5.52 & 7.05 & $\leq 0.05$ & Education $>$ comparator \\
\hline
\end{tabular}


Table 4. Summary of HRQoL scores at follow-up: Clark 1997 (Continued)

\begin{tabular}{lllll} 
Physical dimension & 5.89 & 6.00 & NS & Education = comparator \\
\hline \multicolumn{2}{l}{ Sickness Impact Profile+++ at 18 months } & & Comparison \\
\hline & \multicolumn{1}{l}{ Absolute mean outcome values at follow-up++ } & \\
\cline { 2 - 4 } & Education & Comparator & $\begin{array}{l}\text { Between group P } \\
\text { value }\end{array}$ & NS \\
\hline Total score & 7.93 & 7.41 & NS & Education = comparator \\
\hline Psychosocial dimension & 6.05 & 6.23 & NS & Education = comparator
\end{tabular}

++ for mean scores at follow-up (adjusted for baseline scores)

+++ lower score higher HRQoL

NS: No significant difference demonstrated

Education = Comparator: no significant difference $(P>0.05)$ in HRQoL between the education and the comparator groups at follow-up.

Education > Control: significant difference $(P \leq 0.05)$ in HRQoL in favour of the education group at follow-up.

Comparator > Education: significant difference $(P \leq 0.05)$ in $H R Q$ oL in favour of the comparator group at follow-up.

Favours education: Available evidence favours the intervention group but direct statistical comparison between intervention and control groups was not reported.

Favours comparator: Available evidence favours the control group but direct statistical comparison between intervention and control groups was not reported.

Table 5. Summary of HRQOL scores at follow-up: Clark 2000

\begin{tabular}{|c|c|c|c|c|}
\hline \multicolumn{5}{|c|}{ Sickness Impact Profile at 12 months } \\
\hline \multirow[t]{2}{*}{ Clark 2000(12 months) } & \multicolumn{3}{|c|}{ Absolute means at follow-up++ } & \multirow[t]{2}{*}{ Comparison } \\
\hline & Education & Comparator & $\begin{array}{l}\text { Between group } P \\
\text { value }\end{array}$ & \\
\hline Psychosocial dimension & 5.15 & 5.91 & 0.144 & Education = comparator \\
\hline Physical dimension & 7.09 & 7.66 & 0.05 & Education $>$ comparator \\
\hline
\end{tabular}

Means were adjusted to take account of baseline values

NS: No significant difference demonstrated

Education = Comparator: no significant difference $(P>0.05)$ in HRQoL between the education and the comparator groups at follow-up.

Education $>$ Control: significant difference $(P \leq 0.05)$ in $\mathrm{HRQoL}$ in favour of the education group at follow-up.

Comparator > Education: significant difference $(P \leq 0.05)$ in $\mathrm{HRQ}$ oL in favour of the comparator group at follow-up.

Favours education: Available evidence favours the intervention group but direct statistical comparison between intervention and control groups was not reported.

Favours comparator: Available evidence favours the control group but direct statistical comparison between intervention and control groups was not reported.

Table 6. Summary of HRQOL scores at follow-up: Clark 2009

\section{Sickness Impact Profile at 12 months}


Table 6. Summary of HRQoL scores at follow-up: Clark 2009 (Continued)

\begin{tabular}{|c|c|c|c|c|c|}
\hline & Education & $\begin{array}{l}\text { Education self di- } \\
\text { rected }\end{array}$ & Comparator & $\begin{array}{l}\text { Between } \\
\text { group P value }\end{array}$ & \\
\hline Total score & $8.13(8.63)$ & $9.79(10.17)$ & $9.49(9.46)$ & NS & Education = comparator \\
\hline $\begin{array}{l}\text { Psychosocial di- } \\
\text { mension }\end{array}$ & $5.84(8.02)$ & $7.31(10.74)$ & $6.75(9.39)$ & NS & Education = comparator \\
\hline $\begin{array}{l}\text { Physical dimen- } \\
\text { sion }\end{array}$ & $8.07(9.63)$ & $9.46(10.11)$ & $9.85(10.79)$ & NS & Education = comparator \\
\hline \multicolumn{6}{|c|}{ Sickness Impact Profile at 18 months } \\
\hline Total score & $8.44(9.13)$ & $8.98(10.29)$ & $9.64(9.45)$ & NS & Education = comparator \\
\hline $\begin{array}{l}\text { Psychosocial di- } \\
\text { mension }\end{array}$ & $5.74(9.68)$ & $6.16(8.20)$ & $7.17(10.40)$ & NS & Education = comparator \\
\hline $\begin{array}{l}\text { Physical dimen- } \\
\text { sion }\end{array}$ & $8.27(10.02)$ & $8.98(9.33)$ & $9.65(10.19)$ & NS & Education = comparator \\
\hline
\end{tabular}

Note: analysis of these data was reported, but the individual results were not. These were obtained by contacting the author directly NS: No significant difference demonstrated

Education = Comparator: no significant difference $(P>0.05)$ in HRQoL between the education and the comparator groups at follow-up.

Education > Control: significant difference $(P \leq 0.05)$ in $\mathrm{HRQ}$ oL in favour of the education group at follow-up.

Comparator > Education: significant difference $(\mathrm{P} \leq 0.05)$ in $\mathrm{HRQ}$ oL in favour of the comparator group at follow-up.

Favours education: Available evidence favours the intervention group but direct statistical comparison between intervention and control groups was not reported.

Favours comparator: Available evidence favours the control group but direct statistical comparison between intervention and control groups was not reported.

Table 7. Summary of HRQoL scores at follow-up: Cohen 2014

\section{SF-12 (Short Form 12 item survey) at 6 months}

\begin{tabular}{llcll}
\hline & \multicolumn{2}{c}{ Mean (SD) outcome values at follow-up } & \multicolumn{1}{c}{$\begin{array}{l}\text { Between group } \\
\text { P value }\end{array}$} & Comparison \\
\cline { 2 - 5 } & Education & Comparator & 0.43 & Education = comparator \\
\hline $\begin{array}{l}\text { Mental component } \\
\text { summary }\end{array}$ & $47.5(11.2)$ & $47.7(11.2)$ & 0.44 & Education = comparator \\
\hline $\begin{array}{l}\text { Physical component } \\
\text { summary }\end{array}$ & $47.5(9.3)$ & $47.3(9.4)$ & & \\
\hline
\end{tabular}

Negative baseline-follow-up difference favours intervention and positive favours control

NS: No significant difference demonstrated

Education = Comparator: no significant difference $(P>0.05)$ in HRQoL between the education and the comparator groups at follow-up.

Education > Control: significant difference $(P \leq 0.05)$ in HRQoL in favour of the education group at follow-up.

Comparator > Education: significant difference $(\mathrm{P} \leq 0.05)$ in $\mathrm{HRQ}$ oL in favour of the comparator group at follow-up.

Favours education: Available evidence favours the intervention group but direct statistical comparison between intervention and control groups was not reported.

Favours comparator: Available evidence favours the control group but direct statistical comparison between intervention and control groups was not reported. 
Table 8. Summary of HRQoL scores at follow-up: Cupples 1994

\section{Nottingham Health Profile+ at 24 months}

\begin{tabular}{|c|c|c|c|}
\hline & $\begin{array}{l}\text { MD }(95 \% \mathrm{Cl}) \text { between groups in change } \\
\text { from baseline at follow-up }\end{array}$ & $\begin{array}{l}\text { Between group } P \\
\text { value }\end{array}$ & Comparison \\
\hline $\begin{array}{l}\text { Emotional reac- } \\
\text { tion }\end{array}$ & $0.0(-5.2$ to 5.2$)$ & NS & Education = comparator \\
\hline Energy & $0.5(-7.8$ to 8.8$)$ & NS & Education = comparator \\
\hline Physical mobility & $-0.4(-5.2$ to 4.5$)$ & NS & Education = comparator \\
\hline Pain & $0.5(-4.7$ to 5.6$)$ & NS & Education = comparator \\
\hline Sleep & $3.0(-4.0$ to 9.9$)$ & NS & Education = comparator \\
\hline Social isolation & $-2.2(-6.6$ to 2.1$)$ & $P<0.05$ & Education > comparator \\
\hline \multicolumn{4}{|c|}{ Nottingham Health Profile+ at 60 months } \\
\hline & $\begin{array}{l}\text { MD }(95 \% \mathrm{Cl}) \text { between groups in change } \\
\text { from baseline at follow-up }\end{array}$ & $\begin{array}{l}\text { Between group } P \\
\text { value }\end{array}$ & Comparison \\
\hline $\begin{array}{l}\text { Emotional reac- } \\
\text { tion }\end{array}$ & $-2.1(-7.5$ to 3.3$)$ & NS & Education = comparator \\
\hline Energy & $-4.7(-13.2$ to 3.7$)$ & NS & Education = comparator \\
\hline Physical mobility & $-1.3(-6.3$ to 3.6$)$ & $<0.05$ & Education > comparator \\
\hline Pain & $-3.4(-9.2$ to 2.3$)$ & $<0.05$ & Education > comparator \\
\hline Sleep & $-2.4(-9.3$ to 4.5$)$ & NS & Education = comparator \\
\hline Social isolation & $0.0(-4.3$ to 4.3$)$ & NS & Education = comparator \\
\hline
\end{tabular}

+ Higher scores reflect poorer quality of life

The value quoted is the mean difference (MD) $(\mathrm{Cl})$ between groups from baseline to follow-up

$P$ related to t-tests (two tailed)

NS: No significant difference demonstrated

Education = Comparator: no significant difference $(P>0.05)$ in HRQoL between the education and the comparator groups at follow-up.

Education > Control: significant difference $(P \leq 0.05)$ in HRQoL in favour of the education group at follow-up.

Comparator > Education: significant difference $(P \leq 0.05)$ in $\mathrm{HRQ}$ oL in favour of the comparator group at follow-up.

Favours education: Available evidence favours the intervention group but direct statistical comparison between intervention and control groups was not reported.

Favours comparator: Available evidence favours the control group but direct statistical comparison between intervention and control groups was not reported.

Table 9. Summary of HRQoL scores at follow-up: Cupples 1994

\section{Participant' self assessment of quality of life on a five-point scale at 24 months}

\begin{tabular}{lllll}
\hline $\begin{array}{l}\text { Initial scores } \\
\text { (\% participants) }\end{array}$ & $\begin{array}{l}\text { Follow-up scores } \\
\text { (\% participants) }\end{array}$ & $\begin{array}{l}\text { Between } \\
\text { group P } \\
\text { value }\end{array}$ \\
\cline { 2 - 5 } & Education & Comparator & Education & Comparator \\
\hline \hline
\end{tabular}


Table 9. Summary of HRQoL scores at follow-up: Cupples 1994 (Continued)

$\mathrm{P}<0.03 \quad \begin{aligned} & \text { Education }> \\ & \text { comparator }\end{aligned}$

\begin{tabular}{lllll}
\hline Poor & 6.3 & 5.3 & 6.9 & 8.3 \\
\hline Fair & 27.8 & 23.3 & 18.9 & 21.7 \\
\hline Average & 35 & 39 & 33.1 & 33.7 \\
\hline Good & 22.7 & 22.7 & 29.3 & 25.3 \\
\hline Very good & 8.2 & 9.7 & 11.7 & 11 \\
\hline
\end{tabular}

Note: the between group P value represents the overall "comparison of change in individuals' assessment for intervention and control groups" the significant difference being in favour of the intervention group

NS: No significant difference demonstrated

Education = Comparator: no significant difference $(P>0.05)$ in HRQoL between the education and the comparator groups at follow-up.

Education > Control: significant difference $(P \leq 0.05)$ in $\mathrm{HRQ}$ oL in favour of the education group at follow-up.

Comparator > Education: significant difference $(\mathrm{P} \leq 0.05)$ in $\mathrm{HRQ}$ oL in favour of the comparator group at follow-up.

Favours education: Available evidence favours the intervention group but direct statistical comparison between intervention and control groups was not reported.

Favours comparator: Available evidence favours the control group but direct statistical comparison between intervention and control groups was not reported.

Table 10. Summary of HRQoL scores at follow-up: Furuya 2014

\section{SF-12* (Short Form 12 item survey) at 6 months}

\begin{tabular}{|c|c|c|c|c|}
\hline & \multicolumn{2}{|c|}{ Mean (SD) outcome values at follow-up } & \multirow{2}{*}{$\begin{array}{l}\text { Between group } \\
\text { P value }\end{array}$} & \multirow[t]{2}{*}{ Comparison } \\
\hline & Education & Comparator & & \\
\hline $\begin{array}{l}\text { Mental component } \\
\text { summary }\end{array}$ & $51.7(9.5)$ & $48.4(9.2)$ & 0.73 & Education = comparator \\
\hline $\begin{array}{l}\text { Physical component } \\
\text { summary }\end{array}$ & $43.3(10.6)$ & $41.0(11.0)$ & 0.28 & Education = comparator \\
\hline
\end{tabular}

\section{SF-36* (Short Form 36 item survey)}

\begin{tabular}{|c|c|c|c|c|}
\hline & \multicolumn{2}{|c|}{ Mean (SD) outcome values at follow-up } & \multirow{2}{*}{$\begin{array}{l}\text { Between group } \\
\text { P value }\end{array}$} & \multirow[t]{2}{*}{ Comparison } \\
\hline & Education & Comparator & & \\
\hline Social functioning & $79.2(25.1)$ & $64.2(28.4)$ & 0.1 & Education = comparator \\
\hline Mental health & $70.9(22.7)$ & $70.1(19.1)$ & 0.98 & Education = comparator \\
\hline Physical functioning & $72.5(23.9)$ & $64.5(27.8)$ & 0.2 & Education = comparator \\
\hline General health & $66.1(19.8)$ & $63.9(20.0)$ & 0.61 & Education = comparator \\
\hline Vitality & $69.7(20.6)$ & $62.5(20.7)$ & 0.52 & Education = comparator \\
\hline Bodily pain & $63.8(28.5)$ & $55.7(24.2)$ & 0.22 & Education = comparator \\
\hline
\end{tabular}


Table 10. Summary of HRQoL scores at follow-up: Furuya 2014 (Continued)

\begin{tabular}{lllll} 
Role-emotional & $77.8(36.4)$ & $64.4(36.0)$ & 0.72 & Education = comparator \\
\hline Role-physical & $52.5(40.7)$ & $50.0(44.0)$ & 0.96 & Education = comparator \\
\hline
\end{tabular}

${ }^{*}$ Negative baseline - follow-up difference favours intervention; positive difference favours control

NS: No significant difference demonstrated

Education = Comparator: no significant difference $(P>0.05)$ in HRQoL between the education and the comparator groups at follow-up.

Education $>$ Control: significant difference $(P \leq 0.05)$ in $\mathrm{HRQ}$ oL in favour of the education group at follow-up.

Comparator > Education: significant difference $(P \leq 0.05)$ in $\mathrm{HRQ}$ oL in favour of the comparator group at follow-up.

Favours education: Available evidence favours the intervention group but direct statistical comparison between intervention and control groups was not reported.

Favours comparator: Available evidence favours the control group but direct statistical comparison between intervention and control groups was not reported.

Table 11. Summary of HRQoL scores at follow-up: Hanssen 2007

\section{SF-36* (Short Form 36 item survey) at 6 months}

\begin{tabular}{|c|c|c|c|}
\hline & $\begin{array}{l}\text { Between group difference in mean change } \\
\text { from baseline } \\
(95 \% \mathrm{Cl}) \text { at follow-up }\end{array}$ & $\begin{array}{l}\text { Between group } \mathbf{P} \\
\text { value }\end{array}$ & Comparison \\
\hline Overall physical & $-2.33(-4.54$ to -0.12$)$ & 0.039 & Education = comparator \\
\hline Physical functioning & $-1.16(-3.28$ to 0.95$)$ & 0.28 & Education = comparator \\
\hline Role physical & $-1.84(-5.32$ to 1.64$)$ & 0.299 & Education = comparator \\
\hline Bodily pain & $-1.74(-4.54$ to 1.05$)$ & 0.22 & Education = comparator \\
\hline General health & $-0.36(-2.64$ to 1.91$)$ & 0.752 & Education = comparator \\
\hline Overall mental & $1.07(-1.71$ to 3.86$)$ & 0.447 & Education = comparator \\
\hline Vitality & $-0.07(-2.23$ to 2.10$)$ & 0.951 & Education = comparator \\
\hline Social functioning & $0.36(-2.96$ to 3.67$)$ & 0.832 & Education = comparator \\
\hline Role-emotional & $0.78(-3.29$ to to 4.84$)$ & 0.706 & Education = comparator \\
\hline Mental health & $0.4(-1.81$ to 2.60$)$ & 0.723 & Education = comparator \\
\hline \multicolumn{4}{|c|}{ SF-36* (Short Form 36 item survey) at 18 months } \\
\hline & $\begin{array}{l}\text { Between group difference in mean change } \\
\text { from baseline } \\
(95 \% \mathrm{Cl}) \text { at follow-up }\end{array}$ & $\begin{array}{l}\text { Between group } P \\
\text { value }\end{array}$ & Comparison \\
\hline Overall physical & $-1.44(-3.89$ to 1.02$)$ & 0.25 & Education = comparator \\
\hline Physical functioning & $-0.79(-3.06$ to 1.48$)$ & 0.491 & Education = comparator \\
\hline Role physical & $-0.94(-4.76$ to 2.88$)$ & 0.627 & Education = comparator \\
\hline Bodily pain & $-0.77(-4.00$ to 2.47$)$ & 0.641 & Education = comparator \\
\hline
\end{tabular}


Table 11. Summary of HRQoL scores at follow-up: Hanssen 2007 (Continued)

\begin{tabular}{llll} 
General health & $0.25(-2.15$ to 2.64$)$ & 0.838 & Education = comparator \\
\hline Overall mental & $1.65(-1.35$ to 4.65$)$ & 0.28 & Education = comparator \\
\hline Vitality & $0.58(-1.95$ to 3.12$)$ & 0.65 & Education = comparator \\
\hline Social functioning & $0.55(-3.95$ to 2.85$)$ & 0.751 & Education $=$ comparator \\
\hline Role-emotional & $2.59(-1.58$ to 6.77$)$ & 0.221 & Education $=$ comparator
\end{tabular}

*Negative baseline - follow-up difference favours intervention; positive difference favours control NS: No significant difference demonstrated

Education = Comparator: no significant difference $(P>0.05)$ in HRQoL between the education and the comparator groups at follow-up.

Education $>$ Control: significant difference $(P \leq 0.05)$ in $\mathrm{HRQOL}$ in favour of the education group at follow-up.

Comparator > Education: significant difference $(P \leq 0.05)$ in $\mathrm{HRQ}$ oL in favour of the comparator group at follow-up.

Favours education: Available evidence favours the intervention group but direct statistical comparison between intervention and control groups was not reported.

Favours comparator: Available evidence favours the control group but direct statistical comparison between intervention and control groups was not reported.

Table 12. Summary of HRQoL scores at follow-up: Lie 2009

\section{Seattle Angina Questionnaire at 6 months}

\begin{tabular}{llllll}
\hline & \multicolumn{2}{c}{ Absolute mean (SD) outcome values at follow-up } & & Comparison \\
\cline { 2 - 5 } & Education & P value & Comparator & P value & \\
\hline Physical limitation & $86.4(15.6)$ & $\mathrm{P}<0.001$ & $83.2(18.7)$ & $\mathrm{P}<0.001$ & Education = comparator \\
\hline Angina frequency & $91.7(16.6)$ & $\mathrm{P}<0.001$ & $90.8(18.9)$ & $\mathrm{P}<0.001$ & Education = comparator \\
\hline $\begin{array}{l}\text { Treatment satis- } \\
\text { faction }\end{array}$ & $89.2(15.4)$ & $\mathrm{NS}$ & $88.0(16.1)$ & $\mathrm{NS}$ & Education = comparator \\
\hline $\begin{array}{l}\text { Disease percep- } \\
\text { tion }\end{array}$ & $77.8(20.2)$ & $\mathrm{P}<0.001$ & $73.9(24.2)$ & $\mathrm{P}<0.001$ & Education = comparator \\
\hline
\end{tabular}

SF-36 (Short Form 36 item survey) at 6 months

\begin{tabular}{llccll}
\hline & \multicolumn{2}{c}{ Absolute mean (SD) outcome values at follow-up } & Comparison \\
\cline { 2 - 5 } & Education & P value & Comparator & P value & \\
\hline Overall physical & $47.4(9.6)$ & $\mathrm{P}<0.001$ & $47(10)$ & $\mathrm{P}<0.001$ & Education = comparator \\
\hline $\begin{array}{l}\text { Physical function- } \\
\text { ing }\end{array}$ & $82.2(19.2)$ & $\mathrm{P}<0.001$ & $82.3(19.8)$ & $\mathrm{P}<0.001$ & Education = comparator \\
\hline Role physical & $64(41.2)$ & $\mathrm{P}<0.001$ & $57.2(43.3)$ & $\mathrm{P}<0.001$ & Education = comparator \\
\hline Bodily pain & $77.2(22.3)$ & $\mathrm{P}<0.001$ & $78.5(25.2)$ & $\mathrm{P}<0.001$ & Education = comparator \\
\hline
\end{tabular}


Table 12. Summary of HRQoL scores at follow-up: Lie 2009 (Continued)

\begin{tabular}{llllll} 
General health & $69.9(23.3)$ & $\mathrm{NS}$ & $65.7(27.2)$ & $\mathrm{NS}$ & Education $=$ comparator \\
\hline Overall mental & $52.1(10.7)$ & $\mathrm{P}<0.05$ & $50.5(10.8)$ & $\mathrm{NS}$ & Favours education \\
\hline Vitality & $61.9(23.9)$ & $\mathrm{P}<0.001$ & $60.5(21.6)$ & $\mathrm{P}<0.001$ & Education $=$ comparator \\
\hline Social functioning & $86.3(21.4)$ & $\mathrm{P}<0.001$ & $84.3(21.9)$ & $\mathrm{P}<0.001$ & Education = comparator \\
\hline Role- emotional & $73.3(38.2)$ & $\mathrm{P}<0.01$ & $67.4(41.6)$ & $\mathrm{P}<0.01$ & Education $=$ comparator \\
\hline Mental health & $81.9(17.3)$ & $\mathrm{P}<0.001$ & $78.5(21)$ & $\mathrm{P}<0.01$ & Education = comparator
\end{tabular}

Higher scores indicate better HRQoL

NS: No significant difference demonstrated

Education = Comparator: no significant difference $(P>0.05)$ in HRQoL between the education and the comparator groups at follow-up.

Education > Control: significant difference $(P \leq 0.05)$ in HRQoL in favour of the education group at follow-up.

Comparator > Education: significant difference $(P \leq 0.05)$ in $\mathrm{HRQOL}$ in favour of the comparator group at follow-up.

Favours education: Available evidence favours the intervention group but direct statistical comparison between intervention and control groups was not reported.

Favours comparator: Available evidence favours the control group but direct statistical comparison between intervention and control groups was not reported.

Table 13. Summary of HRQoL scores at follow-up: Lisspers 1999

\section{Angina Pectoris - Quality of Life Questionnaire (AP-QLQ) at 24 months}

\begin{tabular}{|c|c|c|c|c|}
\hline & \multicolumn{2}{|c|}{ Mean (SD) score at follow-up } & \multirow{2}{*}{$\begin{array}{l}\text { Between group } \\
P \text { value }\end{array}$} & \multirow[t]{2}{*}{ Comparison } \\
\hline & Education & Comparator & & \\
\hline QLQ (total) & $4.7(0.8)$ & $4.3(1.0)$ & NS & Education = comparator \\
\hline Somatic symptoms & $4.8(1.0)$ & $4.3(1.1)$ & NS & Education = comparator \\
\hline Physical activity & $4.8(1.0)$ & $4.1(1.2)$ & NS & Education = comparator \\
\hline Emotional distress & $4.8(0.8)$ & $4.6(1.1)$ & NS & Education = comparator \\
\hline Life satisfaction & $4.2(1.0)$ & $3.9(1.2)$ & NS & Education = comparator \\
\hline
\end{tabular}

Figures quoted represent absolute scores on a self-rating scale

NS: No significant difference demonstrated

Education = Comparator: no significant difference $(P>0.05)$ in HRQoL between the education and the comparator groups at follow-up.

Education > Control: significant difference $(P \leq 0.05)$ in HRQoL in favour of the education group at follow-up.

Comparator > Education: significant difference $(\mathrm{P} \leq 0.05)$ in $\mathrm{HRQ}$ L in favour of the comparator group at follow-up.

Favours education: Available evidence favours the intervention group but direct statistical comparison between intervention and control groups was not reported.

Favours comparator: Available evidence favours the control group but direct statistical comparison between intervention and control groups was not reported.

Table 14. Summary of HRQoL scores at follow-up: Melamed 2014

\section{MacNew Heart Disease Quality of Life Questionnaire (MacNew) at 220 days}


Table 14. Summary of HRQoL scores at follow-up: Melamed 2014 (Continued)

\begin{tabular}{lllll} 
& Mean (SD) outcome values at follow-up & Between group P & Comparison \\
\cline { 2 - 4 } & Education & Comparator & \\
\hline Rank sum & $5.75(0.87)$ & $5.74(0.83)$ & 0.056 & $\begin{array}{l}\text { Education = compara- } \\
\text { tor }\end{array}$ \\
\hline
\end{tabular}

NS: No significant difference demonstrated

Education = Comparator: no significant difference $(P>0.05)$ in HRQoL between the education and the comparator groups at follow-up.

Education > Control: significant difference $(P \leq 0.05)$ in HRQoL in favour of the education group at follow-up.

Comparator > Education: significant difference $(P \leq 0.05)$ in $\mathrm{HRQoL}$ in favour of the comparator group at follow-up.

Favours education: Available evidence favours the intervention group but direct statistical comparison between intervention and control groups was not reported.

Favours comparator: Available evidence favours the control group but direct statistical comparison between intervention and control groups was not reported.

Table 15. Summary of HRQoL scores at follow-up: Park 2013

\begin{tabular}{|c|c|c|c|c|}
\hline & \multicolumn{2}{|c|}{ Mean (SD) outcome values at follow-up } & \multirow{2}{*}{$\begin{array}{l}\text { Between group } \\
P \text { value }\end{array}$} & \multirow[t]{2}{*}{ Comparison } \\
\hline & Education & Comparator & & \\
\hline \multicolumn{5}{|l|}{ Physical symptoms } \\
\hline Physical limitation & $90.77(9.97)$ & $85.74(15.37)$ & 0.901 & Education = comparator \\
\hline Angina stability & $78.57(20.09)$ & $64.17(23.38)$ & 0.037 & Education > comparator \\
\hline Angina frequency & $94.29(7.90)$ & $89.33(14.84)$ & 0.543 & Education = comparator \\
\hline $\begin{array}{l}\text { Treatment satisfac- } \\
\text { tion }\end{array}$ & $86.38(12.15)$ & $73.13(16.09)$ & 0.021 & Education > comparator \\
\hline Diseases perception & $74.40(16.03)$ & $52.78(15.98)$ & 0.005 & Education > comparator \\
\hline
\end{tabular}

Higher scores indicate better HRQoL

NS: No significant difference demonstrated

Education = Comparator: no significant difference $(P>0.05)$ in HRQoL between the education and the comparator groups at follow-up.

Education > Control: significant difference $(P \leq 0.05)$ in HRQoL in favour of the education group at follow-up.

Comparator > Education: significant difference $(\mathrm{P} \leq 0.05)$ in $\mathrm{HRQ}$ oL in favour of the comparator group at follow-up.

Favours education: Available evidence favours the intervention group but direct statistical comparison between intervention and control groups was not reported.

Favours comparator: Available evidence favours the control group but direct statistical comparison between intervention and control groups was not reported.

Table 16. Summary of HRQoL scores at follow-up: Pogosova 2008

SF-36 (Short Form 36 item survey) at 12 months

Mean change from baseline $P$ value

Comparison

Education Comparator


Table 16. Summary of HRQoL scores at follow-up: Pogosova 2008 (Continued)

\begin{tabular}{llll} 
Overall physical & $\mathrm{P}>0.05$ & $\mathrm{P} \leq 0.05$ & Favours education \\
\hline Physical functioning & $\mathrm{P}>0.05$ & $\mathrm{P} \leq 0.05$ & Favours education \\
\hline Bodily pain & $\mathrm{P}>0.05$ & $\mathrm{P} \leq 0.05$ & Favours education \\
\hline Overall mental & $\mathrm{P}>0.05$ & $\mathrm{P} \leq 0.05$ & Favours education \\
\hline Vitality & $\mathrm{P}>0.05$ & $\mathrm{P} \leq 0.05$ & Favours education \\
\hline Social functioning & $\mathrm{P}>0.05$ & $\mathrm{P} \leq 0.05$ & Favours education \\
\hline Mental health & $\mathrm{P}>0.05$ & $\mathrm{P} \leq 0.05$ & \\
\hline
\end{tabular}

There were no significant changes demonstrated in the control group but no statistical comparison of the mean change between groups was reported

NS: No significant difference demonstrated

Education = Comparator: no significant difference $(P>0.05)$ in HRQoL between the education and the comparator groups at follow-up.

Education $>$ Control: significant difference $(P \leq 0.05)$ in $\mathrm{HRQ}$ oL in favour of the education group at follow-up.

Comparator > Education: significant difference $(\mathrm{P} \leq 0.05)$ in $\mathrm{HRQ}$ oL in favour of the comparator group at follow-up.

Favours education: Available evidence favours the intervention group but direct statistical comparison between intervention and control groups was not reported.

Favours comparator: Available evidence favours the control group but direct statistical comparison between intervention and control groups was not reported.

Table 17. Summary of HRQoL scores at follow-up: Tingström 2005

\section{SF-36* (Short Form 36 item survey) at 12 months}

\begin{tabular}{|c|c|c|c|c|}
\hline & \multicolumn{2}{|c|}{ Mean change from baseline (SD) } & \multirow{2}{*}{$\begin{array}{l}\text { Between group } \\
\text { P value }^{+}\end{array}$} & \multirow[t]{2}{*}{ Comparison } \\
\hline & Education & Comparator & & \\
\hline $\begin{array}{l}\text { Physical function- } \\
\text { ing }\end{array}$ & $3.6(17.6)$ & $4.4(15.1)$ & 0.749 & Education = comparator \\
\hline Role physical & $38.2(46.9)$ & $33.8(42.4)$ & 0.504 & Education = comparator \\
\hline Bodily pain & $5.69(31.1)$ & $6.18(29.1)$ & 0.911 & Education = comparator \\
\hline General health & $1.4(15.9)$ & $1.8(16.3)$ & 0.862 & Education = comparator \\
\hline Vitality & $5.3(22.7)$ & $4.9(21.8)$ & 0.921 & Education = comparator \\
\hline Social functioning & $9.7(24)$ & $9.1(25.3)$ & 0.869 & Education = comparator \\
\hline Role emotional & $15.8(48.1)$ & $16.5(41.1)$ & 0.913 & Education = comparator \\
\hline Mental health & $2.9(16.6)$ & $4.2(17.8)$ & 0.566 & Education = comparator \\
\hline
\end{tabular}

*Positive values indicate improvement in HRQL from baseline

$+P$ values are calculated on the difference between groups at pre-test and on the mean change (post test minus pre-test).

NS: No significant difference demonstrated

Education = Comparator: no significant difference $(P>0.05)$ in HRQoL between the education and the comparator groups at follow-up.

Education $>$ Control: significant difference $(P \leq 0.05)$ in $\mathrm{HRQOL}$ in favour of the education group at follow-up.

Comparator > Education: significant difference $(P \leq 0.05)$ in $H R Q o L$ in favour of the comparator group at follow-up. 
Favours education: Available evidence favours the intervention group but direct statistical comparison between intervention and control groups was not reported.

Favours comparator: Available evidence favours the control group but direct statistical comparison between intervention and control groups was not reported. 


\begin{tabular}{|c|c|c|c|c|c|c|c|c|}
\hline \multirow{2}{*}{$\begin{array}{l}\text { Variable } \\
\text { Follow-up }\end{array}$} & \multirow{2}{*}{$\begin{array}{l}\text { Clark } 2000 \\
24 \text { months }\end{array}$} & \multirow{2}{*}{$\begin{array}{l}\text { Cupples } 1994 \\
24 \text { months }\end{array}$} & \multicolumn{4}{|c|}{ Esposito 2008} & \multirow{2}{*}{$\begin{array}{l}\text { Southard } \\
2003 \\
6 \text { months }\end{array}$} & \multirow{2}{*}{$\begin{array}{l}\text { Peikes } 2009 \\
25 \text { months }\end{array}$} \\
\hline & & & 6 months & $\begin{array}{l}7 \text { to } 12 \\
\text { months }\end{array}$ & 12 months & 18 months & & \\
\hline Year & 2000 & NR & 2005 to 20 & & & & NR & 2002 to 2005 \\
\hline Currency & USD & GBP & USD & & & & USD & USD \\
\hline \multicolumn{9}{|c|}{ Mean cost of cardiac rehabilitation program per patient } \\
\hline Total costs & USD 187 & GBP 49.72 & USD 162 & & & & USD 453 & USD 196 \\
\hline $\begin{array}{l}\text { Costs con- } \\
\text { sidered }\end{array}$ & $\begin{array}{l}\text { Personnel, instructional ma- } \\
\text { terials, telephone supplies, } \\
\text { ongoing staff training }\end{array}$ & $\begin{array}{l}\text { Direct costs by health } \\
\text { visitors (staff time), } \\
\text { Travel Costs }\end{array}$ & \multicolumn{4}{|c|}{ Average monthly fee paid to the program per member } & $\begin{array}{l}\text { Nurse salary } \\
\text { Overheads } \\
\text { Subscrip- } \\
\text { tion costs }\end{array}$ & $\begin{array}{l}\text { Average month- } \\
\text { ly fee paid to } \\
\text { the program per } \\
\text { member }\end{array}$ \\
\hline Comments & $\begin{array}{l}\text { Participating site overheads } \\
\text { were not measured, a "con- } \\
\text { servatively high" estimate of } \\
\text { these was taken to double the } \\
\text { treatment cost to USD } 374\end{array}$ & $\begin{array}{l}\text { Costs of the health vis- } \\
\text { itor also included time } \\
\text { spent recording data } \\
\text { collection for the study }\end{array}$ & & & & & & $\begin{array}{l}\text { Cost varied } \\
\text { among the } 15 \text { in- } \\
\text { cluded studies. } \\
\text { Negotiated local- } \\
\text { ly with Medicare } \\
\text { and Medicaid } \\
\text { Services. (Range } \\
\text { USD } 50 \text { to USD } \\
444 \text { ) }\end{array}$ \\
\hline \multicolumn{9}{|c|}{ Mean total healthcare costs per patient } \\
\hline $\begin{array}{l}\text { Total cost } \\
\text { (interven- } \\
\text { tion) }\end{array}$ & USD 3300 (calc) & GBP 1801 & USD 1627 & USD 2356 & USD 2288 & USD 1793 & USD 635 & USD $1283^{*}$ \\
\hline $\begin{array}{l}\text { Total cost } \\
\text { (control) }\end{array}$ & USD $\sim 6500$ & GBP 1812 & USD 1632 & USD 2464 & USD 2372 & USD 1818 & USD 2053 & USD $1314^{\star}$ \\
\hline $\begin{array}{l}\text { Between } \\
\text { group dif- } \\
\text { ference }\end{array}$ & USD 1800* & GBP 9.60 & USD 5 & USD 107 & USD 84 & USD 25 & USD 1418 & $\begin{array}{l}\text { USD } 144 \\
\text { (80\% Cl } 99 \text { to } 188 \text { ) }\end{array}$ \\
\hline
\end{tabular}




\begin{tabular}{|c|c|c|c|c|c|c|c|c|}
\hline \multirow{2}{*}{ 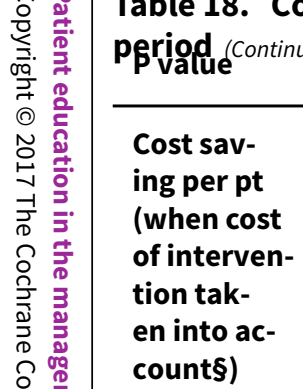 } & ${ }^{d)} \mathrm{NR}$ & \multirow{2}{*}{$\begin{array}{l}\text { NS } \\
\text { GBP } 40\end{array}$} & \multirow{2}{*}{$\frac{0.895}{\text { USD }-157}$} & \multirow{2}{*}{$\begin{array}{l}0.077 \\
\text { USD -55 }\end{array}$} & \multirow{2}{*}{$\frac{0.132}{\text { USD -78 }}$} & \multirow{2}{*}{$\begin{array}{l}0.365 \\
\text { USD }-137\end{array}$} & \multirow{2}{*}{$\begin{array}{l}\text { NR } \\
\text { USD } 965\end{array}$} & \multirow{2}{*}{$\begin{array}{l}<0.001 \\
\text { USD }-52\end{array}$} \\
\hline & $\begin{array}{l}\text { USD } \sim 1610 \text { or USD } \sim 1420 \text { if es- } \\
\text { timated overheads were in- } \\
\text { cluded }\end{array}$ & & & & & & & \\
\hline $\begin{array}{l}\text { Additional } \\
\text { healthcare } \\
\text { costs con- } \\
\text { sidered }\end{array}$ & $\begin{array}{l}\text { Number of admissions (heart } \\
\text { related), number of inpatient } \\
\text { days, In patient cost' emer- } \\
\text { gency department costs }\end{array}$ & $\begin{array}{l}\text { Prescription of drugs, } \\
\text { GP visits, visits to hos- } \\
\text { pital as inpatients and } \\
\text { outpatients, all tests } \\
\text { investigations and } \\
\text { treatments carried out }\end{array}$ & \multicolumn{4}{|c|}{ Medicare medical claims } & $\begin{array}{l}\text { Cardiovas- } \\
\text { cular-relat- } \\
\text { ed emer- } \\
\text { gency de- } \\
\text { partment } \\
\text { visits and } \\
\text { hospitalisa- } \\
\text { tions }\end{array}$ & \\
\hline Comments & $\begin{array}{l}\text { Expenditure was calculated } \\
\text { from differences in } \% \text { utilisa- } \\
\text { tion of hospital services. i.e. } \\
\text { hospital charges for partici- } \\
\text { pants were on average } 49 \% \\
\text { lower and the average annual } \\
\text { expenditure was USD } 6500 . \\
\text { * There was a calculated sav- } \\
\text { ing of a hospital charge of } \\
\text { USD } 3200 \text {, the ratio of pay- } \\
\text { ments to charges was } 0.56 \\
\text { therefore USD } 1800 \text { actual } \\
\text { saving }\end{array}$ & $\begin{array}{l}\text { There was a difference } \\
\text { in the drug usage at } \\
\text { baseline which is not } \\
\text { accounted for in these } \\
\text { figures although this } \\
\text { would make minimal } \\
\text { impact to the results. } \\
\text { The intervention group } \\
\text { were more costly for } \\
\text { drugs, procedures and } \\
\text { service use }\end{array}$ & \multicolumn{4}{|c|}{ Claims quoted are per member per month } & & $\begin{array}{l}{ }^{\star} \text { Expenditure/pt/ } \\
\text { month enrolled } \\
\text { Overall costs } \\
\text { were increased } \\
\text { by } 11 \% \text { when the } \\
\text { care coordination } \\
\text { fees were taken } \\
\text { into account }\end{array}$ \\
\hline $\begin{array}{l}\text { Summary } \\
\text { difference } \\
\text { between } \\
\text { groups }\end{array}$ & Favours Rx & $\mathrm{Rx}=$ Control & \multicolumn{4}{|c|}{$\mathrm{Rx}=$ control (for all time periods studied) } & Favours Rx & Favours control \\
\hline
\end{tabular}

$\S=$ Negative mean difference indicates a net cost of the intervention group

$\mathrm{NR}=$ not recorded

$\mathrm{NS}=$ not significant 
Table 19. Results of univariate meta-regression analysis for total mortality

\begin{tabular}{|c|c|c|c|c|}
\hline Explanatory variable (n trials) & Exp(slope)* & $\begin{array}{l}95 \% \mathrm{Cl} \text { univari- } \\
\text { ate; } \\
\mathrm{P} \text { value }\end{array}$ & $\begin{array}{l}\text { Proportion of } \\
\text { variation ex- } \\
\text { plained }\end{array}$ & Interpretation \\
\hline $\begin{array}{l}\text { Case mix ( } \% \text { myocardial infarc- } \\
\text { tion patients) }(n=11)\end{array}$ & $\mathrm{RR}=1.004$ & $\begin{array}{l}0.988 \text { to } 1.020 \\
P=0.631\end{array}$ & $-190.36 \%$ & $\begin{array}{l}\text { No evidence that RR is associated } \\
\text { with case mix }\end{array}$ \\
\hline Age of participants $(n=13)$ & $\mathrm{RR}=1.005$ & $\begin{array}{l}0.940 \text { to } 1.074 \\
P=0.876\end{array}$ & $-28.26 \%$ & $\begin{array}{l}\text { No evidence that RR is associated } \\
\text { with the age of participants }\end{array}$ \\
\hline $\begin{array}{l}\text { Percentage of male participants } \\
(n=13)\end{array}$ & $\mathrm{RR}=0.991$ & $\begin{array}{l}0.986 \text { to } 1.012 \\
P=0.882\end{array}$ & $-25.27 \%$ & $\begin{array}{l}\text { No evidence that RR is associated } \\
\text { with the percentage of male partici- } \\
\text { pants }\end{array}$ \\
\hline $\begin{array}{l}\text { Type of CR (education only vs. } \\
\text { education plus e.g. exercise or } \\
\text { psychological intervention) ( } n= \\
\text { 13) }\end{array}$ & $\mathrm{RR}=0.181$ & $\begin{array}{l}0.014 \text { to } 2.321 \\
P=0.168\end{array}$ & $28.25 \%$ & $\begin{array}{l}\text { No evidence that RR is associated } \\
\text { with type of } C R\end{array}$ \\
\hline $\begin{array}{l}\text { Method of structured educa- } \\
\text { tional delivery (one-to-one vs. } \\
\text { group versus combination) ( } \mathrm{n}= \\
\text { 13) }\end{array}$ & $\mathrm{RR}=1.010$ & $\begin{array}{l}0.728 \text { to } 1.401 \\
\mathrm{P}=0.948\end{array}$ & $-28.28 \%$ & $\begin{array}{l}\text { No evidence that RR is associated } \\
\text { with method of delivery }\end{array}$ \\
\hline Duration of intervention $(n=12)$ & $\mathrm{RR}=0.978$ & $\begin{array}{l}0.948 \text { to } 1.010 \mathrm{P}= \\
0.152\end{array}$ & $3.69 \%$ & $\begin{array}{l}\text { No evidence that RR is associated } \\
\text { with duration of intervention }\end{array}$ \\
\hline $\begin{array}{l}\text { Theoretical vs. no theoretical } \\
\text { basis to educational interven- } \\
\text { tion }(n=13)\end{array}$ & $\mathrm{RR}=1.473$ & $\begin{array}{l}0.750 \text { to } 2.895 \\
P=0.233\end{array}$ & $-0.31 \%$ & $\begin{array}{l}\text { No evidence that RR is associated } \\
\text { with theoretical basis }\end{array}$ \\
\hline $\begin{array}{l}\text { Involvement of significant oth- } \\
\text { ers (e.g. spouse, family mem- } \\
\text { ber) in the education pro- } \\
\text { gramme }(n=13)\end{array}$ & $\mathrm{RR}=1.245$ & $\begin{array}{l}0.890 \text { to } 1.722 \mathrm{P}= \\
0.166\end{array}$ & $7.06 \%$ & $\begin{array}{l}\text { No evidence that RR is associated } \\
\text { with family involvement }\end{array}$ \\
\hline Study location $(n=13)$ & $\mathrm{RR}=1.050$ & $\begin{array}{l}0.714 \text { to } 1.543 \\
P=0.787\end{array}$ & $-59.78 \%$ & $\begin{array}{l}\text { No evidence that risk ratio is associ- } \\
\text { ated with study location }\end{array}$ \\
\hline $\begin{array}{l}\text { Setting (centre vs. home) }(n= \\
\text { 13) }\end{array}$ & $\mathrm{RR}=1.171$ & $\begin{array}{l}0.773 \text { to } 1.774 \\
P=0.421\end{array}$ & $-44.55 \%$ & $\begin{array}{l}\text { No evidence that RR is associated } \\
\text { with centre status }\end{array}$ \\
\hline Length of follow-up ( $n=13$ ) & $\mathrm{RR}=0998$ & $\begin{array}{l}0.964 \text { to } 1.033 \\
P=0.924\end{array}$ & $-22.64 \%$ & $\begin{array}{l}\text { No evidence that RR is associated } \\
\text { with length of follow-up }\end{array}$ \\
\hline
\end{tabular}

CR - cardiac rehabilitation; RR - risk ratio

Table 20. Results of univariate meta-regression analysis for withdrawal

\begin{tabular}{lllll}
\hline Explanatory variable (n trials) & Exp(slope) & $\begin{array}{l}\mathbf{9 5 \%} \mathbf{C l} \text { univari- } \\
\text { ate } \mathbf{P} \text { value }\end{array}$ & $\begin{array}{l}\text { Proportion of } \\
\text { variation ex- } \\
\text { plained }\end{array}$ & Interpretation \\
\hline $\begin{array}{l}\text { Case mix }(\% \text { myocardial infarc- } \\
\text { tion patients) }(\mathrm{n}=12)\end{array}$ & $\mathrm{RR}=1.002$ & $\begin{array}{l}0.992 \text { to } 1.013 \\
\mathrm{P}=0.611\end{array}$ & $-9.25 \%$ & $\begin{array}{l}\text { No evidence that RR is associated } \\
\text { with case mix }\end{array}$ \\
\hline
\end{tabular}


Table 20. Results of univariate meta-regression analysis for withdrawal (Continued)

\begin{tabular}{|c|c|c|c|c|}
\hline Age of participants $(n=17)$ & $\mathrm{RR}=0.998$ & $\begin{array}{l}0.963 \text { to } 1.034 \\
P=0.903\end{array}$ & $-15.62 \%$ & $\begin{array}{l}\text { No evidence that RR is associated } \\
\text { with the age of participants }\end{array}$ \\
\hline $\begin{array}{l}\text { Percentage of male participants } \\
(n=17)\end{array}$ & $\mathrm{RR}=0.999$ & $\begin{array}{l}0.992 \text { to } 1.005 \\
P=0.621\end{array}$ & $-28.64 \%$ & $\begin{array}{l}\text { No evidence that RR is associated } \\
\text { with the percentage of male partici- } \\
\text { pants }\end{array}$ \\
\hline $\begin{array}{l}\text { Type of CR (education only vs. } \\
\text { education plus e.g. exercise or } \\
\text { psychological intervention) ( } n= \\
\text { 17) }\end{array}$ & $\mathrm{RR}=0.752$ & $\begin{array}{l}0.260 \text { to } 2.174 \\
P=0.575\end{array}$ & $-16.99 \%$ & $\begin{array}{l}\text { No evidence that RR is associated } \\
\text { with type of } C R\end{array}$ \\
\hline $\begin{array}{l}\text { Method of structured educa- } \\
\text { tional delivery (one-to-one vs. } \\
\text { group versus combination) ( } \mathrm{n}= \\
\text { 17) }\end{array}$ & $\mathrm{RR}=1.033$ & $\begin{array}{l}0.860 \text { to } 1.242 \\
P=0.714\end{array}$ & $-29.18 \%$ & $\begin{array}{l}\text { No evidence that mortality risk is as- } \\
\text { sociated with method of delivery }\end{array}$ \\
\hline Duration of intervention $(n=16)$ & $\mathrm{RR}=0.993$ & $\begin{array}{l}0.964 \text { to } 1.023 \\
P=0.625\end{array}$ & $-25.06 \%$ & $\begin{array}{l}\text { No evidence that mortality risk is as- } \\
\text { sociated with duration of interven- } \\
\text { tion }\end{array}$ \\
\hline $\begin{array}{l}\text { Theoretical vs. no theoretical } \\
\text { basis to educational interven- } \\
\text { tion }(n=17)\end{array}$ & $\mathrm{RR}=1.031$ & $\begin{array}{l}0.690 \text { to } 1.541 \\
P=0.874\end{array}$ & $-24.70 \%$ & $\begin{array}{l}\text { No evidence that RR is associated } \\
\text { with theoretical basis }\end{array}$ \\
\hline $\begin{array}{l}\text { Involvement of significant oth- } \\
\text { ers (e.g. spouse, family mem- } \\
\text { ber) in the education }(n=17)\end{array}$ & $\mathrm{RR}=1.016$ & $\begin{array}{l}0.829 \text { to } 1.245 \\
P=0.872\end{array}$ & $-33.62 \%$ & $\begin{array}{l}\text { No evidence that RR is associated } \\
\text { with family involvement }\end{array}$ \\
\hline Study location $(n=17)$ & $\mathrm{RR}=0.942$ & $\begin{array}{l}0.801 \text { to } 1.109 \\
P=0.449\end{array}$ & $24.47 \%$ & $\begin{array}{l}\text { No evidence that RR is associated } \\
\text { with study location }\end{array}$ \\
\hline $\begin{array}{l}\text { Setting (centre vs. home) }(n= \\
17)\end{array}$ & $\mathrm{RR}=1.096$ & $\begin{array}{l}0.873 \text { to } 1.374 \\
P=0.404\end{array}$ & $-13.38 \%$ & $\begin{array}{l}\text { No evidence that RR is associated } \\
\text { with centre status }\end{array}$ \\
\hline Length of follow-up $(n=17)$ & $\mathrm{RR}=0.976$ & $\begin{array}{l}0.955 \text { to } 0.998 \\
P=0.035\end{array}$ & $90.79 \%$ & $\begin{array}{l}\text { Significant evidence that risk of } \\
\text { withdrawal is increased in studies } \\
\text { with a shorter follow-up }\end{array}$ \\
\hline
\end{tabular}

CR - cardiac rehabilitation; RR - risk ratio

Table 21. Results of sensitivity analysis for total mortality

\begin{tabular}{|c|c|c|c|c|}
\hline $\begin{array}{l}\text { Explanatory variable ( } \mathrm{n} \text { tri- } \\
\text { als) }\end{array}$ & $\operatorname{Exp}(\text { slope })^{\star}$ & $\begin{array}{l}95 \% \mathrm{Cl} \text { univariate } \\
\mathrm{P} \text { value }\end{array}$ & $\begin{array}{l}\text { Proportion of } \\
\text { variation ex- } \\
\text { plained }\end{array}$ & Interpretation \\
\hline Year of publication $(n=13)$ & $\mathrm{RR}=0.998$ & $\begin{array}{l}0.950 \text { to } 1.047 \\
P=0.913\end{array}$ & $-61.7 \%$ & $\begin{array}{l}\text { No evidence that RR is associated } \\
\text { with year of publication }\end{array}$ \\
\hline $\begin{array}{l}\text { Risk of bias (low risk in } \geq 5 \\
\text { items vs. }<5 \text { items) }(n=13)\end{array}$ & $\mathrm{RR}=1.105$ & $\begin{array}{l}0.421 \text { to } 3.831 \\
P=2.899\end{array}$ & $-84.29 \%$ & $\begin{array}{l}\text { No evidence that RR is associated } \\
\text { with risk of bias }\end{array}$ \\
\hline
\end{tabular}

RR - risk ratio 
Table 22. Results of sensitivity analysis for withdrawal

\begin{tabular}{lllll}
\hline Explanatory variable (n trials) & Exp(slope) & $\begin{array}{l}\text { 95\% Cl univari- } \\
\text { ate } \mathbf{P} \text { value }\end{array}$ & $\begin{array}{l}\text { Proportion of } \\
\text { variation ex- } \\
\text { plained }\end{array}$ & Interpretation \\
\hline $\begin{array}{l}\text { Year of publication (before } 2000 \\
\text { vs. } 2000 \text { or later) }(\mathrm{n}=17)\end{array}$ & $\mathrm{RR}=1.017$ & $\begin{array}{l}0.982 \text { to } 1.052 \\
\mathrm{P}=0.327\end{array}$ & $-7.02 \%$ & $\begin{array}{l}\text { No evidence that RR is associated } \\
\text { with year of publication }\end{array}$ \\
\hline $\begin{array}{l}\text { Risk of bias (low risk in } \geq 5 \text { items } \\
\text { vs. }<5 \text { items) }(\mathrm{n}=17)\end{array}$ & $\mathrm{RR}=1.437$ & $\begin{array}{l}1.069 \text { to } 1.931 \\
\mathrm{P}=0.020\end{array}$ & $15.35 \%$ & $\begin{array}{l}\text { Significant evidence that risk of } \\
\text { withdrawal is increased in studies } \\
\text { with higher risk of bias }\end{array}$ \\
\hline
\end{tabular}

\section{AP PE N DICES}

\section{Appendix 1. Search strategies}

\section{CENTRAL}

\#1 MeSH descriptor: [Myocardial Infarction] explode all trees

\#2 myocardial infarct*:ti,ab,kw (Word variations have been searched)

\#3 MeSH descriptor: [Angina Pectoris] explode all trees

\#4 angina pectoris:ti,ab,kw (Word variations have been searched)

\#5 angor pectoris:ti,ab,kw (Word variations have been searched)

\#6 stenocardia*:ti,ab,kw (Word variations have been searched)

\#7 coronary artery bypass*:ti,ab,kw (Word variations have been searched)

\#8 CABG:ti,ab,kw (Word variations have been searched)

\#9 aortocoronary bypass ${ }^{*}$ :ti,ab,kw (Word variations have been searched)

\#10 (coronary near/3 angioplast ${ }^{\star}$ ):ti,ab,kw (Word variations have been searched)

\#11 PTCA:ti,ab,kw (Word variations have been searched)

\#12 (coronary near/2 dilatation*):ti,ab,kw (Word variations have been searched)

\#13 MeSH descriptor: [Coronary Disease] explode all trees

\#14 (coronary near/2 disease*):ti,ab,kw (Word variations have been searched)

\#15 MeSH descriptor: [Myocardial Revascularization] explode all trees

\#16 coronary artery stent*:ti,ab,kw (Word variations have been searched)

\#17 MeSH descriptor: [Percutaneous Coronary Intervention] explode all trees

\#18 (percutaneous coronary near/2 (interven* or revascular $\left.{ }^{\star}\right)$ ):ti,ab,kw (Word variations have been searched)

\#19 MeSH descriptor: [Angioplasty] explode all trees

\#20 angioplast* :ti,ab,kw (Word variations have been searched)

\#21 ((coronary or arterial) near/4 dilat*):ti,ab,kw (Word variations have been searched)

\#22 endoluminal repair*:ti,ab,kw (Word variations have been searched) 
\#23 MeSH descriptor: [Stents] explode all trees

\#24 stent*:ti,ab,kw (Word variations have been searched)

\#25 (pci or ptca):ti,ab,kw (Word variations have been searched)

\#26 Atherectomy:ti,ab,kw (Word variations have been searched)

\#27 atherectom*:ti,ab,kw (Word variations have been searched)

\#28 acute coronary syndrom*:ti,ab,kw (Word variations have been searched)

$\# 29 \# 1$ or \#2 or \#3 or \#4 or \#5 or \#6 or \#7 or \#8 or \#9 or \#10 or \#11 or \#12 or \#13 or \#14 or \#15 or \#16 or \#17 or \#18 or \#19 or \#20 or \#21 or $\# 22$ or \#23 or \#24 or \#25 or \#26 or \#27 or \#28

\#30 MeSH descriptor: [Patient Education as Topic] this term only

\#31 MeSH descriptor: [Health Education] this term only

\#32 MeSH descriptor: [Telemedicine] this term only

\#33 (patient ${ }^{\star}$ near/6 (educat* or communicat $^{\star}$ or interacti ${ }^{\star}$ or inform ${ }^{\star}$ or advi $\left.{ }^{\star}\right)$ ):ti,ab,kw (Word variations have been searched)

\#34 (educat* near/6 (intervention* or rehabilation* or program)):ti,ab,kw (Word variations have been searched)

\#35 (education near/6 (service* or group* or program or session*)):ti,ab,kw (Word variations have been searched)

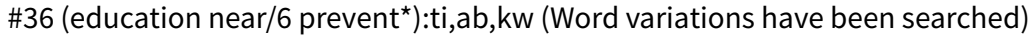

\#37 ((rehabilitati* or educat $^{\star}$ ) near/6 (literature or audiovisual or av or audio visual or internet or web* or telecare or telemedicine or telephone* or phone $^{\star}$ or teleconference* or telehealth or transtelephonic* or podcast* ${ }^{\star}$ or email* or e-mail $\left.\left.{ }^{\star}\right)\right)$ :ti,ab,kw (Word variations have been searched)

\#38 ((educat* or intervent $\left.^{\star}\right)$ near/6 (communit* or famil $^{\star}$ or spouse* or nurs $\left.\left.{ }^{\star}\right)\right):$ ti,ab,kw (Word variations have been searched)

\#39 \#30 or \#31 or \#32 or \#33 or \#34 or \#35 or \#36 or \#37 or \#38

\#40 \#29 and \#39 Publication Year from 2010 to 2016

\section{MEDLINE}

1 exp Myocardial Infarction/ (153085)

2 myocardial infarct ${ }^{\star}$. tw. $(146020)$

3 exp Angina Pectoris/ (48551)

4 angina pectoris.tw. (16788)

5 angor pectoris.tw. (37)

6 stenocardia*.tw. (929)

7 coronary artery bypass ${ }^{\star}$. tw. (30408)

8 CABG.tw. (12609)

9 aortocoronary bypass ${ }^{\star}$. tw. $(2354)$

10 (coronary adj3 angioplast ${ }^{\star}$ ).tw. (13556)

11 PTCA.tw. (6101)

12 (coronary adj2 dilatation $\left.{ }^{\star}\right) . t w .(565)$

13 exp Coronary Disease/ (189971)

14 (coronary adj2 disease $\left.{ }^{\star}\right) . t w . ~(108936)$ 
15 exp Myocardial Revascularization/ (82266)

16 coronary artery stent*..tw. (870)

17 exp Percutaneous Coronary Intervention/ (38918)

18 (percutaneous coronary adj2 (interven* or revascular $\left.{ }^{\star}\right)$ ).tw. (17683)

19 exp Angioplasty/ (56065)

20 angioplast ${ }^{\star}$.tw. (36109)

21 ((coronary or arterial) adj4 dilat*).tw. (4567)

22 endoluminal repair ${ }^{\star}$.tw. (207)

23 exp Stents/ (57098)

24 stent $^{\star}$. tw. (63468)

25 (pci or ptca).tw. (19345)

26 exp Atherectomy/ (2017)

27 atherectom ${ }^{\star}$.tw. (2227)

28 acute coronary syndrom ${ }^{\star}$.tw. (18048)

29 or/1-28 (503551)

30 Patient Education as Topic/ (72978)

31 Health Education/ (53706)

32 Telemedicine/ (12531)

33 (patient $^{\star}$ adj6 (educat ${ }^{\star}$ or communicat ${ }^{\star}$ or interacti $^{\star}$ or inform $^{\star}$ or advi $\left.^{\star}\right)$ ).tw. (133035)

34 (educat* adj6 (intervention* or rehabilation* or program*)).tw. (54507)

35 (education adj6 (service* or group ${ }^{\star}$ or program* or session $\left.\left.{ }^{\star}\right)\right)$. tw. (43822)

36 (education adj6 prevent $\left.{ }^{\star}\right)$.tw. (7681)

37 ((rehabilitati* ${ }^{*}$ r educat $\left.{ }^{\star}\right)$ adj6 (literature or audiovisual or av or audio visual or internet or web* or telecare or telemedicine or telephone* or phone $e^{\star}$ or teleconference ${ }^{\star}$ or telehealth or transtelephonic ${ }^{\star}$ or podcast* or email $^{\star}$ or e-mail*)).tw. (6087)

38 ((educat $^{\star}$ or intervent $\left.{ }^{\star}\right)$ adj6 (communit* or famil $^{\star}$ or spouse or nurs $\left.\left.^{\star}\right)\right) . t w$. (71758)

39 or/30-38 (354368)

40 randomized controlled trial.pt. (404415)

41 controlled clinical trial.pt. (91176)

42 randomized.ab. (297250)

43 placebo.ab. (155316)

44 drug therapy.fs. (1811236)

45 randomly.ab. (210643)

46 trial.ab. (308679)

47 groups.ab. (1332430)

4840 or 41 or 42 or 43 or 44 or 45 or 46 or 47 (3410956) 
49 exp animals/ not humans.sh. (4078149)

5048 not $49(2906978)$

5129 and 39 and 50 (3534)

$52\left(20108^{\star}\right.$ or $201009^{\star}$ or $201010^{\star}$ or $201011^{\star}$ or $201012^{\star}$ or $2011^{\star}$ or $2012^{\star}$ or $2013^{\star}$ or $2014^{\star}$ or $2015^{\star}$ or $\left.2016^{\star}\right)$. ed. (3869988)

5351 and $52(804)$

\section{Embase}

1 exp Myocardial Infarction/ (281562)

2 myocardial infarct ${ }^{\star}$. tw. (199379)

3 exp Angina Pectoris/ (78516)

4 angina pectoris.tw. (20262)

5 angor pectoris.tw. (54)

6 stenocardia*.tw. (836)

7 coronary artery bypass ${ }^{\star}$.tw. (40577)

8 CABG.tw. (22875)

9 aortocoronary bypass ${ }^{\star}$.tw. (2231)

10 (coronary adj3 angioplast ${ }^{\star}$ ).tw. (16678)

11 PTCA.tw. (7865)

12 (coronary adj2 dilatation*).tw. (725)

13 exp Coronary Disease/ (239803)

14 (coronary adj2 disease ${ }^{\star}$ ).tw. (154969)

15 exp Myocardial Revascularization/ (23708)

16 coronary artery stent ${ }^{\star}$.tw. (1348)

17 exp Percutaneous Coronary Intervention/ (67150)

18 (percutaneous coronary adj2 (interven* or revascular $\left.{ }^{\star}\right)$ ).tw. (33814)

19 exp Angioplasty/ (70172)

20 angioplast*.tw. (49254)

21 ((coronary or arterial) adj4 dilat*).tw. (5705)

22 endoluminal repair ${ }^{\star}$.tw. (245)

23 exp Stents/ (114572)

24 stent $^{\star}$.tw. $(109268)$

25 (pci or ptca).tw. (40833)

26 exp Atherectomy/ (3792)

27 atherectom ${ }^{\star}$.tw. (3109)

28 acute coronary syndrom*.tw. (33277)

29 or/1-28 (720658) 
30 Patient Education as Topic/ (91427)

31 Health Education/ (79681)

32 Telemedicine/ (13152)

33 (patient ${ }^{\star}$ adj6 (educat ${ }^{\star}$ or communicat ${ }^{\star}$ or interacti* or inform $^{\star}$ or advi $\left.{ }^{\star}\right)$ ).tw. (218886)

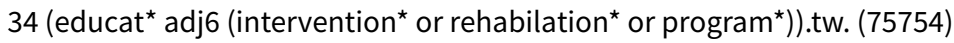

35 (education adj6 (service* or group ${ }^{\star}$ or program* or session $\left.\left.{ }^{\star}\right)\right)$. tw. (60070)

36 (education adj6 prevent ${ }^{\star}$ ).tw. (10354)

37 ((rehabilitati* or educat $^{\star}$ ) adj6 (literature or audiovisual or av or audio visual or internet or web* or telecare or telemedicine or telephone* or phone or teleconference $^{\star}$ or telehealth or transtelephonic* or podcast* or email ${ }^{\star}$ or e-mail*)).tw. (9451)

38 ((educat ${ }^{\star}$ or intervent $\left.{ }^{\star}\right)$ adj6 (communit* or famil $^{\star}$ or spouse $^{\star}$ or nurs $\left.\left.^{\star}\right)\right)$.tw. (90582)

39 or/30-38 (505428)

40 random\$.tw. (986880)

41 factorial\$.tw. (25324)

42 crossover\$.tw. (52424)

43 cross over\$.tw. (23038)

44 cross-over\$.tw. (23038)

45 placebo\$.tw. (216471)

46 (doubl\$ adj blind\$).tw. (152174)

47 (singl\$ adj blind\$).tw. (15997)

48 assign\$.tw. (263111)

49 allocat\$.tw. (94003)

50 volunteer\$.tw. (189353)

51 crossover procedure/ (43468)

52 double blind procedure/ (121614)

53 randomized controlled trial/ (376146)

54 single blind procedure/ (20516)

5540 or 41 or 42 or 43 or 44 or 45 or 46 or 47 or 48 or 49 or 50 or 51 or 52 or 53 or 54 (1555250)

56 (animal/ or nonhuman/) not human/ (4831248)

5755 not $56(1374700)$

5829 and 39 and 57 (2796)

$59\left(20108^{\star}\right.$ or $201009^{\star}$ or $201010^{\star}$ or $201011^{\star}$ or $201012^{\star}$ or $2011^{\star}$ or $2012^{\star}$ or $2013^{\star}$ or $2014^{\star}$ or $2015^{\star}$ or $\left.2016^{\star}\right)$. dd. $(7210311)$

6058 and 59 (1249)

61 limit 60 to embase (1113)

\section{PsycINFO}

1 exp Myocardial Infarction/ (2478) 
2 myocardial infarct $^{\star}$.tw. (3655)

3 exp Angina Pectoris/ (274)

4 angina pectoris.tw. (331)

5 angor pectoris.tw. (0)

6 stenocardia*.tw. (8)

7 coronary artery bypass ${ }^{\star}$. tw. $(740)$

8 CABG.tw. (375)

9 aortocoronary bypass ${ }^{\star}$. tw. (8)

10 (coronary adj3 angioplast $^{\star}$ ).tw. (106)

11 PTCA.tw. (51)

12 (coronary adj2 dilatation*).tw. (2)

13 (coronary adj2 disease ${ }^{\star}$ ).tw. (5470)

14 coronary artery stent ${ }^{\star}$. tw. (3)

15 (percutaneous coronary adj2 (interven* or revascular*)).tw. (146)

16 angioplast ${ }^{\star}$. tw. (299)

17 ((coronary or arterial) adj4 dilat*).tw. (46)

18 endoluminal repair ${ }^{\star}$.tw. (0)

19 exp Stents/ (0)

20 stent $^{\star}$. tw. (370)

21 (pci or ptca).tw. (499)

$22 \exp$ Atherectomy/ (0)

23 atherectom ${ }^{\star}$.tw. (0)

24 acute coronary syndrom*.tw. (410)

25 Health Education/ (10509)

26 Telemedicine/ (2882)

27 (patient $^{\star}$ adj6 (educat* or communicat* or interacti* or inform ${ }^{\star}$ or advi $\left.{ }^{\star}\right)$ ).tw. (38816)

28 (educat* ${ }^{\star}$ adj6 (intervention* or rehabilation* or program*)).tw. (51901)

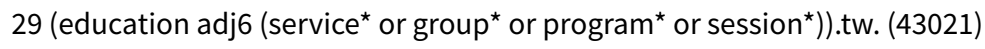

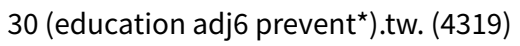

31 ((rehabilitati ${ }^{\star}$ or educat $^{\star}$ ) adj6 (literature or audiovisual or av or audio visual or internet or web ${ }^{\star}$ or telecare or telemedicine or telephone* or phone ${ }^{\star}$ or teleconference ${ }^{\star}$ or telehealth or transtelephonic ${ }^{\star}$ or podcast $^{\star}$ or email ${ }^{\star}$ or e-mail $\left.\left.{ }^{\star}\right)\right)$.tw. (8262)

32 ((educat ${ }^{\star}$ or intervent $\left.{ }^{\star}\right) \operatorname{adj6}\left(\right.$ communit* $^{\star}$ or famil ${ }^{\star}$ or spouse or nurs $\left.\left.^{\star}\right)\right)$. tw. $(54258)$

33 or/25-32 (161409)

34 or/1-24 (10643)

35 random\$.tw. (144014) 
36 factorial\$.tw. (15416)

37 crossover $\$ . t w . ~(5725)$

38 cross-over\$.tw. (2130)

39 placebo\$.tw. (33120)

40 (doubl\$ adj blind\$).tw. (19491)

41 (singl\$ adj blind\$).tw. (1662)

42 assign\$.tw. (75187)

43 allocat\$.tw. (22136)

44 volunteer\$.tw. (31178)

45 control $^{*}$.tw. (528436)

46 "2000".md. (30342)

47 or/35-46 (712946)

4833 and 34 and 47 (297)

49 limit 48 to $y r=" 2010$-Current" (102)

\section{CINAHL}

S58 S40 AND S57 Limiters - Published Date: 20100801-20160510

S57 S41 or S42 or S43 or S44 or S45 or S46 or S47 or S48 or S49 or S50 or S51 or S52 or S53 or S54 or S55 or S56 or S57

S56 TX cross-over*

S55 TX crossover*

S54 TX volunteer*

S53 (MH "Crossover Design")

S52 TX allocat*

S51 TX control*

S50 TX assign*

S49 (MH "Placebos")

S48 TX random*

S47 TX (doubl* N1 mask ${ }^{\star}$ )

S46 TX (singl ${ }^{\star}$ N1 mask ${ }^{\star}$ )

S45 TX (doubl* N1 blind ${ }^{\star}$ )

S44 TX (singl ${ }^{\star}$ N1 blind ${ }^{\star}$ )

S43 TX (clinic* N1 trial?)

S42 PT clinical trial

S41 (MH "Clinical Trials+")

S40 S29 AND S39

S39 S30 OR S31 OR S32 OR S33 OR S34 OR S35 OR S36 OR S37 OR S38 
S38 ((educat ${ }^{\star}$ or intervent $\left.{ }^{\star}\right)$ N6 (communit* or famil $^{\star}$ or spouse* or nurs $\left.^{\star}\right)$ )

S37 ((rehabilitati* or educat $\left.{ }^{\star}\right)$ N6 (literature or audiovisual or av or audio visual or internet or web* or telecare or telemedicine or telephone* or phone* or teleconference* or telehealth or transtelephonic ${ }^{\star}$ or podcast* or email ${ }^{\star}$ or e-mail $\left.{ }^{\star}\right)$ )

S36 (education N6 prevent*)

S35 (education N6 (service* or group* or program* or session*))

S34 (educat* N6 (intervention* or rehabilation* or program*))

S33 (patient ${ }^{\star}$ N6 (educat ${ }^{\star}$ or communicat* or interacti ${ }^{\star}$ or inform $^{\star}$ or advi ${ }^{\star}$ )) Search modes - Boolean/Phrase Interface - EBSCOhost

S32 (MH "Telemedicine")

S31 (MH "Health Education+")

S30 (MH "Patient Education")

S29 S1 OR S2 OR S3 OR S4 OR S5 OR S6 OR S7 OR S8 OR S9 OR S10 OR S11 OR S12 OR S13 OR S14 OR S15 OR S16 OR S17 OR S18 OR S19 OR S20 OR S21 OR S22 OR S23 OR S24 OR S25 OR S26 OR S27 OR S28

S28 acute coronary syndrom ${ }^{\star}$

S27 atherectom*

S26 (MH "Atherectomy+")

S25 (pci or ptca)

S24 stent*

S23 (MH "Stents+")

S22 endoluminal repair ${ }^{\star}$

S21 ((coronary or arterial) N4 dilat $\left.{ }^{\star}\right)$

S20 angioplast $^{\star}$

S19 (MH "Angioplasty+")

S18 (percutaneous coronary N2 (interven* or revascular $\left.{ }^{\star}\right)$ )

S17 (MH "Angioplasty, Transluminal, Percutaneous Coronary")

S16 coronary artery stent ${ }^{\star}$

S15 (MH "Myocardial Revascularization+")

S14 (coronary N2 disease*)

S13 (MH "Coronary Disease+")

S12 (coronary N2 dilatation*)

\section{S11 PTCA}

S10 (coronary N3 angioplast*)

S9 aortocoronary bypass*

S8 CABG

S7 coronary artery bypass ${ }^{*}$

S6 stenocardia*

S5 angor pectoris

Patient education in the management of coronary heart disease (Review) 
S4 angina pectoris

\section{S3 (MH "Angina Pectoris+")}

S2 myocardial infarct*

S1 (MH "Myocardial Infarction+")

\section{WHO ICTRP}

"education" AND "coronary artery disease" OR "education" AND "coronary heart disease"

\section{Clinicaltrials.gov}

"education" AND "coronary artery disease" OR "education" AND "coronary heart disease"

\section{UK Clinical Trials Gateway}

"education" AND "coronary artery disease" OR "education" AND "coronary heart disease"

\section{F E E D B A C K}

\section{Conflict of interest, July 2017}

\section{Summary}

"Further research is needed to evaluate the most clinically and cost-effective ways of providing education for people with heart disease."

Actually, we know how to most efficiently and effectively teach. The research is unequivocal: Assessment, individualized teaching with active involvement, evaluation of understanding, and health coaching over time to help the learner apply these new skills consistently.

Our problem is we are not yet applying evidence to practice when educating patients. In addition, studies of patient education do not control variables that impact education, so evaluations of effectiveness are invalid.

Do you have any affiliation with or involvement in any organisation with a financial interest in the subject matter of your comment?

\section{Reply}

Thank you for your comment. We would like to clarify that we are specifically referring to the lack of high quality RCT evidence for educationbased interventions in coronary heart disease (CHD), rather than the totality of evidence in this area. We accept there may well be other evidence not in the scope of this review that may support implementation of educational interventions in CHD. Also, we would wish to clarify that the ongoing RCTs (funded by the National Health Service in the United Kingdom) that are mentioned in the Declarations of Interest statement for Prof Taylor are of a comprehensive rehab intervention in heart failure and not specifically to do with an education based intervention. We have no other interests, financial or otherwise, in this area to declare.

\section{Contributors}

Feeback submitted by: Fran London

Reply by review author: Rod Taylor

Feedback editor: William Cayley

\section{WHAT'S NEW}

\begin{tabular}{lll}
\hline Date & Event & Description \\
\hline 25 June 2021 & Review declared as stable & $\begin{array}{l}\text { The authors and editors of Cochrane Heart conider this review of } \\
\text { limited clinical value as the intervention is often integrated into } \\
\text { comprehensive cardiac rehabilitation which is a topic covered by } \\
\text { several other reviews. }\end{array}$ \\
\hline
\end{tabular}

\section{H I S T O R Y}

Protocol first published: Issue 12, 2010 
Review first published: Issue 12, 2011

\begin{tabular}{lll}
\hline Date & Event & Description \\
\hline 18 October 2018 & Amended & Phrasing changed for interpretation of results. \\
\hline 6 September 2017 & Feedback has been incorporated & Feedback and authors' response added \\
\hline 12 October 2016 & $\begin{array}{l}\text { New citation required but conclusions } \\
\text { have not changed }\end{array}$ & $\begin{array}{l}\text { An additional 9 new RCTs (8215 participants) have been added in } \\
\text { this update }\end{array}$ \\
\hline 30 June 2016 & New search has been performed & $\begin{array}{l}\text { The searches were re-run on 30 June 2016 and the results from } \\
\text { this new search were subsequently incorporated into the review. }\end{array}$ \\
\hline
\end{tabular}

\section{CONTRIBUTIONS OF AUTHORS}

LA undertook the study selection, data extraction and risk of bias assessment, and led the writing of the updated review.

JPRB led the writing of the original version of the review and contributed to the editing of the updated review.

AMC contributed to the original version of the review and contributed to the editing of the updated review.

HD contributed to the original version of the review and contributed to the editing of the updated review.

HKR undertook data extraction and risk of bias assessment and contributed to the editing of the updated review.

CB conducted the searches.

RST contributed to the original version of the review, undertook study selection, data extraction, led the analysis of this review and contributed to the editing of the updated review.

The final manuscript was approved by all authors.

\section{DECLARATIONS OF INTEREST}

LA is an author on number of other Cochrane cardiac rehabilitation reviews.

RST is co-author on a number of Cochrane rehabilitation reviews and in receipt of two ongoing NIHR research grants in cardiac rehabilitation (PGFAR RP-PG-0611-12004; HTA 15/80/30 and one past (HTA 12/189/06).

JPRB, DH, AC, HKR and CB declare no conflicts of interest.

\section{SOURCES OF SUPPORT}

\section{Internal sources}

- University of Exeter Medical School, UK

\section{External sources}

- No sources of support provided

\section{DIFFERENCES BETWEEN PROTOCOLAND REVIEW}

To reflect current practice and terminology, "percutaneous transluminal coronary angioplasty" (PTCA) was replaced by "percutaneous coronary intervention" (PCI), a term which encompasses the use of balloons, stents, and atherectomy.

The list of primary and secondary outcomes was changed for clarity. The subheadings "Total cardiovascular events" and "Proportion of patients requiring admission in the follow-up period following the intervention" were deleted. Adverse events was added as a secondary outcome measure to comply with Methodological Expectations of Cochrane Intervention Reviews (MECIR) Standards (MECIR 2016). Where reported, adverse events were extracted from all studies included in this update. 
In the protocol we stated that we planned to use meta-regression and stratified meta-analyses to explore heterogeneity and to compare and investigate the different modalities of education delivery and to investigate particular subgroups of coronary heart disease (CHD) patients. However, as outlined in this review, there were insufficient data to undertake these analyses for any outcomes other than total mortality and withdrawal. We examined the effect of all predefined potential treatment effect modifiers on these outcomes, with the exception of timing after index event, which was poorly reported in the study reports.

We created a 'Summary of findings' table using the following outcomes: total mortality, fatal and/or non fatal myocardial infarction (MI), other fatal and/or non-fatal cardiovascular events, total revascularisations, hospitalisations, withdrawals and health-related quality of life (HRQoL).

We added a post-hoc sensitivity analysis by statistical model (mixed- versus fixed-effects). Although we reported results of the randomeffects modelling in the text, we also reported the results of both models for all outcomes (Table 1).

\section{IN DEX TERMS}

\section{Medical Subject Headings (MeSH)}

Cardiac Rehabilitation [ ${ }^{*}$ methods]; Coronary Disease [economics] [ ${ }^{*}$ mortality] [ ${ }^{*}$ rehabilitation]; Health Care Costs; Health Services Needs and Demand [statistics \& numerical data]; *Health Status; Hospitalization [statistics \& numerical data]; Myocardial Infarction [mortality] [prevention \& control]; Myocardial Revascularization [statistics \& numerical data]; *Patient Education as Topic; Quality of Life; Randomized Controlled Trials as Topic

\section{MeSH check words}

Adult; Humans; Middle Aged 